\title{
COMPONENT FAILURE DATA HANDBOOK
}

\author{
C. D. Gentillon
}

APRIL 1991

IDAHO NaTIONAL EngineERING LabORATORY

EG\&G IDAHO, INC. IDAHO FALLS, IDAHO $\mathbf{8 3 4 1 5}$

PRepared for the

U.S. NUCLEAR REGULATORY COMMISSION WASHINGTON, D.C. 20555

UNDER DOE CONTRACT NO. DE-ACO7-76ID01570

FIN No. D6152 


\section{ABSTRACT}

This report presents generic component failure rates that are used in reliability and risk studies of commercial nuclear power plants. The rates are computed using plant-specific data from published probabilistic risk assessments supplemented by selected other sources. Each data source is described. For rates with four or more separate estimates among the sources, plots show the data that are combined. The method for combining data from different sources is presented. The resulting aggregated rates are listed with upper bounds that reflect the variability observed in each rate across the nuclear power plant industry. Thus, the rates are generic. Both per hour and per demand rates are included. They may be used for screening in risk assessments or for forming distributions to be updated with plant-specific data.

FIN NO. D6152

SPECIAL PROJECTS 


\section{SUMMARY}

This handbook presents failure rates for components used in reliability and risk studies. It was developed by EG\&G Idaho, Inc. (EG\&G) at the Idaho National Engineering Laboratory (INEL) as a part of the Integrated Risk Assessment Data Acquisition Program (IRADAP). The IRADAP, sponsored by the U.S. Nuclear Regulatory Commission's (USNRC's) Office for Analysis and Evaluation of Operational Data (AEOD), was to meet USNRC operational data needs through two primary activities. The first was to disseminate existing data; the second was to develop taxonomies, statistical aggregation techniques, and software that permit the data to be fully useful and traceable. The generic component failure data set described herein is based primarily on published plant-specific sources of data, jathered in 1987. For each component and failure mode, available data were combined to form a single rate and bound for use in risk assessments, thus fulfilling the IRADAP objective.

During the same period in 1987 that the IRADAP was seeking component failure data, the Nuclear Computerized Library for Assessing Reactor Risk (NUCLARR) program at the INEL was expanding. Component failure data were to be added to the NUCLARR data base to supplement the existing hurnan error probability data. The NUCL.ARR program, sponsored by the USNRC's office of Research, provided the computer data base environment for storing the data acquired through IRADAP.

Selected component failure data have been entered into this data base. The primary sources are plant-specific data from probabilistic risk assessments (PRAs). Failure rates and probabilities of failure on demand for mechanical and electrical components and instrumentation are included, with failure modes that are typically used in PRAs. Care has been taken not to duplicate data that may be contained in more than one source. Because of 
such stipulations for the data reflected in this handbook, not all of the component failure data contained in NUCLARR are used.

To provide generic component failure data for use in screening probabilistic risk assessments and in other risk analyses of $U$. S. commercial nuclear power plants, the capability of combining relevant data from many sources is required. The resulting aggregates are point estimates of either failure rates or probabilities of failure on demand for specified components and failure modes. Upper tolerance bounds are also calculated. The bounds are assessments of the variability in the occurrence rates or probabilities across the population of sites and specific components described in the data sources. The aggregation methods are implemented in NUCLARR.

Software was developed for IRADAP to display and summarize the component failure data rates. The NUCLARR data files and aggregation and plotting algorithms were accessed to produce tables showing the mean, median, upper tolerance bound, and error factor for each component and failure mode. The tables also show how many data points contributed to each aggregation and the number of sources represented. Plots that show the data going into each aggregation containing at least four records from NUCLARR were also generated.

Descriptions including the key features of each source were written to assist handbook users in judging the applicability of each rate. They address issues such as the purpose of the data collection effort and the considerations that went into processing the data for NUCLARR. Knowledge concerning the types of facilities that provided the data together with the variations in the data shown in the plots will help the user to better understand the data. The recommended method for using data from a particular source rather than an aggregate from several sources is to obtain access to NUCLARR. In some cases, a user may also identify such yalues from the plots. 


\section{FOREWORD}

The purpose of this foreword is to provide historical background information on the relationship between the Integrated Risk Assessment Data Acquisition Program (IRADAP) at the Idaho National Engineering Laboratory (INEL) sponsored by USNRC's Office for Analysis and Evaluation of Operational Data (AEOD) and the Nuclear Computerized Library for Assessing Reactor Risk (NUCLARR) program at the INEL sponsored by USNRC's Office of Research.

Gathering generic component failure data in one place and developing methods to combine them were needs identified in the IRADAP's 1986 ranking of data needs to support USNRC requirements for operational data. Work on this task was authorized in early 1987 under the auspices of the IRADAF.

During the same period in 1897 that IRADAP personnel were considering how to process component failure data, Dr. Thomas G. Ryan, the USNRC Technical Monitor for the NUCLARR program, wanted the NUCLARR program at the INEL to expand to include such data. The benefits of the two programs working together were clear: IRADAP could supply component failure data and, from a review of the use of component failure data in several probabilistic risk assessments (PRAs), could supply component failure data base taxnomy suggestions. Meanwhile, NUCLARR could provide a software environment for storing the data and using them at computer work stations. Ms. Bennett M. Brady, the "SNRC Technical Monitor for the IRADAP, concurred.

In conjunction with IRADAP, a data base structure and taxonomy were devised for NUCLARR to contain failure rates with a variety of searchable information. In addition to the component type and failure mode, attributes such as component desigr, normal state, system, plant, failure severity, and data collection dates were included. For certain components, codes describe applications or functions, such as the parameter being monitored for instrumentation, the internal environment, or the voltage level for an application. Data origin information, including the type of records used to extract the failure data, and a comment field are also included. 
Many of these attributes are not necessary for most base level reliability analyses. For this generic component failure data handbook, only attributes such as the component type, design, normal state, failure mode, nature of the original data sources, and source documentation references are used. The additional attributes aid in fine tuning the failure rates for specific applications. This capability was envisioned for the IRADAP data collection effort but not for the handbook itself. Access to NUCLARR allows full use of these capabilities.

The calculation of aggregated rates from a set of component failure data records is another area in which the NUCLARR program support has been beneficial for the IRADAP component failure data analyses. The algorithms were derived in 1987 primarily under NUCLARR funding and were implemented on a PC entirely under NUCLARR funding. The rates presented in this handbook would not have been possible without this support.

The NUCLARR documentation (NUREG/CR-4639, Volume 5, Part 3) includes a data sheet for each component failure data record in the NUCLARR data base; in addition, Volume 5 part 4 contains aggregations of the data by component and failure mode. A11 records described in Volume 5 having a data entry date prior to May 25, 1989 and noted as being IRADAP Suitable were used in the aggregations for this handbook. The differences between the aggregations for this handbook and the NUCLARR aggregations are as follows:

1. Only data viewed as being "IRADAP Suitable" are included in this handbook. This results in an exclusion of

- Data from the Licensee Event Report (LER) Summaries, since consistent reporting of LERs among units is not expected and the denomiriator's for the LER rates are rough estimates (particularly for per demand data)

- Data from WASH-1400 
- Data points that have been excluded for various reasons discussed in Section 3 of the main text.

(Note that these data have been entered into NUCLARR, using NUCLARR funding, to provide coverage for a wide variety of data within NUCI.ARR. The philosophy for data entry for NUCLARR is that sufficient information be present to allow a failure rate to be classified by component and failure mode. As a repository or library of source data, NUCLARR does not have a list of restrictions for data entry such as those discussed for IRADAP. The philosophy for NUCLARR data is that the suitability for a selected data point in a given application ultimately rests with the end user of the system. While this responsibility exists for the user of data from any source, the IRADAP data have additional safeguards to ensure their quality and applicability for risk assessment and thus are a subset of the NUCLARR component failure data.)

2. The handbook displays provide additional information to assist the user in judging the applicability of the data. The summary tables provide an indication of the sources of the data. Plots labelled by source allow the reader to see which studies gave rise to the highest and lowest failure rate estimates. The data source descriptions in Appendix A provide information to help the user judge the usefurness of the rates.

In summary, the IRADAP component failure data aggregations are more selective than those reported in the NUCLARR series.

The NUCLARR program has an ongoing mission to collect component failure data as well as human error probabilities. As more data become available, updates to this report might, be feasible. However, the IRADAP was discontinued in 1988. A Special Frojects Program under AEOD funding was instituted in 1988; completion of a draft of this handbook in 1898 was one of its initial chartered tasks. The current handbook, issued in 1991, incorporates in the text minor changes from an NRC peer review of the 1989 handbook. 
The software developed under Special Projects funding to display the tables and plots of this report using the NUCLARR data base could be used at some future time in the NUCLARR program to provide updates to this report as more plant-specific component failure data become available. NUCLARR personnel would in such a case apply the principles discussed herein in assessing the "IRADAP Suitable" indicator for data from additional sources. Documentation similar to the information in Appendix $A$ would also be needed for each new source with suitable data. 


\section{ACKNOWLEDGMENTS}

The efforts of the Integrated Risk Assessment Data Acquisition Program (IRADAP) staff at the Idaho National Engineering Laboratory (INEL) are appreciated. Special thanks are extended to Michael R. Groh who was instrumental in developing the component failure data taxonomy on which the handbook is based. Oren V. Hester's reviews of probabilistic risk assessment to provide a firm foundation for the taxonomy is appreciated. Helpful review comments on the taxonomy by William J. Galyean are also appreciated. Quinn R. Decker is thanked for his collection of data sources and development of a system for tracking them. Quinn R. Decker, Frank G. Farmer, and Bruce S. Anderson are thanked for selecting and encoding data. Appreciation is extended to Osmond J. Call, who developed the software that produces tables and plots for this handbook.

In addition, the assistance of the Nuclear Computerized Library for Assessing Reactor Reliability (NUCLARR) staff is gratefully acknowledged; this includes computer software support from a team originally headed by Gretchen $H$. Beers and more recently by Osmond J. Call, data encoding and processing by B. Gay Gilbert and Wendy J. Reece, and overall program coordination by Dr. David I. Gertman.

Sincere appreciation is expressed to Joseph R. Fragola and the staff of his New York and Clearwater, Florida offices of Science A.pplications International Corporation (SAIC) for plant-specific component failure data fricii several nuclear power $\mathrm{plant}$ units and for advice in selecting and displaying the failure information.

Finally, the author would like to thank Bennett M. Brady and Thomas G. Ryan, both of the USNRC staff. Ms. Brady has provided support since 1986 as AEOD Program Manager for the IRADAP and for the Special Projects on behalf of the USNRC's Office for Analysis and Evaluation of Operational Data. Dr. Ryan's support as the Technical Monitor for the NUCLARR program, particularly in the development of aggregation algorithms, is gratefully acknowledged. 


\section{CONTENTS}

Page

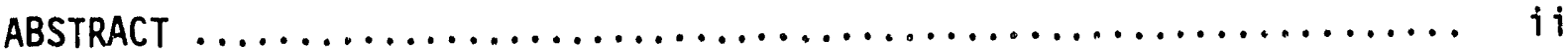

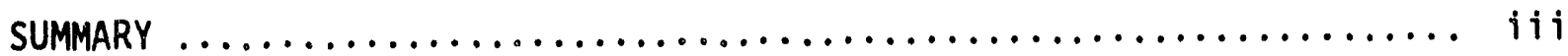

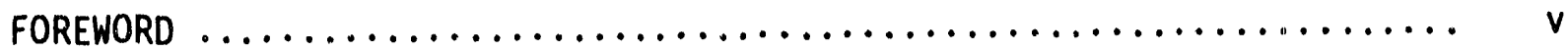

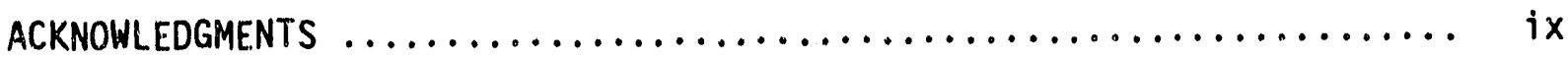

NOMENCLATURE $\ldots \ldots \ldots \ldots \ldots \ldots \ldots \ldots \ldots \ldots \ldots \ldots \ldots \ldots \ldots \ldots \ldots \ldots \ldots \ldots$

1. INTRODUCTION $\ldots \ldots \ldots \ldots \ldots \ldots \ldots \ldots \ldots \ldots \ldots \ldots \ldots \ldots \ldots \ldots \ldots$

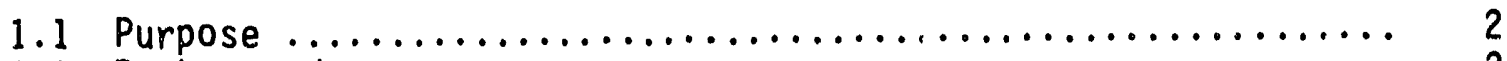

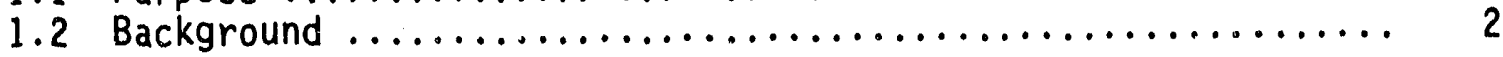

2. SCOPE OF COMPONENT FAILURE DATA $\ldots \ldots \ldots \ldots \ldots \ldots \ldots \ldots \ldots \ldots \ldots$

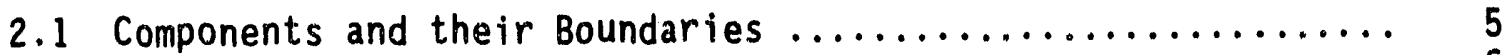

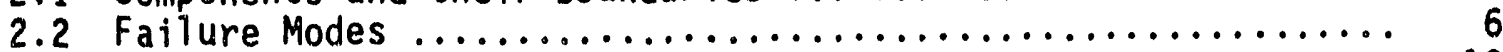

2.3 Individual Failure Data Records .................... 10

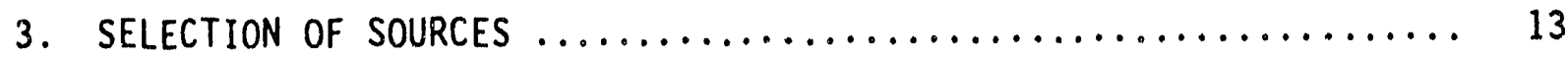

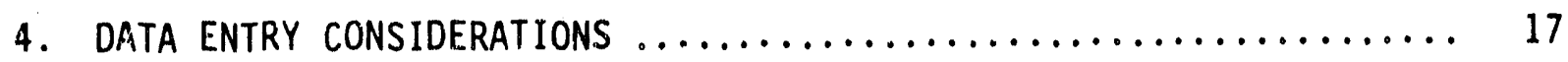

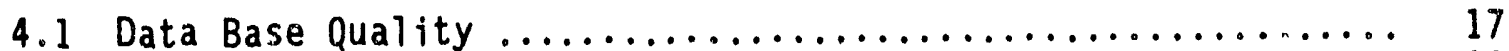

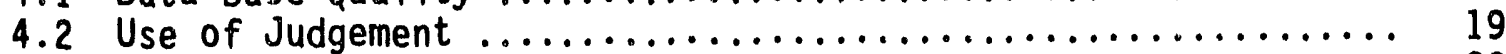

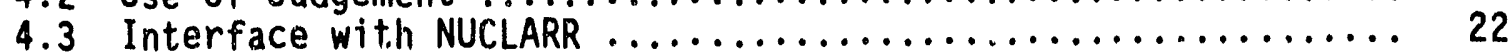

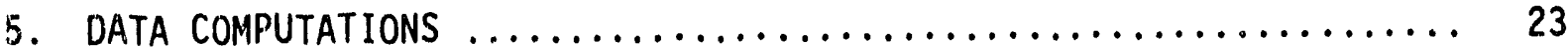

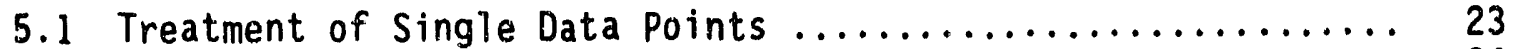

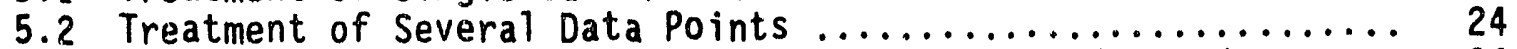

5.3 Adjustments to the NUCLARR-Calculated Means ard Bounds ...... 26

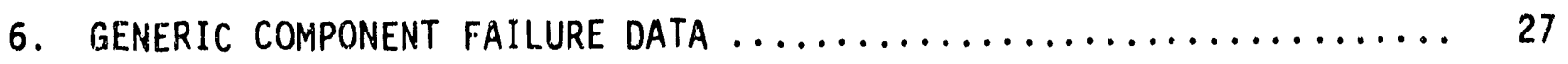

7. QUALITY OF DATA IN THE HANDBOOK $\ldots \ldots \ldots \ldots \ldots \ldots \ldots \ldots \ldots \ldots \ldots$

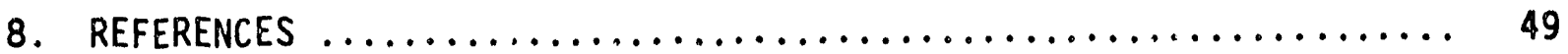

APPENDIX A--COMPONENT FAILURE DATA SŨURCES $\ldots \ldots \ldots \ldots \ldots \ldots \ldots \ldots \ldots$

APPENDIX B--COMPONENT FAILURE DATA PLOTS ..................... B-1

APPENDIX C--AGGREGATION METHODS $\ldots \ldots \ldots \ldots \ldots \ldots \ldots \ldots \ldots \ldots \ldots \ldots \ldots$ 


\section{TABLES}

1. Data Sources in NUCLARR and their Use in This Handbook .......... 14

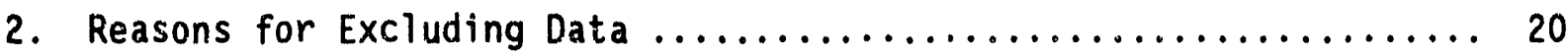

3. Generic Failure Rates for Mechanical Components .............. 30

4. Generic Failure Rates for Electrical/Instrumentation Components ... 33

5. Generic Failure Rates for Mechanical Components with Various

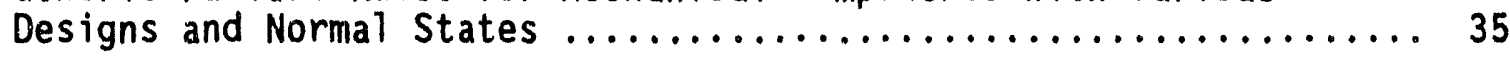

6. Generic Failure Rates for Electrical/Instrumentation Components with Various Designs and Normal States ..................... 42 


\section{NOMENCLATURE}

\section{DEFINITIONS}

Aggregation: An aggregate is "any total or whole considered with reference to its constituent parts" (The American Heritage Dictionary, Second College Edition). Most of the failure rates and per demand probabilities described in this handbook are aggregates, derived from more than one datum for a specified component and failure mode. Aggregation in the current context is the process of combining individual records from one or more data sources to form these estimates and their bounds.

Component Boundary: The component boundary includes the basic component (i.e., valve) with its operator (i.e., motor valve operator) and associated circuit breaker and control circuits. For a pump the boundary would include: the pump, its control circuitry, its driver (a motor or turbine), and the motor's circuit breaker and controller or the turbine's stop and throttle valves and associated control mechanism.

Failure: A failure is a particular type of fault that represents an irreversible state of a component such that it must be repaired in order for it to perform its design function. Failures are further classified as primary or secondary failures:

a. A primary failure is a failure that results from wearout or apparently random problems within a component. No clear external cause can be found for such failures.

b. A secondary failure results when the component is subject to conditions that exceed its design envelope (for example, excessive voltage, pressure, shock, vibration, or temperature).

Failure Mode: The failure mode is the specification of the aspect of the failure process that is of concern and includes a description of how the failed component/system state differs from the desired state ("...the effect by which a failure is observed to occur..." --IEEE Std 500-1984, Appendix A).

Homogeneous: This term applies to a population of components whose failure rate per unit time or failure probability per demand for a particular failure mode can reasonably be assumed to be constant. This implies that, for per hour rates, there is no reason to expect the number of failures not to be Poisson. For per demand probabilities, this term applies whenever there is no evidence to show that the number of failures in a fixed number of demands is not described by the binomial distribution.

Repair: Repair is the restoration of a component to an operable state following the failure of that component. To repair a component requires that the component be removed from service (i.e., made unavailable). Repair may be as simple as adjusting the setpoint or as drastic as the total replacement of the component. 


\section{ACRONYMS/ABBREVIATIONS}

AEOO Office for Analysis and Evaluation of Operational Data (USNRC) BWP Boiling water reactor

CFD Component fallure daca

CRPS Component Rellability Parameter System

EB Empirical Bayes

EG\&G EG\&G Idaho, Inc.

FID Facitity identifier

IBM

International Business Machines Corporation

IFEE Institute of Electrical and Electronics Engineers, Inc.

INEL Idaho National Engineering Laboratory

IRADAP Integrated Risk Assessment Data Acquisition Program

LER Licensee Event Report

LWR Light water reactor

NUCLARR Nuclear Computerized Library for Assessing Reactor Reliability

PC

Personal computer

PWR Pressurized water reactor

SAIC Science Applications Interriational Corporition

USNRC United States Nuclear ReguTatory Commissior: 


\section{COMPONENT FAILURE DATA HANDBOOK}

\section{INTRODUCTION}

This handbook contains failure rates and probabilities for failure on demand for components that are typically used in United States commercial nuclear power plants. These data are provided from sources identified in 1987 in the USNRC's Integrated Risk Assessmi.nt Data Acquisition Program (IRADAP) administered by the Uffice for Analysis and Evaluation of Operational Data (AEOD).

This handbook provides the following information:

1. A discussion of the scope of the component failure data, inciuding the components and failure modes considered

2. Information on the methods used for selecting data sources

3. A discussion of data entry considerations

4. Notes on the calculations for medians, means and upper bounds

5. Tables listing the component failure data by component and failure mode and then more specifically by component design and normal state as well as failure mode

6. A brief discussion of the quality of the data

7. An appendix describing each data source used in the handbook, including the purpose of the data collection effort and any assumptions used in screening the data for the handbook 
8. An appendix providing plots of the individual records that were aggregated to form the rates 1 isted in the tables (for all cases in which at least four records were combined to form a rate) and

9. An appendix descritsing the aggregation methods.

With this information in a handbook, selected recommended component failure data and supporting information are available in a portable, convenient format.

In the subsections below, the purpose of the handbook is restated and background information for this project is provided.

\subsection{Purlpose}

The purpose of this handbook is to present in a single place generic component failure data for various tasks.

\subsection{BACKGROUND}

Several types of operational data are needed for risk assessments of commercial nuclear power plants. These include basic generic component failure data, data on the frequency and duration of both corrective and preventive maintenance outages during plant operation, common cause data, data on internal and external initiating events, and probabilities for successful recovery actions by plant operators. In addition, data sets on root causes and the effect of aging are needed to assess lifetime extension issues and prevent the recurrence of problems that impact reactor safety.

In the 1986 IRADAP rariking of the USNRC's data needs, ${ }^{1}$ generic failure rate data were ranked second in importance in satisfying USNRC programmatic operational data requirements in support of reliability and risk analysis. Oniy common cause data had a slightly higher importance ranking. 
In comparison to common cause data, the generic failure rate data set was chosen to be built first since it could be developed efficiently and in a cost-effective manner by combining existing data sets.

In 1987, the Nuclear Computerized Library for Assessing Reactor Reliability (NUCLARR) program ${ }^{2}$ added a module to store, process and display component failure data (CFD) in addition to human error probabilities in its PC-based computer work station. Sponsored by the USNRC office of Nuclear Regulatory Research, this software tool makes the raw data available in a form that facilitates sensitivity studies and evaluations of subsets. From inception, both the development of a component failure data handbook through IRADAP and the development of a hardware component failure data module for NUCLARR have been complementary efforts, each program benefitting from the other. The IRADAP program provided data and, from a review of the use of component failure data in several probabilistic risk assessments (PRAs), component failure data base taxnomy suggestions for NUCLARR. Conversely, NUCL.ARR has provided IRADAP a software environment in which the data can be stored and aggregated.

Further documentation for some of the topics discussed in this handbook Can be found in the NUCLARR series of NUREGs (NUREG/CR-4639; Reference 2). In particular, the scope of the component failure data and the nature of the aggregation methods are discussed in Volume 4: User's Guide, Part 3: NUCLARR System Description. Data entry considerations are also included. However, they are discussed from a different perspective in the NUCLARR reports because NUCLARR is intended to be a library or repository for data. Data entry considerations for NUCLARR focus on whether the operational data provide enough information to permit their classification in the NUCLARR system. The "IRADAP Suitable" field in NUCLARR allows the data within NUCLARR that are flagged for the component failure data handbook to be distinguished from the remaining data.

Additional documents from the NUCLARR series would be of use to those who would like to study the component failure handbook data in more depth. 
Part 3: Hardware Component Failure Data (HCFD) of Volume 5 contains a page for every component failure data entry in NUCLARR, including those used for this handbook. This document is updated periodically as new data are entered into NUCLARR.

The best method for further study of these data is to obtain access to the NUCLARR system itself. The system allows one to identify subsets of component failure data and form aggregations on-line, so that the effect of selecting particular data sources or individual records to form a failure rate estimate can be immediately seen. On-line plots of such data also can be obtained. Names and phone numbers for obtaining further information regarding the NUCL.ARR System are as follows:

Thomas G. Ryan

U. S. Nuclear Regulatory Commission--RES

Reliability and Human Factors Branch

5650 Nicholson Lane, NL/N-316

Rockville, MD 20852 USA

Phone: 301-492-3550 (FTS 492-3550)

David I. Gertman

NUCLARR Data Clearinghouse

Idaho National Engineering Laboratory

P. 0. Box 1625

Idaho Falls, ID 83415-2405 USA

Phone: 208-526-0652 (FTS 583-0652) 


\section{SCOPE OF COMPONENT FAILURE DATA}

The types of data regarded as basic "generic component failure data" are described below.

\subsection{Components and Their Boundaries}

The components selected for the component failure data handbook (CFDH) are those components that are typically involved in basic events in fault tree models of nuclear power plant systems. Thus, they are for the most part components of the type found in safety systems. For convenience, the component list has been divided into two sections, mechanical and electrical/instrumentation. Forty-two general categories of mechanical components and 33 categories of electrical components have been identified. These component types have been further characterized by their design. The components and designs are listed in the component failure data section (Section 5) for cases in which data exist. A complete list, including NUCLARR data base codes, can be found in Volume 4 of the NUCLARR NUREG series (Reference 2).

The component list is intended to be fairly complete. The availability of failure data for every component/design combination in the list is not expected, at least until more operating experience is acquired and improved data collection schemes are available. The existence of the overall list is beneficial in determining where additional data collection efforts for NUCLARR might be warranted.

To maintain consistency between different data sources contained within the generic failure rate data, some general discussion on component boundaries for apportioning the failures is appropriate. If possible, each component's boundary should include the physical boundary of the component itself plus that of any associated, dedicated auxiliary equipment. This 
boundary would include closely associated equipment that is physically coupled, such as generators or pumps with their drivers (diesel engines, motors, etc.) and valves or dampers with their operators (motor, pneumatic, etc.). Also, this boundary would include dedicated control circuits and circuit breakers associated with pump motors, valve operators and diesel generators. For diesel generators it would additionally include dedicated air starting systems and dedicated batteries. Similarly, lube oil cooling failures would be included in the data set for those - omponents that provide their own lube oil cooling function.

Note that the rates in this handbook are combinations or aggregates of rates from various sources, not all of which conform to the component boundary definition just stated. For PRA purposes, most of them do. In any case, component boundary guidelines are provided here for any future data collection efforts that might contribute data for updates to NUCLARR.

\subsection{Failure Modes}

This handbook contains generic failure rates and probabilities of failure on demand that are used in PRAs. Thus, these rates and probabilities apply to the types of events that typicaily are found in the basic events of fault trees. These events are unplanned and render the components unavailable to perform their function. Thus, "catastrophic" failures are of interest rather than degraded or incipient conditions that may cause some reduction of function. If $\mathrm{plant}$ personnel have some flexibility in deciding when to repair the components and do not have to declare the component inoperable, the basic function of the component must be available.

More specifically, the following failure modes are the primary failure modes considered for the generic component failure data:

$$
\begin{aligned}
& \text { Fails to operate } \\
& \text { Fails to start } \\
& \text { Fails to run } \\
& \text { Fails to open } \\
& \text { Fails to close }
\end{aligned}
$$


Fails to energize

Fails to de-energize

Fails to transfer electrically

Spurious operation

Spurious start

Spurious open (transfer open)

Spurious close (transfer closed)

Spurious energize

Spurious de-energize

Spurious transfer electrically

Leakage

External leakage/rupture

Internal leakage

Blockage

Plugged

The "fails to operate" mode applies to nearly all components. This mode includes cases where data sources say "operational failure," "improper operation," "no output," or, just "fails." In all of these cases, the mode applies to failures per hour. However, per demand probabilities can also be associated with this mode, as in "fails to operate on demand." Specific r.xamples of components whose catastrophic failure mode will for consistency always be denoted "fails to operate" are:

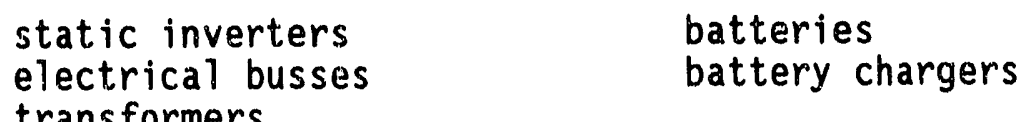

transformers

"Fails to start", "fails to run", and the other modes listed above under "fails to operate" are more specific descriptions of the failure events. For standby components, these modes may have both per hour and per demand rates, depending on whether the mechanisms associated with the failures are associated with the component's use or are aging mechanisms that occur even when the component is not being used. These modes also typically apply to particular compons nt groups; for example, "fails to start" and "fails to run" apply to pumps and generators while "fails to open" and "fails to close" apply to valves and breakers and "fails to energize" and "fails to deenergize" apply 
to relays and other electrical components. The "fails to transfer electrically" mode applies to auto bus transfer (ABT) devices. For relief valves, the per demand rate, "fails to close", describes failure to reseat.

For components such as fans and compressors, "failure to run" and "failure to operate" may both be used to describe failure events in the fail to operate (per hour) group. For consistency, the fail to run mode will be used whenever the component also has a "fail to start" failure mode; otherwise, the "fail to operate" mode will be used.

The "spurious operation" failure mode group is similar in that it, too, contains mode: that typically apply to particular components. The spurious category incluaes failures that are described in the data sources as "premature open," "function without signal," "normally open fails closed," and "fails high." Unlike the "fails to operate" category, all spurious operation failures give rise to per hour rates only.

Failure modes associated with leakage apply to components that form a pressure boundary; primarily valves. External leakage is typically leakage through valve packing; internal leakage is leakage across the valve seat. Hourly rates for failure to seat or reseat are described by the leakage failure mode. The "internal leakage" mode for check valves is back leakage. All leakage rates are per hour.

Blockage, like leakage, applies to certain hourly rates for components that form a pressure boundary. The "plugged" failure mode applies when the blockage is known to be complete.

A feature of the failure mode scheme described above is that it is hierarchical. That is, more detailed modes are listed under general modes so that different types of data can be accommodated. Thus, for example, sources that provide data for the "fails to open/fails to close" failure mode can be used as well as those that provide separate characterizations for a component's failure to open and failure to close. 
Three other general comments appiy to the failure modes and the events they describe. The first is that the failure courits for the numerators of the failure rates or demand probabilities for operating components are counts of failures that occurred during operation. Failures that have no effect on the components during operation (for example, failures detected and corrected during preoperational testing) generally do not count. The sane statement applies to the denominators.

The second comment is related to the first: the mode of operation of a component is important. The normal state of a component can have a major influence on its fallure rates. For example, normally operating pumps generally have a lower probability for failure to start than normally standby pumps have. Where possible, the normal state for components is noted in collecting data for this handbook. The following normal states are considered in NUCLARR:

\begin{tabular}{lll} 
Code & \multicolumn{1}{c}{ Definition } & Shortur form, used in data tables \\
\cline { 2 - 3 } NO & Normally open & Open \\
NC & Normally close & Closed \\
NE & Normally energized & Energized \\
ND & Normally de-energized & De-energized \\
NR & Normally running & Running or oper. \\
NS & Normally in standby & Standby \\
NA & Normally alternating & Alt. \\
NL & Normally locked-out & Locked-out \\
XX & Unknown (unspecified) & Unsp.
\end{tabular}

The normal state codes have special interpretations when applied to passive components such as pipes and heat exchangers. For these components, running or operating indicates wet flowing; standby indicates a wet stagnant condition, not flowing; locked out indicates a dry condition; and alternating is between running and standing by. In cases where the normal state is not stated, it is often implied by the failure mode; for example, the "fails to close" mode is typically associated with a normally open valve. Separate aggregations are performed for differing normal states.

The final general conment is that secondary failures should be excluded. That is, failures that are caused by common support systems or improper 
inputs are not included in the failure rates if possible because these are modeled separately in most risk assessments. For example, consider a front line system pump failure caused by a loss of the pump's lube oil cooling due to a failure in the component cooling water system. Ideally, no front line system pump failure would be counted even though the front line system pump experienced a failure that required repair. Such failures should not be included in the failure data because their occurrence is entirely dependent on the sperific designs of the systems involved. They are not needed in the failure data sets because PRA system models will identify what components will fail due to the loss of each support system. Thus, the ideal failure rate data would be dependent only on the component and its immediate environment and application and would be independent of the specific plant and system designs. Sources that include secondary failures in the basic failure rate data will have higher failure rate estimates; however, data from these sources are still included in the data base because in most cases the impact of these failures is minimized by the protective devices commonly installed on components.

\subsection{Individual Failure Data Records}

Component failure data records are designed to supply information for failure rates (failures/hour) or probabilities of failure on demand (failures/demand). The level of detail for which the operational experience allows for distinguishing separate rates within a component type is another aspect of the scope. For example, failures could be counted separately for each pump in a plant, resulting in a failure record unique to each pump, or the operating experience could be combined to form an overall pump failure rate for all pumps. As another example, separate rates for each year of operational experience could be reported. The desired scope of the data in the generic failure rate data set to a certain extent depends on the information available. The two possibilities are discussed below.

Ideally, this generic failure rate data set will contain data at a level of detail such that the failure rate can reasonably be assumed to be 
constant. Thus, data for components having the same design, function, application, and operating environment may be combined. If there is any reason to expect differences in the rates (e.g., perhaps a particular component was recently replaced), the preferred approach is to separate the data into separate records. On the other hand, since the focus is primarily on generic failure rate data, individual component identifications are not a part of the data stored. In summary, the optimal data record supporting the component failure data handbook is a statement of the number of failures of a particular type and corresponding operating history (times or demands) for a set of homogeneous components.

If this level of detail is not available, the failure data will describe a collection or population of components whose failure rates vary. For such data, an important feature is to supply tolerance intervals that describe this population variability. If no tolerance intervals are available, the data will still be accepted and the variability will be characterized through the combining (aggregating) of data from several sources. 


\section{SELECTION OF SOURCES}

Generic failure rates that are based solidly on operational eaperience were obtained for this manual by combining or aggregating plant-specific data from several plants across the industry: A bibliography of data sources for use in risk assessment ${ }^{3}$ completed in the FY-1987 IRADAP activities served as a starting point for gathering these data. This document describes 38 studies, five nonnuclear sources, six foreign data bases, and the data efforts documented in 27 U.S. commercial nuclear power plant probabilistic risk assessments (PRAs). Among these sources, available recent PRAs with component failure data are the prime generic failure data source. The PRA data are plant-specific, and are for the most part collected at a level of detail to support variations in equipment design and use since they were collected specifically for risk assessment purposes.

Other sources are regarded as supplements to this basic set of sources. Foi certain components, little plant-specific data from nuclear power plants exist. Generic sources including some nonnuclear sources are used in this case. Care is taken to avoid the use of sources that duplicate each other. The principle is to combine data from the best possible sources for each specified component and failure mode.

Table 1 describes the data sources currently contained in the hardware component failure data module of NUCLARR, the program that identified the source, the program that encoded data for the source, and whether data from the source are used in this handbook. Each data source used in this handbook is described in Appendix A. Complete bibliographic information for these sources is provided there.

Processing of sources that become available in the future is expected under the NUCLARR program. Ongoing risk assessments may generate data that are solidly based on maintenance work requests and plant-specific analyses of the number of demands; these would he ideal inputs to the NUCLARR Clearinghouse as they become available. 
TABle 1. Data SOURces in NUCLARR and Their Use in this Handbook

\begin{tabular}{|c|c|c|c|c|}
\hline $\begin{array}{l}\text { Study ID } \\
\text { PRA Sources }\end{array}$ & Data Source & $\begin{array}{l}\text { Program } \\
\text { Identifying } \\
\text { Source } \\
\end{array}$ & $\begin{array}{l}\text { Program } \\
\text { Coding } \\
\text { Data } \\
\end{array}$ & $\begin{array}{c}\text { Use } \\
\text { in } \\
\text { Handbook }\end{array}$ \\
\hline $\begin{array}{l}\text { HNSI - PRA } \\
\text { IPS2-PRA } \\
\text { ZIS-PRA } \\
\text { NEE3-PRA } \\
\text { X-PRA } \\
\text { Y-PRA } \\
\text { EUR-PRA } \\
\text { A-PRA } \\
\text { B-PRA } \\
\text { C-PRA } \\
\text { D-PRA } \\
\text { E-PRA } \\
\text { F-PRA } \\
\text { G-PRA }\end{array}$ & $\begin{array}{l}\text { Big Rock Point I } \\
\text { Haddam Neck Plant (Conn. } \\
\text { Yankee) } \\
\text { Millstone } 1 \\
\text { Indian Point } 2 \\
\text { Zion Station } \\
\text { Oconee } 3 \\
\text { Plant "X" } \\
\text { Plant "Y" } \\
\text { European Plant } \\
\text { Plant "APRA" } \\
\text { Plant "BPRA" } \\
\text { Plant "CPRA" } \\
\text { Plant "OPRA" } \\
\text { Plant "EPRA" } \\
\text { Plant "FPRA" } \\
\text { Plant "GPRA" }\end{array}$ & $\begin{array}{l}\text { IRADAP } \\
\text { IRADAP } \\
\text { IRADAP } \\
\text { IRADAP } \\
\text { IRADAP } \\
\text { IRADAP } \\
\text { IRADAP } \\
\text { Note c } \\
\text { Note c } \\
\text { Note c } \\
\text { Note c } \\
\text { Note c } \\
\text { Note c } \\
\text { Note c }\end{array}$ & $\begin{array}{l}\text { IRADAP } \\
\text { IRADAP } \\
\text { IRADAP } \\
\text { IRADAP } \\
\text { IRADAP } \\
\text { IRADAP } \\
\text { IRADAP } \\
\text { NUCLARR } \\
\text { INUC!.ARR } \\
\text { NUCLARR } \\
\text { NUCLARR } \\
\text { NUCLARR } \\
\text { NUCLARR } \\
\text { NUCLARR }\end{array}$ & $\begin{array}{l}\text { Yes } \\
\text { Yes } \\
\text { Yes } \\
\text { Yes } \\
\text { Yes } \\
\text { Yes } \\
\text { Yes } \\
\text { Noc } \\
\text { No } \\
\text { No } \\
\text { No } \\
\text { No } \\
\text { No } \\
\text { No }\end{array}$ \\
\hline \multicolumn{5}{|c|}{ Additional Data Sources } \\
\hline $\begin{array}{l}\text { IEEE - } 500 \\
\text { IPRDS }\end{array}$ & $\begin{array}{l}\text { IEEE-Standard } 500-1984 \\
\text { In-Plant Reliability Data } \\
\text { System (pumps, valves, } \\
\text { electrical components) }\end{array}$ & $\begin{array}{l}\text { IRADAP } \\
\text { IRADAP }\end{array}$ & $\begin{array}{l}\text { IRADAP } \\
\text { IRADAP }\end{array}$ & $\begin{array}{l}\text { Yes } \\
\text { Yes }\end{array}$ \\
\hline SWD-HBK & $\begin{array}{l}\text { Swedish Reliability Data } \\
\text { Book }\end{array}$ & IRADAP & Both & Yes \\
\hline RAC & $\begin{array}{l}\text { Reliability Analys is Center } \\
\text { (Nonelectronic component.s) }\end{array}$ & IRADAP & IRADAP & Yes \\
\hline NSAC- 108 & $\begin{array}{l}\text { Reliability of Emergency } \\
\text { Diesel Generators }\end{array}$ & IRADAP & NUCLARR & Yes \\
\hline $\begin{array}{l}\text { PBS } \\
\text { WASH- } 1400 \\
\text { LER-SUMM }\end{array}$ & $\begin{array}{l}\text { Pipe Break Frequency } \\
\text { Reactor Safety Study } \\
\text { LER Summaries (pumps, valves, } \\
\text { channels, inverters) }\end{array}$ & $\begin{array}{l}\text { IRADAP } \\
\text { NUCLARR } \\
\text { NUCLARK }\end{array}$ & $\begin{array}{l}\text { IRADAP } \\
\text { NUCLARR } \\
\text { NUCLARR }\end{array}$ & $\begin{array}{l}\text { Yes } \\
\text { No } \\
\text { No }\end{array}$ \\
\hline $\begin{array}{l}\text { A-REL } \\
\text { B-REL }\end{array}$ & $\begin{array}{l}\text { Rel iabllity Study "A" } \\
\text { Rel iability Study "B" }\end{array}$ & $\begin{array}{l}\text { Note c } \\
\text { Note } c\end{array}$ & $\begin{array}{l}\text { NUCLARR } \\
\text { NUCLARR }\end{array}$ & $\begin{array}{l}\text { No } \\
\text { No }\end{array}$ \\
\hline
\end{tabular}

a. This table addresses data sources for the hardware component fallure data module of NUCLARR as of June 8, 1989. It does not describe the human error probability module. Data entry was a NUCLARR function except for data from the first six PRAs listed above. for the Swedish Reliability Data Book, some records were coded by NUCLARR personnel and some were coded by IRADAP personnel. 
Table 1. Data SOURCes in NUClaRR and Their Use In this Handbook ${ }^{a}$ (continued)

\begin{tabular}{|c|c|c|c|c|}
\hline Study ID & Data Source & $\begin{array}{c}\text { Program } \\
\text { Identifying } \\
\text { Source }\end{array}$ & $\begin{array}{l}\text { Program } \\
\text { Coding } \\
\text { Data } \\
\end{array}$ & $\begin{array}{c}\text { Use } \\
\text { in } \\
\text { Handbook }\end{array}$ \\
\hline
\end{tabular}

(continuation of notes)

b. Yes: some data from the source were used for this handbook (individual data points may still be excluded). No: no data from the source were used for the handbook. The "IRADAP Suitable" field in NUCLARR records from these sources do not contain " $Y$ ". Exclusions are due to considerations discussed in Section 2.

c. Data from Plants APRA through GPRA and the A and B reliability studies were provided to NUCLARR in May of 1989 , too late to be included in this handbook.

d. These are Data Summaries of Licensee Event Reports (LERs) from U. S. commercial nuclear power plants (NUREG/CR-1205, -1363,-1740, and -3867). They contain failure rates estimated from LERs as recent as 1982 . They are not included in the handbook because LERs were not complete in-plant maintenance records and because plant-specific information on the number of demands or the components was not available. 


\section{DATA ENTRY CONSIDERATIONS}

This section provides further information about the considerations that influence the selection of specific records for the CFDH. These considerations affect both the data identified for NUCLARR by the IRADAP team and the assessment of the "IRADAP Suitable" flag for any records subsequently added to the data base by NUCLARR personnel. Section 2 discussed the handbook data scope in broad terms; more detailed statements of selection and encoding principles are provided here.

\subsection{Data base quality}

As stated in Section 3, the primary data source is plant-specific data from probabilistic risk assessments of nuclear power plants. One would expect most such data to be applicable and appropriate for the component failure data base. Among other sources, some contain commercial nuclear power plant operational data that are directly suitable for PRA applications and others have generic data that may not be applicable. For most of the generic sources, only a selected subset of the data presented has been entered into NUCLARR to fill gaps in plant-specific data. The Component Reliability Parameter System (CRPS) developed by Science Applications International Corporation ${ }^{3}$ provided guidance for the selection of particular rates from sources such as IEEE-500 and RAC. Generaliy, generic data were only used for component type/design/normal state/failure mode combinations that have less than two nuclear power plant stations represented among the plant-specific raw data or less than three plant-specific data points. Another consideration that influenced the selection of sources and general guidelines for entry of data from sources is the desire to avoid duplication of data sets. For each data source, general criteria for selection of data to enter are presented in Appendix A.

Once a source is selected and $v$ eliminary data entry criteria have been established, all data meeting the criteria are entered. However, there still 
may remain records among the set entered from a source whose validity is dubious. For example, some PRAs present plant-specific data and then later discount selected data points because of some defect, such as the belief that the station records do not contain enough accessible information to assess the number of demands for a particular component and failure mode with sufficient accuracy. The "IRADAP Suitable" field in NUCLARR is an indicator that permits such records to be flagged and excluded from the aggregations that form the generic failure rates for this handbook.

In addition to known defects in the data, the IRADAP flag may be set for data points that are believed to be not applicable even though they were included in the initial assessment of data from a source. For example, a source may provide plant-specific data for a particular component for all U.S. commercial nuclear power plants. The IRADAP flag will be set for data from known atypical facilities, such as Ft. St. Vrain (a gas-cooled reactor), unless the INEL IRADAP team knows from other sources that the component application at such facilities is similar to a generic PRA application. Known atypical component boundaries would be another reason for setting the IRADAP flag.

A final reason for setting the IRADAP flag is that the corresponding data value (failure rate or demand probability) is significantly different from other sources as shown by plots of the data. This test can only be made for component/failure mode groups that have at least four data points with bounds (the bounds are discussed more in the next chapter). When a data value and its bounds stand out in comparison to values and bounds from other sources, one suspects either an atypical application or a data quality concern. In some cases, the difference can be explained. For example, if one source reports one or more failures and has much more data (much more service time) than other sources that report no failures, the source with failures will have a distinctly higher failure rate estimate than the others, and yet will still be valid.. When such explanations are lacking, atypical data points are excluded from the aggregations that form data for this handbook. 
Other fields are present in the data base that could influence the selection of data for aggregations that contribute to the rates presented herein. For example, the data could be restricted to U.S. domestic data, to data based on primary failures only, to data for which the boundaries include control circuits, to data based solely on nuclear grade components, or to data having only nuclear power plant operating experience as the failure data source. However, these restrictions are not made because the sparsity of the resulting data would reduce their usefulness and quality in characterizing the population variability that exists among failure rates at different sites. Furthermore, many sources do not give clear guidance on some of these topics; this would contribute even more to the data sparsity if records having "not specified" in some of these fields had to be excluded. These fields are present in the data base for possible future use when more data are available, and for current use in sensitivity studies directly accessing NUCLARR.

Table 2 provides a summary of the data quality considerations. In each case where the IRADAP $\mathrm{flag}$ is set, an explanation is provided in the record's comment field.

\subsection{USE OF JUDGEMENT}

An issue in processing the component failure data is the treatment of fields for which the data source information is incomplete. Although the data base has been designed to accomodate data that lack detail, its usefulness increases if some of the gaps in fields such as component design, system, nuclear grade, and component application can be filled. Using data from many plants to estabiish population variability curves is desirable; this is inhibited if the data for a particular component type and failure mode are splite into a common design category for the components and a "not specified" category, when in reality most of the latter data are probably also from the same common design category. Examples of specific situations of this type, and their treatment, are discussed below. 
Table 2. Reasons for Excluding Data

Reason

Not Applicable - Poor Quality Other Reasons

Data Source: Commercial nuclear power plant operational data

(PRA data or other sources that support PRAs)

Known atypical Underestimated

component

boundary

Known atypical

facility number of demands

Listed but not

used in PRA

Any known defect

in the data
Plot differences (see text)

Avoiding duplication of data

Data Source: Other (generic) sources

Not catastrophic Any known defect

Plot differences

Atypical

Avoiding duplication of data

Existence of at least 3 plantspecific data points from at least 2 stations

Two fields that have largely been encoded using judgement are normal state and safety grade. The normal state can often be inferred from a knowledge of the system and the failure mode. For example, auxiliary feedwater pumps are standby at nearly all commercial nuclear power plants. Another example is that the presence of a "spurious open" failure mode for a set of valves and no "spurious close" mode implies that the associate valves are normally closed.

The safety grade field is included in the data base because the design, inspection procedures, and test and maintenance environment of a component can be influenced by whether it is safety grade. Most components that are covered by technical specifications are safety grade. Thus, separate evaluations of components in safety-grade systems and non-safety grade systems may 
be useful. However, few data sources distinguish whether a component is safety grade. Therefore, the IRADAP team has assigned safety grade codes for selected records based on their system. Components in the Class $1 E$ power systems, the emergency onsite power supply system, systems that provide engineered safety features, and systems that actuate safety functions such as the plant protection system and engineered safety features actuation system are flagged as safety grade, while components in balance of $\mathrm{plant}$ systems are flagged as not being safety grade. For the remaining records, the safety grade remains unspecified unless it is provided in the source.

For data from PRAs, turbine-driven and diesel-driven pumps are nearly always separated out; these pumps are expected to have higher failure rates than motor-driven pumps because their supporting systems are more complicated. Therefore, in encoding PRA data, pumps whose drivis were not specified were assumed to be motor-driven unless the pumps wers in the following systems that are known to often have other types of drivers for pumps: auxiliary/emergency feedwater, high pressure coolant injection, reactor core isolation cooling, fire protection, and main feedwater.

The voltage application of main electrical distribution system breakers has in several cases been inferred by the IRADAP team from information contained in the report, Data Summaries of Licensee Event Reports of Relays and Circuit Breakers at U.S. Commercial Nuclear Power P1ants, January 1, 1976 to December 31, 1983 (draft NUREG/CR-4126, January, 1985, by S. R. Brown).

In these cases, the codes assigned are not always compared with plant sources such as drawings and safety analysis reports; thus, they are not known to be absolutely accurate. However, the assignments are reasonable and they are accurate in most cases. The increased usefulness of the data base makes these assessments worthwhile. 


\subsection{INTERFACE WITH NUCLARR}

Two methods have been used for input of data for the component failure data handbook to NUCLARR. For the first six PRAs listed in Table 1, PC-based data files were formed containing the data. A part of the NUCLARR data input software processed these files. Data from all the other sources have been entered using the regular NUCLARR data entry software, which displays a series of forms on a computer screen for entering the information needed for each record. Prior to data entry, coding sheets (printed versions of the blank forms) were filled out for each record.

For each of the 42 mechanical component types and each of the 33 electrical/instrumentation component types defined within NUCLARR, the NUCLARR data base can support a maximum of 250 records. The entry of records describing motor-driven pumps for each plant unit from the LER Summaries virtually filled this area of the data base. To enter further $p l a n t-s p e c i f i c$ data from Plant $X$ and the Swedish Reliability Data Book, some of the LER-based records were pooled. The LER-based records are regarded as having lower quality because LER reporting reflected in the Data Summaries depended on plant-specific technical specifications and thus varied among plants; also, plant-specific estimates of how often the pumps were started were not available for those studies. 


\section{DATA COMPUTATIONS}

Two types of calculations are performed by the NUCLARR system for the component failure data. The first is processing of individual records as they are entered into the system, while the second concerns tine cumbining or aggregating of failure rates from several sources for a particular type of failure. A brief discussion of these computations and adjustments for the component failure data handbook will help the handbook user better appreciate the significance of the medians, means, and bounds presented in the generic component failure data tables.

\subsection{Treatment of Single Data Points}

On data entry, the NUCLARR system computes a median, upper bound, and lower bound for each data point (if sufficient information is available). The error factor is defined as the upper bound divided by the median, and the lower bound is the median divided by the error factor. If a record supplies raw data (numbers of failures and corresponding operating hours or demand counts) and meets the criteria established in the NUCLARR system for homogeneity, upper tolerance bounds are computed using the raw data. The calculations are described in Volume 4 Part 3 of the NUCLARR series [Reference 2d]. The results of these computations are approximately as follows:

\begin{tabular}{cr}
$\begin{array}{c}\text { Number } \\
\text { of } \\
\text { Failures }\end{array}$ & $\begin{array}{r}\text { Assessed Upper } \\
\text { Divided by } \\
\text { (Error Fact }\end{array}$ \\
\cline { 2 - 2 } 0 & 8.4 \\
0 & 3.3 \\
1 & 2.6 \\
2 & 2.2 \\
3 & 2.0 \\
4 & 1.7 \\
7 & 1.5 \\
15 & 1.4 \\
20 & 1.3 \\
50 &
\end{tabular}

(This table contains ratios of 95 th percentiles to 50 th percentiles for 
chi-square distributions with two times the number of failures plus one as the degrees of freedom). Since approximately $90 \%$ of the data fall into this raw data category, bounds from most of the single-record failure rates reflect these conditions. Individual bounds show in the plots in Appendix B; most of the cases for which the median to upper bound span is one cycle on the logarithmic scale (and thus the error factor is approximately 10) are cases where no failures were observed.

In cases where no raw data are provided, bounds for individual points are computed from bounds in the data sources if these are available. The bounds are adjusted so that the upper bounds are approximately $95 \%$ bounds. In risk assessment, knowledge of upper bounds on failure rates is important in analyses the seek to limit the risk. Ore is seldom concerned about now small a failure rate might be. Therefore, lower bounds are simply plotted as medians divided by error factors, and do not appear in the generic component failure data tables.

The NUCLARR system retains point estimates of failure rates such as estimates directly cited in a data source or numbers of failures divided by numbers of demands. However, the means and medians used in this handbook are generated by the routines used in NUCLARR's ad hoc aggregation. This means that they fit a lognormal distribution.

\subsection{Treatment of Several Data Points}

Appendix $C$ describes the methods implemented in NUCLARR for combining and aggregating data from difference systems or plants. Some consequences of these methods that influence the interpretation of the upper bounds are presented here.

A common feature of the plots in Appendix B is that many points 1 ie outside, and particularly above, the plotted aggregated bounds. Three aspects of the methodology account for this phenomenon: 
- Points showing high failure rates are often cases where little experience is available (that is, often such points are high because the denominators are low)

- In aggregations using raw data, often the data are pooled. The aggregate is based on the combined experience of the various sources. In cases where many of the solrces show no failures, the resulting average (sum of numerators divided by sum of denominators) is lower than any of the values contributing to it

- The sources are weighted in proportion to the amount of experience that they represent. That is, individual rates (numbers of failures divided by numbers of demands or operating hours) having large denominators are most influential in the results. These rates are often, though not, always, among the lower values shown in the plots.

Two situations in the aggregation algoritims can give rise to low error factors. The first is the presence of a data point showing several failures and millions of operating hours or demands. A large number of failures drives down the uncertainty in the failure rate, as shown above. When these failures are associated with a data point showing a large amount of experience, other data sources showing a variety of rates have little influence due to the weighting of the data. This problem is compounded by the fact that data points that reflect a great deal of experience often have been pooled across several components; it is possible that these components as a group do not have a constant failure rate.

Second, lower error factors may also be the result of an anomoly in the upper bound calculation for the aggregation algorithm itself. As explained in Appendix $C$, the algorithm attempts to characterize the distribution of failure rates by considering different estimates of a rate rather than the uncertainty estimated for each individual rate. The Bayesian procedures estimate a variance between separate estimates of failure rates, subtracting out the variation associated with the individual estimates. Unusually low error 
factors result if, for example, two points are close together even though their individual uncertainty bounds are large.

\subsection{Adjustments to the nuClarR-Calculated Means and Bounds}

As noted above, the aggregation algorithms in some cases result in anomolies; for example, unusually low error factors have been observed. Causes for the low error factors were discussed above. Some variety is expected for generic rates that will apply across the nuclear power plant industry; thus, the heavy influence of just one point or two points that are close together as described above may not be desirable. Because, in both of these situations, the assumptions being used to model the data processing appear unrealistic, the software that generates tables for this handbook from NUCLARR adjusts low error factors. Specifically, error factors that are less than 1.5 are set equal to 1.5 and the upper bounds and mean values (based on a fitted lognormal distribution) are recomputed. 


\section{GENERIC COMPONENT FAILURE DATA}

Generic aggregated failure rates for components and failure modes based on data gathered in late 1987 and entered into the NUCLARR data base in 1988 and early 1989 are presented in a series of four tables following the text in this section. Two levels of detail are provided. Tables 3 and 4 present, respectively, data for mechanical and for electrical/instrumentation components by just component type and failure mode. These tables contain the most aggregated rates, with little detail required to qualify a record for inclusion in the aggregate. For many component type groups, only a single failure rate or probability for each failure mode is required for gross screening purposes, and Tables 3 and 4 provide this level of detail. The entries are listed in order by the codes used in the NUCLARR data base; this corresponds to an alphabetical ordering in most cases. Note that, for miscellaneous groups such as "electrical function items," no group-level aggregate is formed.

In Tables 3 and 4 , seven pieces of information are given for the corresponding aggregate. They are: the units [per hour $(h)$ or per demand (d)], the number of data base records contributing to the rate, four parameters from the derived lognormal distribution, and a comment on the data source. The lognormal parameters are the mean, median, upper $95 \%$ bound, and error factor. The Source column contains data source acronyms or "Study-IDs" from Appendix $A$ if less than three sources are involved. Where there are two sources, numbers in parentheses after the study-ids indicate the number of records from each source contributing to the aggregated data. If three or more sources are involved, the Source column contains the number of sources followed by "/Plant" for operational data from commercial nuclear power plants, "/Generic" for generic data from other sources, or "/Both." Data are classified as operational data from commercial nuclear power plants if the "Failure Data Origin" field in NUCLARR is "PLNT"; for "IRADAP Suitable" records this means that maintenance work orders or other in-depth $\mathrm{plant}$ records were examined to determine the failure rates. 
For applications requiring more detail than just component type and failure mode, Tables 5 and 6 are provided. These tables are in the same format as Tables 3 and 4 , but characterize the rates by component design and normal state in addition to the obvious component type and failure mode.

In generating Tables 5 and 6 from NUCLARR, the term "operating" was substituted for the normal state in place of "running" in some cases to increase clarity. This change was made whenever the normal state was listed as running and the failure mode was "fail to operate" or "spurious operation." "Not specified" is a possible value for the design (these are denoted as "Unknown" in NUCLARR). Similarly, "Unspecified" appears in these tables when the normal state is unknown. In addition, "general (preaggregated)" is a possibility for the component design. This designation indicates that the corresponding data were classified as preaggregated; i.e., as reflecting a mixture of the component designs. NUCLARR records from sources such as IEEE-500 that supply data combined across component designs contribute to these entries.

Some overlap exists in Tables 3 and 5 and in Tables 4 and 6 . Records for component types having only one design defined, such as battery chargers, contribute in the same way to both the generic failure data tables and the more detailed tables. The same is irue in cases where a group-level aggregate is formed and all the data contribu ing to that aggregate come from one component design. On the other hand, only Tables 3 and 4 have aggregates across component designs and only Tables 5 and 6 have data for component designs that are in groupings for which a component-type-level aggregate is not meaningful. Specifically, the following are only in Tables 5 or 6:

\section{Elbows}

\section{Nozzles}

Auctionneers, averagers, and other specific computation modules

Inverters, controlled rectifiers, and other solid state power electranics

Some applications may require additional detail, such as knowledge of the specific system or a particular plant unit. Tables containing aggregated rates for data grouped by one of these variables in addition to the variables 
in Tables 5 and 6 are not presented herein, because of the extreme sparsity of such data. Many records in NUCLARR lack plant unit information, and even more 1 ack system details.

For applications requiring such additional detail, Part 3 , Hardware Component Failure Data, of Volume 5 of the NUCLARR documentation [Reference 2e] lists the supporting data that contribute to each aggregate. It contains a data sheet for each of the records in the NUCLARR hardware component failure data base. The records are listed in order by component type, design, failure mode, and normal state. Virtually all information stored in the data base is listed. The sheets which have a " $y$ " for the "IRADAP Suitable" entry, a data input date before June 8, 1989, and an earlier year than "1989" as the NUCLARR document reference year are included in the aggregates shown in this handbook. a

In addition, the plots of the data included in Appendix B provide further information for component/failure mode/design/normal state groupings having at least four records. The reader can form more tailored aggregations using these data. Access to NUCLARR allows such aggregations to be performed automatically.

Note that, aithough "fail to open" and "fail to close" are special cases of the "fail to operate" failure mode, the data tables do not contain data aggregated across failure modes. The presentation of this type of aggregation in the tables is cumbersome since such aggregates must be distinguished from rates that are based solely on the more general failure mode categories. Also, the user might want to sum such rates rather than average them. Again, reference to the NUCLARR documents or access to NUCLARR will allow the user to form such rates if desired.

\footnotetext{
a. Recall from Table 1 that data werf received for entry to NUCLARR ton late to be included in this handbook.
} 


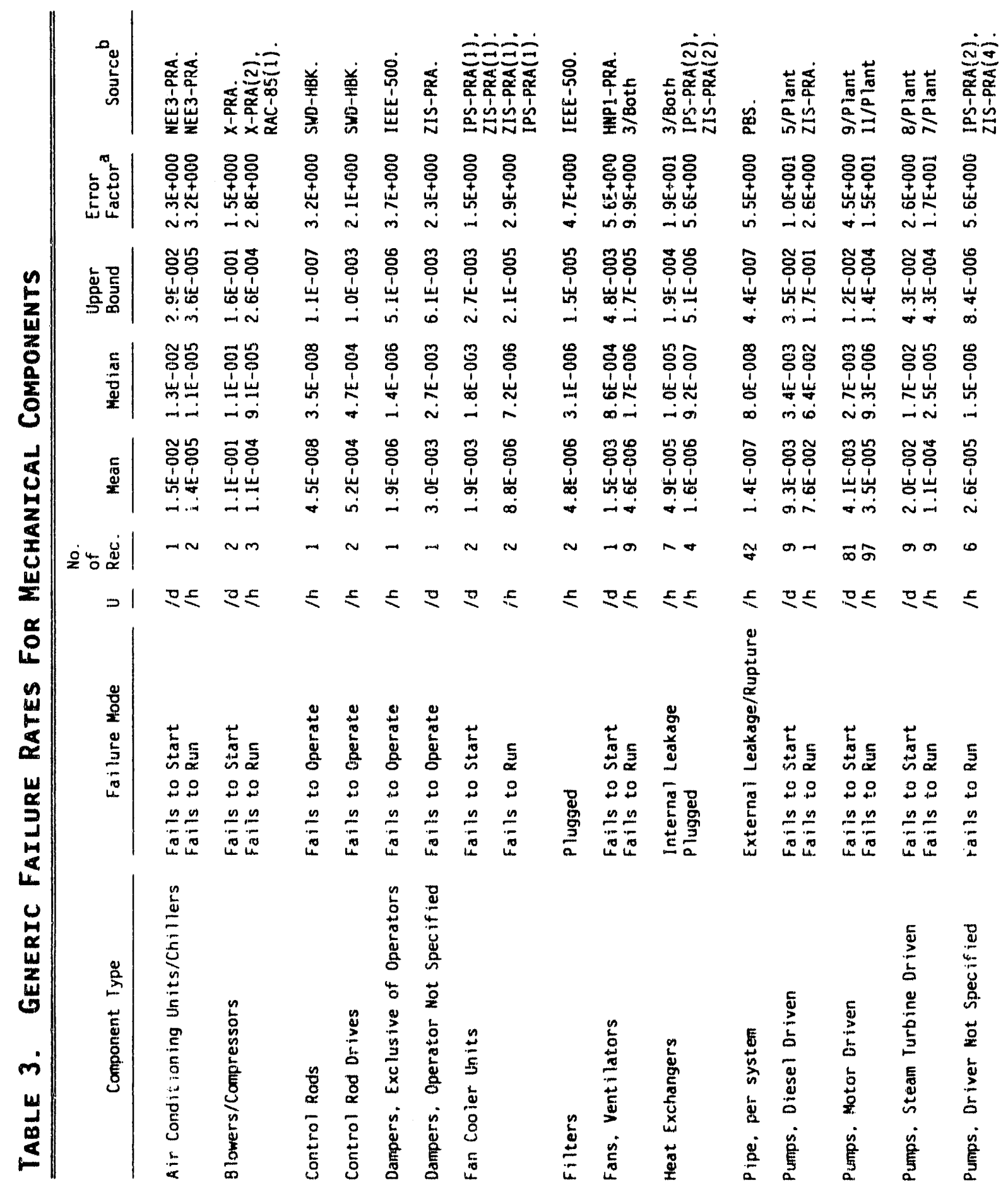




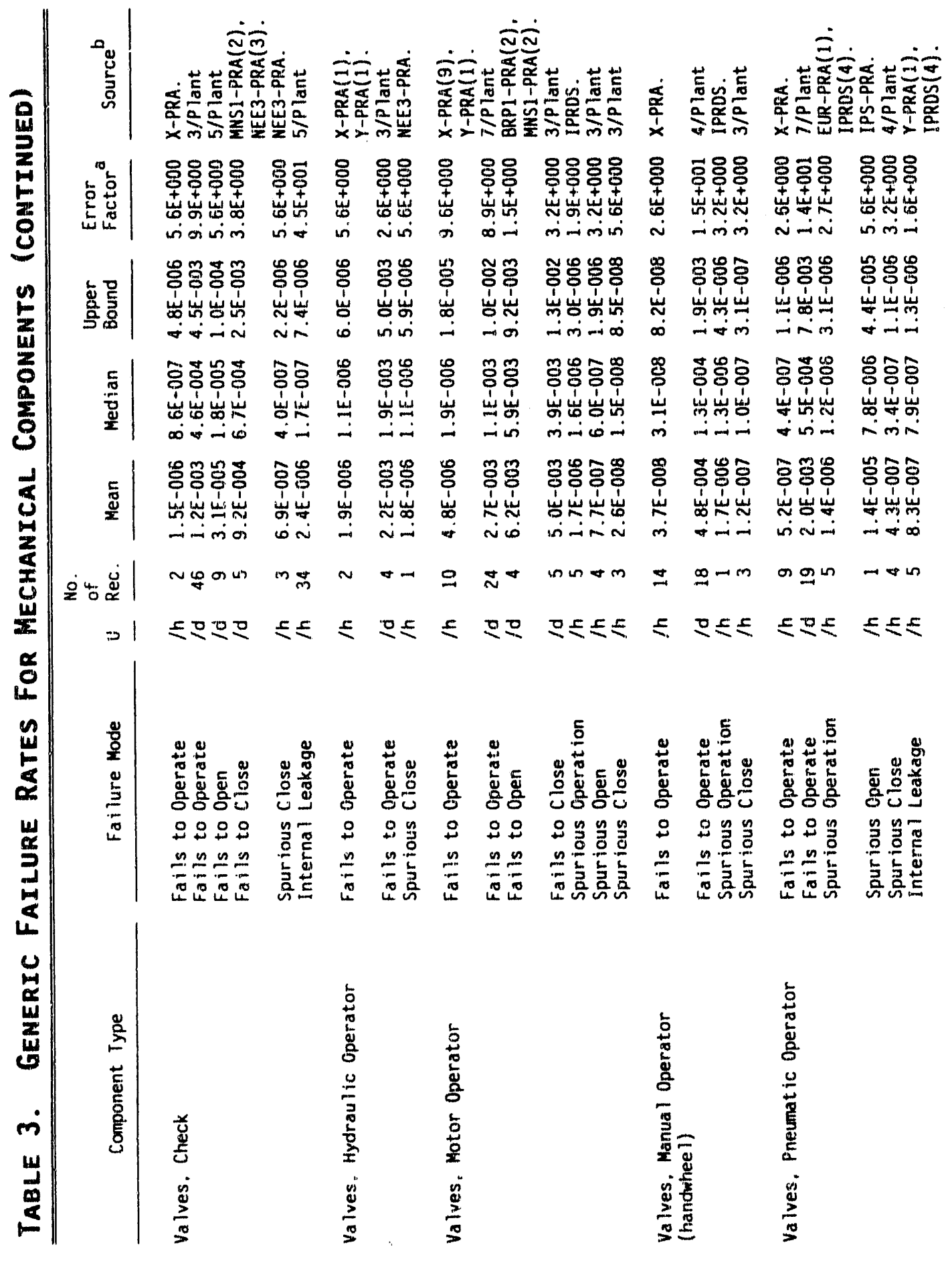




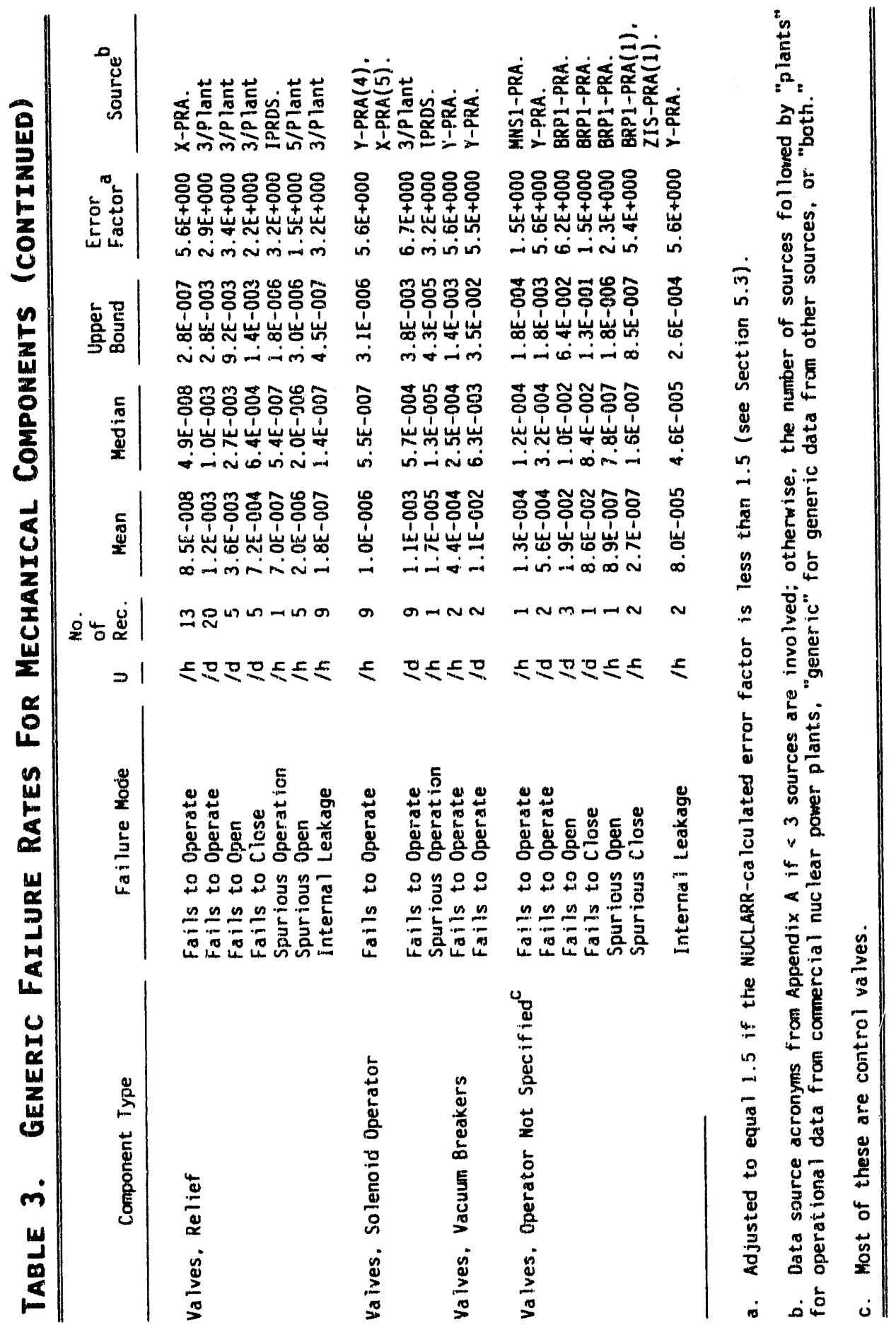




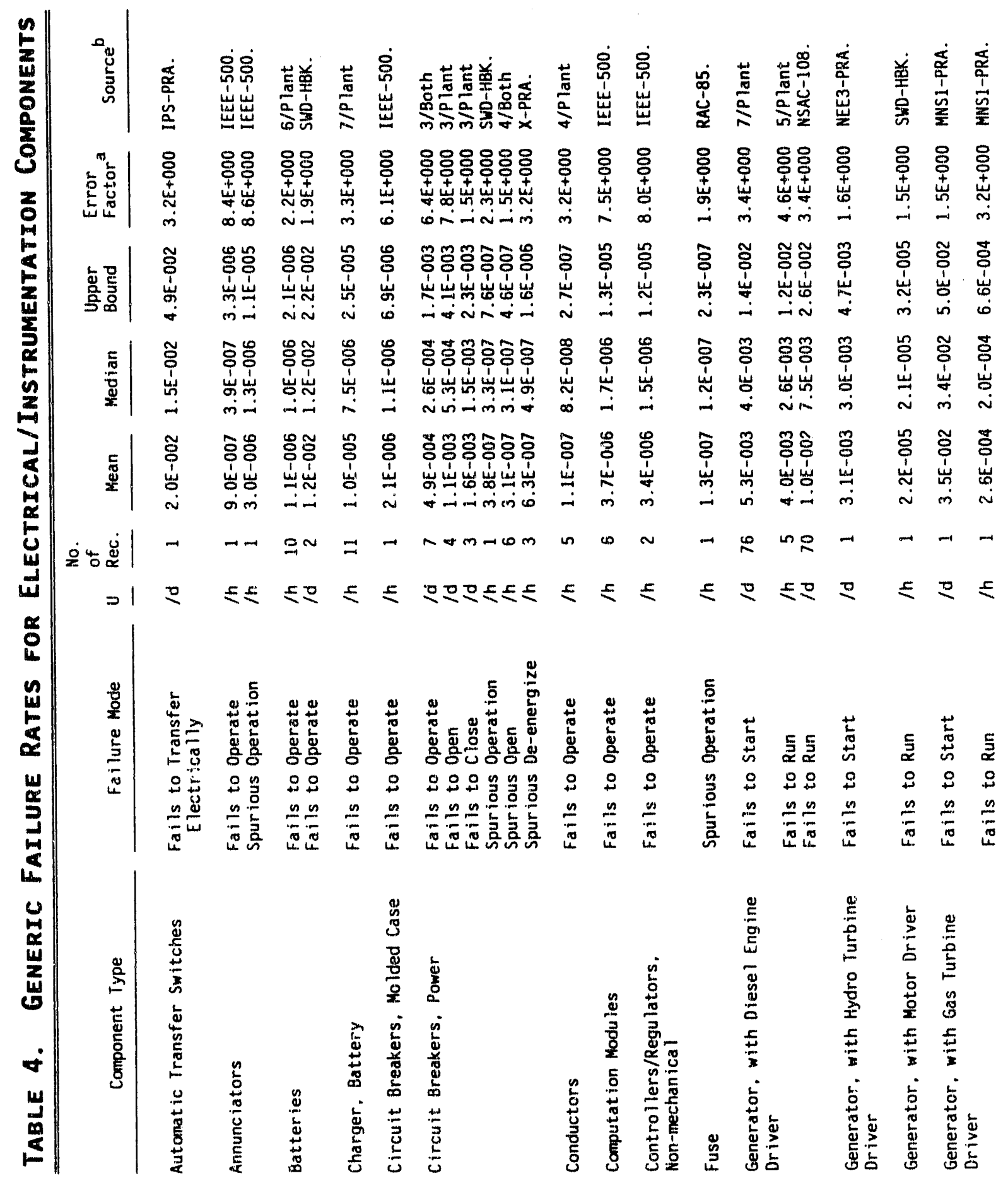




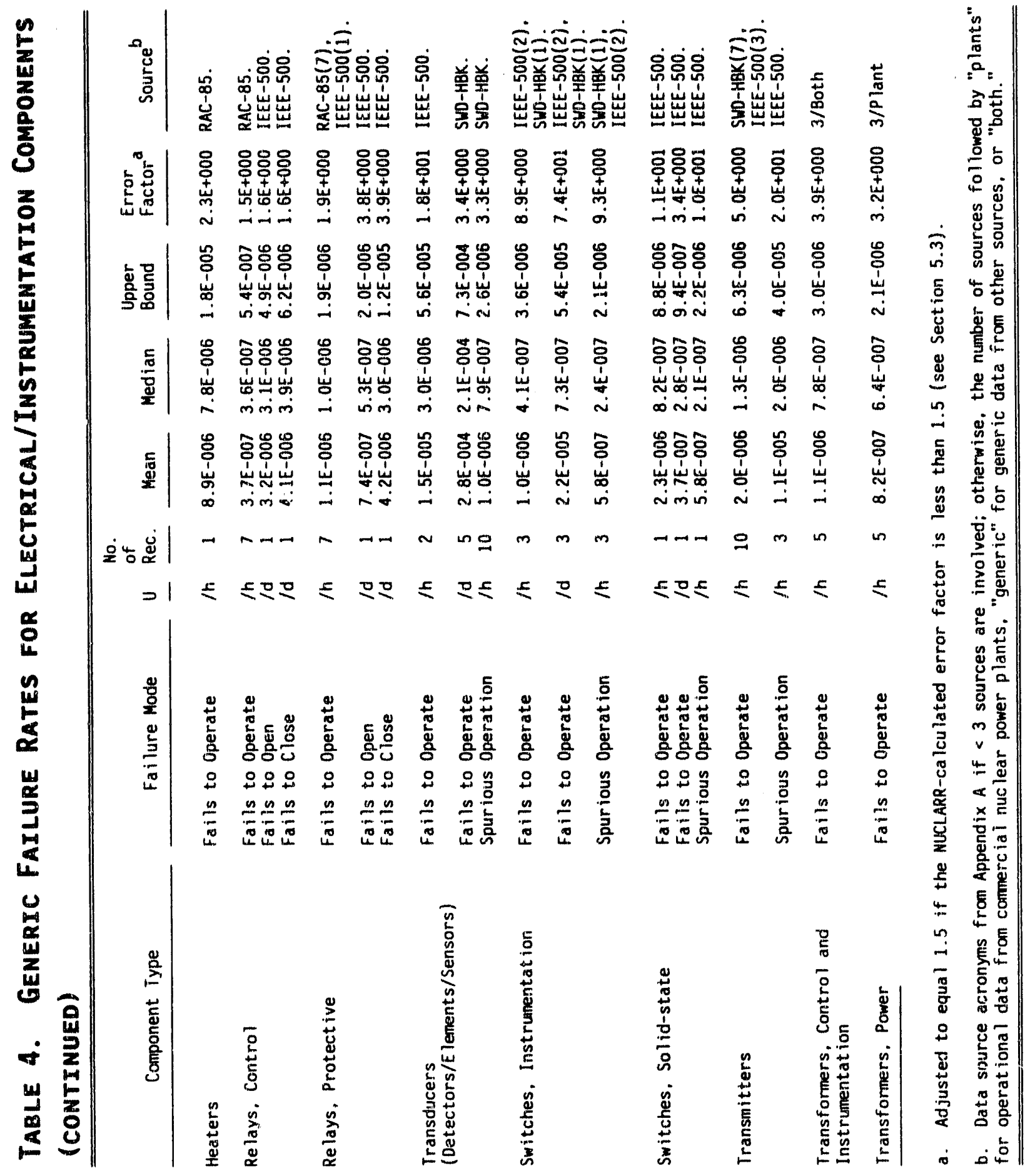




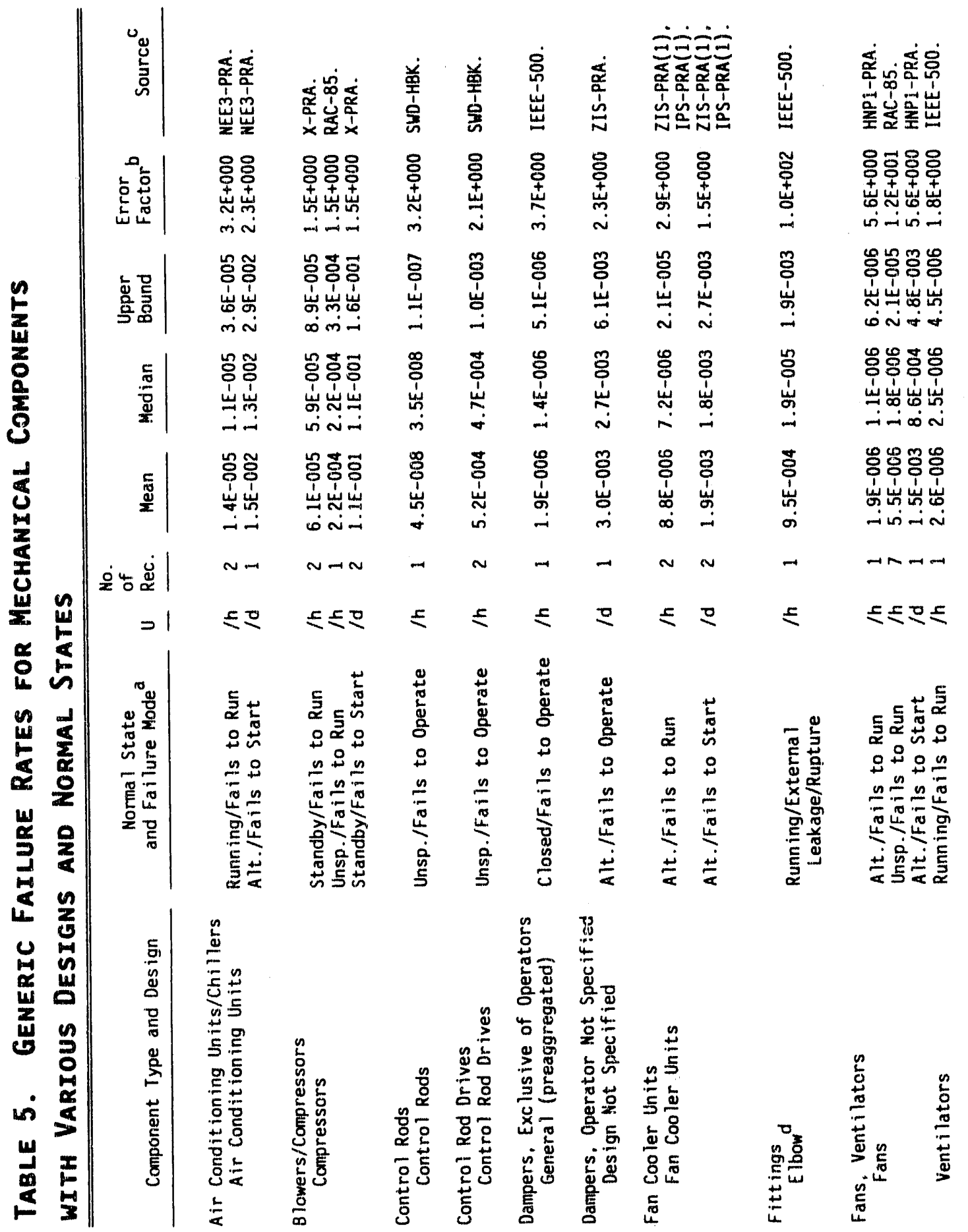




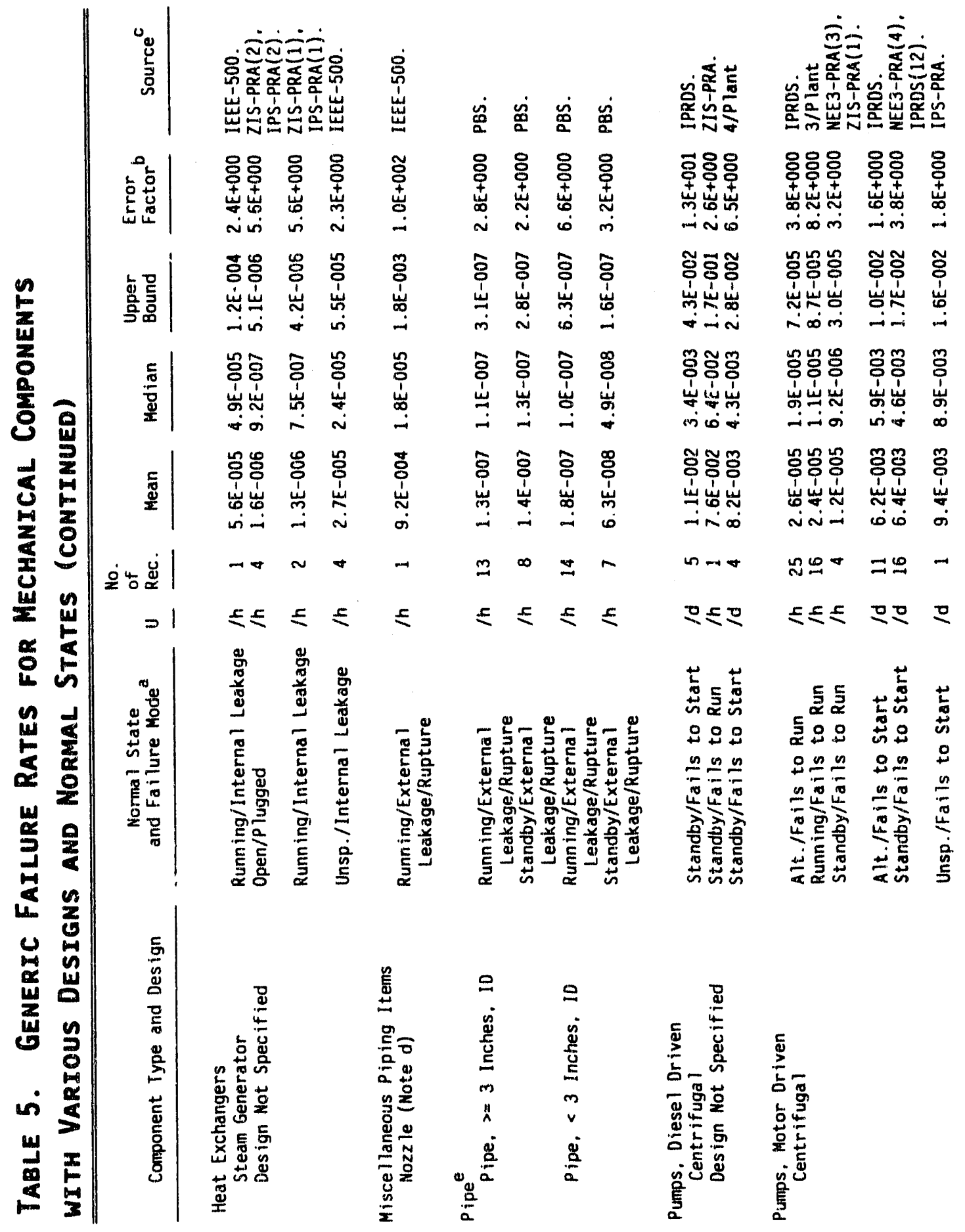




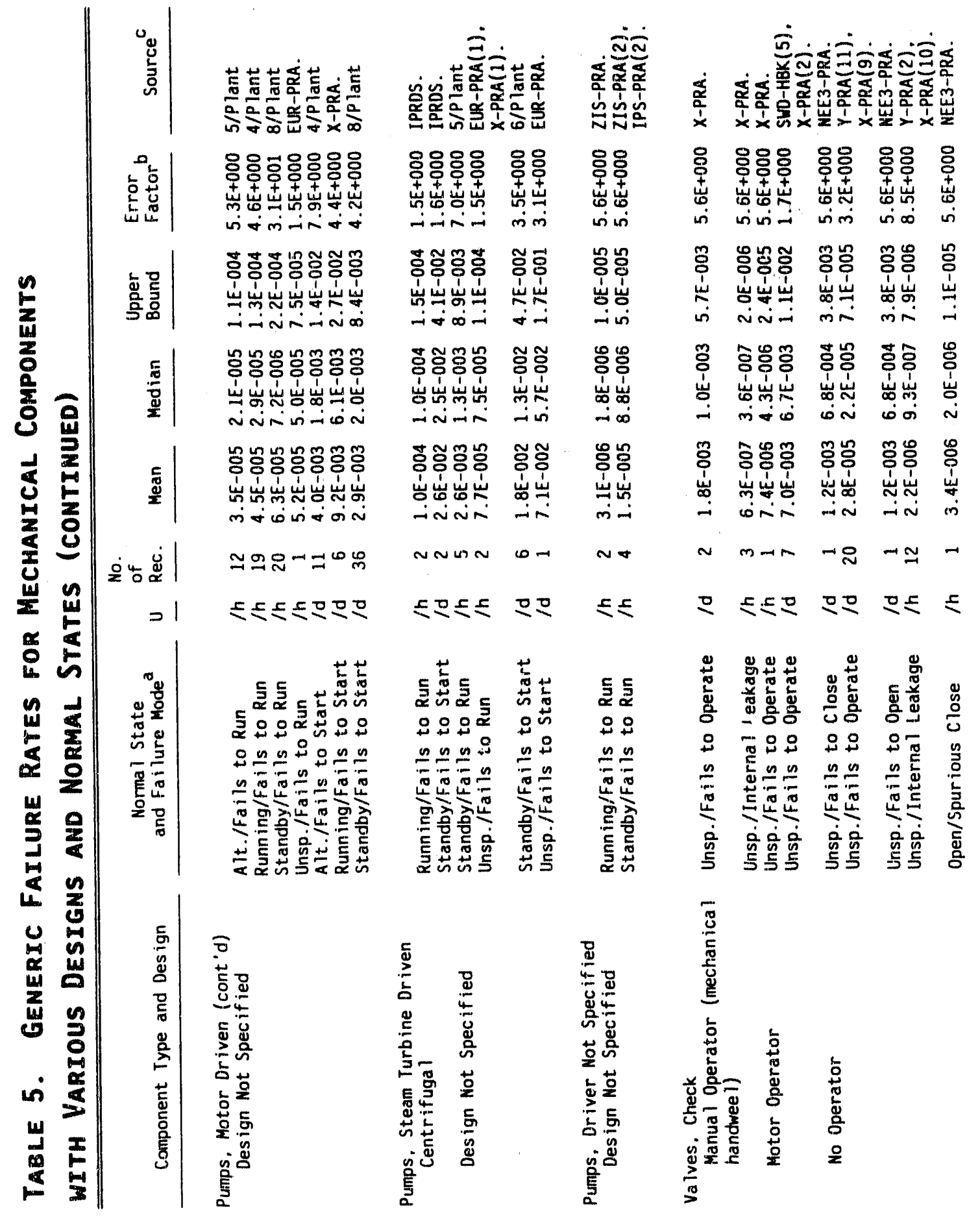




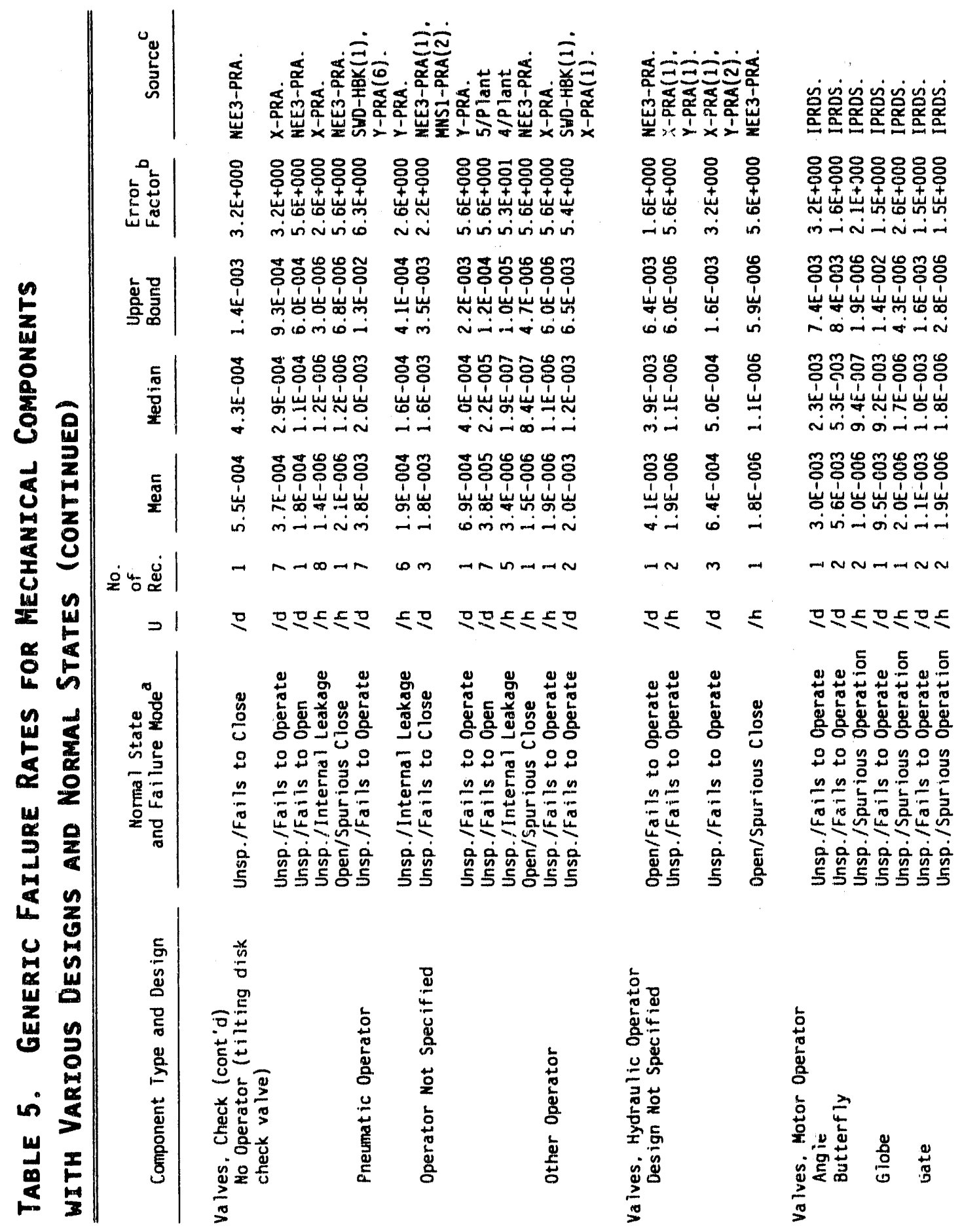




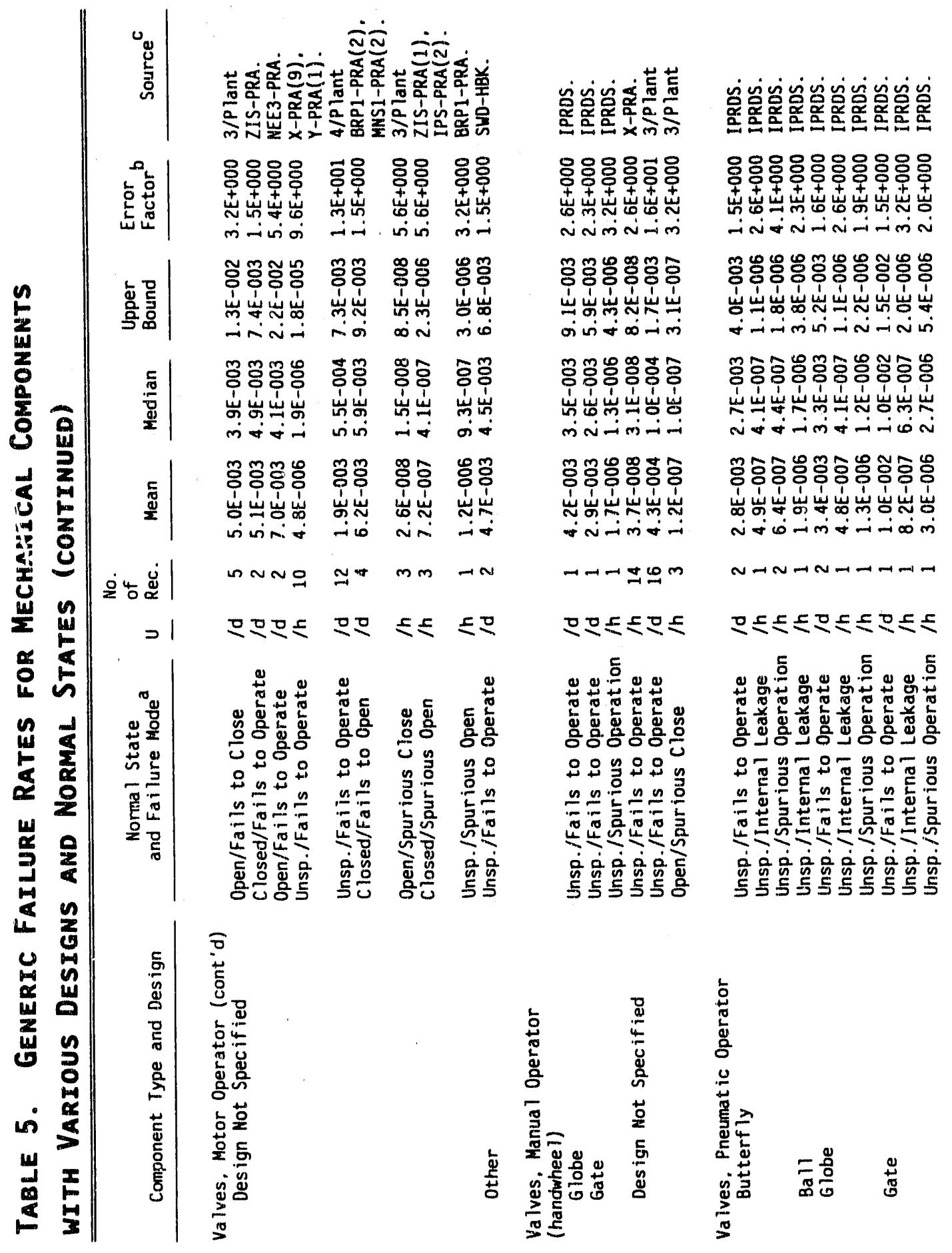




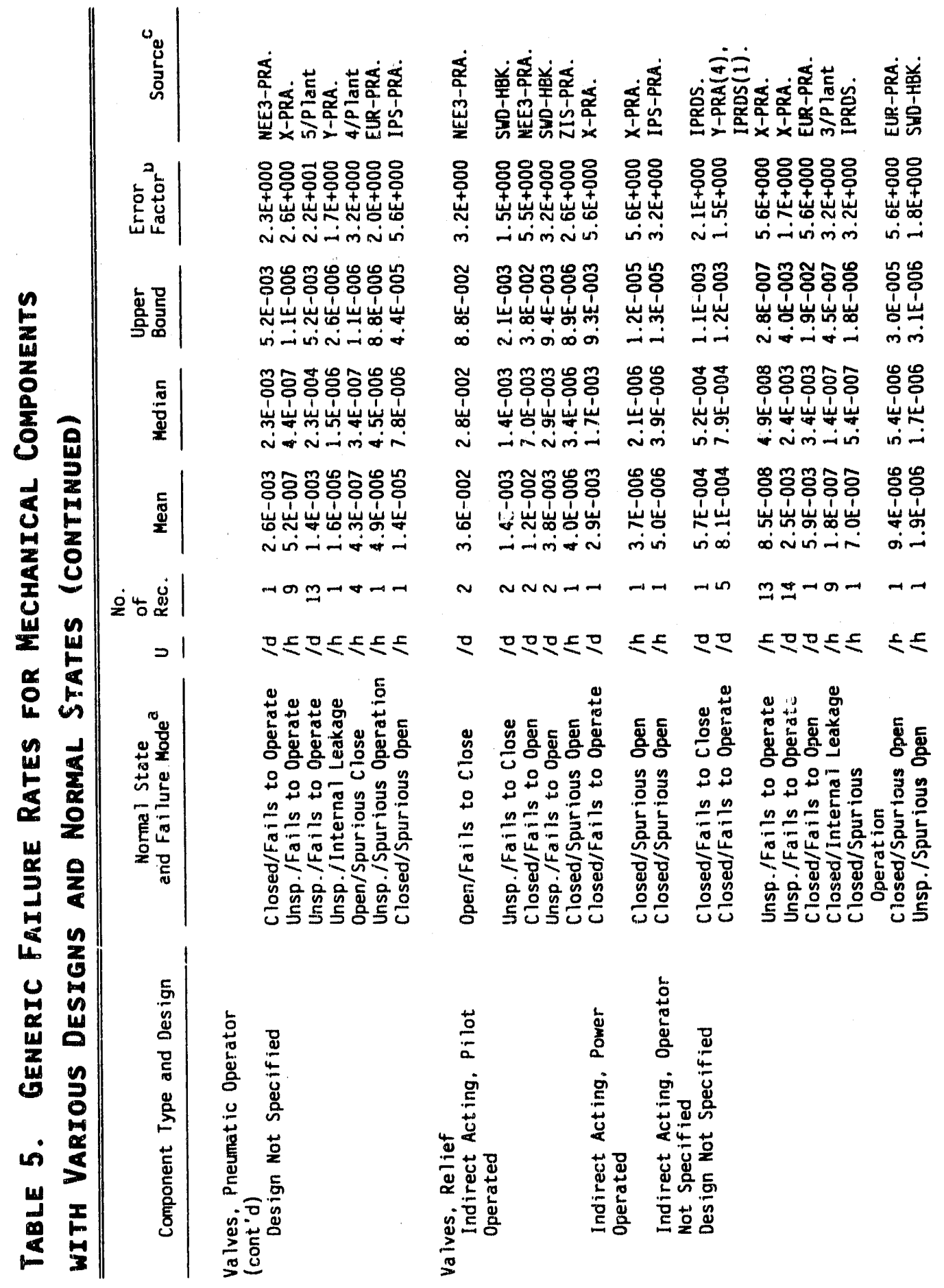




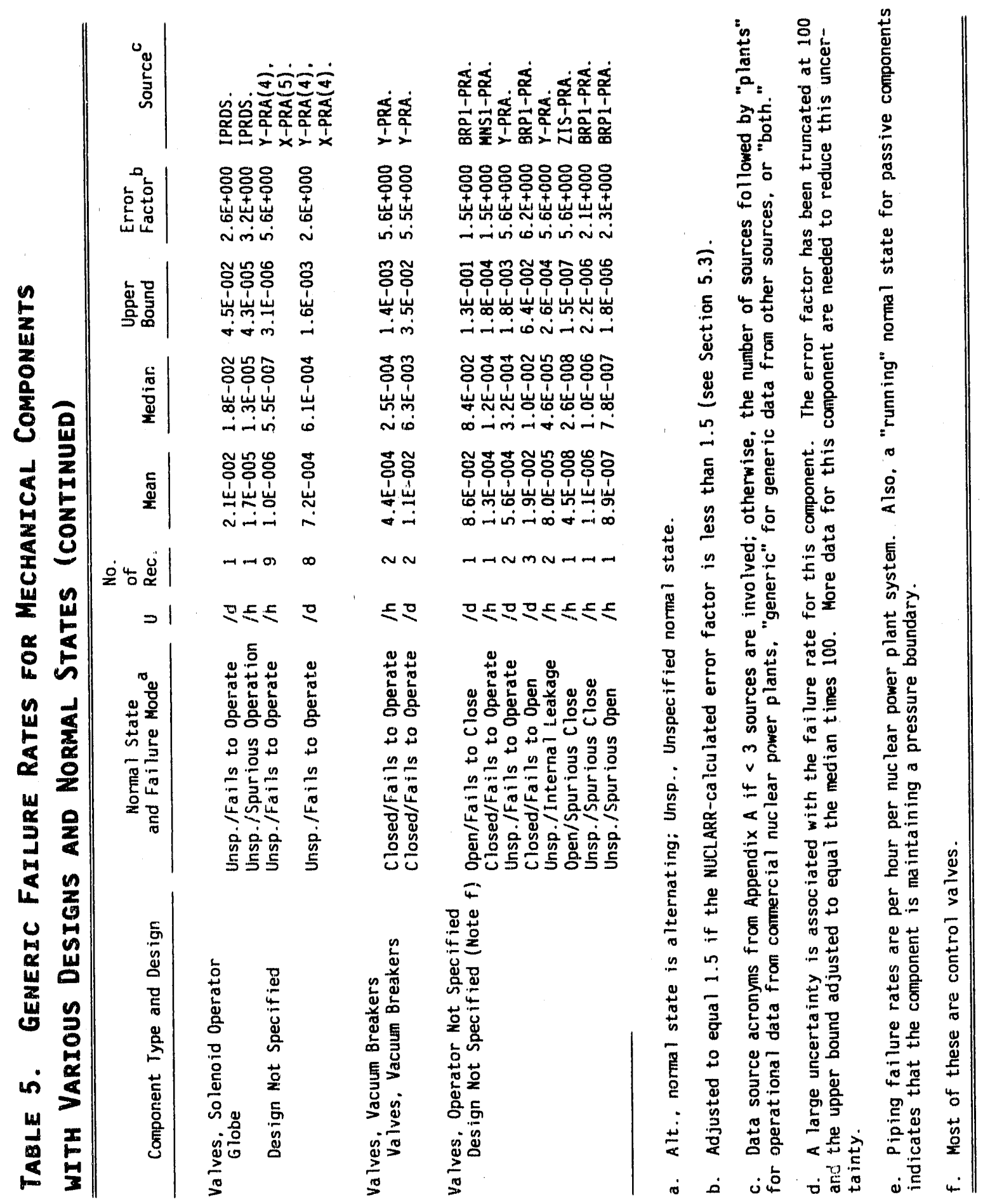




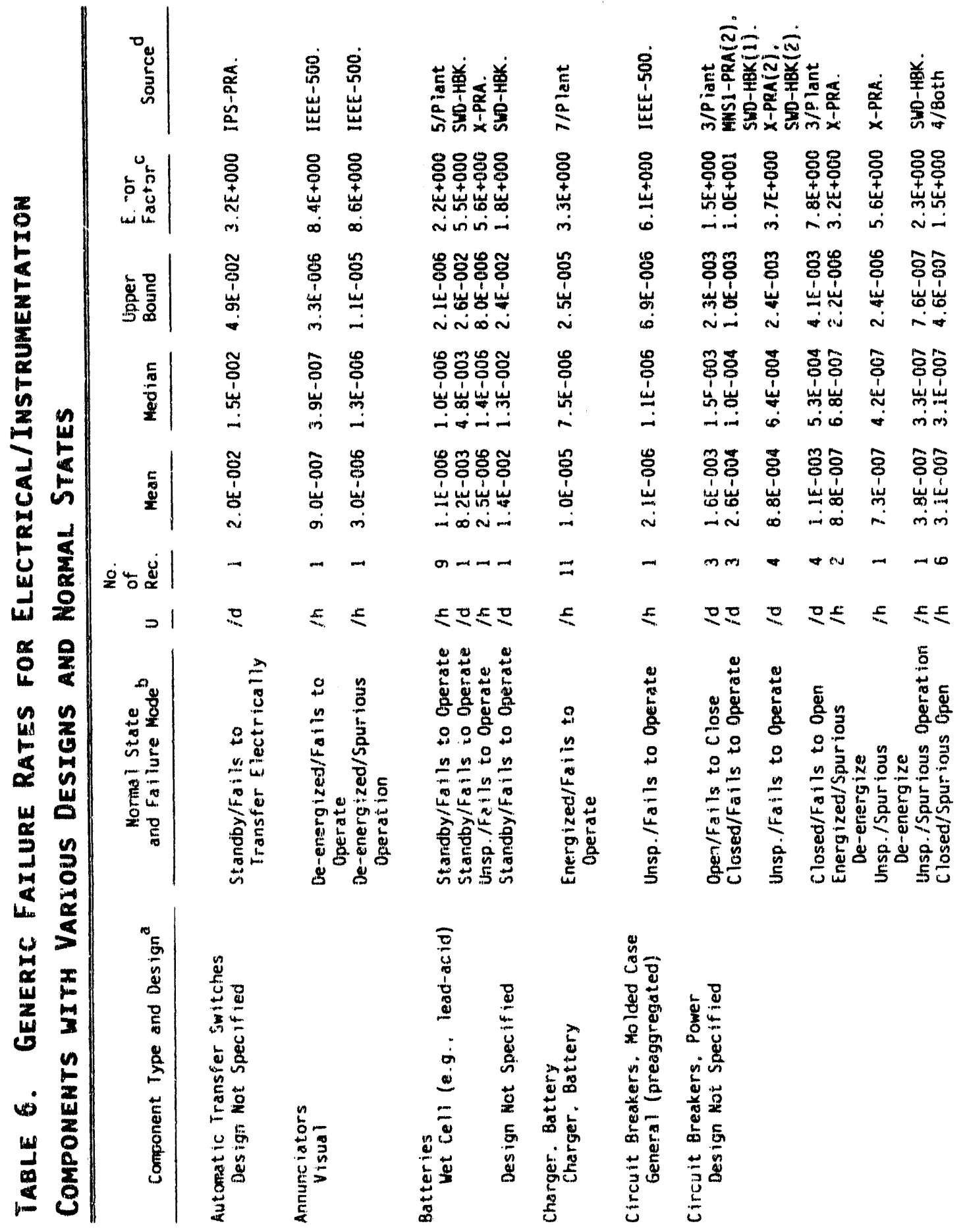




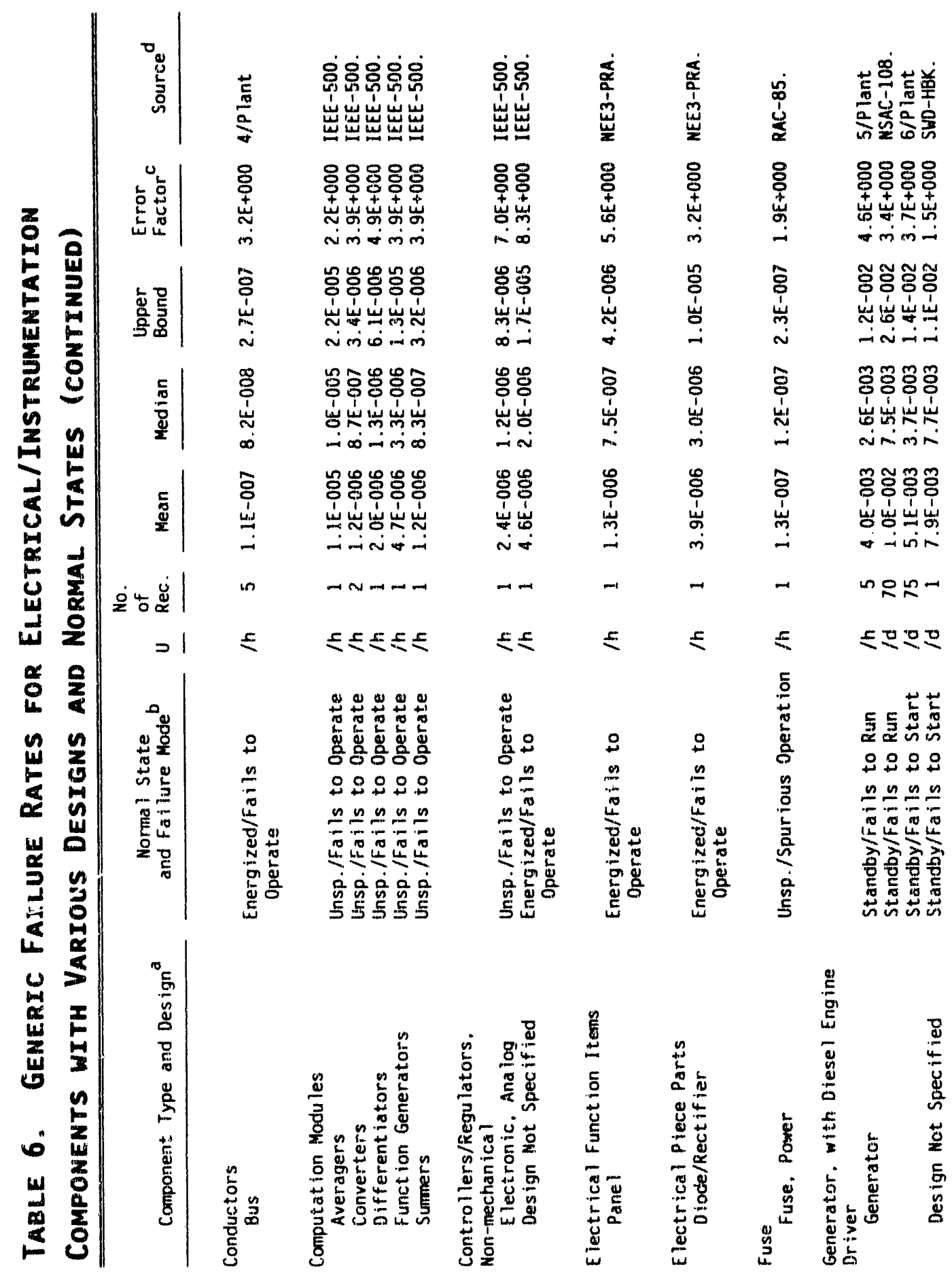




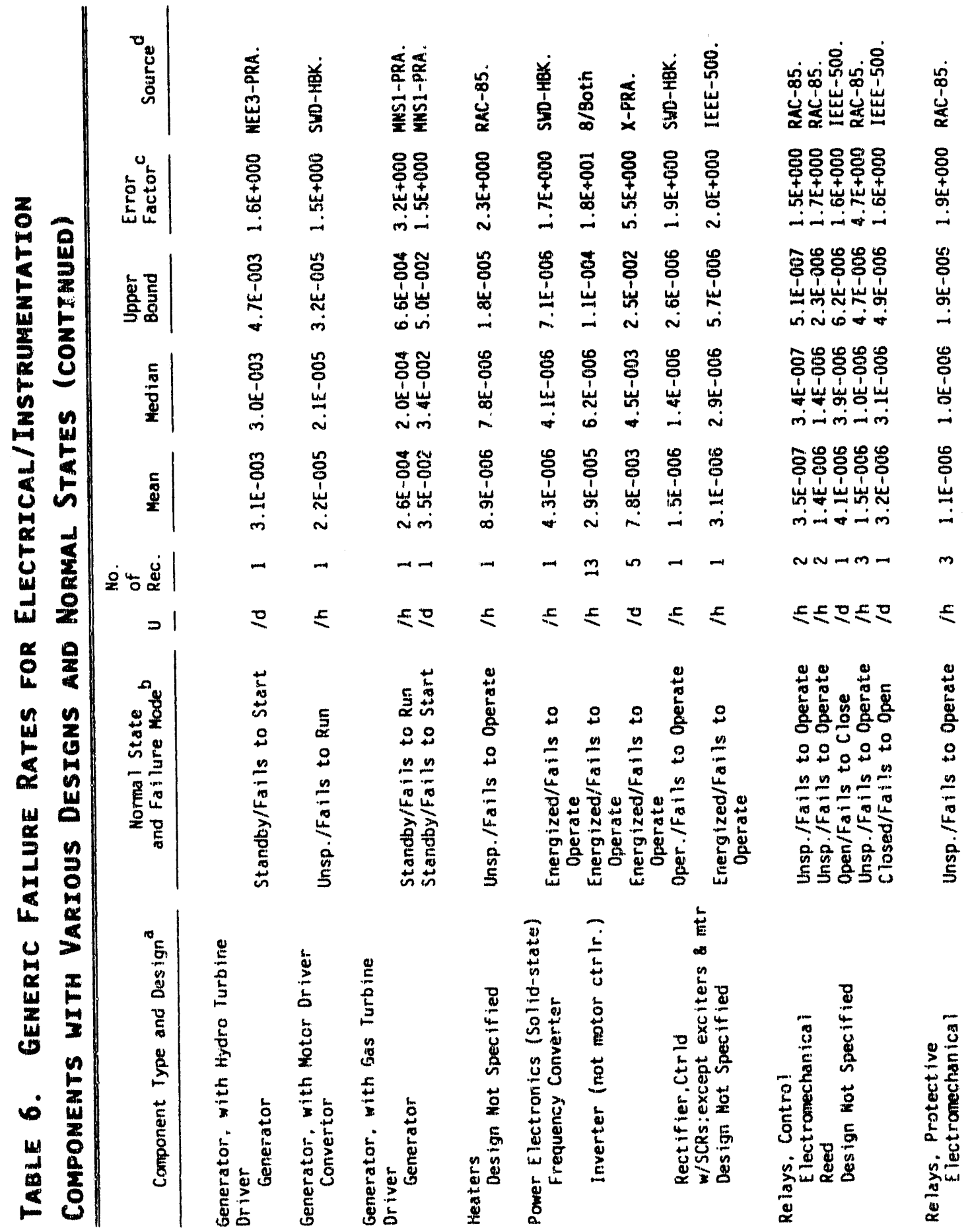




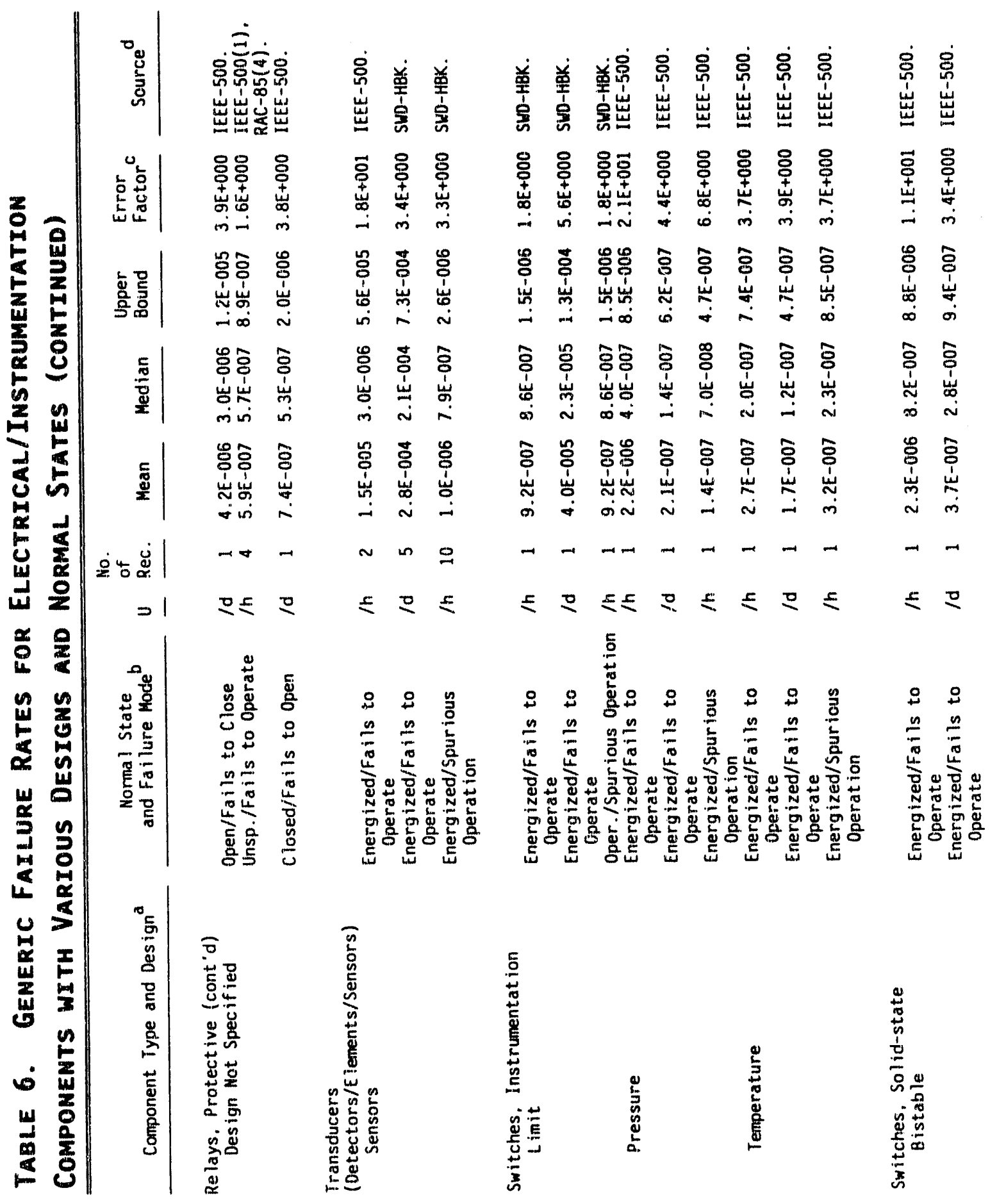




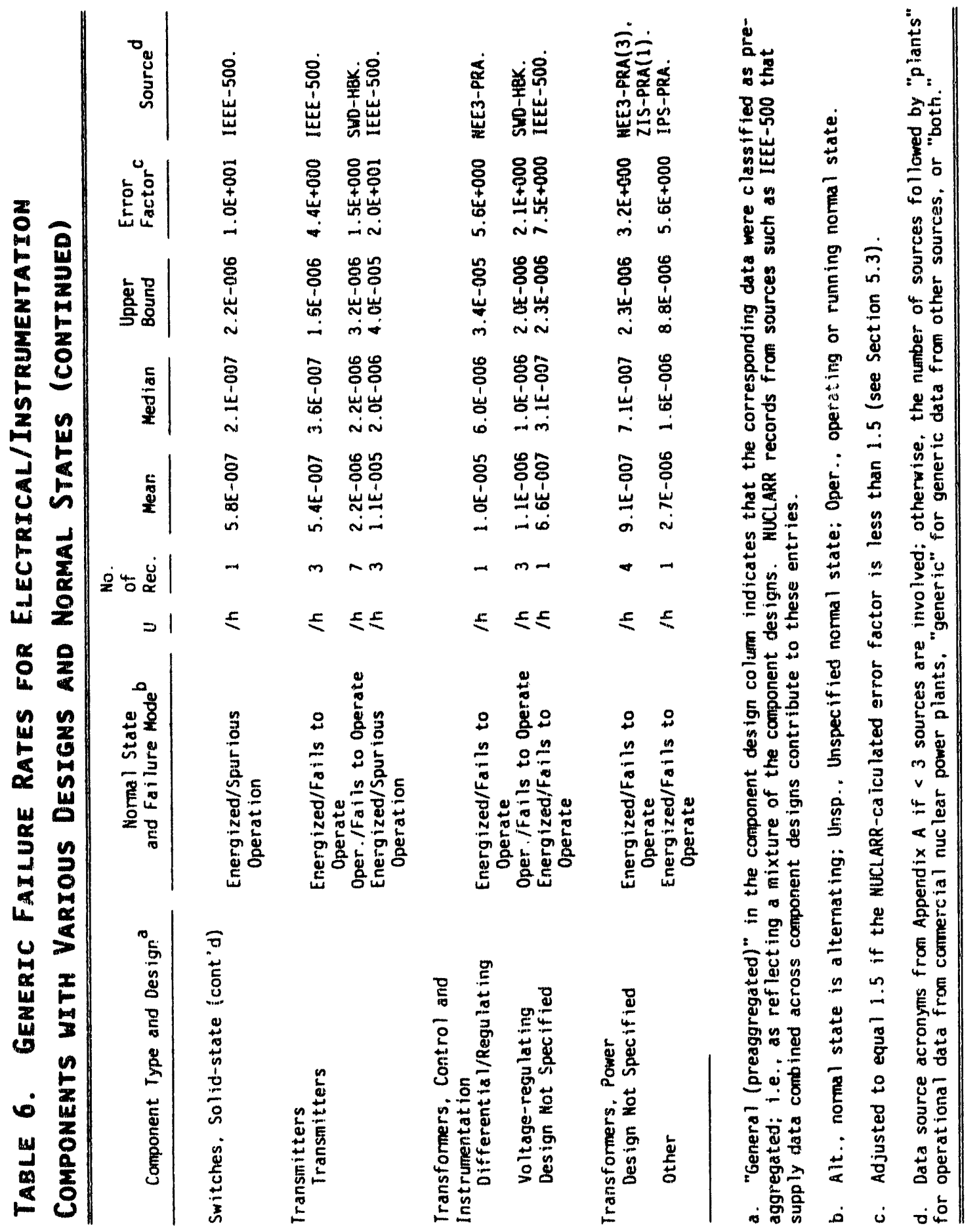




\section{QUALITY OF DATA IN THE HANDBOOK}

Although collected in 1987, the data in this handbook may be useful as a source of generic component failure rates for components that are typically found in risk assessments. These data offer some advantages over other generic failure data sources.

Past generic failure data sets developed for use in USNRC-sponsored risk assessments have been based largely on expert judgement. For example, the National Reliability Evaluation Program (NREP) developed a generic data set by assembling data experts from across the nuclear power plant industry and obtaining their concensus on values to be used for screening purposes in PRAs. ${ }^{5}$ More recently, the Risk Management Integration and Evaluation Program (RMIEP) has developed a data base for the La Salle PRA by using judgement in selecting from past generic data sources. ${ }^{6}$ The same is true for much of the generic data used in the NUREG-1150 Reactor Risk Document studies; ${ }^{7}$ a major source of generic data for this series of risk evaluations has been the Interim Reliability Evaluation Program (IREP) Procedures Guide ${ }^{8}$ and it contains the NREP data.

This handbook differs from generic component failure data sources used in past USNRC-sponsored risk assessments because this represents the first USNRC-sponsored effort to collect in one place the existing published component failure rates that are based on U.S. commercial nuclear power plant operational data. Thus, the data herein are based on U.S. commercial nuclear power $\mathrm{plant}$ experience. This $\mathrm{plant}$ experience serves as a baseline, thus reducing any dependence on expert judgement to obtain generic component failure rates (of course, expert judgement is always required in the processing and interpreting of operational events and other plant information to obtain failure rates).

The data tables show the number of data points and data sources contributing to each failure rate estimate. This information helps the user assess 
the credibility of the data and shows where additional data collection efforts would be warranted. Because of the care taken not to duplicate data, rates that are backed by many sources represent experience across the nuclear power plant industry and are not likely to be biased by plant-specific data from possibly atypical plants.

Although this handbook is based mostly on plant experience data, other sources have been used. They are only to fill gaps, and all such instances are clearly identified in the enclosed data tables. Furthermore, all such uses are fully traceable. Page numbers are provided in NUCLARR for every data point, and an appendix discusses the general features of each source.

Another feature of the data base is its quality assurance. Automated checks ensure the validity and reasonableness of every entry. In addition, over half of the records for the component failure data handbook have been compared with the original sources after entry into NUCLARR.

Finally, when data from different sources are combined, the aggregation routines use standard techniques to capture the population variability. Plots allow the user to further assess the compatibility of different sources.

The existence of the NUCLARR data base itself is another asset; one can acquire NUCLARR and do one's own tailoring of the data for specific applications and sensitivity studies. 


\section{REFERENCES}

1. 0. V. Hester, C. D. Gentillon, and J. R. Fragola, Evaluation of the NRC Operational Data Requirements, EGG-REQ-7361, August 1986.

2a. D. I. Gertman, W. E. Gilmore, W. J. Galyean, M. R. Groh, C. D. Gentillon, B. G. Gilbert, Nuclear Computerized Library for Assessing Reactor Reliability (NUCLARR) Volume 1: Summary Description, NUREG/CR-4639 (EGG-2458), February 1988.

2b. G. Beers, 0. J. Call, Nuclear Computerized Library for Assessing Reactor Reliability (NUCLARR) Volume 2: Programmer's Guide, NUREG/CR-4639 (EGG-2458), August 1988.

2c. W. E. Gilmore, D. I. Gertman, B. G. Gilbert, W. J. Galyean, Nuclear Computerized Library for Assessing Reactor Rel iability (NUCLARR) Volume 3: Data Base Management Guide for Processing Data and Revising the Data Manual, NUREG/CR-4639 (EGG-2458), November 1988.

2d. W. E. Gi7more, C. D. Gentillon, D. I. Gertman, G. H. Beers, W. J. Galyean, B. G. Gilbert, Nuclear Computerized Library for Assessing Reactor Reliability (NUCLARR) Volume 4: User's Guide, NUREG/CR-4639 (EGG-2458), June 1988.

2e. D. I. Gertman, B. G. Gilbert, W. E. Gilmore, W. J. Galyean, Nuclear Computerized Library for Assessing Reactor Reliability (NUCLARR) Volume 5: Data Manual, NUREG/CR-4639 (EGG-2458), June 1988.

3. 0. V. Hester, S. R. Brown, and C. D. Gentillon, Annotated Bibliography of Reliability and Risk Data Sources, NUREG/CR-5050 (EGG-REQ-7827), March, 1988 .

4. J. R. Fragola, P. Appignani, M. Studzke, Component Reliability Parameter System Data Sheets, Science Applications Internationai Corporation, September 1987 (unpublished).

5. A. J. Oswald, C. D. Gentillon, S. D. Matthews, and T. R. Meachum, Generic Data Base for Data and Models Chapter of the National Reliability Evaluation Program (NREP) Guide, EGG-EA-5887, June 1982.

6. A. C. Payne, Jr., February 3, 1987 correspondence from Sandia Laboratories to Oren Hester at EG\&G Idaho, Inc.

7. M. T. Drouin, F. T. Harper, A. L. Camp, Analys is of Core Damage Frequency from Internal Events: Methodology Guidelines, Volume 1, NUREG/CR-4550 (SAND86-2084), September, 1987.

8. D. D. Carlson, Interim Reliability Evaluation Program (IREP) Procedures Guide, NUREG/CR-2728, SAND 82-1100, January 1983. 


\section{APPENDIX A}

\section{COMPONENT FAILURE DATA SOURCES}




\section{CONTENTS}

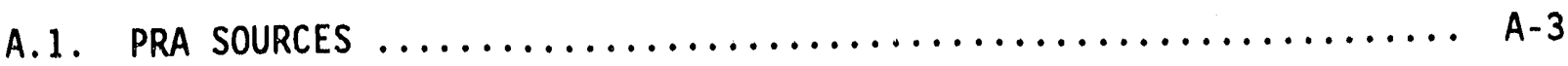

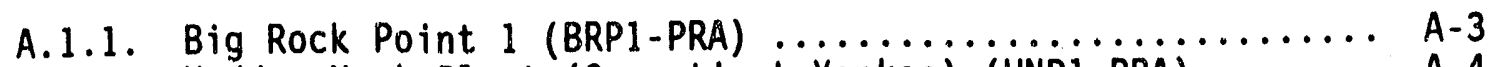

A.1.2. Haddam Neck Plant (Conneticut Yankee) (HNP1-PRA) ........ A-4

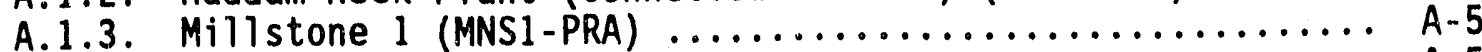

A.1.4. Indian Point 2 (IPS2-PRA) $\ldots \ldots \ldots \ldots \ldots \ldots \ldots \ldots \ldots \ldots \ldots \ldots \ldots \ldots \ldots \ldots \ldots$

A.1.5. Zion Station (ZIS-PRA) $\ldots \ldots \ldots \ldots \ldots \ldots \ldots \ldots \ldots \ldots \ldots \ldots \ldots \ldots \ldots \ldots \ldots \ldots$

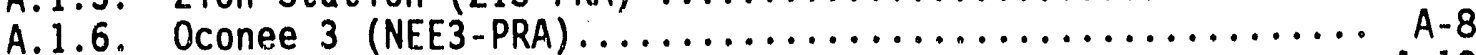

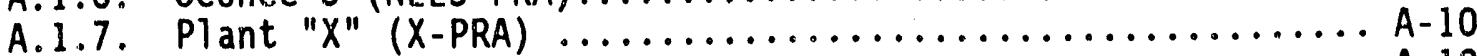

A.1.8. Plant "Y" (Y-PRA) $\ldots \ldots \ldots \ldots \ldots \ldots \ldots \ldots \ldots \ldots \ldots \ldots \ldots \ldots \ldots \ldots \ldots \ldots \ldots \ldots \ldots \ldots \ldots \ldots \ldots, 12$

A.1.9. European Plant (EUR-PRA) $\ldots \ldots \ldots \ldots \ldots \ldots \ldots \ldots \ldots \ldots \ldots \ldots \ldots \ldots \ldots \ldots \ldots \ldots$

A.2. ADDITIONAL DATA SOURCES $\ldots \ldots \ldots \ldots \ldots \ldots \ldots \ldots \ldots \ldots \ldots \ldots \ldots \ldots \ldots \ldots \ldots \ldots \ldots \ldots$

A.2.1. IEEE-Standard 500-1984 (IEEE-500) ................ A-14

A.2.2. In-Plant Reliability Data System (IPRDS) $\ldots \ldots \ldots \ldots \ldots \ldots$ A-18

A.2.3. Swedish Reliability Data Book (SWD-HBK) $\ldots \ldots \ldots \ldots \ldots \ldots$.

A.2.4. Reliability Analys is Center (RAC) .................... 22

A.2.5. Reliability of Emergency Diesel Generators (NSAC-108) ...A-24

A.2.6. Pipe Break Frequency (PBS) $\ldots \ldots \ldots \ldots \ldots \ldots \ldots \ldots \ldots \ldots \ldots \ldots \ldots \ldots \ldots \ldots \ldots$

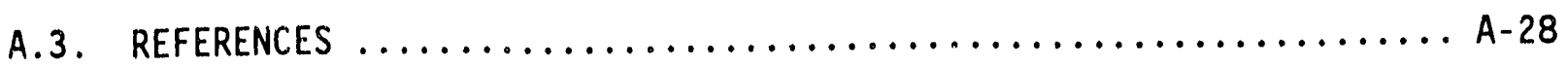

A.3.1. General References ......................... A-28

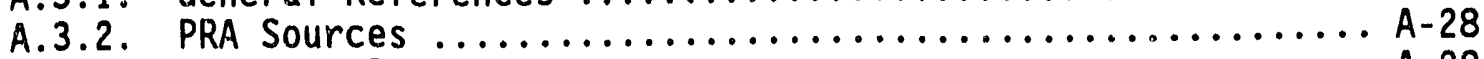

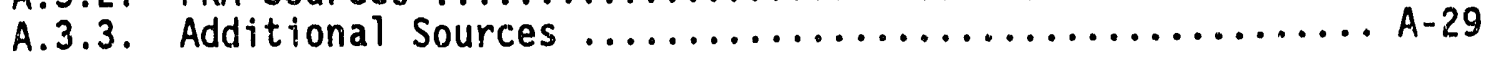

\section{TABLES}

A-1. Selected Fields in NUCLARR Component Failure Data Base ........ A-2

A-2. Supplemental References For IEEE-500 Data ................. 17 


\section{APPENDIX A \\ COMPONENT FAILURE DATA SOURCES}

This appendix contains a brief description of each source contributing data to the component failure data (CFD) handbook. The probabilistic risk assessments (PRAs) used as sources are presented first, followed by other types of data sources. Each PRA source description provides tabular information such as the sponsor of the study, the number of records in the component failure handbook aggregates from the source, and an overview of its plant-specific data treatment. This is followed by a brief discussion of the associated data that addresses their quality and the major sourcespecific assumptions (if any) made in entering the data into the Nuclear Computerized Library for Assessing Reactor Risk (NUCLARR), from which the handbook rates are derived. In general, these data sets are all suitable for PRA applications as they were developed and structured for that purpose.

Similar information is supplied for the additional data sources.

Table A-1 provides a brief description of the major non-numeric data fields used in NUCLARR to describe the component failure data. All the fields are explained fully in Volume 4, Part 3 of the NUCLARR NUREG series. ${ }^{A-1}$ They are defined just briefly here for reference because some of the source descriptions refer to them in explaining how the data were interpreted and entered into the data base. Handbook users need an understanding of the assumptions made in processing data from each source in order to make informed judgements on the use of the data for particular applications.

The title of each subsection below contains the "Study ID" acronym used in the main text data tables. The Integrated Risk Assessment Data Acquisition Program (IRADAP) bibliography of data bases ${ }^{A-2}$ contains further information on most of these sources. 
Table A-1. Selected fields in nuClarR Component failure Data Base Field

Description

Event-Defining Attributes

Component Type 3-char. component code (mechanical or electrical/instrum.)

Design

Failure Mode

Normal State

2-char. component design code

code for the undesired change or lack of change of state

Code for normal state of a component during operation

Additional Information

Application As many as three attributes for particular component types

(such as internal environment for valves)

Failure Origin Origin for failure data (in-depth plant records, expert

judgement, laboratory test reports, other)

Fail.Rec. Type Specific types of records that were sources for the failure information.

Exposure Orig. Origin for exposure data (in-depth $\mathrm{plant}$ records, expert judgement, calendar hours, critical hours, other)

Exp. Rec. Typ. Specific types of records that were sources for the denominators of the failure rates

Data Co11. Per. Starting and ending years for data collection

Incl. Circuit Whether control circuits are included in the component boundary for assessing failures

Nuclear Orig. Whether the data come from nuclear power plant experience

Bayesian Upd. Whether Baysian methods were used to calculate a rate from data and prior experience

IRADAP Suit. Safety Grade Whether the data record is to be included in this handbook

Primary Fail. Whether the data describe safety grade components Whether only primary failures are included in the numerator of the failure rate (rather than both primary and secondary failures)

Origin. Fac. Nuclear power plants or groups of nuclear power $p$ ? ants whose experience is aggregated to form a failure rate

Severity

Degree

Include System Whether the failures counted for the failure rate are catestrophic, degraded, or just incipient code for details on the nature of degraded failures

System Nuclear power plant system(s) associated with the failures

subsys. Train Text field ( 36 char.) for subsystem or train information

Reference Information

Document No.

Detail Ref.

Supplemental Ref Up to 20 char. of acronyms for original sources cited by

A 3-digit document code followed by the year of publication A page number or table number

the reference document

Additional Comments

Comments

Additional information that cannot be conveyed in the coded fields 


\section{A.1. PRA SOURCES}

PRA and reliability analysis sources using plant-specific data are described below.

\section{A.1.1. BIg Rock PoInt 1 (BRP1-PRA)}

Sponsor of study:

Performing organization:

PRA completion date:

NUCLARR qualified record count: 30

Reference number:

Facility attributes:

CFD attributes:
Consumers Power Company

Wood-Leaver Associates

March 1981

AP-1

U. S., commercial, General Electric, BWR. Raw data for hourly and per demand rates with confidence limits for the diesel generators and certain pumps and valves. Most components characterized by system.

The BRP plant is one of the oldest in the United States, having started commercial operation in Decenber, 1965. Because of its extensive operating experience and the uniqueness of the BRP design, BRP plant-specific data were used whenever possible in the PRA. Plant-specific data sources included plant maintenance orders, control room log books, surveillance tests, LERs, event reports, deviation reports, plant review committee meeting minutes, and USNRC correspondence. The plant-specific data used spanned the period from 1970 to 1979; data before 1970 do not include maintenance orders or surveillance tests and therefore were excluded.

A11 BRP plant-specific component failure data were entered into NUCLARR except for a per-demand rate for containment isolation valves failing leak tests. The failure mode for this event would be "failure to 
close" (i.e., remain closed) but the event was judged not to be catastrophic. [A11 "leakage" events are per hour in the NUCLARR since one would never request a component to leak.]

\section{A.1.2. Haddam Neck Plant (Conmecticut Yankee) (HNP1-PRa)}

Sponsor of study:

Performing organization:

PRA completion date:

NUCLARR qualified record count:

Reference number:

Facility attributes:

CFD attributes:
Northeast Utilities (NU)

Northeast Utilities

December 1985
21

AP-2

U. S., commercial, Westinghouse, PWR.

Hourly and per demand rates from raw data and means and variances obtained through Bayesian updates using conjugate prior distributions.

The Connecticut Yankee PRA describes the process used to gather component failure history, demand history, and run time experience over a 10-year period beginning in 1974. Included in the process was the retrieval of event-specific data from the Baseline Events Analysis Reliability Data System (BEARDS), a proprietary NU data base that includes failure and maintenance reports. All plant-specific component failure data were entered into NUCLARR. Data are given for pumps (by system), containment air recirculation fans, batteries, chargers, inverters, and diesels. The PRA contains no plant-specific valve data.

The PRA report also presents updated component failure data. The results reflect a Bayesian update of WASH-1400, IEEE-500, and Westinghouse Nuclear Technology Division means and variances, using plant-specific experience where available. Failure-on-demand rates were modeled using beta-distributed priors. Hourly failure rates were modeled using gamma-distributed priors. Although these updated means and variances are stored in NUCLARR, the aggregation methods use just the raw plant-specific operational data. 


\section{A.1.3. Millstone 1 (MNS1-PRA)}

Sponsor of study:

Performing organization:

PRA compietion date:

NUCLARR qualified record count: 37

Reference number:

Facility attributes:

CFD attributes:
Northeast Utilities

Northeast Utilities

July, 1985

AP-3

U. S., commercial, General Electric, BWR. Hourly and per demand rates based on raw data with means and variances obtained through Bayesian updates using conjugate prior distributions.

The Millstone Unit I PRA was quantified using plant-specific system and component failure history, demand history, and run time experience over a 13-year period of commercial operation. The data collection process was similar to that of the HNPI PRA, including extracting data from the Base1 ine Events Analysis Rellability Data System (BEARDS). Data are present for valves, diesel and gas turbine generators, breakers, and battery chargers. In addition, raw plant-specific data are provided for pumps from 13 systems for failure to start and from 8 systems for failure to run.

Updated component failure data reflect a Bayesian update of WASH-1400 means and variances using the plant-specific experience. Rates for Faiture on demands vere modeled using beta-distributed priors. Hourly failure rates were modeled using gamma-distributed priors. These data are present in NUCLARR for archival and display; they are not used in the aggregation calculations.

\section{A.1.4. INDIAN POINT 2 (IPS2-PRA)}

Sponsor of study:

Consolidated Edison Company 
Performing organizations:

PRA completion date:

NUCLARR qualified record count:

Peference number:

Facility attributes:

CFD attributes:
Pickard, Lowe \& Garrick, Inc.; Westinghouse Electric Corporation; and Fauske \& Associates

March, 1982
39

AP -4

U. S., commercial, Westinghouse, PWR.

Raw data for hourly and per demand rates, with means and variances obtained through Bayesian updates using discrete prior distributions.

The site-specific and generic component failure and service hour data sections of the Indian Point Unit 2 PRA were available for entry of site-specific component failure data. In the PRA, the Licensee Event Reports (LERs) generated after th: plant became critical (from May 23, 1973 to December 31,1979 ) were used as the primary source of component failure data. This was supplemented by operating logs, and component maintenance and testing records, and significant occurrence reports to clarify the LER narratives in some cases. Command faults and failures from problems outside the component boundaries were excluded; thus, the "primary failures only" indicator is set for these data. In addition, the documentation explains that control circuits are included within the component boundary for pumps.

System drawings, unit operating status summaries, and test plans were used to establish the exposure times or number of demands. Exposure times for running equipment were in most cases based on the sum of plant hours in operation and in hot shutdown.

The resulting raw failure information is documented in a set of 39 data summaries that describe the types of failures that occurred and the assumptions made for each estimate. For some components, specification of the system was included because of its impact on the data values. For example, motor-driven pumps are distinguished by system for the failure to run failure mode but not for the failure to start failure mode. Data are 
present for pumps, valves, heat exchangers, diesels, fan cooling units, batteries, chargers, breakers, transformers, inverters, automatic transfer devices, and buses. For the spurious close failure mode, manual and motor-operated valves were combined.

Generic data from WASH-1400, IEEE Std 500, and the LER data sumimaries on valves, pumps, and diesels were combined with plant-specific failure data using discrete prior distributions. Updated failure information based on the resulting discrete posterior distributions is stored in NUCLARR but is not used in the aggregations.

LERs have been criticized as a source of failure data because reporting criteria differ among plants. However, the analysts for the Indian Point Station argue that the LERs for this station are good sources because the technical specifications required LERs for all significant events that directly affect plant safety or those systems designed to maintain the plant in a safe condition, and the PRA is directly concerned with such events. Furthermore, the LERs at this station are "a source of relatively consistent, reviewed, and generally complete event descriptions" (Reference AP-4, page 1.5-2).

\section{A.1.5. ZION STATION (ZIS-PRA)}

Sponsor of study:

Performing orgarizations:

PRA completion date:

NUCLARR qualified record count:

Reference number:

Facility attributes:

CFD attributes:
Commonwealth Edison Company

Pickard, Lowe \& Garrick, Inc.; Westinghouse Electric Corporation; and Fauske \& Associates

September, 1981

40

AP-5

U. S., comnercial, Westinghouse, PWR.

Raw data for hourly and per demand rates, with means and variances obtained through Bayesian updates using discrete prior distributions. 
The Zion PRA data base is very similar in form to that of Indian Point. Both PRAs were performed by Picard, Lowe and Garrick, and the approach used for each PRA's data was the same. LERs were the primary failure data source, for the same reasons as stated above for Indian Point 2's PRA. These were supplemented by control room log books, plant maintenance logs, plant maintenance test records, and deviation reports. Demands were in most cases obtained from a study of test procedures and $p l a n t$ drawings, while operating hours were computed from the monthly operating status reports. Most of the component failure rates were applicable to all systems, but exceptions are noted in some cases. Data are presented for pumps, valves, containment fan cooling units, reactor building fan cooler dampers, heat exchangers, diesel generators, bus feeder and reactor protection system breakers, metal-enclosed busses, transformers, battery chargers, batteries, and inverters. As with the IPS2 PRA, motor-driven pump data were combined across system for the "fail to start" failure mode but not for the "failure to run" mode.

The documentation format for the plant-specific failure data and their use to form updated distributions with means and variances are identical to that of the IPS2 PRA.

\section{A.1.6. OCONEE 3 (NEE3-PRA)}

Sponsor of study:

Performing organization:

PRA completion date:

NUCLARR qualified record count:

Reference number:

Facility attributes:

CFD tributes:
EPRI and Duke Power Company

EPRI's Nuclear Safety Analysis Center (NSAC)

May, 1981

54

AP-6

U. S., commercial, Babcock \& Wilcox, PWR.

Raw data for hourly and per demand rates, with means and variances obtained through Bayesian updates.

A-8 
The Oconee Unit 3 PRA contains plant-specific raw data for valves; pumps; reactor building cooling units; isolating diode assemblies; instrument inverters; four sizes of transformers; panel boards; low and high voltage busses; buswork; DC, low voltage, and high voltage circuit breakers; batteries; battery chargers; and hydro-driven generators. Nearly all the data are system-specific except for the valve data. For motor-operated valves that fail to operate, data for the condenser circulating water system are separately listed. The oconee data are unique in its detailed treatment of check valves; data for swing check, stop check, and tilting disk check valves are distinguished.

The failure data for these rates are obtained from maintenance work requests supplemented by incidence reports and Licensee Event Reports from the 1975-1980 time period. The work requests provide a complete history of all repairs performed at oconee. They are not restricted to safety-related systems, they are written during all modes of unit operation, and they are not produced in response to licensing-based criteria. Thus, their use provides completeness, traceability, compatibility with success data, and a resulting reduction in data-base uncertainty.

Periodic test reports, control room operating logs, and piping and instrumentation diagrams were used to compute the numbers of demands. Operating hours were based on run hour logs for the motor-driven pumps and cooling units; a review of normal plant operating procedures, system line. ups, and periodic test records provided component service hours for other component/failure mode combinations. An appendix to the PRA contains a data summary table for each failure rate estimate describing its basis.

For the PRA, the plant-specific data were updated using discrete lognormal prior distributions that were derived from generic data. The updated median, mean, and upper and lower tolerance bounds are in the data tables. These are stored in NUCLARR but only the raw plant-specific data are used in the aggregations. 


\section{A. 1.7. PLANT " $X "$ (X-PRA)}

Sponsor of study:

Performing organization:

PRA completion date:

NUCLARR qualified record count:

Reference number:

Facility attributes:

CFD attributes:
(Proprietary information)

Science Applications International Corp. (SAIC)

Data received in 1987

Approximately 130

AP-7

U. S., commercial, Babcock \& Wilcox, PWR.

System-specific raw data for hourly and per demand rates for pumps, valves, the instrument air compressors, and electrical equipment

Science Applications International Corp. (SAIC) provided handwritten tables describing proprietary PRA data for a U.S. commercial Babcock and Wilcox power plant which it denotes "Plant $X . "$ The data are based on a review of the plant's daily operating history covering a time period from 1978 to 1984. Plant work authorizations, LERs, NPRDS records, and NRC Monthly Operating reports were all used as plant-specific input to the data base. Numbers of demands and operating hours were based on a SAIC questionnaire filled out by $p l a n t$ personnel for each system, supplemented by $p l a n t$. drawings and the Final Safety Analysis Report (FSAR). Interfacing demands caused by testing and maintenance were considered in the construction of component demand histories.

Tables were received for valves, pumps, instrument air compressors, battery chargers, batteries, inverters, diesel generators, and breakers. The valve tables provided information on air operated, motor operated, handhweel, hydraulic, pressure relief/safety, and check valves for several systems at $P$ lant $X$. The check valves are further classified as swing, tilting disk, hand weilded stop check valves, and motor operated stop check valves. Failure, demand, and operating hour counts are provided on a per pump basis for the pumps in several plant systems. Tables for the air 
compressors and the electrical equipment other than breakers are also on a component-specific basis. Breakers are grouped in to 4160 VAC pump breakers, 480 VAC valve breakers, and VDC breakers. For NUCLARR, data for specific components having the same normal operating state were pooled for each system.

The tables do not provide detailed failure mode information. Each failure is classified as demand-related or time-related; counts of each are given. Because the data were collected for use in a PRA, all failures were classed as failures that could disable a train of a system so that it could not perform its intended function. That is, the failures were classed in NUCLARR as having a "castestrophic" severity. Unless otherwise known (see the next paragraph), failure modes were assigned as follows:

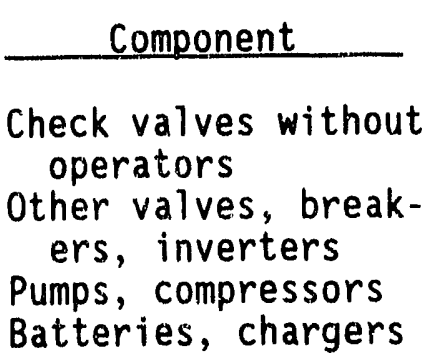

Time-Related Failure

IL.

$\operatorname{FTO}(/ h)$

FTR

FTO
Demand-Related

Failure

FTO

$\mathrm{FTO}(/ \mathrm{d})$

FTS

Recall that the fail to operate hourly failure mode (FTO/h) refers to general operational failure and is not a detailed failure mode.

Diesel generator data were omitted in order to avoid duplication with Reference AA-8, described in Section A.2.5, which has plant-specific diesel generator data from all plants.

Data sheets from SAIC's Component Reliability Parameter System (CRPS) were also provided to the INEL; some of these contained data from Plant $X$. The CRPS is a data base system developed by SAIC in 1987 to allow the display and aggregation of component failure data. Four Plant $X$ entries in NUCLARR came from these sheets. These entries reflect combined data over the entire plant, including systems that were not included in the handwritten sheets. For these data, NUCLARR's Detailed Reference field includes 
the component and failure mode codes that identify the individual data sheets in the CRPS. The CRPS sheets were also used to clarify the failure mode descriptions for over 60 of the NUCLARR records from Plant $X$.

\section{A.1.8. PLANT "Y" (Y-PRA)}

Sponsor of study:

Performing organization:
(Proprietary information)

Science Applications International Corp. (SAIC)

Data received in 1987

PRA completion date:

NUCLARR qualified record count: Approximately 70

Reference number: AP-8

Facility attributes:

A U. S. commercial BWR

CFD attributes:

Raw data for hourly and per demand rates for pumps and valves, by system

Handwritten data tables summarizing a study of pump and valve records for a U.S. commercial General Electric plant having two units were received from SAIC. The sheets are based on plant records, equivalent to maintenance work authorizations, for the period from 1980 to 1985. Although the data are proprietary when identified by the plant name, they can be released for use in a generic data base with the plant identified simply as "Plant Y."

The data tables had the same format as that described for Plant $X$, above, and were treated in the same manner. The tables describe the emergency service water, high pressure service water, residual heat removal, reactor core isolation cooling, and core spray systems. Approximately half of the data were also described in CRPS sheets; these provided additional clarification for failure modes. 


\section{A.1.9. European Plant (EUR-Pra)}

Sponsor of study:

Performing organization:

PRA completion date:

NUCLARR qua fied record count: 13

Reference number:

Facility attributes:

CFD attributes:
(Proprietary information)

Science Applications International Corp. (SAIC)

Data received in 1987

SAIC has performed a number of plant-specific operational data assessments supporting PRAs. The data analysis results are proprietary if specific plant names are provided. However, such data are valuable for use in generic data bases even if the $p l a n t$ name is not provided. Such is the case for data from a European commercial nuclear power plant.

The data, for pumps and valves, were received at the INEL in the form of entries in CRPS data sheets. The CRPS is a data base system developed by SAIC in 1987 to allow the display and aggregation of component failure data. This transmittal was included in an August 31, 1987 first draft of the Component. Failure Data Handbook for NRC/AEOD under the IRADAP. The page numbers in the data set for NUCLARR refer to the page numbers that were applied to the SAIC data sheets in that draft. NUCLARR's Detailed Reference field also includes the component and failure mode codes that identify individual data sheets in the CRPS. Although only selected failure rates were available, these were entered into NUCLARR for use in this handbook because plant-specific maintenance records, the equivalent of work authorization forms, were processed to derive them. 


\section{A.2. ADDITIONAL DATA SOURCES}

Additional data sources are listed below. Although these sources were not developed for specific risk assessments, use in risk assessments was a primary purpose for developing most of them.

\section{A.2.1. IEEE-STANDARD 500-1984 (IEEE-500)}

Sponsor of study:

Performing organization:

Completion date:

NUCLARR qualified record count:

Reference number:

Facility attributes:

CFD attributes:
The Institute of Electrical and Electronic Engineers, Inc. (IEEE)

Fluor Engineers, Inc.

1983

Approximately 70

$A A-1$

Primarily U. S., commercial, nuclear.

Hourly and per demand rates with upper and lower bounds for various failure modes for electrical, instrumentation, and mechanical components in nuclear power plants. Where available, repair times are also included.

The IEEE Standard 500 document was originally issued in 1977 as a manual of reliability data on electrical, electronic, and sensing components. Since that time, data have been gathered on mechanical equipment reliability, making the 1984 version of IEEE Std 500 a more comprehensive work that includes data on over 1,000 events. The primary source for the reliability data presented in IEEE Std 500-1977 was the judgment of nearly 200 experts on component reliability in the nuclear power field. The Delphi method was used to compile and refine the expert opinion data. This information is included in IEEE Std 500-1984 (IEEE-500) for the nonmechanical components, but it is supplemented by data from 24 additional sources. 
The Std 500-1984 reliability data set for electrical and electronic components is useful for PRA applications because this is one of the few sources that exists for many of the components it covers. However, users should be aware of the original sources used and the fact that some of them may overlap (a single failure may be reflected both in LERs and IPRDS, for example). There is also overlap between design-based groupings and application-based groupings of the data. For example, the pump data are primarily structured at a high level by the pump's internal method of operation (centrifugal, positive displacement) rather than by type of driver (turbine, diesel), but data sheets with pump and driver both are included and some data sheets have this information at a system-specific level. The amount of actual operational data supporting the rate estimates should be evaluated from a knowledge of the sources used by IEEE. For this handbook, the catestrophic mode failure data from IEEE-500 are used as a source only if there is a lack of several plant-specific data sources.

In encoding selected data sheets from IEEE-500, information on IEEE-500's sources has been made readily available. The "Supplemental Reference" field is provided to capture the original sources of referenced data. Table A-2 shows the codes that have been used for supplemental references for IEEE-500 data.

A11 the data in IEEE-500 are in the form of rates; no raw data (numbers of components and failures) are supplied. Furthermore, the upper and lower bounds included in the document are weighted averages of upper and lower bounds in the original source documents and as such have no specified coverage probability. In entering the data for NUCLARR, the "recommended rates" have been treated as medians and bounds have been conservatively treated as $20 \%$ and $80 \%$ tolerance bounds.

Since the IEEE-500 data have been combined from many sources, the assignment of values for fields in NUCLARR such as data collection period and nuclear origin requires further explanation. The data collection 
Identifier

500

493

LER

RMDB

Corps of Engineers (HND) R/M Data Base, Ground Stationary Equipment, Rep No 16, 04/12/73.

RAC Norielectric Parts Reliability Data (NPRD-2) Summer 1981, Reliability Analysis Center, Rome Air Development Center, Griffiss Air Force Base, NY 13441.

N06666 NUREG-06666, April 1981, A Probabilistic Safety Analysis of DC Power Supply Requirements for Nuclear Power Plants.

NERS80-02 Failure Data Estimates for Diesel Generators in US Commercial Nuclear Power Plants. NERS 80-02 (CRBR Project) July 1980.

E46 Nuclear Unit Productivity Analysis (Special EPRI Report No 46) Aug 1976 (Nonredundant Equipment Oniy).

EA 2205 EPRI Rep No AP 2205, Feb 1982, Component Failure and Repair Data; Gasification-Combined-Cycle Power Generation Units.

$$
\text { A-16 }
$$


table A-2. Supplemental References for IEEE-500, CONTINUed

\begin{tabular}{|c|c|}
\hline dentifier & Reference \\
\hline EA 2071 & $\begin{array}{l}\text { EPRI Rep No AP } 2071 \text {, Oct } 1981 \text {, Component Failure and Repair } \\
\text { Data for Coal Fired Power Units. }\end{array}$ \\
\hline EA 2321 & $\begin{array}{l}\text { EPRI Rep No AP 2321, March 1982, High Reliability Gas Turbine } \\
\text { Combined-Cycle Development Program: Phase } 11 .\end{array}$ \\
\hline EJ & $\begin{array}{l}\text { R\&D Status Report-Advanced Power Systems Division, EPRI Jour- } \\
\text { nal, March 1982, p } 37 \text {. }\end{array}$ \\
\hline NPRD & $\begin{array}{l}\text { NUREG/CR-2232, Nuclear P1ant Reliability Data System (NPRDS) } \\
1980 \text { Annual Reports of Cumulative System and Component Reli- } \\
\text { ability. }\end{array}$ \\
\hline IPRD & $\begin{array}{l}\text { NUREG/CR } 2886 \text {, May } 1982 \text {, In-Plant Reliability Data System } \\
\text { (IPRDS) Interim Draft Report on the Reliability Characteris- } \\
\text { tics of Selected Pumps in Four Nuclear Plants. }\end{array}$ \\
\hline CIGRE & $\begin{array}{l}\text { The First. International Enquiry on Circuit Breakers Failure } \\
\text { and Defects in Service. Extract from Electra No } 79 \text { (CIGRE) } \\
\text { (1974-1977). }\end{array}$ \\
\hline SHIM & $\begin{array}{l}\text { SHIMIZU, Use of Experience Data of Nuclear Power Plant } \\
\text { Diesel-Generator Emergency Power Systems in Reliability Analy- } \\
\text { sis. Presented at the Annual West Coast Reliability Sympo- } \\
\text { sium, Feb 26, } 1977 \text {. }\end{array}$ \\
\hline UA & Utility "A" \\
\hline AEA & Architectural Engineering Company "A" \\
\hline AEB & Architectural Engineering Company "B" \\
\hline PWR10 & Pressurized Water Reactor - Plant No 10 \\
\hline GTA & Gas Turbine Manufacturer "A" \\
\hline
\end{tabular}

period for a data sheet was taken to be from the earliest date present among the sources to the latest date. In some cases, the ending date was based on the source's publication date. For the nuclear origin field, a value (yes or no) was assigned if it was known to be applicable for all the sources contributing to the aggregated value; when the analyst was in doubt, the field was left blank. A similar situation applies for the data A-17 
origin field; for example, a "plant" designation was used for data from IPRDS or from the "PWR 10" reference. When the same failure origin type did not apply to all the sources, "other" was encoded in this field and "See Sup. Ref" was included in the comment field to refer the analyst to the supplemerital reference. For the failure record type field, the record types known by the INEL analysis team to be used in the associated root sources were assigned. For example, LERs are a failure record type for failure rates from the LER Summary series of NUREG reports. Where the INEL encoding team lacked such detailed knowledge of the sources, the fields were left blank. The exposure origin and record type are blank for all the IEEE-500 records because no raw exposure data are provided.

\section{A.2.2. In-Plant Reliability Data System (IPRDS)}

Sponsor of study:

Performing organization:

Completion date:

NUCLARR qualified record count:

Reference number:

Facility attributes:

CFD attributes:
U. S. NRC Office of Nuclear Regulatory Research

Oak Ridge National Laboratory

March, 1982

Approximately 120

$A A-2$ through $A A-5$

U. S., commercial, nuclear power plants; five PWR units and four BWR units.

$\mathrm{Pl}$ ant and system-specific hourly and per demand rates for pumps, values, and main electrical distribution system components based on raw data, with confidence bounds based on the binomial and Poisson distributions. Repair action records also exist in some cases.

The main objective of the In-Plant Reliability Data System (IPRDS) is to develop a comprehensive and component-specific data base for PRA and other component reliability-related statistical analysis. ${ }^{A A-2}$ To accomplish this objective, in the 1978-1981 time period data base personnel visited selected $p l a n t s$ and copied all the plant maintenance work 
requests. They also gathered plant equipment lists and plant drawings and in some cases interviewed plant personnel for information on component populations and duty cycles. An $14 \mathrm{~L}$ committee participated in selecting the specific plants; three PWR statiuns and two BWR stations were visited. Because some plants participated on the condition that their identity would not be divulged, the plants are denoted by numbers.

The maintenance records describe preventive as well as corrective maintenance. IPRDS personnel screened the maintenance records for selected components to separate out the cases of corrective maintenance occurring since the start of commercial operation. These records were reviewed to determine such things as failure modes, severity, and, if possibie, failure cause. The data from these reports were encoded into a computerized data base. By having a team of data base experts process all the data, problems with differences in the interpretation of reporting requirements were minimaed. Using in-plant records provides assurance that even disabling incipient hardware problems are included. Thus, the resulting data base has consistency and depth.

The IPRDS data for NUCLARR and the component failure data handbook have been entered from the three reports that have been issued containing IPRDS failure data. These reports describe pumps, ${ }^{A A-3}$ valves, ${ }^{A A-4}$ and major electrical components. ${ }^{A \prime-5}$ The electrical component report presents data for diesel generators, batteries, battery chargers, and inverters in nuclear power plant essential ac power distribution systems. The table below shows the time span and numbers of componunts and $f_{2}$..ure records that were analyzed to derive the failure rates:

$\begin{array}{llccc} & \text { Plant Numbers } & \text { Population } & \text { Eailurs } & \text { Unit } \\ & \text { Years } \\ \text { Pumps } & 1 \text { through 4 } & 1468 & 3998 & 27 \\ \text { Valves } & 1 \text { and 4 } & 24825 & 5712 & 24 \\ \text { Electrical } & 1 \text { through } 5 & 213 & 698 & 33\end{array}$


The IPRDS data that were described as catestrophic in severity were encoded for NUCLARR. ${ }^{\text {a }}$ Because the primary data source is maintenance work requests, the "primary failures only" indicator was set to show both primary and secondary failures; ail of these would result in corrective maintenance. The component boundaries are described in the IRDS reporis and all include control circuits. The data time frames were estimated for each of the five stations ( $p$ lants) submitting data from the known years of commercial operation per component and estimated data collection dates as indicated in the following table.

\begin{tabular}{|c|c|c|c|c|c|c|}
\hline $\begin{array}{l}\text { Plant } \\
\text { No. } \\
1 \\
2 \\
3 \\
4 \\
5\end{array}$ & $\begin{array}{l}\text { FID } \\
\text { IPI } \\
\text { IP2 } \\
\text { IP3 } \\
\text { IP4 } \\
\text { IP5 }\end{array}$ & $\begin{array}{l}\text { Plant } \\
\text { Type } \\
\text { PWR } \\
\text { PWR } \\
\text { BWR } \\
\text { BWR } \\
\text { PWR }\end{array}$ & $\begin{array}{c}\text { No. of } \\
\text { Units } \\
1 \\
1 \\
3 \\
1 \\
5\end{array}$ & $\begin{array}{l}\text { Years of Commercial } \\
\text { Operation (per unit) } \\
\qquad \begin{array}{c}5.1 \\
1.3 \\
3.1 \\
6.2 \\
3.8\end{array}\end{array}$ & $\begin{array}{c}\text { Data } \\
\text { Start Date } \\
74 \\
79 \\
77 \\
75 \\
77\end{array}$ & $\begin{array}{c}\text { Data } \\
\text { End Date } \\
79 \\
80 \\
80 \\
80 \\
81\end{array}$ \\
\hline
\end{tabular}

The IPRDS data base is very helpful for corrective maintenance frequencies and repair times. However, further information on component duty cycles and use would improve the demand-based failure rate estimates contained in the reports. In addition, because the data base was developed from relatively few nuclear power stations, caution should be used for other than generic applications. For the component failure data handbook, these data are combined with other plant-specific data to obtain failure rates.

\section{A.2.3 SWedish Reliability Data Book (SWD-hBK)}

Sponsor of study: Nuciear Safety Board of the Swedish Utilties (RKS) and the Swedish Nuclear Power Inspectorate (SKI)

\footnotetext{
a. Diesel cenerator data were omitted in order to avoid duplication with other sources (such an Reference AA-8, described in section A.2,5, which has plant-specific data from all plants). Also, to avoid high failure rate estimates based on little data, a rule was adopted for entry of failure to start data for pumps. Whenever 0 failures were observed, the data were not entered unless the number of demands exceeded 300 .
} 
Performing organization:

ASEA-ATOM and Studsvik Energiteknik $A B$

Completion date:

1985

NUCLARR qualified record count: Approximately 75

Reference number:

AA- 6

Facility attributes:

7 Swedish PWR units (from 4 stations) and 1 Swedish BWR unit

CFD attributes:

Numbers of failures and either demands or operating hours for pumps, valves, control rods and control rod drives, electrical equipment, and instruments, with means and upper bounds based on fitting gamma distributions

The Swedish Reliability Data Book was developed to provide improved failure data for reliability calculations. It is based primarily on evaluations of failure reports in the Swedish Thermal Power Reliability Data System (ATV), a data collection system jointly established by the Swedish utilities and maintained and managed by the Swedish State Power Board at Stockholm, Sweden. LER reported to the Swedish Nuclear Power Inspectorate and information provided by the operation and mnaintenance staff of each plant also contributed to the results presented in the Data Book.

The data cover operating periods starting as early as 1974 and continuing through to the end of 1982 for the BWR units and through the middle of 1981 for the BWR unit, Ringhals 2. The initial startup periods for each reactor are not included. The data pertain primarily to safety-related systems, since these systems are tested regularly in accordance with the technical specifications and have the most clear reporting requirements. Demand counts were obtained from a knowledge of testing requirements; the impact of events such as scrams was considered in some cases. Time clocks have been installed on pumps to record actual exposure time. For other components, the operational profiles of the plants were used to calculate exposure times. 
Data for pumps, valves, control rods and drives, sensors, and electrical equipment were entered in NUCLARR. No records from the Data Book were pooled; instead, the application field was used (where applicable) to capture additional differentiating attributes for the data such as voltage levels for electrical components. The Data Book presents data combined across systems and, for the BUR plants, across units. The mean values estimated from the gamma distribution fit to the data were entered into NUCLARR, although they are not used in the calculations for this handbook.

The Data Book contains a discussion of failure modes for each type of component. It distinguishes "critical failures" and "degraded/incipient failures." Only data for critical failures (catestrophic failures) were entered into NUCLARR. The Data Book also contains a discussion of the failure events that are common for each component type and schematics that show typical component boundaries.

\section{A.2.4 Reliability Analysis Center (RAC)}

Sponsor of study:

Performing organization:

Completion date:

NUCLARR qualified record count:

Reference number:

Facility attributes:

CFD attributes:
U. S. Department of Defense

IIT Research Institute, contractor for the Reliability Analysis Center managed by Rome Air Development Center, Griffiss AFB, NY 13441-5700

Fal1, 1985

Approximately 20

$$
A A-7
$$

U. S. commercial and military installations

Numbers of failures and numbers of thousands of operating hours for more than 380 major nonelectronic part types, categorized by component design, environment, and whether the source was m:litary or commercial. 
The Reliability Analysis Center (RAC) is charged with the collection, analysis, and dissemination of reliability information pertaining primarily to parts used in electronic systems; however, data are also collected for selected nonelectronic parts used in military, space, and commercial applications. A special system is in place for the collection and analysis of data on operating and $p l$ anned military systems and equipment. Data are also collected on a continuous basis from such sources as testing laboratories, device or equipment manufacturers, government laboratories, and equipment users. Automatic distribution lists, volunatary data submittal, and field failure reporting systems supplement an intensive data solicitation program. A three-year period of strong emphasis on data acquisition provided more data for the 1985 edition of Nonelectronic Parts Reliability Data. ${ }^{\mathrm{a}}$

To support nuclear power plant risk assessment, data for fans, compressors, heaters, relays, and fuses were selected for entry into NUCLARR. These are areas for which relatively little specific nuclear power plant operational data exist. In all cases, the entered data were from ordinary commercial applications with a "ground fixed" environment or from military applications with a "ship sheltered" or "submarine" environment. These terms are defined as follows:

Ground fixed--conditions less than ideal to include installation in permanent racks with adequate cooling air, maintenance by military personnel and possible installation in unheated buildings.

Ship sheltered--surface conditions similar to Ground Fixed but subject to occasional high shock and vibration.

\footnotetext{
a. This comment in the report was the bas is for assessing the data collection period as from 1982 to 1984. Some older data may also have been used. The report does not state specific data sources.
} 
Submarine--conditions normal to operation aboard a submerged vessel. Temperature and humidity controlled.

The RAC failure rates are not differentiated with regard to failure modes. A separate section of the report provides a failure mode breakdown for most of the components. Factors (percentages) from these tables could be used to break the ovill failure rates into rates for particular failure modes. However, the evvironments for those failures are not shown, and thus they may not be applicable for particular sets of data. These factors were not used in assessing the data for this Handbook. Thus, failure mode designations for data from RAC must be interpreted broadly.

\section{A.2.5. Reliability of Emergency Diesel Generators (NSAC-108)}

Sponsor of study:

Performing organization:

Completion date:

NUCLARR qualified record count:

Reference number:

Facility attributes:

CFD attributes:
Electric Power Research Institute (EPRI)

Nuclear Safety Analys is Center (NSAC)

September, 1986

Approximately 250

AA-8

U. S., commercial, LWRs from 52 sites.

Numbers of failures and demands for emergency diesel generator failure to start and for failure to load and run for the required duration.

EPRI's NSAC surveyed the U. S. nuclear power plant industry in order to determine emergency diesel generator (DG) reliability for the years from 1983 to 1985. For each of 154 diesel generators, reliability data are provided for each of these three years. Both testing and unplanned demands and associated failures were included. However, the unplanned demands represent only about 2 percent of the total and have very few failures for the 75 units and three years in the study, there were 431 start demands and 223 load-run demands with oniy 2 start failures and 4 load-run failures). Because of this sparsity, only the total demands and associated failures were entered into the data base. These are present on a unit-specific 
basis. Note that starts and load-runs that were conducted as an aid to trouble-shooting and maintenance were not included in the NSAC study since they do not provide an indication of the $D G^{\prime} s$ ability to fulfill its mission in a real emergency.

Two failure modes were considered in the NSAC study. The first is failure to start; in addition to unplanned demands this includes both fast start tests (less than 10 seconds) and slow start tests (where the requirement to start allows approximately 5 minutes from the first start attempt to stable performance at rated frequency and voltage). Since fast start testing causes stress and wear on the diesel and fast starts are needed only for a simultaneous blackout and loss of coolant accident (which is expected to occur only very rarely if ever), fast start testing is done very infrequently. There were no observed failures during the few tests that were classified this way, and the report authors recommend combining these tests into a single category.

The failure to run mode includes all failures occurring from the time when load was applied to the DG until the diesel is no longer needed (for unplanned demands) or until the end of the running duration required by technical specifications (for a test). Although failure to run is often represented by a per hour failure rate, the focus of the NSAC study was on unreliability; i.e. Whether the DG could run long enough to supply the power needed for a mission. For plants with one hour testing durations, these estimates will coincide. More generally, any intention to operate the DG at greater than $50 \%$ of plant ESF load rating for one hour or longer was counted as a potential load-run demand.

For both failure modes, terminations caused by conditions other than the DG and its immediate support systems were not counted (as demands or as failures). Conditions that invalidated tests or demands for this study include any operating errors that would not have prevented the DG from being restarted (possibly manualiy, but from the control room) and brought to load in a few minutes without corrective maintenance; incorrect trip signals that would not have been operative in the emergency mode; and minor 
water or oil leaks that would not have precluded operation of the DG in an emergency. Also, cases of start or load-run failures that occurred during successive retry attempts, and that were caused by the same malfunction before it was realized that an underlying problem existed, were considered to be one demand and one failure (unless the DG was maintained, declared operable, and returned to service between attempts).

In summary, data from this source are highly recommended for use in reliability and risk assessment studies. EPRI made an unremitting effort to ensure that the data were both comprehensive and reported/evaluated on a consistent basis. Data from this sour e were entered at a plant unit level, unless the diesels are shared in which case station-specific records were presented.

\section{A.2.6 Pipe Break frequency (PBS)}

Sponso study:

U. S. NRC Office of Nuclear Regulatory Research

Performing organization: Idaho National Engineering Laboratory (EG\&G Idaho, Inc.)

Completion date:

May, 1987

NUCLARR qualified record count: 44

Reference number:

$A A-9$

Facility attributes:

81 U. S. commercial nuclear power plants.

CFD attributes:

Nineteen occurrences of pipe failures (breaks), supplemented by expert-opinion estimates of frequencies of safety significant pipe breaks in commercial U.S. nuclear power plants

This study empirically developed frequencies and bounds for safetysignificant pipe failures in commercial nuclear power plants. Its purpose is to update the pipe break frequencies reported in the Reactor Safety Study (WASH-1400), ${ }^{A-3}$ which are used in many risk analyses. The study involved reviewing various data sources for actual piping failure 
events of significant magnitude. More specifically, all breaks in U.S. commercial nuclear power plant piping ( 81 plants) during the time frame from commercial operation through December, 1984 having a leak rate of at least $1 \mathrm{gpm}$ for pipes at least 2 inches in diameter and all leak rates of $50 \mathrm{gpm}$ or more regardless of pipe size were recorded. The primary data sources were LERs and the Nuclear Power Experience notebooks published and updated by S. M. Stoller Corporation. To the extent possible, information on conditional factors such as the system in which the failure occurred, the operational mode of the plant, end the size of the pipe involved was obtained for each event to permit estimation of conditional pipe break frequencies useful to risk analysts. The study also includes a survey of the amount of piping and number of welds typically found in major nuclear power plant systems.

Because there have been few significant pipe failures, the sparse real data were supplemented with expert-opinion data. The report presents the results of combining the real and subjective data through Bayesian statistical methods. In addition, an analysis of variance on the combined output to provide a model for the effect of system, pipe size, and the operational mode of the plant was performed.

Due to wide variations in the expert-opinion data, the results of the analyses that used that data were inconclusive. Therefore, the component failure data set contains, at a system level, just the raw data provided by this study. 


\section{A.3. REFERENCES}

\section{A.3.1. General References}

A-1. W. E. Gilmore, C. D. Gentillon, D. I. Gertman, G. H. Beers, W. J. Galyean, B. G. Gilbert, Nuclear Computerized Library for Assessing Reactor Reliability (NUCLARR) Volume 4: User's Guide, NUREG/CR-4639 (EGG-2458), June 1988.

A-2. 0. V. Hester, S. R. Brown, and C. D. Gentillon, Annotated Bibliography of Reliability and Risk Data Sources, EGG-REQ-7827, September 1987.

A-3. Reactor Safety Study, "Appendix III--Failure Data," WASH-1400, NUREG-75/014, U. S. Nuclear Regulatory Commission, 1975.

\section{A.3.2. PRA SOURCES}

AP-1. Consumers Power Company, Big Rock Point Probabilistic Risk Assessment, March 1981 .

AP-2. Northeast Utilities, Connecticut Yankee Probabilistic Safety Study, NUSC0-149, February 1986 .

AP-3. Northeast Utilities, Millstone 1 Probabilistic Safety Study, NUSCO-147, JuTy 1985.

AP-4. Pickard, Lowe and Garrick, Inc., Westinghouse Electric Corporation, and Fauske \& Associates, Inc., Indian Point Probabilistic Safety Study, internal document prepared for Commonwealth Edison Company of New York, Inc. and the New York Power Authority, March, 1982.

AP-5. Pickard, Lowe and Garrick, Inc., Westinghouse Electric Corporation, and Fauske \& Associates, Inc., Zion Probabilistic Safety Study, prepared for Commonweal th Edison Company, September 1981.

AP-6. Electric Power Research Institute (Nuclear Safety Analysis Center), OCONEE-3 PRA A Probabilistic Risk Assessment of Oconee Unit 3 , NSAC-60, Vols. 1-4, June 1984.

Af-7. J. R. Fragola, P. Appignani, et. al., Unpublished plant-specific PRA data for a commercial U. S. Babcock and Wilcox nuclear power plant ("Plant X") [Handwritten tables and Component Reliability Parameter System (CRPS) sheets], Science Applications International Corp., received in August, 1987. 
AP-8. J. R. Fragola, P. Appignani, et. al., Unpublished plant-specific PRA data for a commercial U. S. General Electric nuclear power plant ("Plant $Y$ ") [Handwritten tables and Component Reliability Parameter System (CRPS) sheets], Science Applications International Corp., 1987 (handwritten data received in January, 1988).

AP-9. J. R. Fragola, P. Appignani, et. a1., Unpublished plant-specific PRA data for a European commercial nuclear power plant [Component Reliability Parameter System (CRPS) sheets], Science Applications International Corp., 1987 (handwritten data received in January, 1988).

\section{A.3.3. Additional SOURCes}

AA-1. IEEE Guide to the Collection and Presentation of Electrical, Electronic, Sensing Component, and Mechanical Equipment Reliability Data for Nuclear Power Generating Stations, IEEE Std-500-1984, Nuclear Power Engineering Committee, IEEE Power Engineering Societ.y, 1983.

AA-2. J. P. Drago, R. J. Borkowski, D. H. Pike, and F. F. Goldberg, The In-Plant Reliability Data Base for Nuclear Power Plant Components: Data Collection and Methodology Report, NUREG/CR-2641, ORNL/TM-8271, JuTy 1982.

AA-3. J. P. Drago, R. J. Borkowski, J. R. Fragola, and J. W. Johnson, The In-Plant Reliability Data Base for Nuclear Plant Components: Interim Data Report--The Pump Component, NUREG/CR-2886, ORNL/TM-8465, December 1982.

AA-4. R. J. Borkowski et al., The In-Plant Reliability Data Base for Nuclear Plant Components: Interim Data Report--The Valve Compositit, NUREG/CR-3154, ORNL/TM-8647, December 1983.

AA-5. W. K. Kahl and R. J. Borkowski, The In-Plant Reliability Data Base for Nuclear Plant Components: Interim Report--Diesel Generators, Batteries, Chargers, and Inverters, NUREG/CR-3831, ORNL/TM-9216, January 1985.

AA-6. J-P. Bento, et al., Reliability Data Book for Components in Swedish. Nuclear Power Plants, RKS 85-25, 1985.

AA-7. Reliability Analys is Center, Nonelectronic Parts Reliability Data, NPRD-3, Rome Air Development Center, Griffiss AFB, New York, 13441, Summer 1985.

AA-8. H. Wyckoff, The Reliability of Emergency Diesel Generators at U.S. Nuclear Power Plants, NSAC-108, September, 1986.

AA-9. R. E. Wright, J. A. Steverson, and W. F. Zuroff, Pipe Break Frequency Estimation for Nuclear Power Plants, NUREG/CR-4407, EGG-2421, May 1987. 


\section{APPENDIX B}

\section{COMPONENT FAILURE DATA PLOTS}




\section{FIGURES}

B-1. Failure rates and bounds for mechanical components $\ldots \ldots \ldots$.... B-3

B-2. Failure rates and bounds for electrical and instrumentation

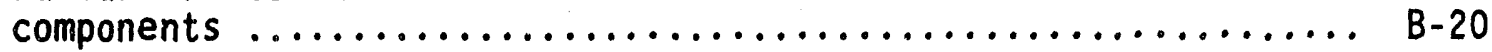

8-3. Failure rates and bounds for mechanical components with various designs and normal states ................... B-28

B-4. Failure rates and bounds for electrical and instrumentation components with various designs and normal states .......... B-45 


\section{APPENDIX B \\ COMPONENT FAILURE DATA PLOTS}

Each row in Tables 3-6 in the body of this report contains a record count; plots in this appendix display the data set corresponding to each row having a record count equalling or exceeding four. The plots are organized in four multi-paged figures, one set of pages for each table, as follows:

Table Number Iype of Components Format Figure Number

$\begin{array}{llll}3 & \text { Mechanical } & \text { Simple } & \text { B-1 } \\ 4 & \text { Electrical } & \text { Simple } & \text { B-2 } \\ 5 & \text { Mechanical } & \text { Detailed } & \text { B-3 } \\ 6 & \text { Electrical } & \text { Detailed } & \text { B-4 }\end{array}$

The electrical components listing contains both electrical and electronic components. For the detailed format, components are listed by their design and normal state as well as their failure mode. Plots for component/failure mode combinations appear in the same order as the respective entries in Tables 3 through 6 . The units (per hour or per demand) for each plot show in the $y$ axis 1 abet.

In each figure, there are three frames of plots per page. Each frame can accomodate a maximum of 20 data points. These points are estimates of median failure rates or probabilities of failure on demand, with associated bounds (if available). Each record in the Nuclear Computerized Library for Assessing Reactor Risk (NUCLARR) that is included in this handbook and is in a group with at least four records gives rise to one such point.

Within each set of data, points are sorted from small to large. The bars show the upper $95 \%$ and 10 wer $5 \%$ bounds of the corresponding fitted 
lognormal distribution for each individual failure rate or probability; the points marked with dots are the medians. Horizontal dotted lines show the $5 \%$ and $95 \%$ bounds of the fitted lognormal distribution for the aggregate of the data set as a whole. Each bar is marked on the abscissa with the study-id of its data source.

For component/failure mode combinations (or, for the detailed tables, a) so component designs and normal states) for which more than 20 "IRADAP "itable" records exist, several successive frames are used to capture the information. Regardless of whether one frame or several frames are used to plot each group of data, plots for successive groups are separated by dashed lines. The cases with multiple frames of plots are denoted by a "Part $n$ of $\mathrm{m}^{\prime}$ indication below the corresponding frame. Note that the scale for the vertical axis is not necessarily the same for each plot withir, one if these groups; the scale for each individual frame is selected based on the specific data to be plotted. 
Fans, Ventilators-F dils to Run

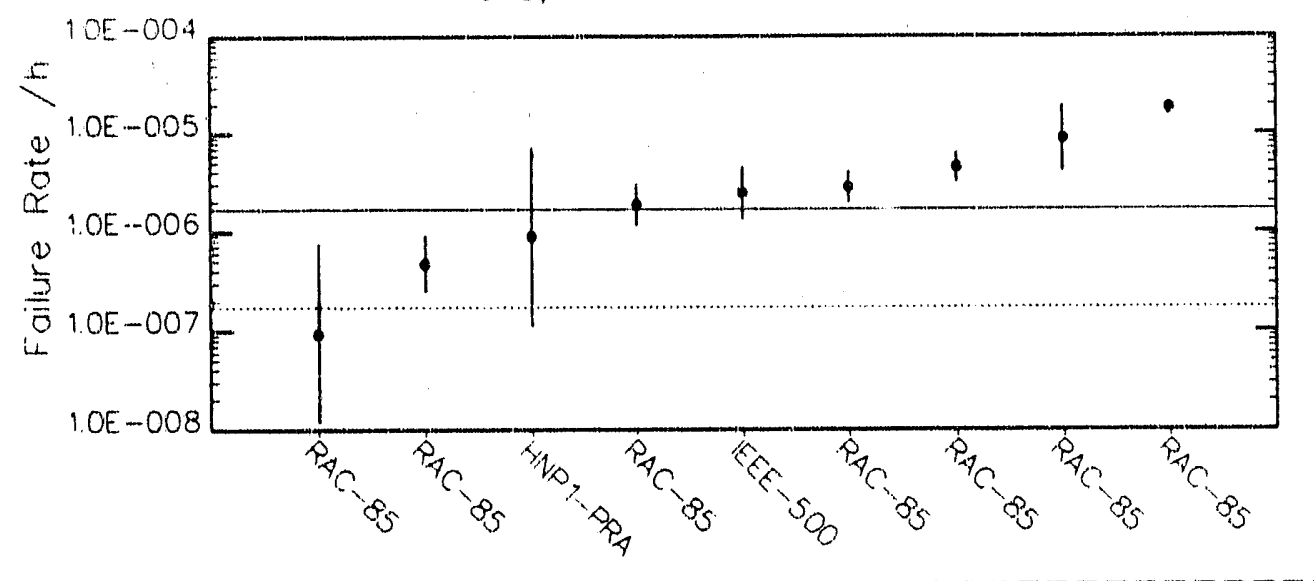

Heat Exchongers-Internal Leakage

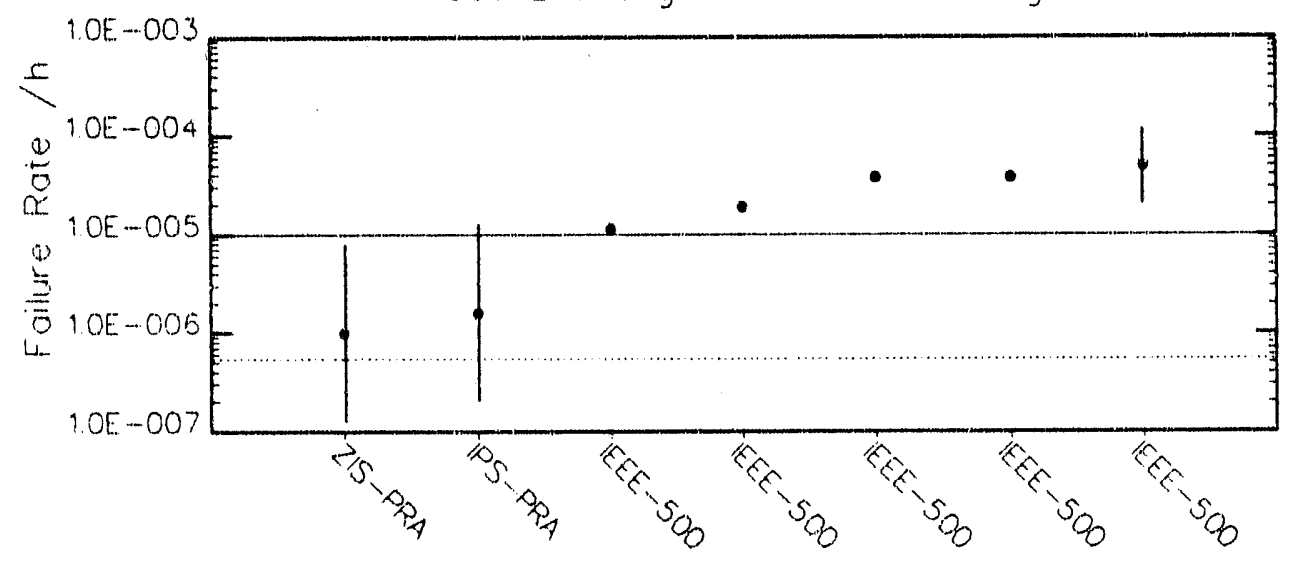

Heat Exchangers-Plugged

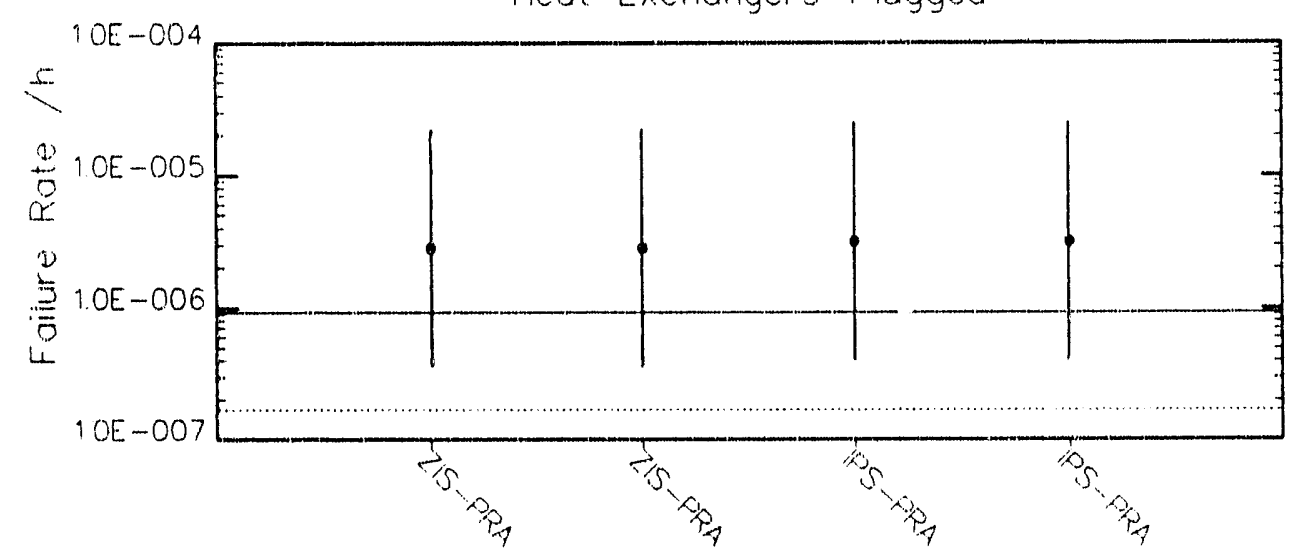

Figure B-1. Foilure rotes and bounds for mechanical components. 


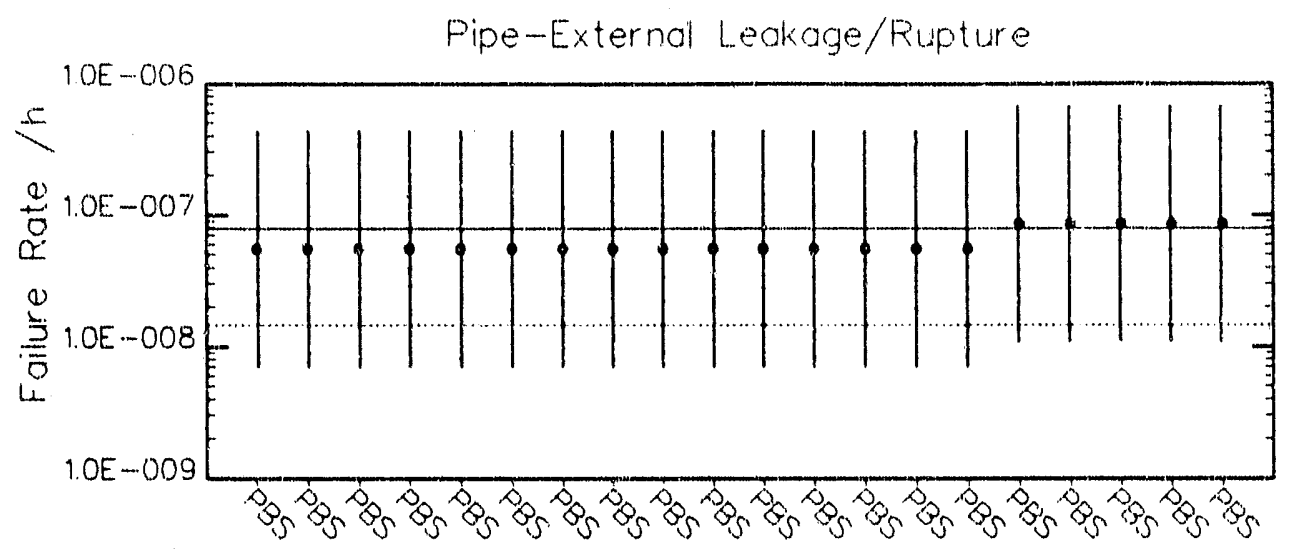

Part 1 of 3 (42 Records Total)

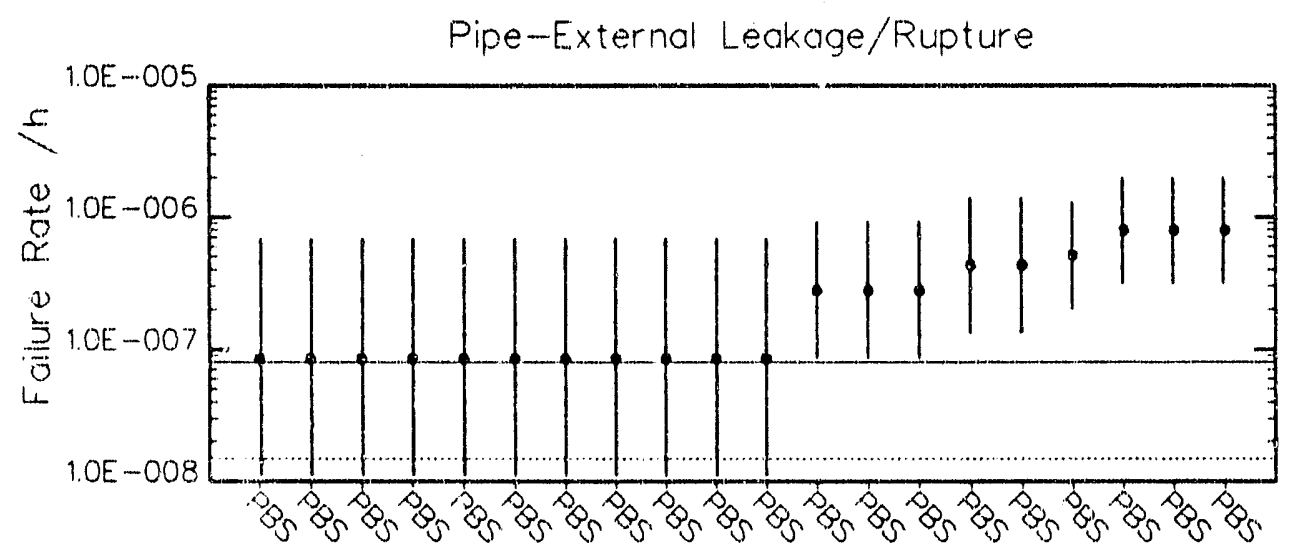

Fart 2 of 3 (42 Records Total)

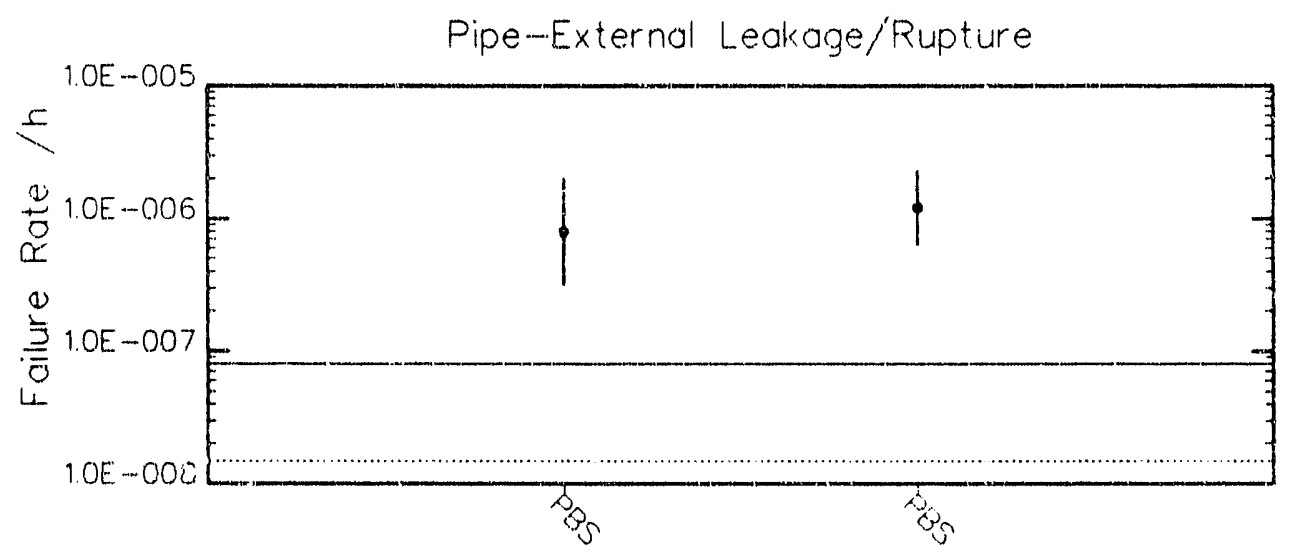

Part 3 of 3 (42 Records Total)

Figure $B-1$. Failure rates and bounds for mechanical components (continued). 

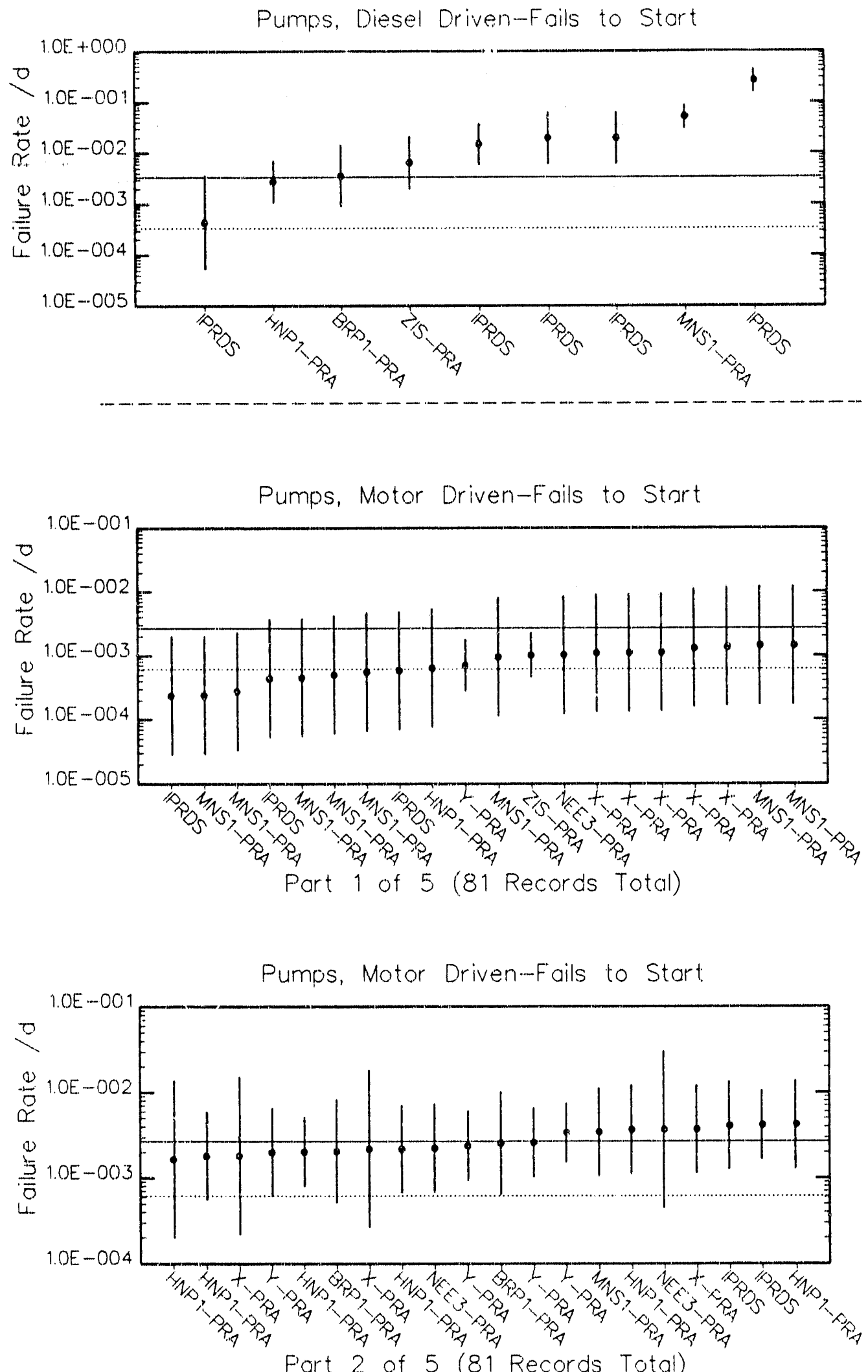

Figure $B-1$. Failure rates and bounds for mechanical components (continued). 

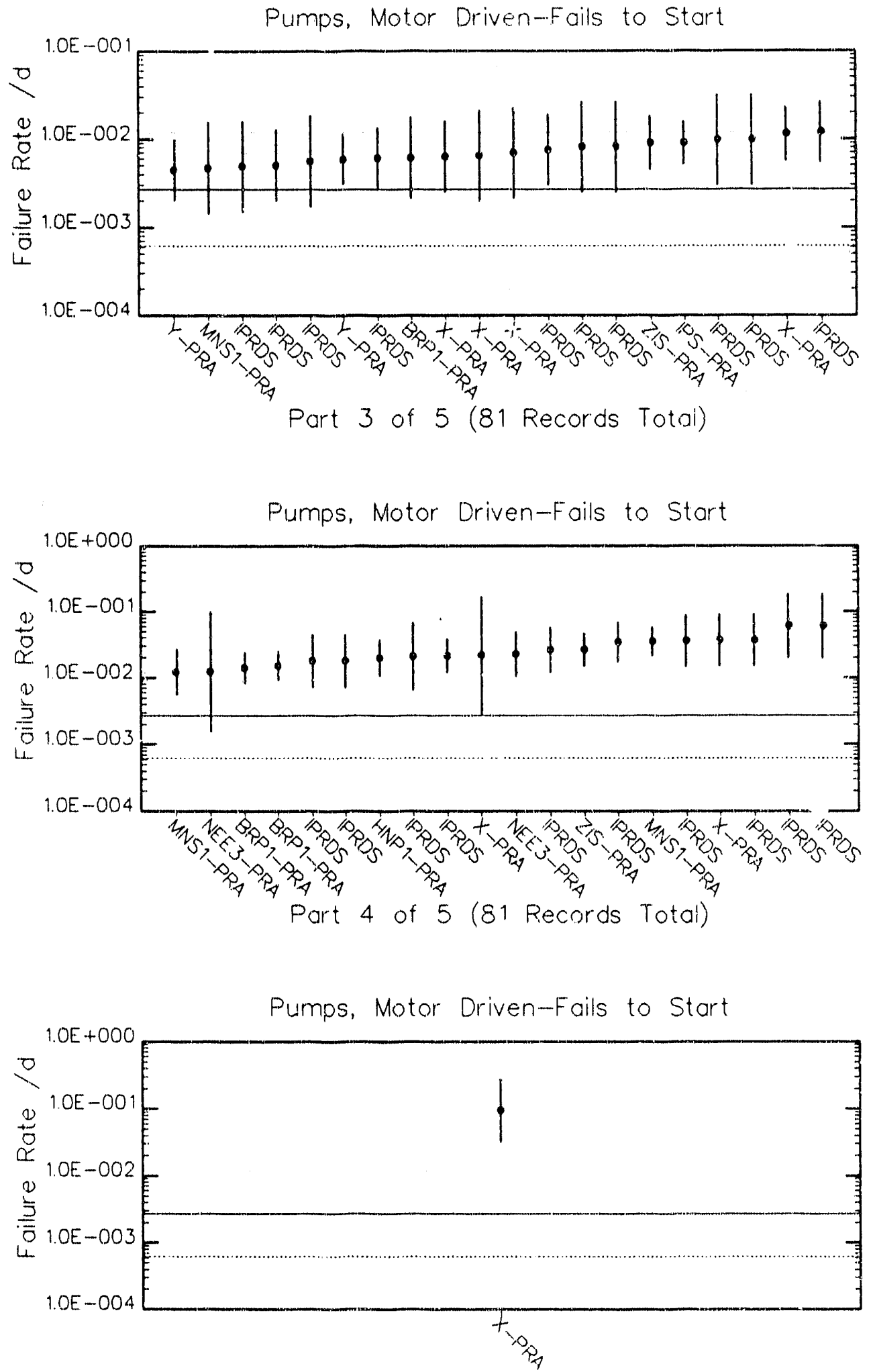

Part 5 of 5 (81 Records Total)

Figure B-1. Failure rotes and bounds for mechanical components (continued). 

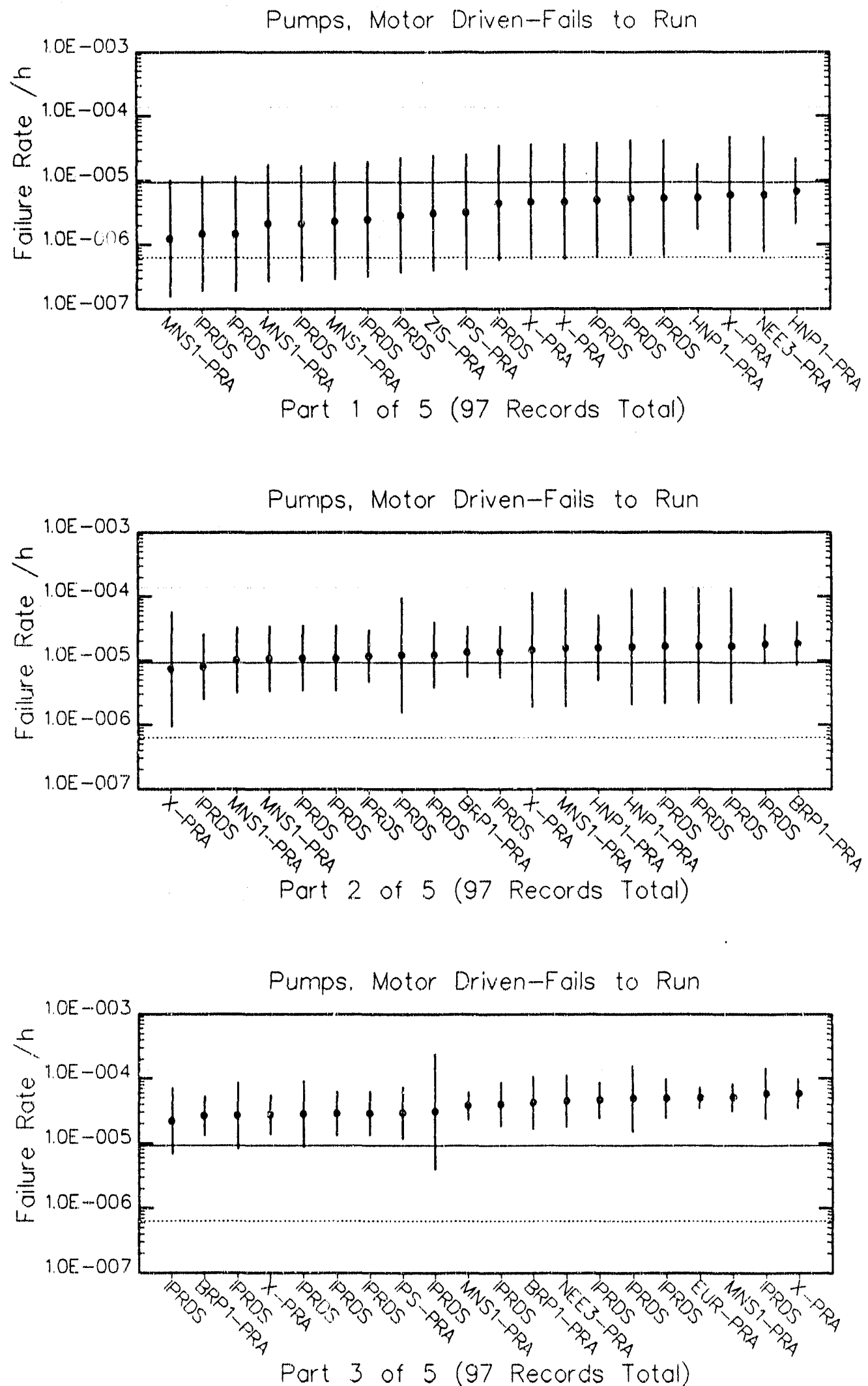

Figure $\mathrm{B}-1$. Failure rates and bounds for mechanical components (continued) 

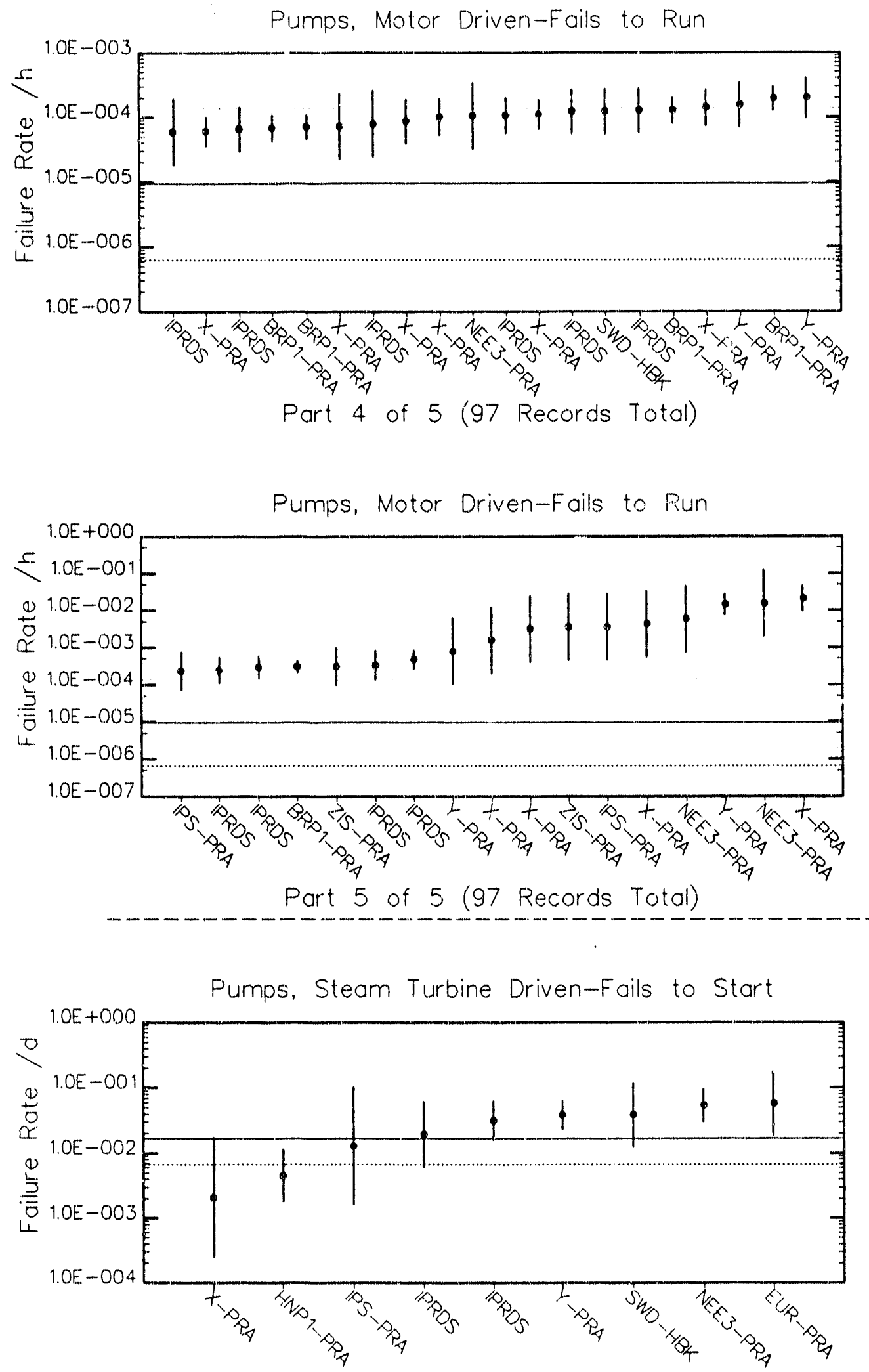

Figure B-1. Failure rates and bounds for mechanical components (continued). 

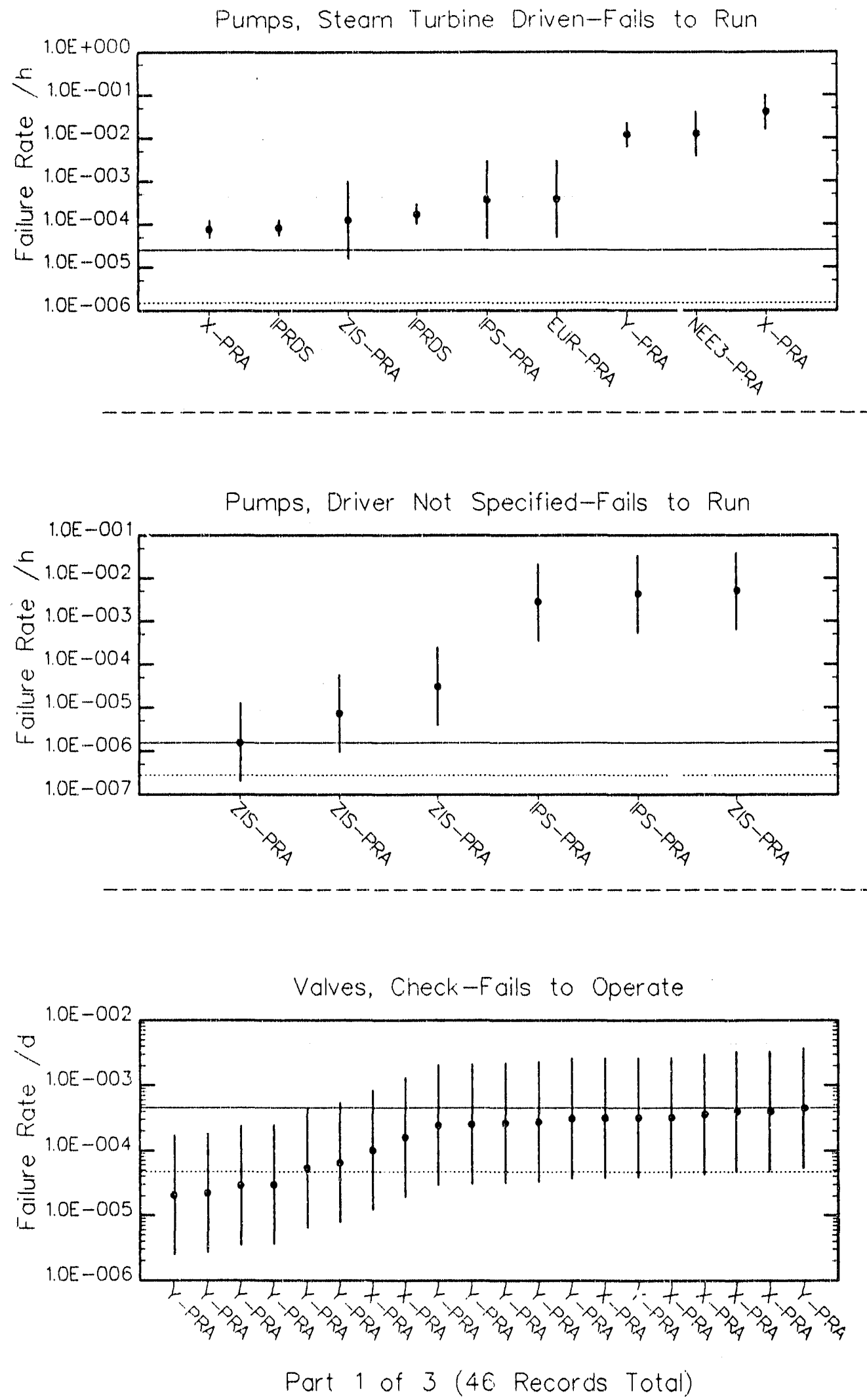

Figure B-1. Failure rates and bounds for mechanical components (continued). 

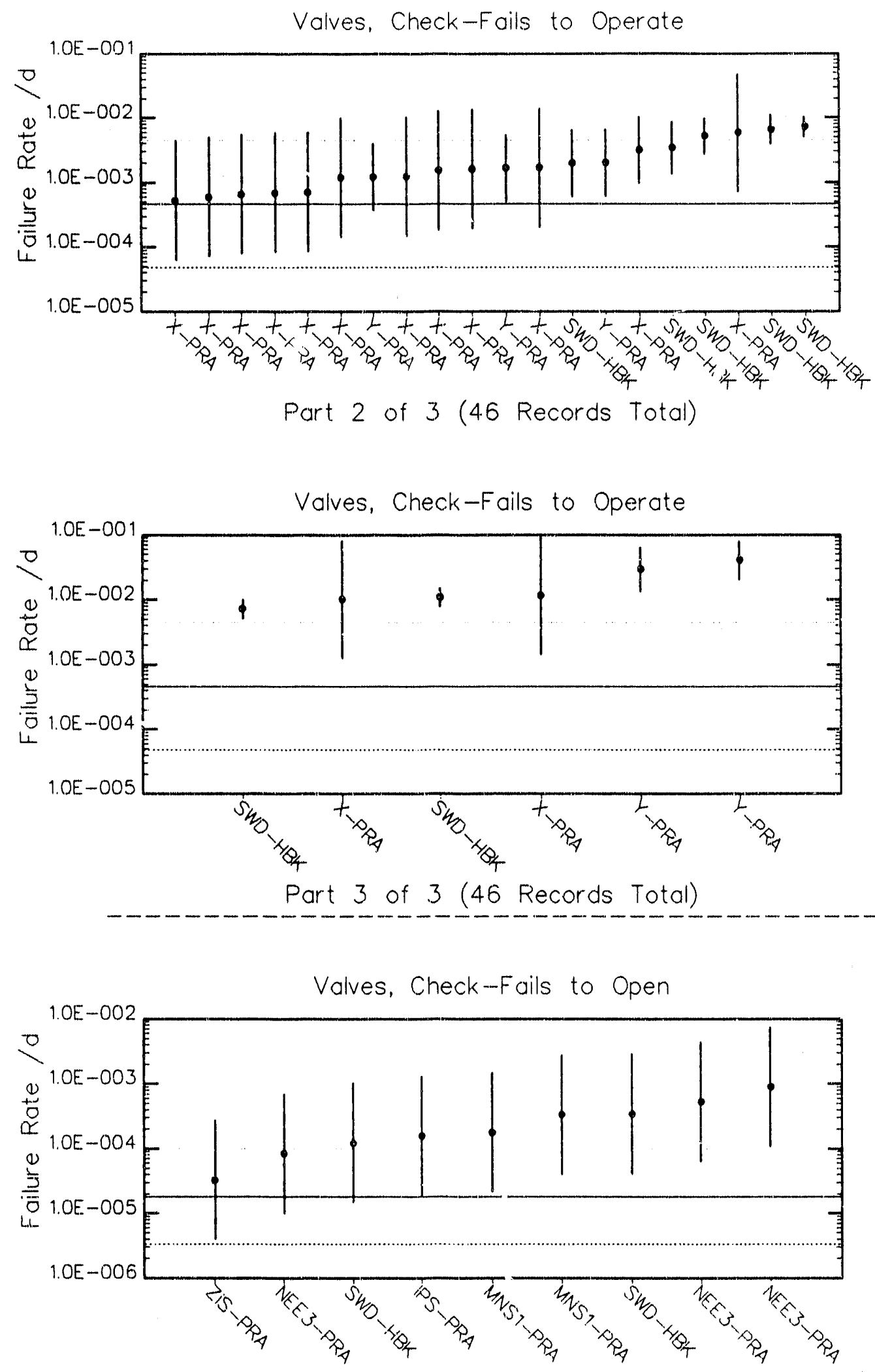

Figure $B-1$. Failure rates and bounds for mechanical components (continued). 

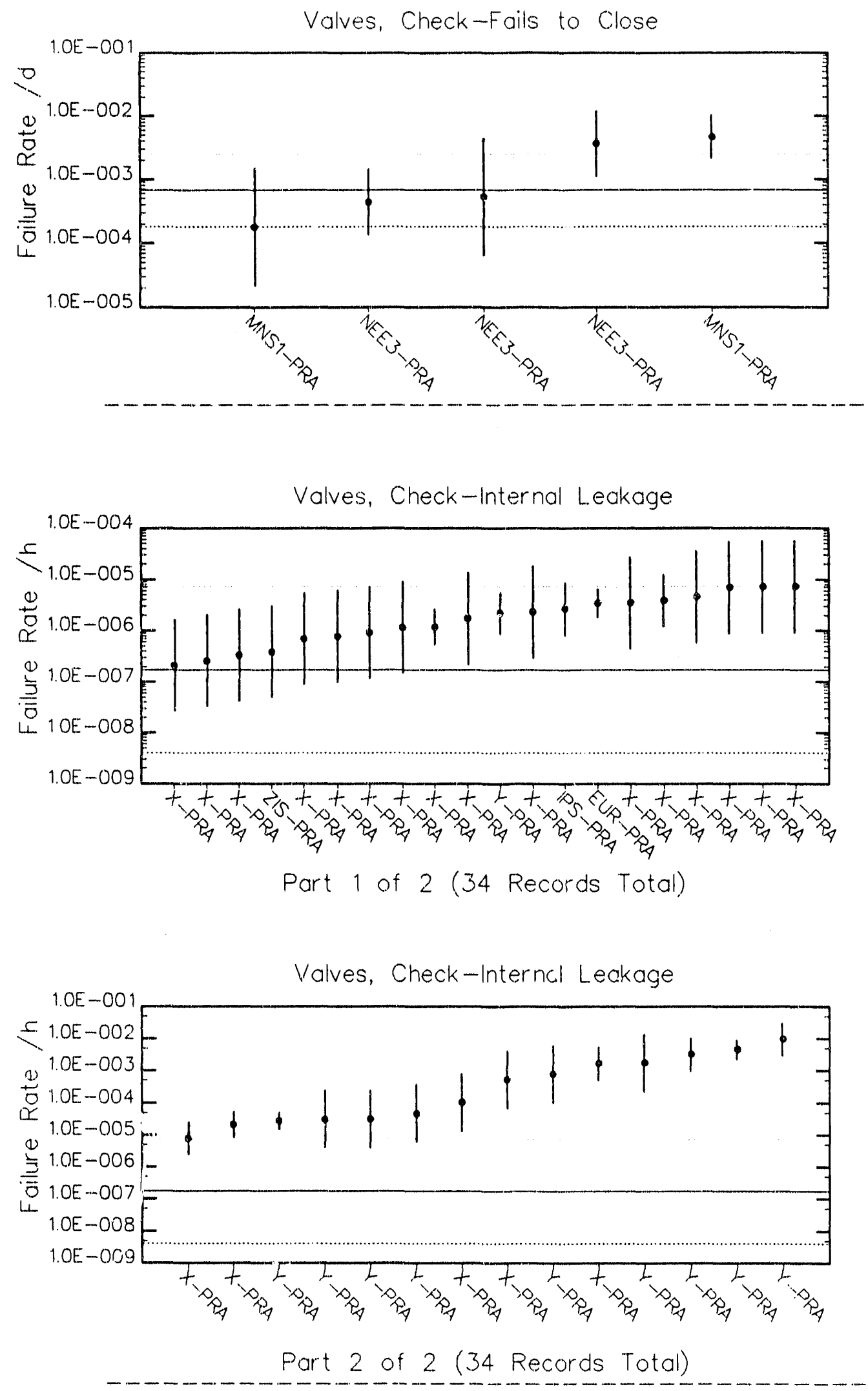

Figure $B-1$. Foilure rates and bounds for mechanical components (continued). 

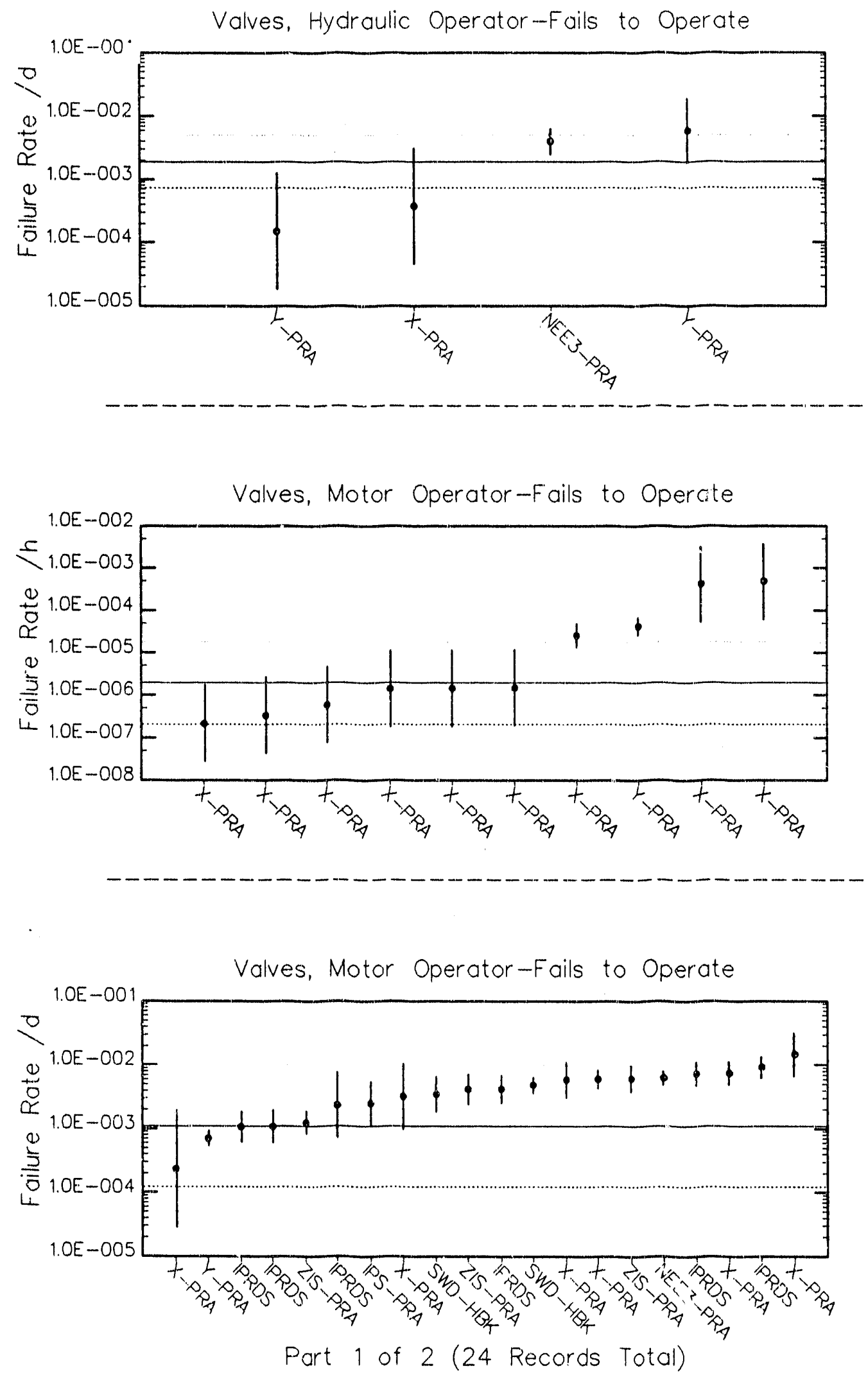

figure B-1. Failure rates and bounds for mechanical components (continued). 

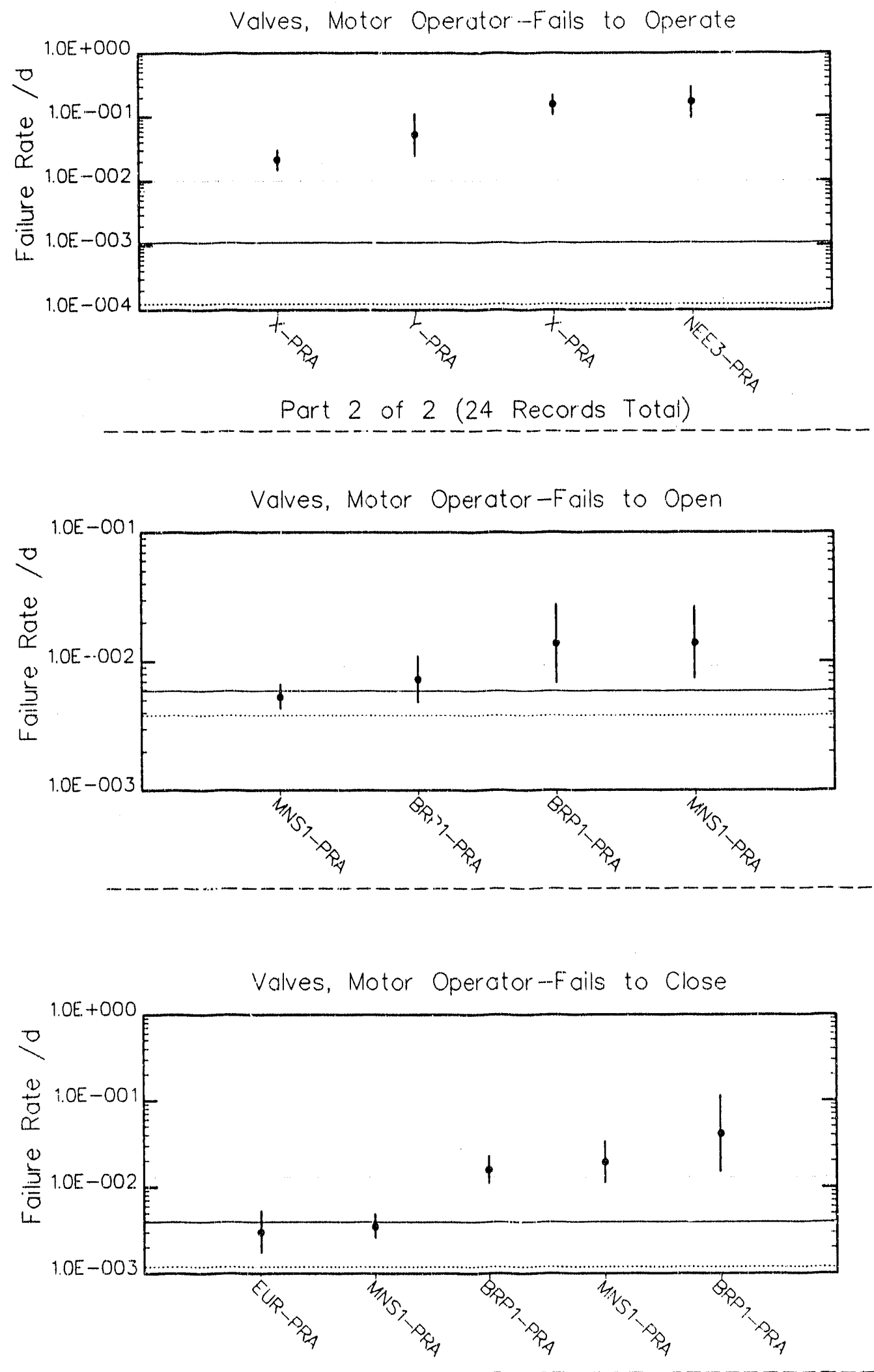

Figure B-1. Failure rates and bounds for mechanical components (contirued). 

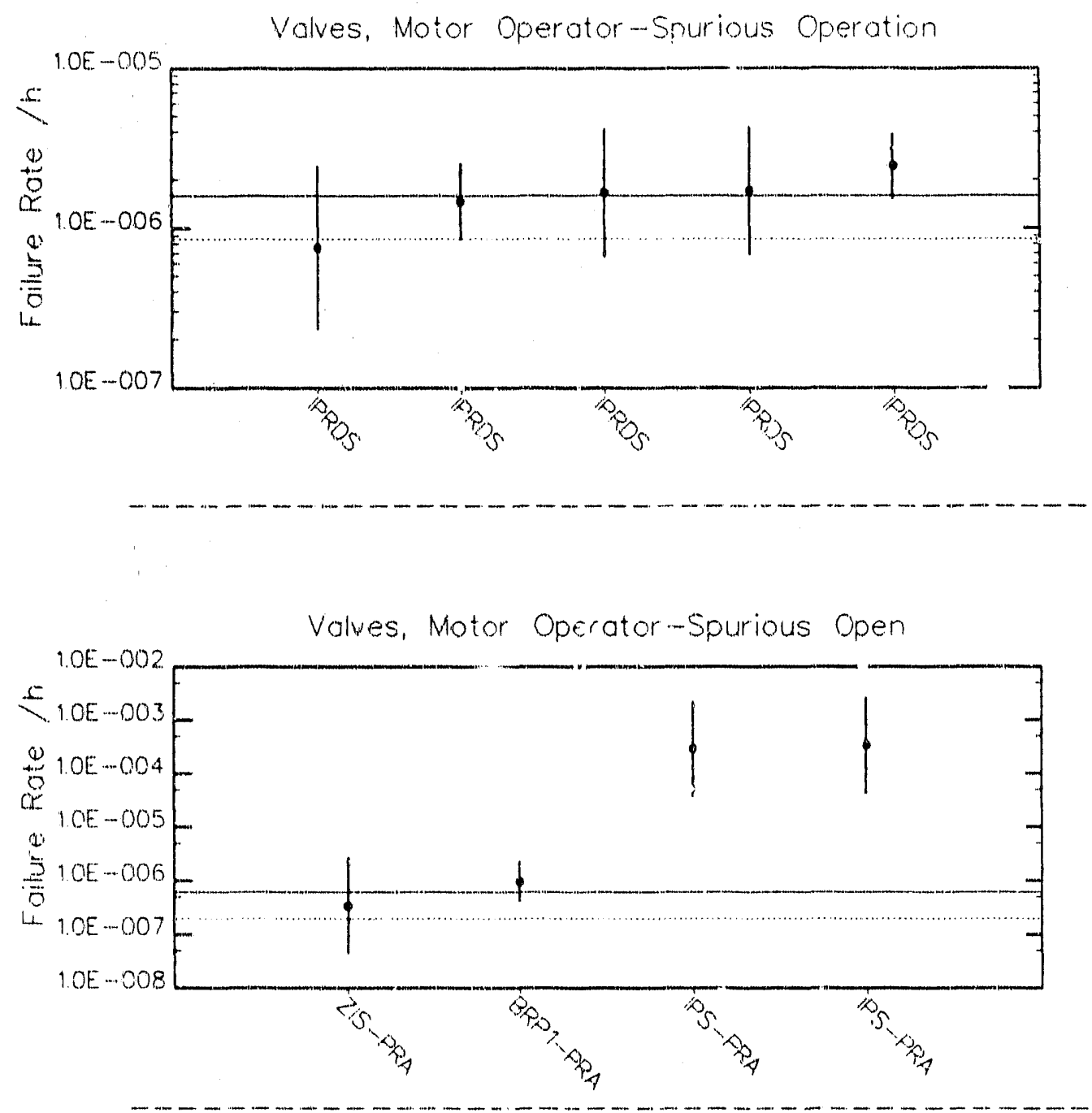

Volves, Manual Operator (mechanical handwheel)-Fails to Operate

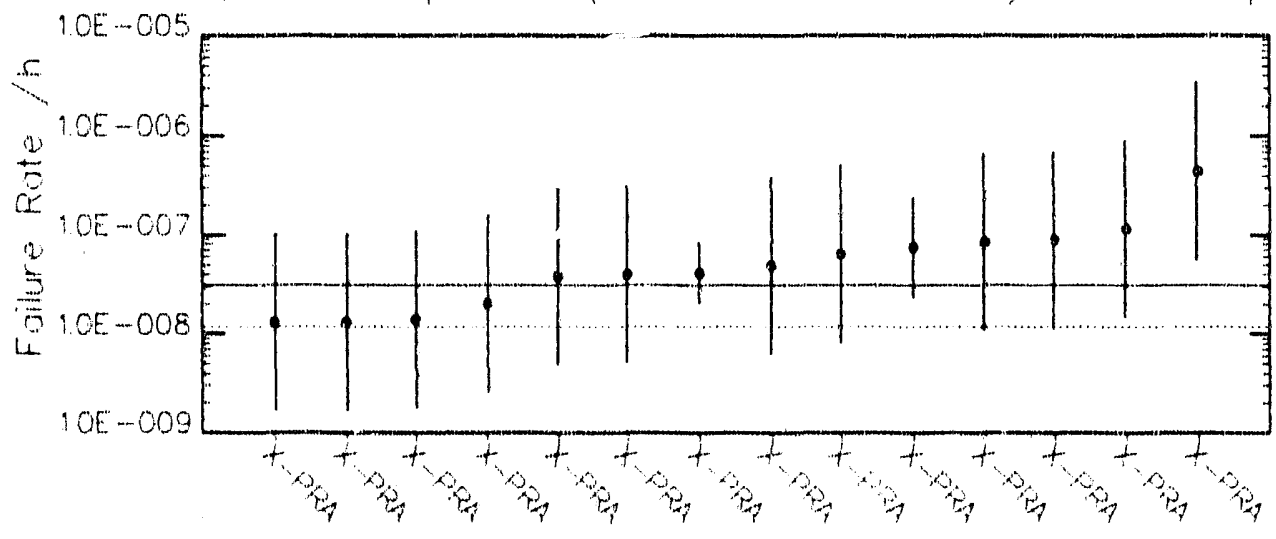

Fioure E-1. Folure rotes ond bounds for mechonico components continues) 

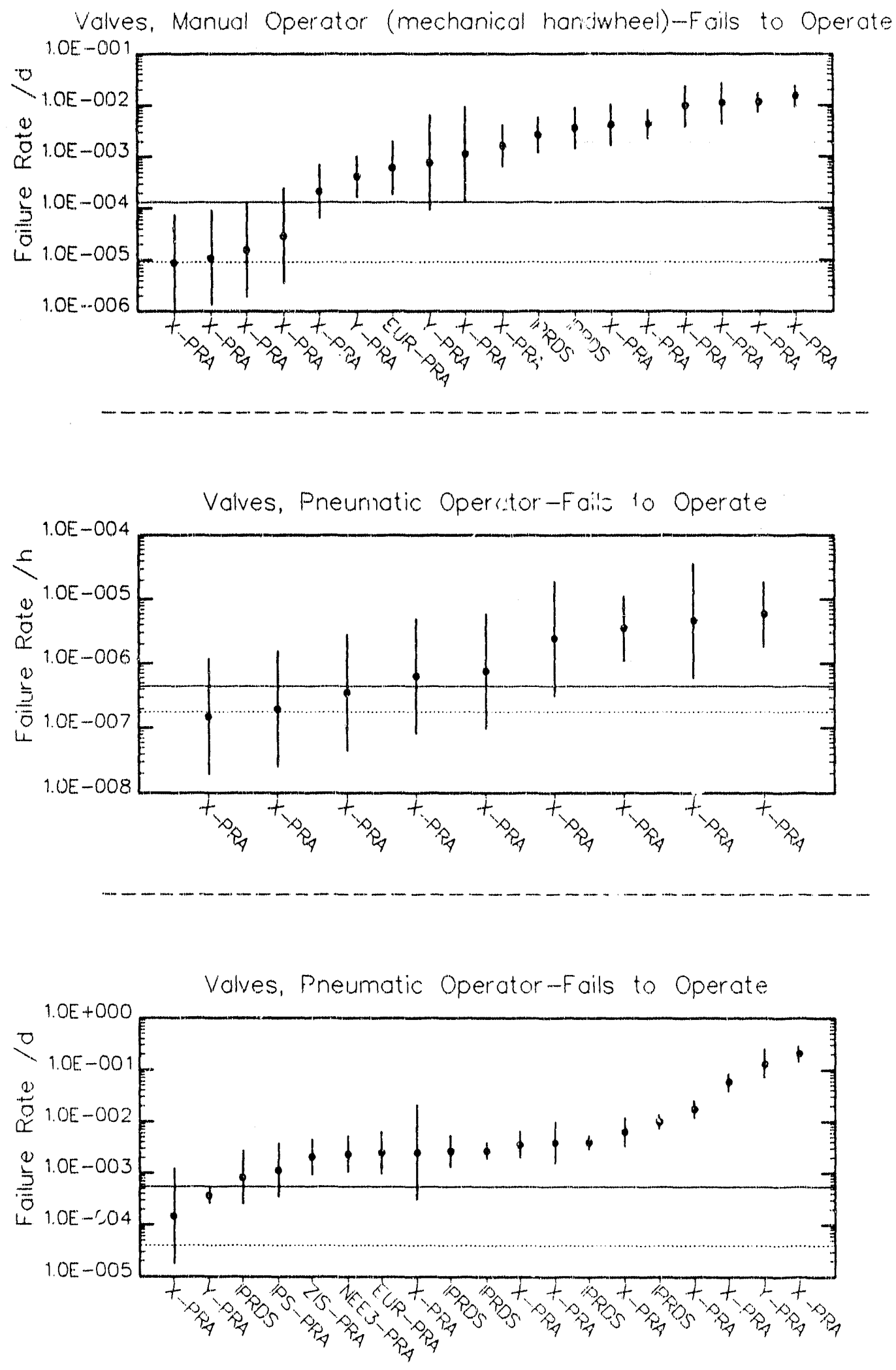

Figure B-1. Foilure rates and bounds for mecharical components (continued). 

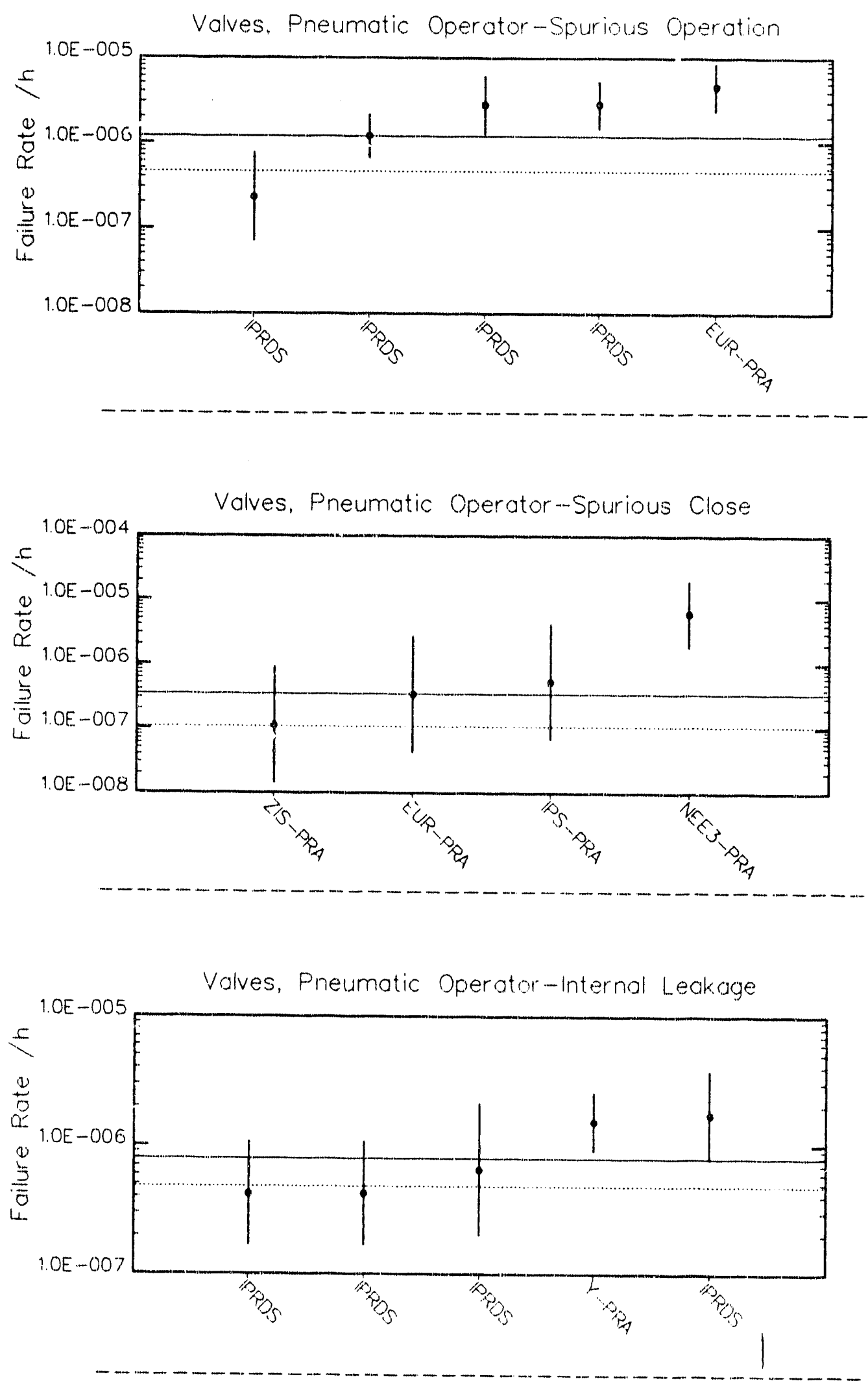

Figure B-1. Foilure rates and bounds for mechanical components (continued). 

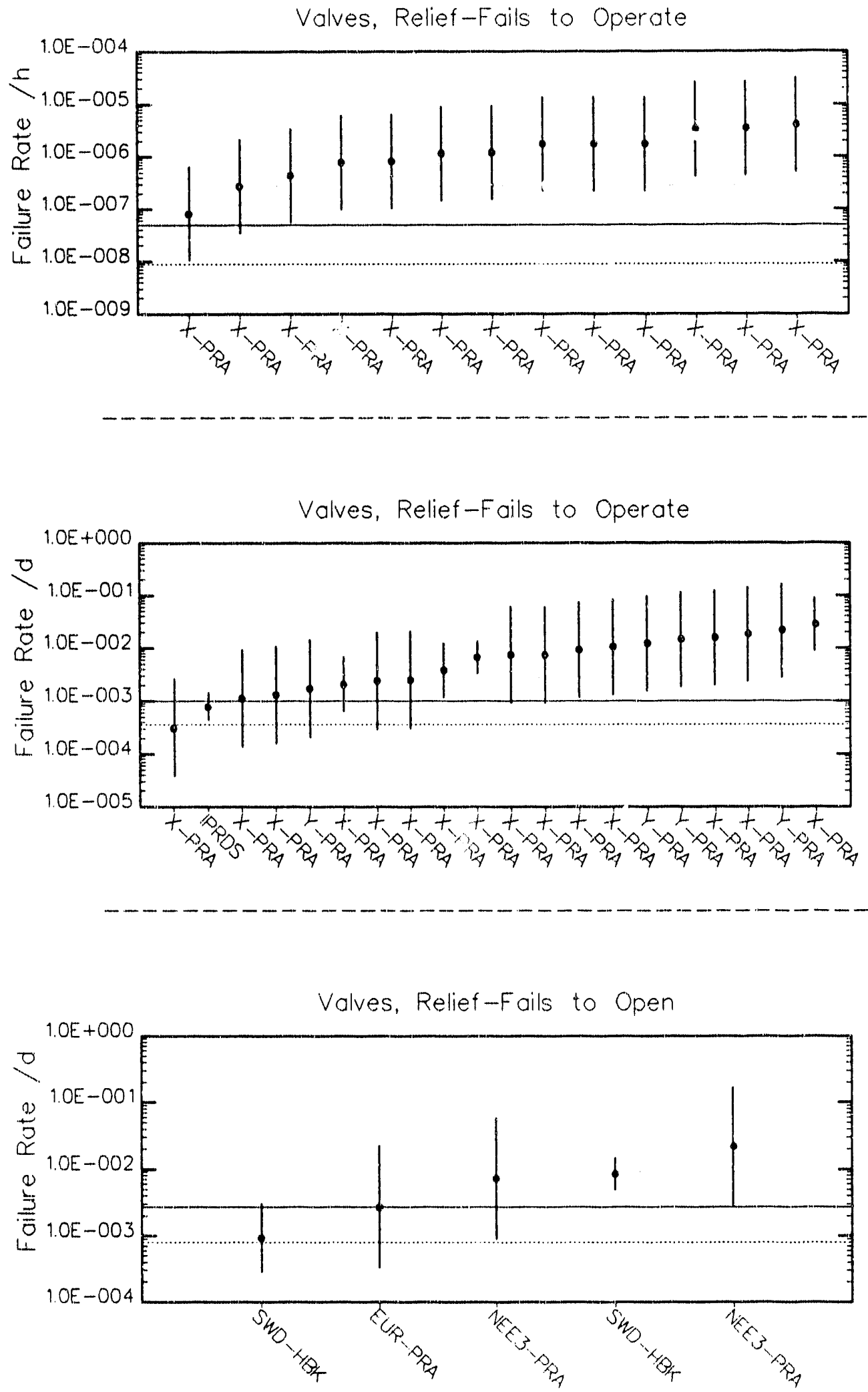

Figure $8-1$. Failure rates and bounds for mechanical components (continued). 

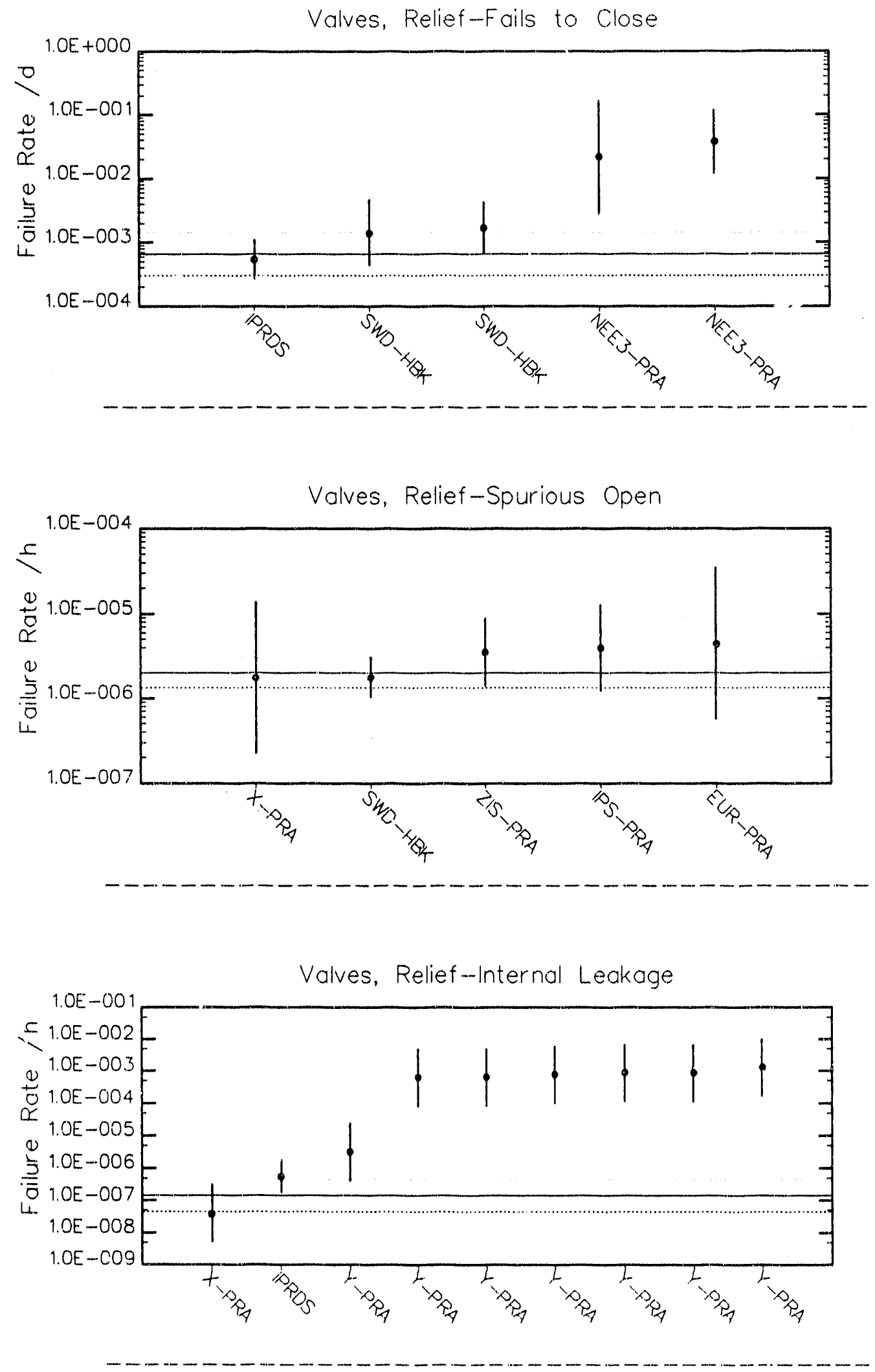

Figure $B-1$. Failure rates and bounds for mechanical components (continued). 

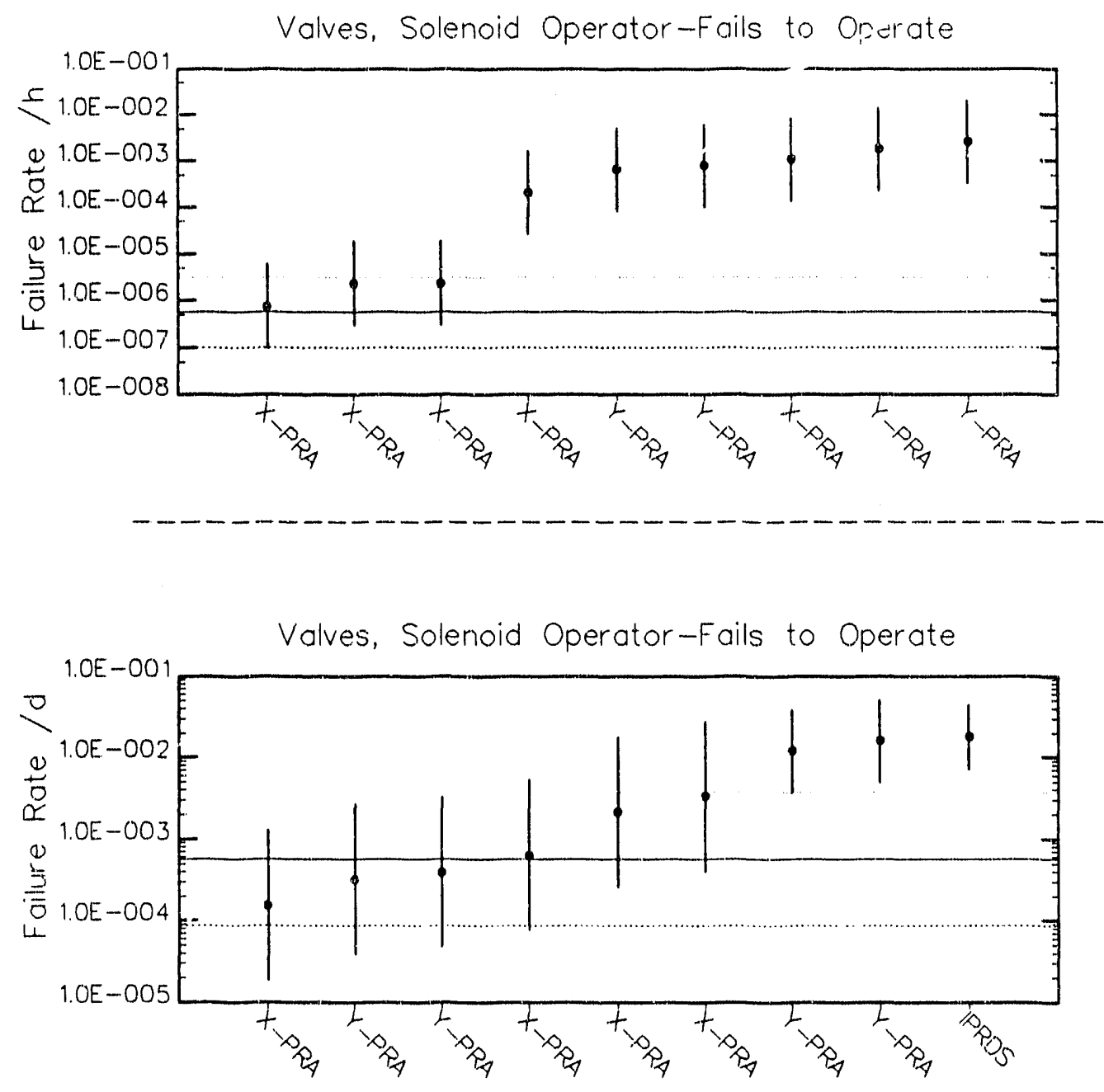

Figure $B-1$. Failure rates and bounds for miechanical components (continued). 

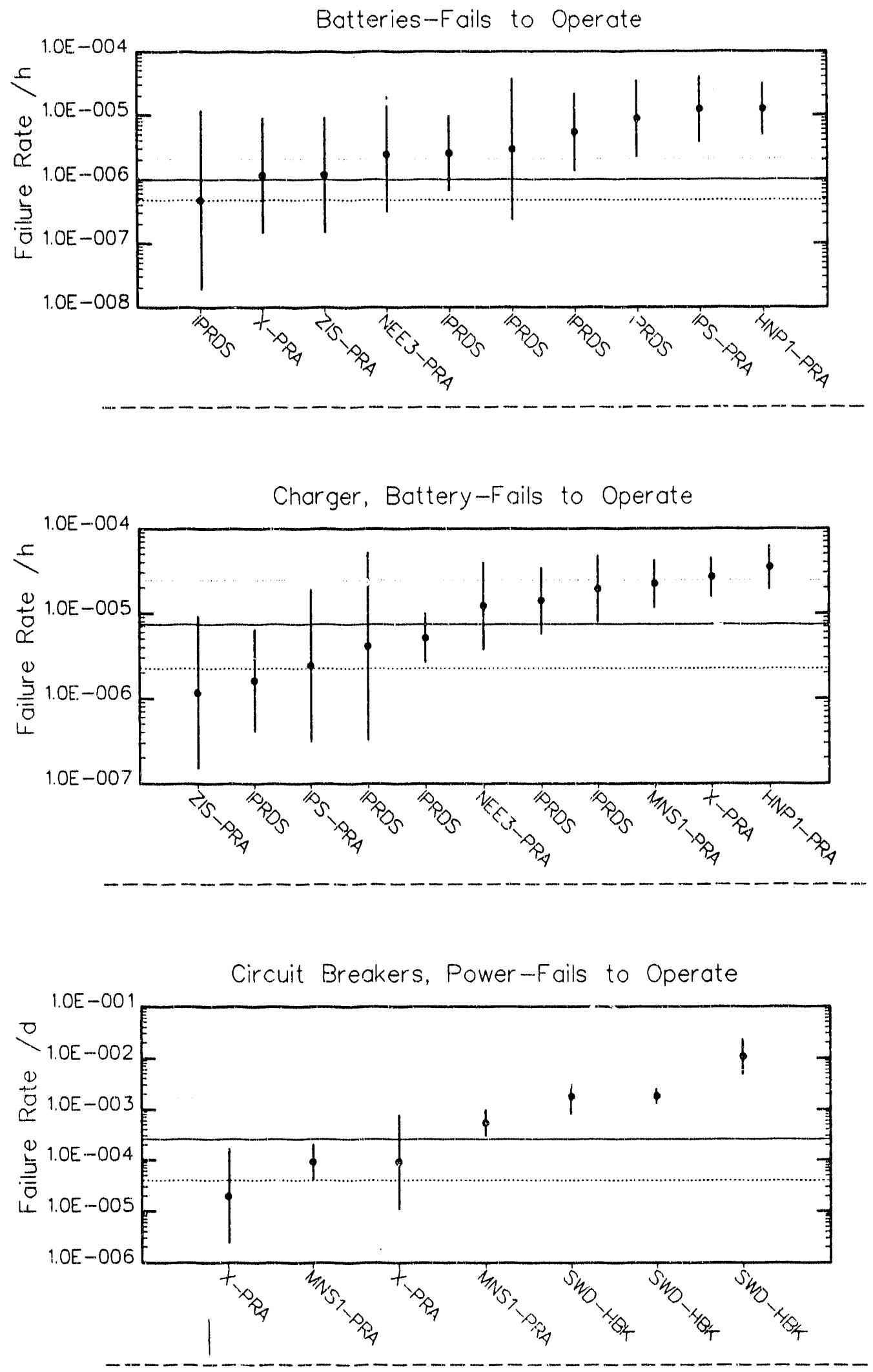

Figure $B-2$. Failure rates and bounds for electrical and instrumentation components. 

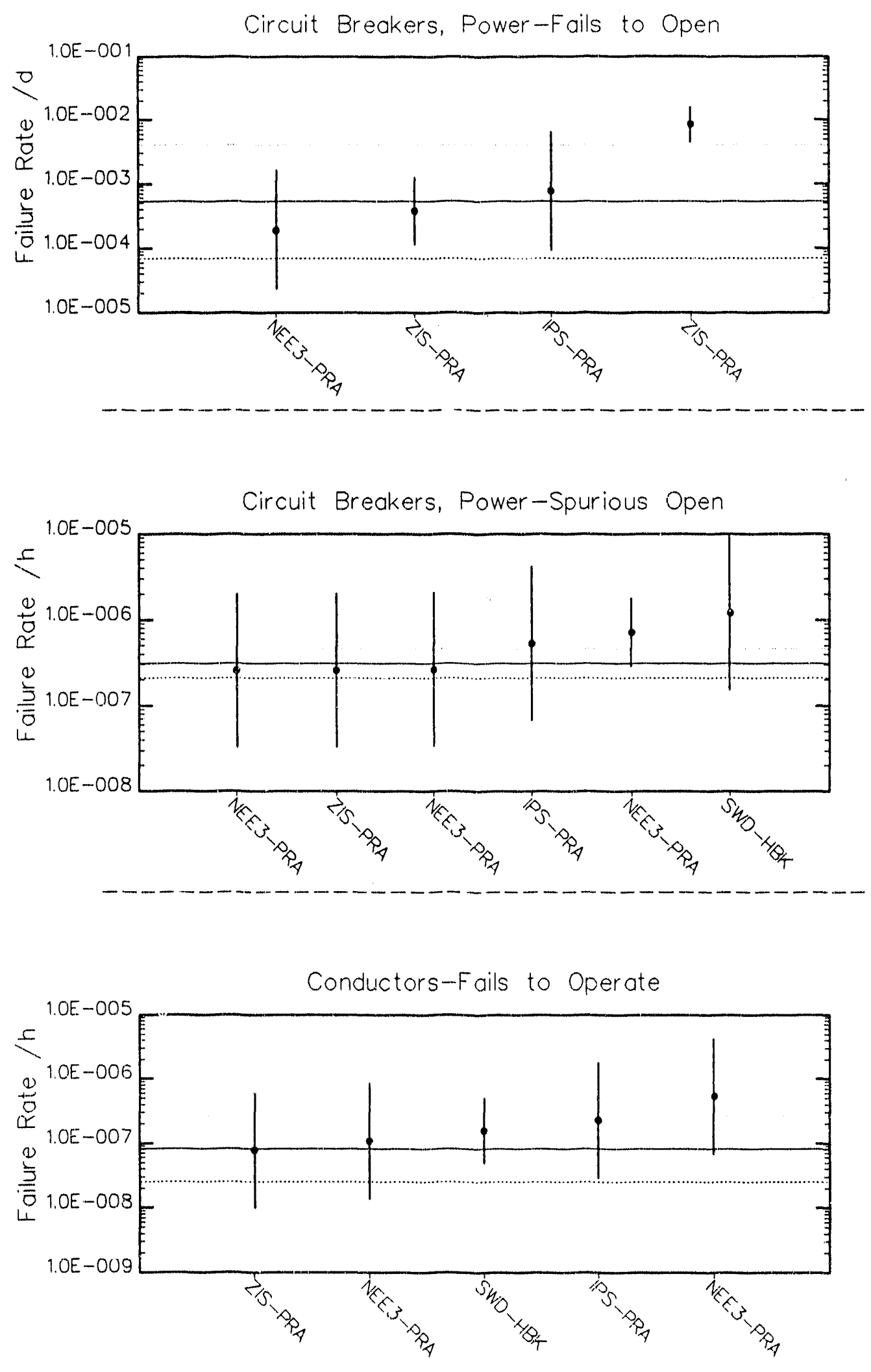

Figure B-2. Failure rates and bounds for electrical and instrumentation components (continued). 

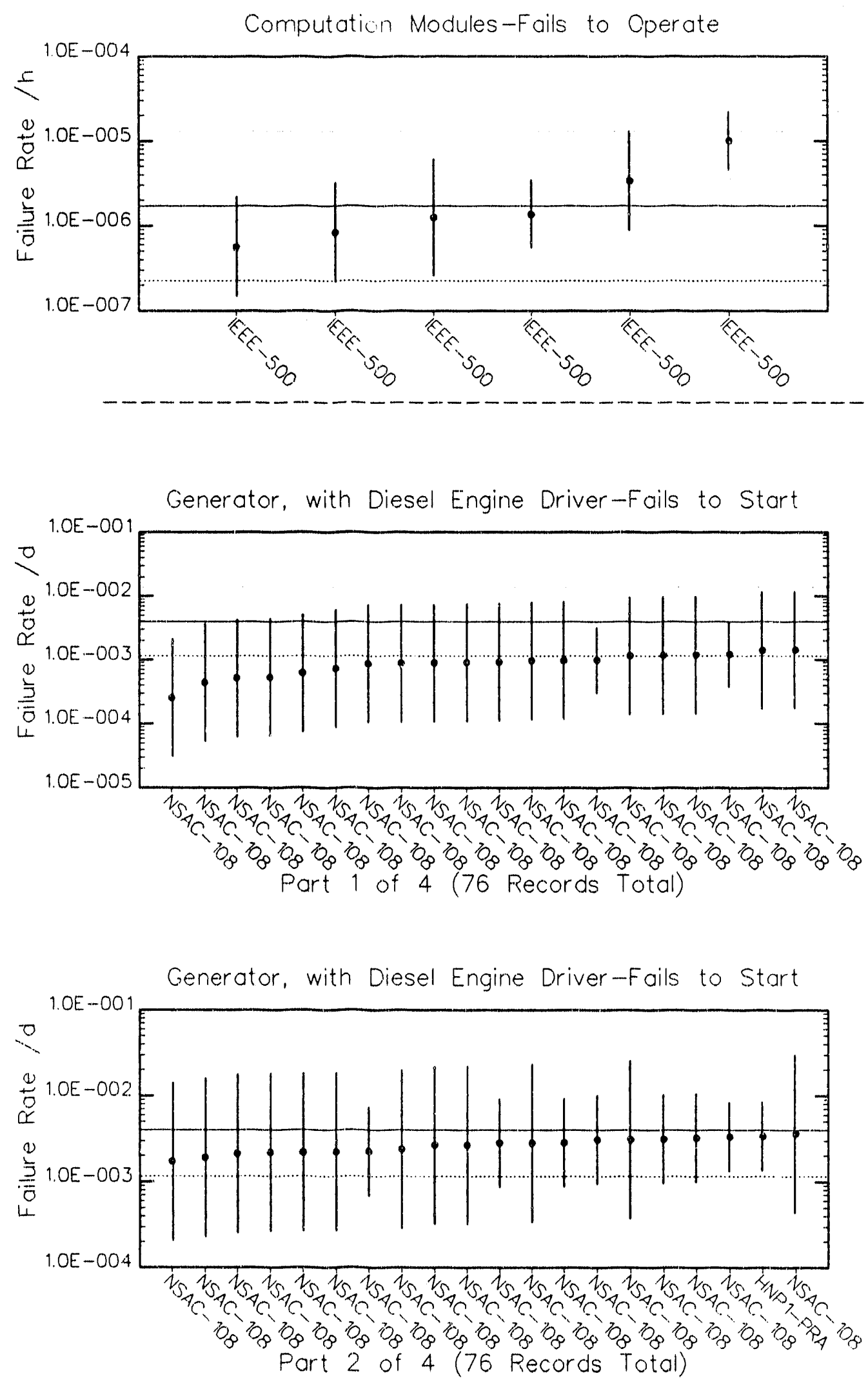

Figure B-2. Failure rates and bounds for electrical and instrumentation components (continued). 

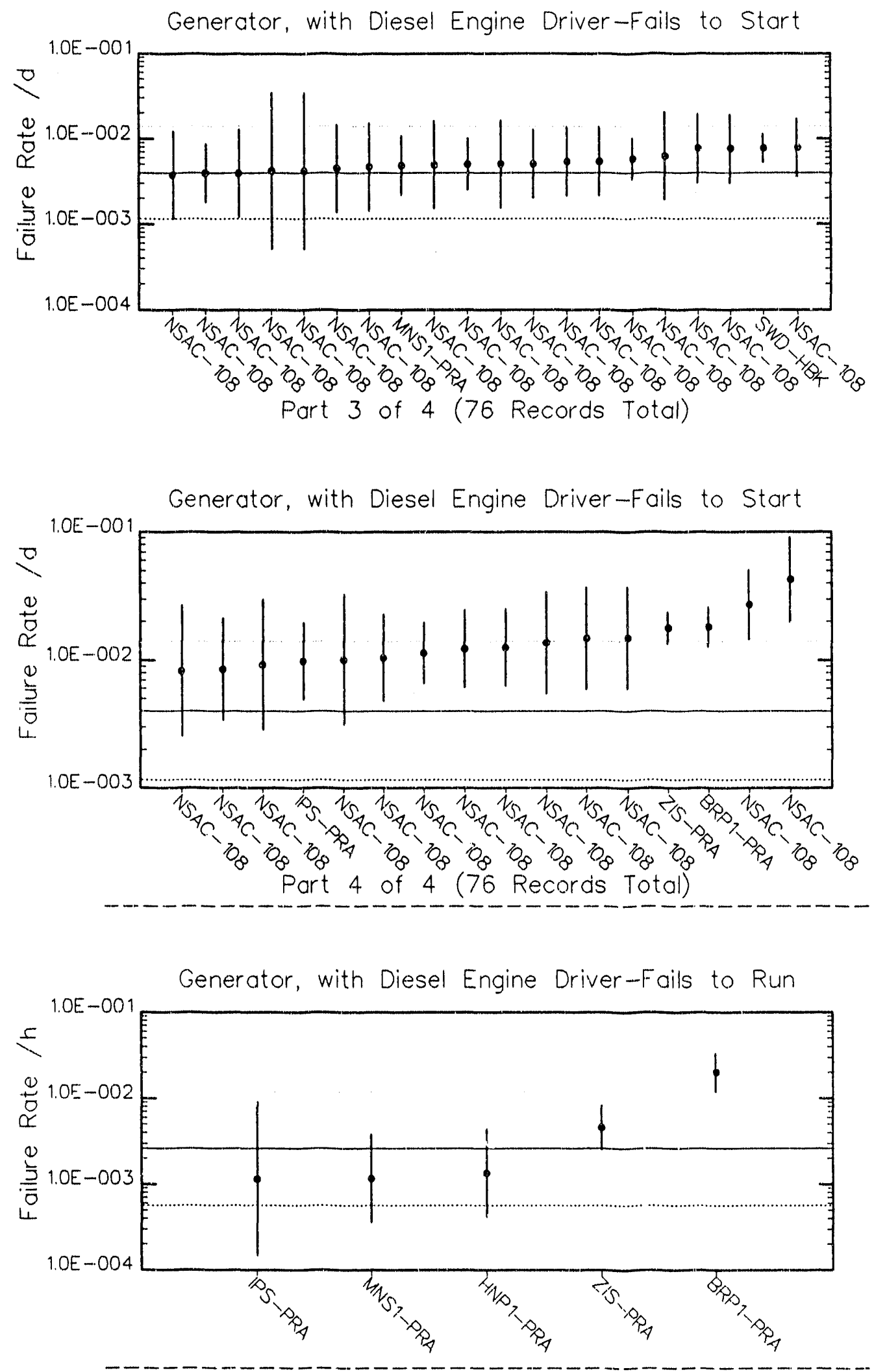

Figure B-2. Failure rates and bounds for electrical and instru-mentation components (continued). 

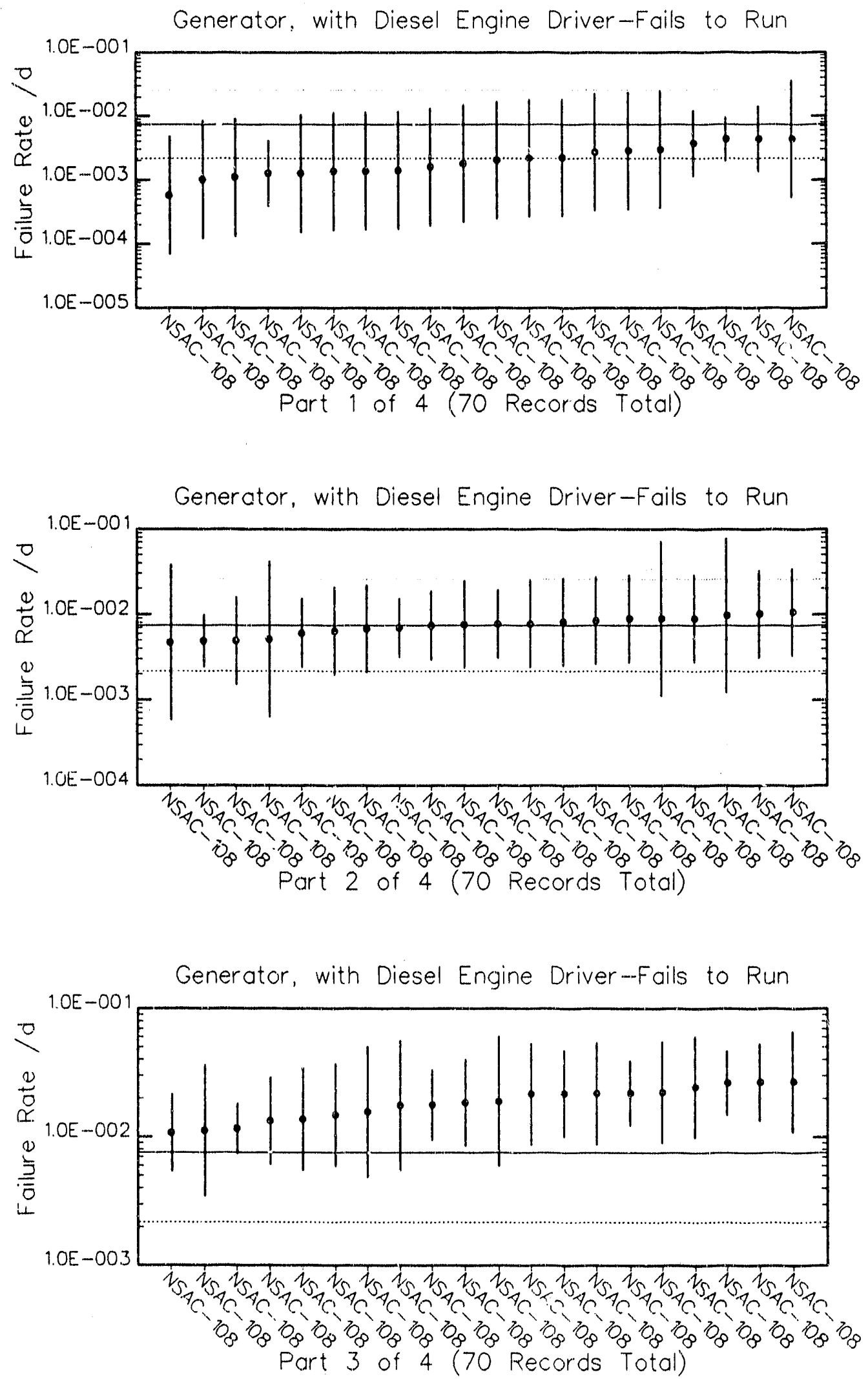

Figure $\mathrm{B}-2$. Failure rates and bounds for electrical and instrumentation components (continued). 

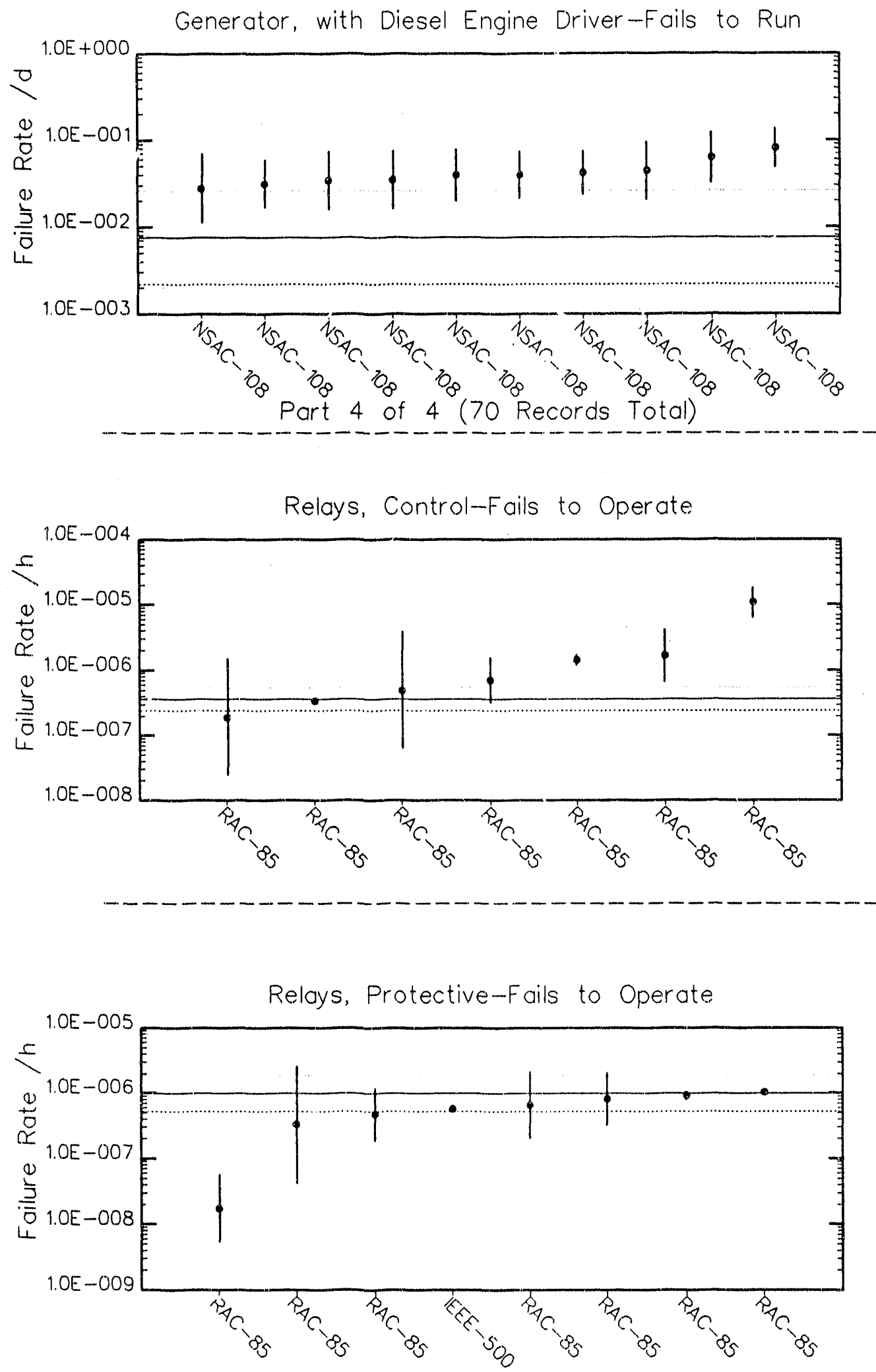

Figure $\mathrm{B}-2$. Failure rates and bounds for electrical and instrumentation components (continued). 

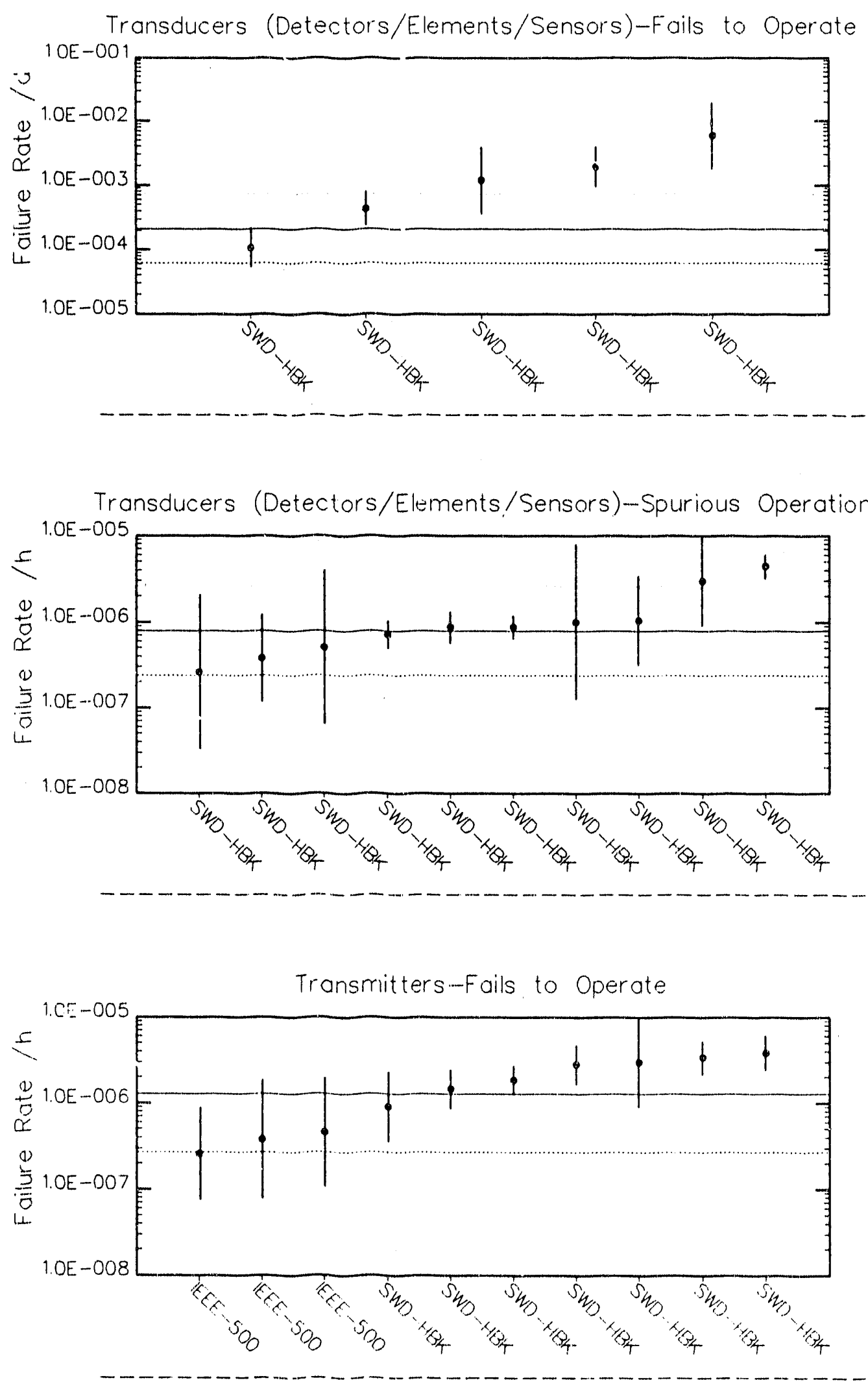

Figure B-2. Failure rates and bounds for electrical and instrumentation components (continued). 

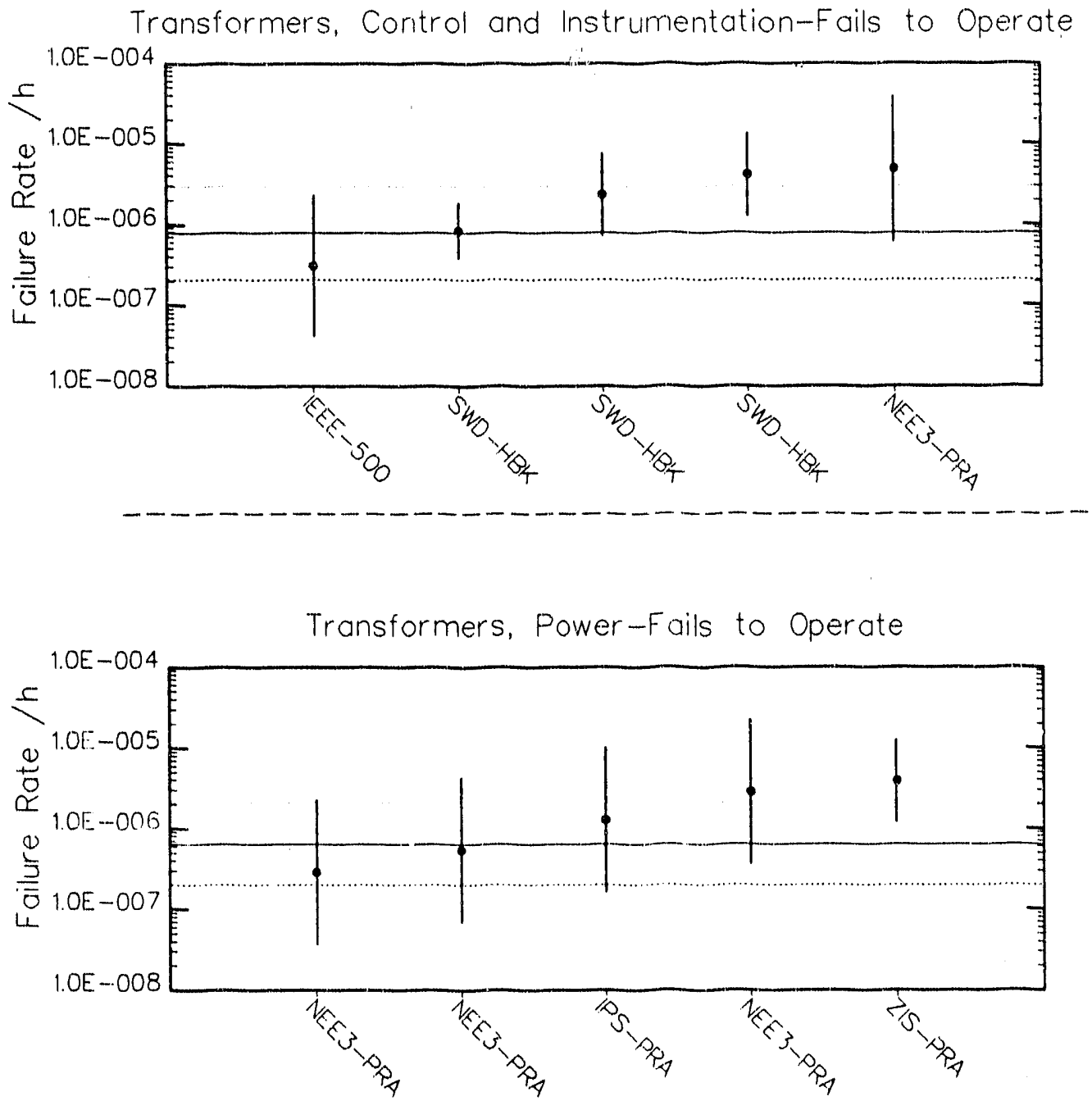

Figure B-2. Failure rates and bounds for electrical and instrumentation components (continued). 

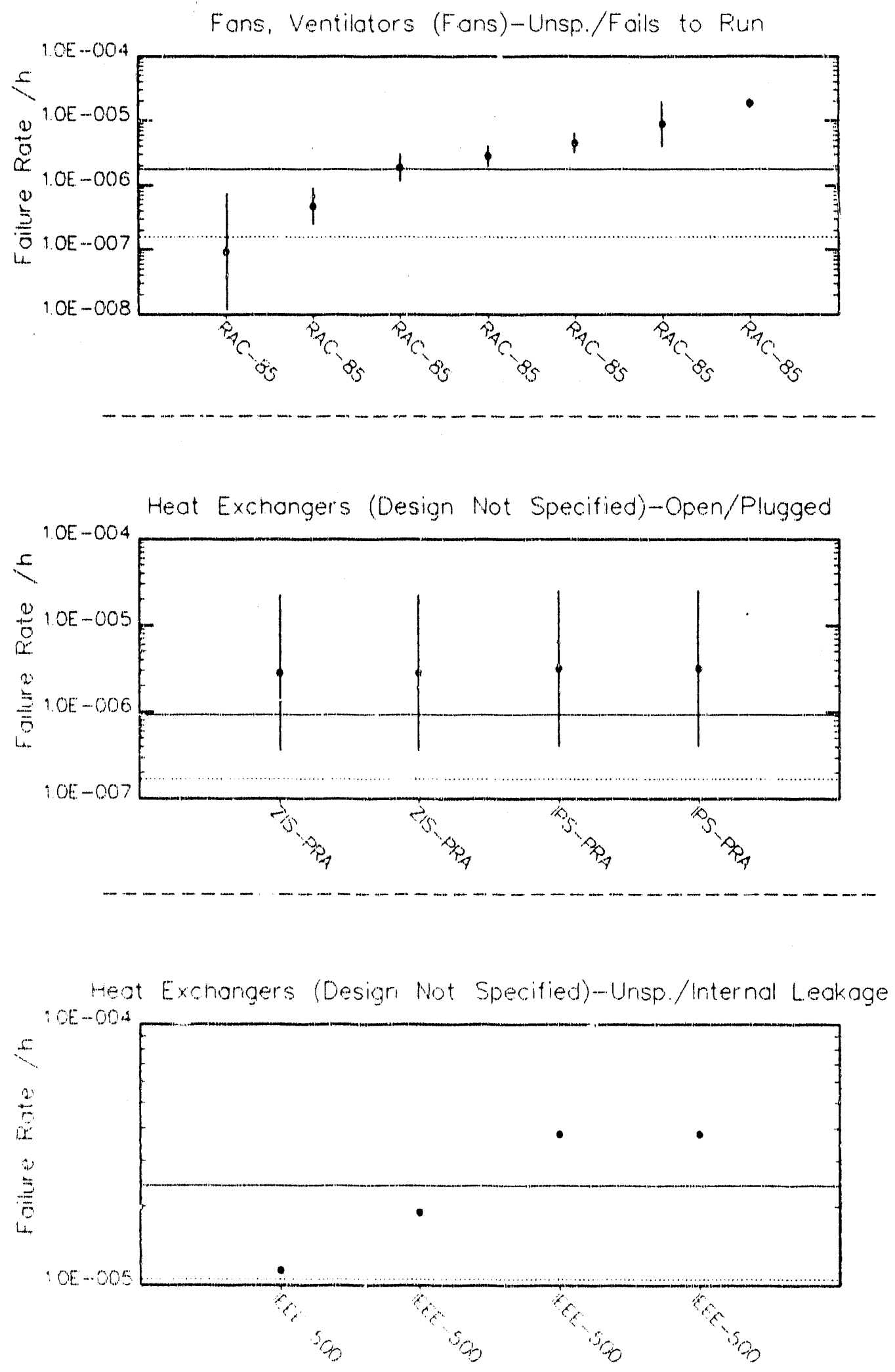

Figute E-3. Folure ates and bounds for mechorical components with vories oesigne orid normol stotes. 

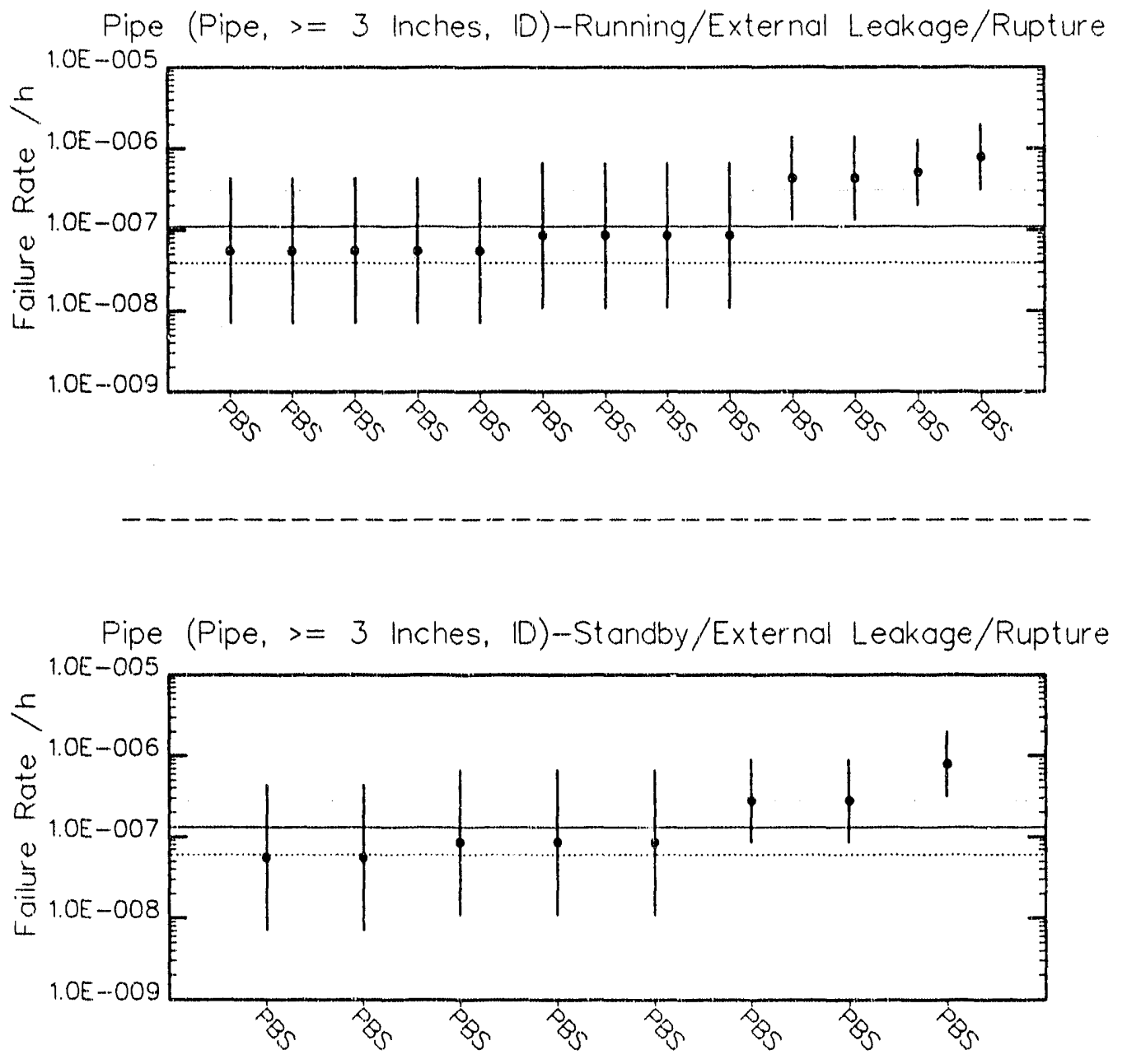

Pipe (Pipe, < 3 Inches, ID)-Running/External Leakage/Rupture

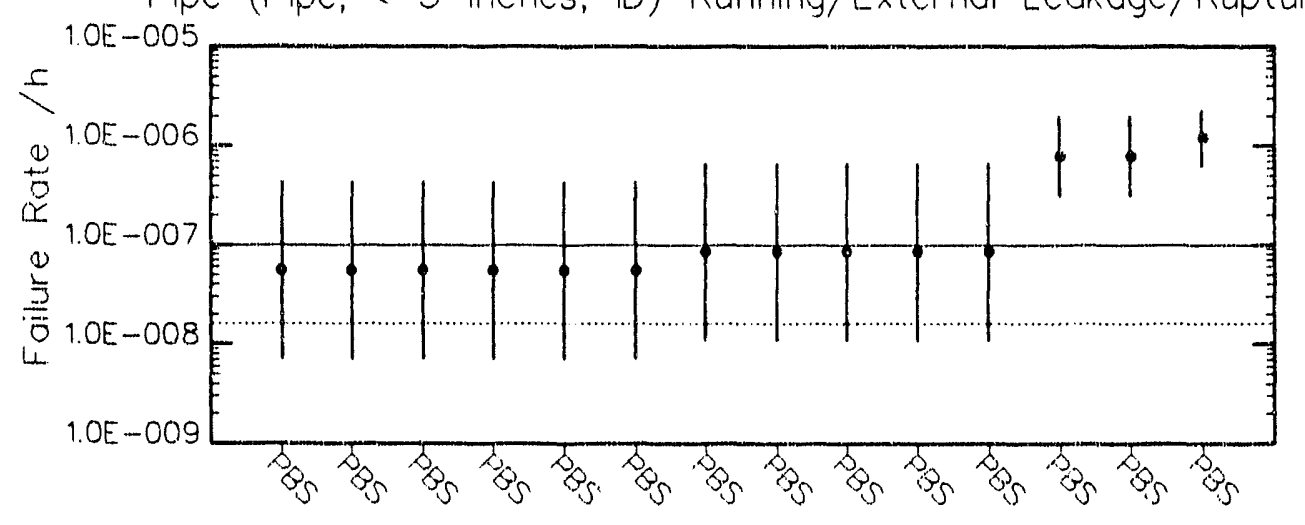

Figure $\mathrm{B}-3$. Failure rates and bounds for mechanical components with various designs and normal states (continued). 
Pipe (Pipe, < 3 Inches, ID)--Standby/External Leakage/Rupture
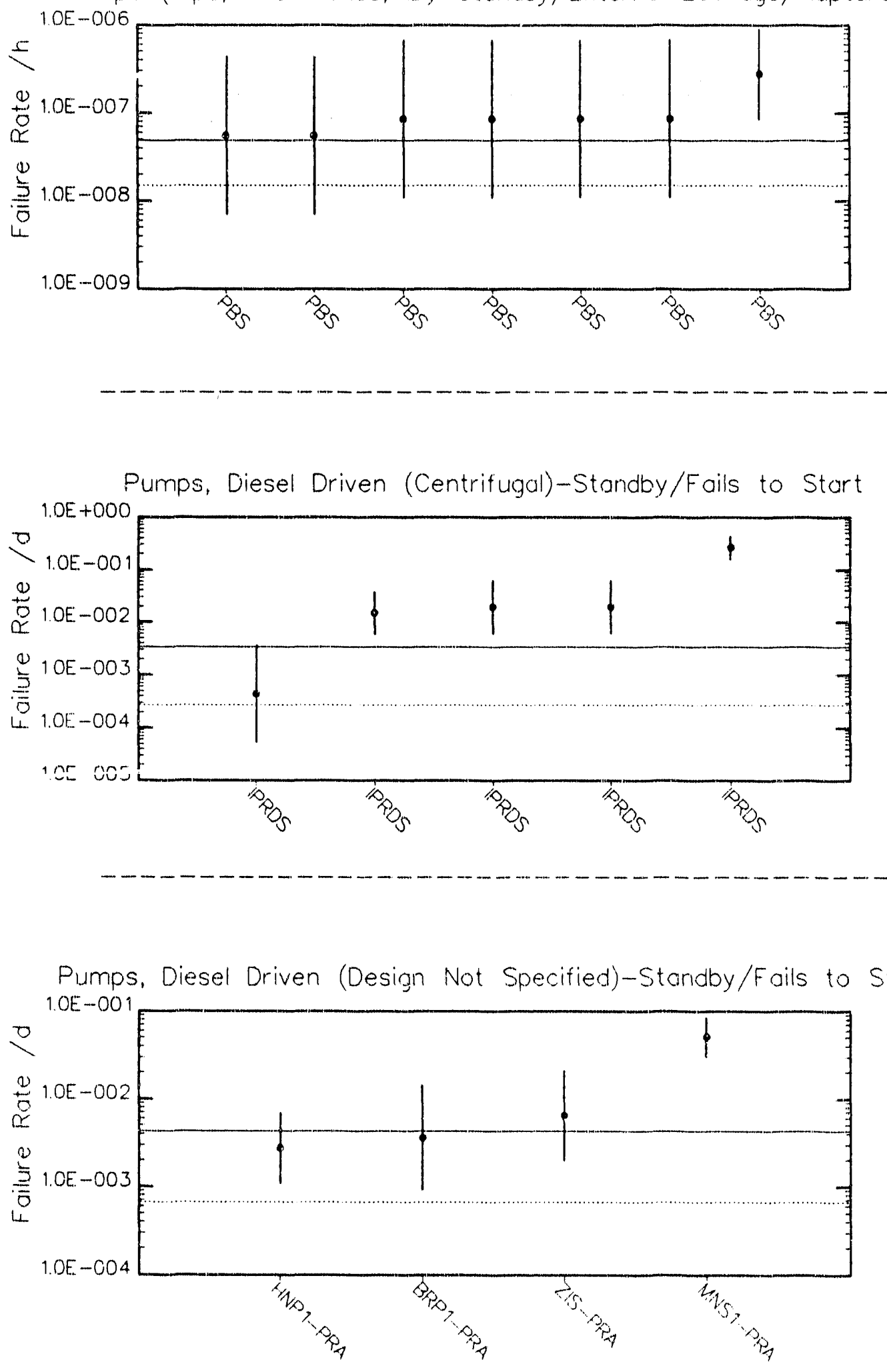

Figure B-3. Failure rates and bounds for mechanical components with various designs and normai states (continued). 

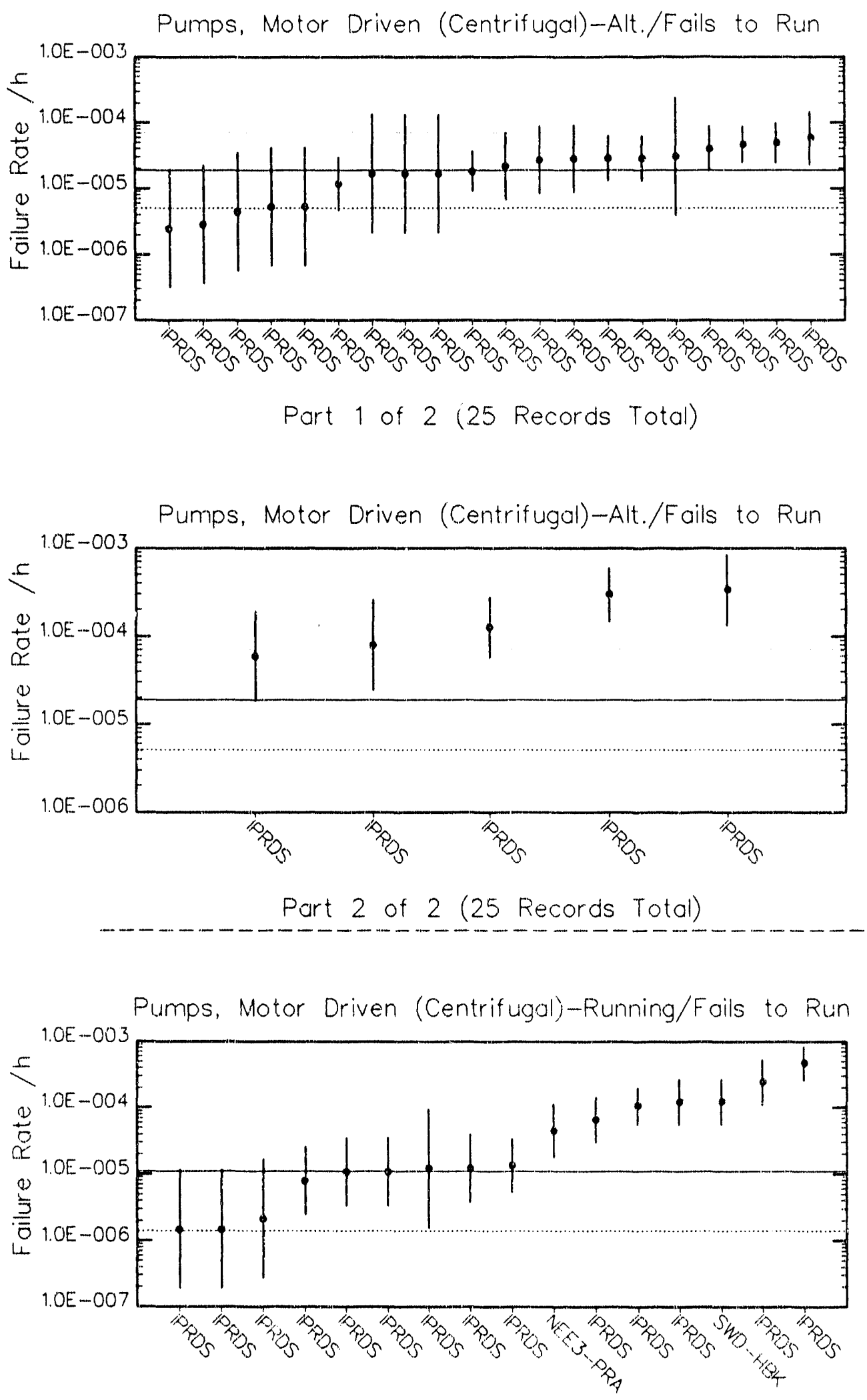

Figure $\mathrm{B}-3$. Failure rates and bounds for mechanical components with various designs and normal states (continued). 

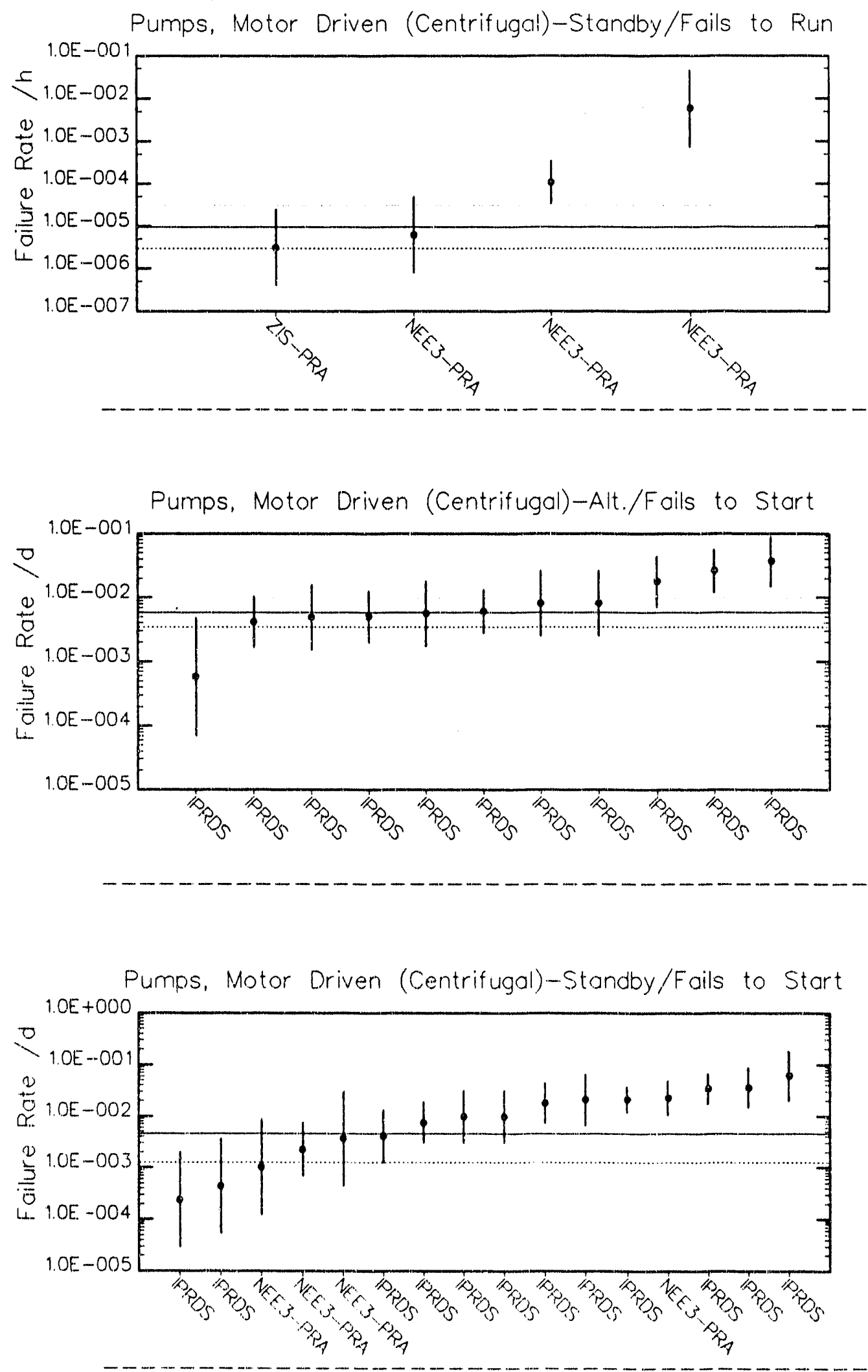

Figure B-3. Failure rates and bounds for mechanical components with various designs and normai states (continued). 

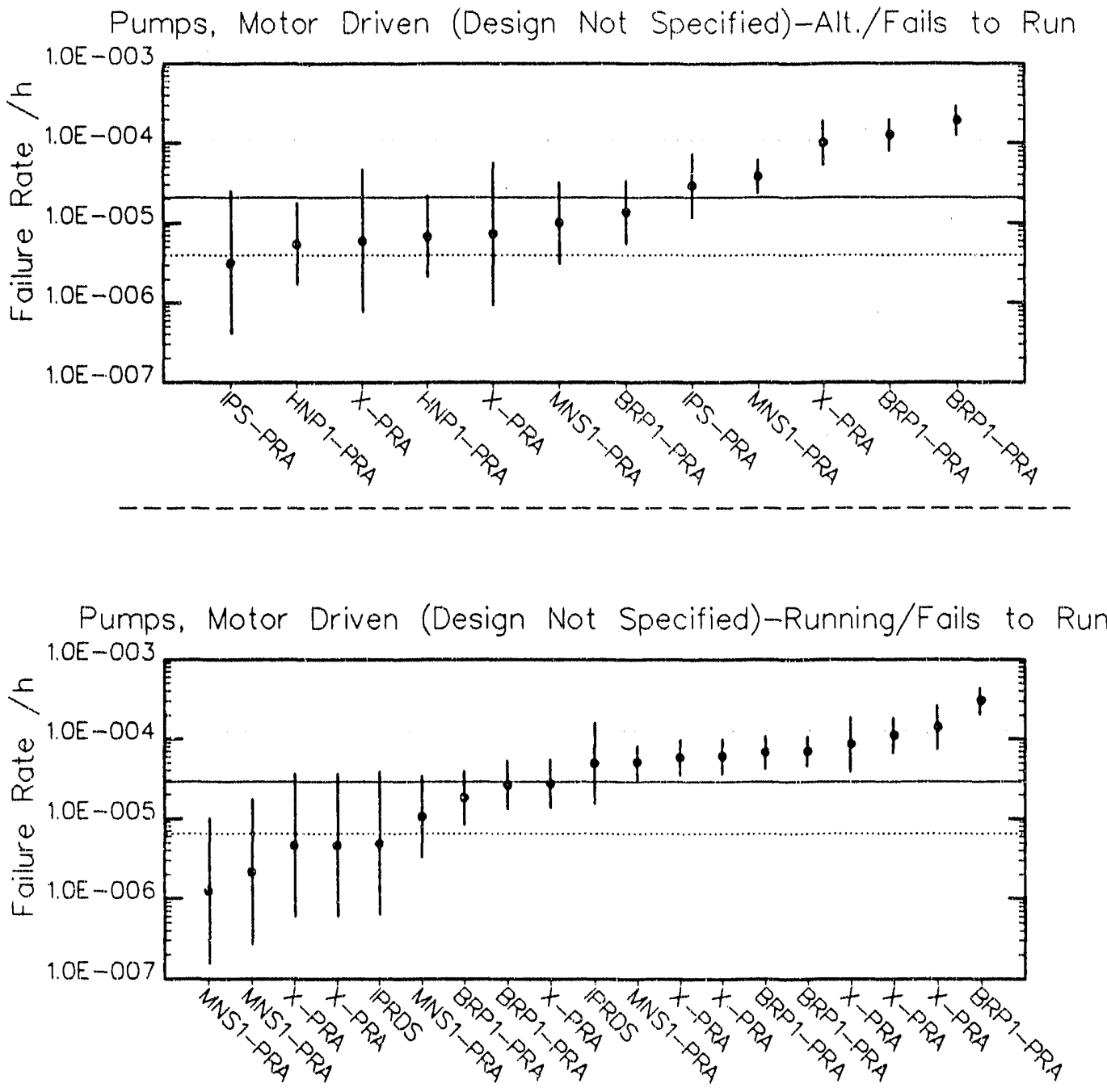

Pumps, Motor Driven (Design Not Specified)-Standby/Fails to Run

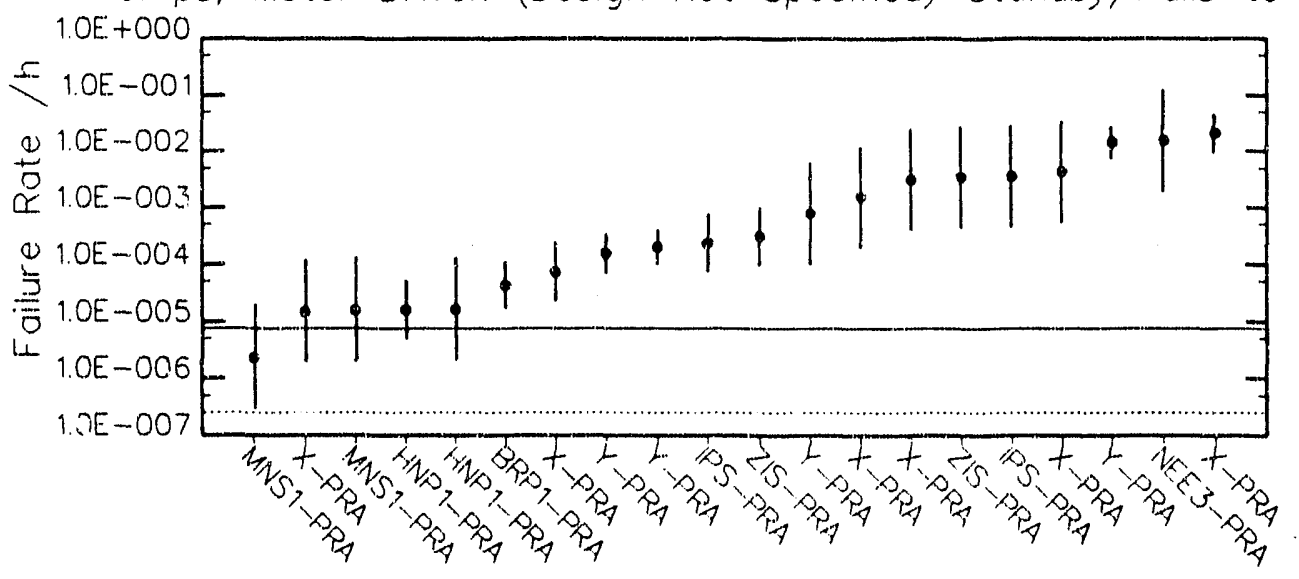

Figure B-3. Failure rates and bounds for mechanical components with various designs and normal states (continued). 

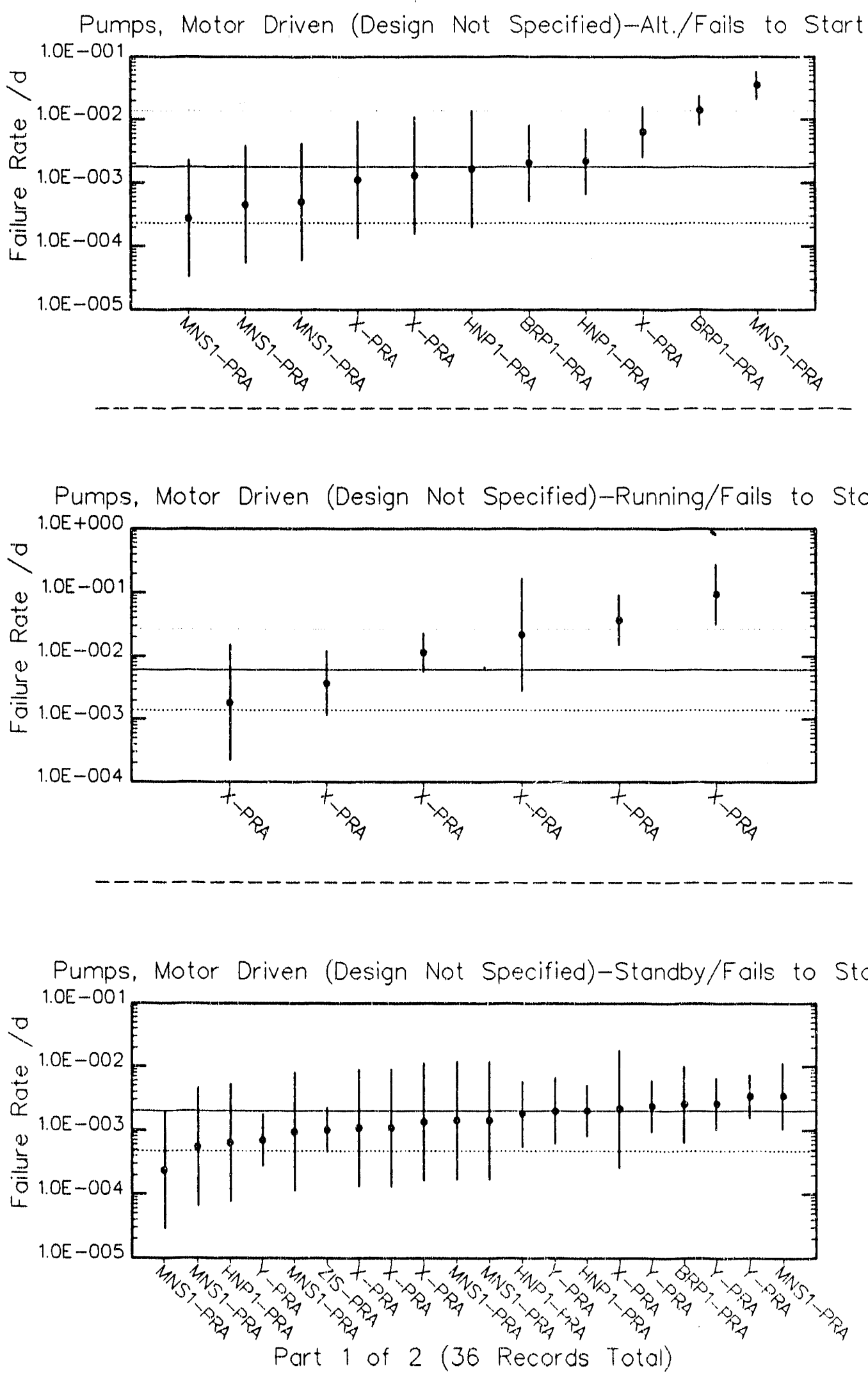

Figure B-3. Failure rates and bounds for mechanical components with various designs and normal states (continued). 


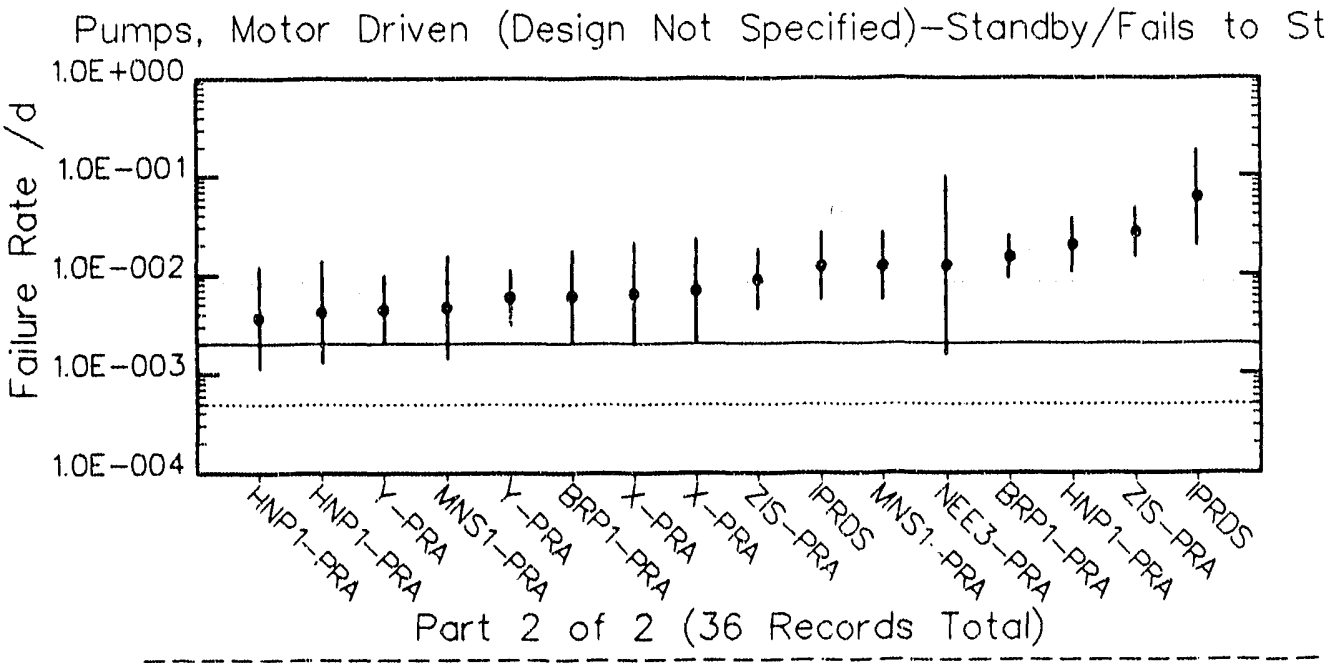

Pumps, Steam Turbine Driven (Design Not S...cified)-Standby/Fails to Run

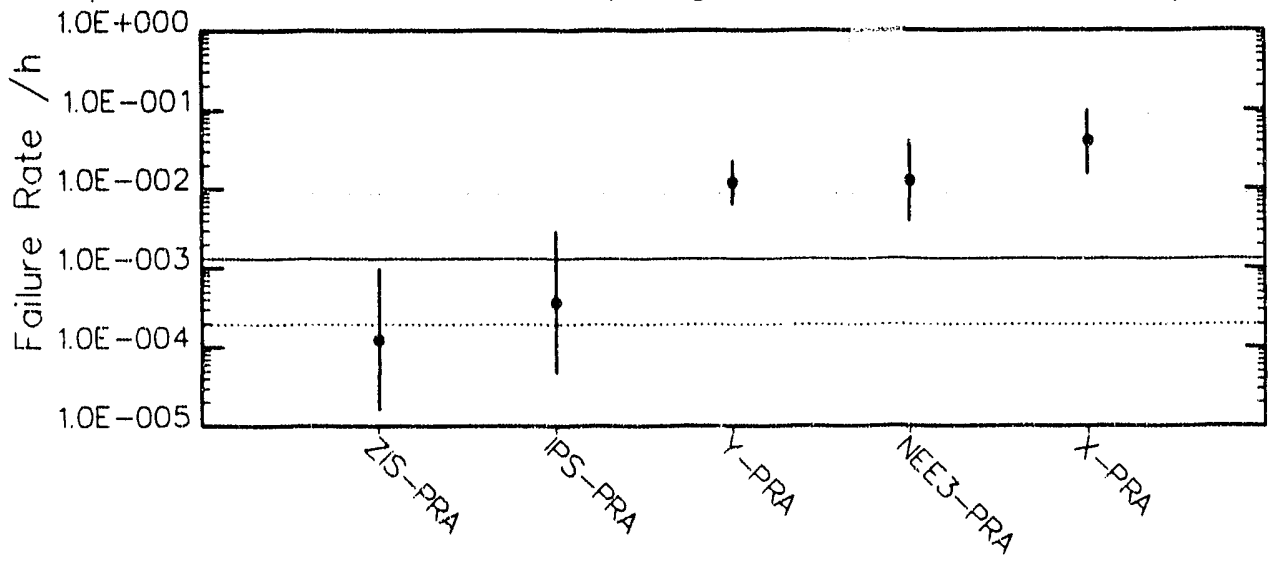

Pumps, Steam Turbine Driven (Design Not Specified)-Standby/Fails to Start

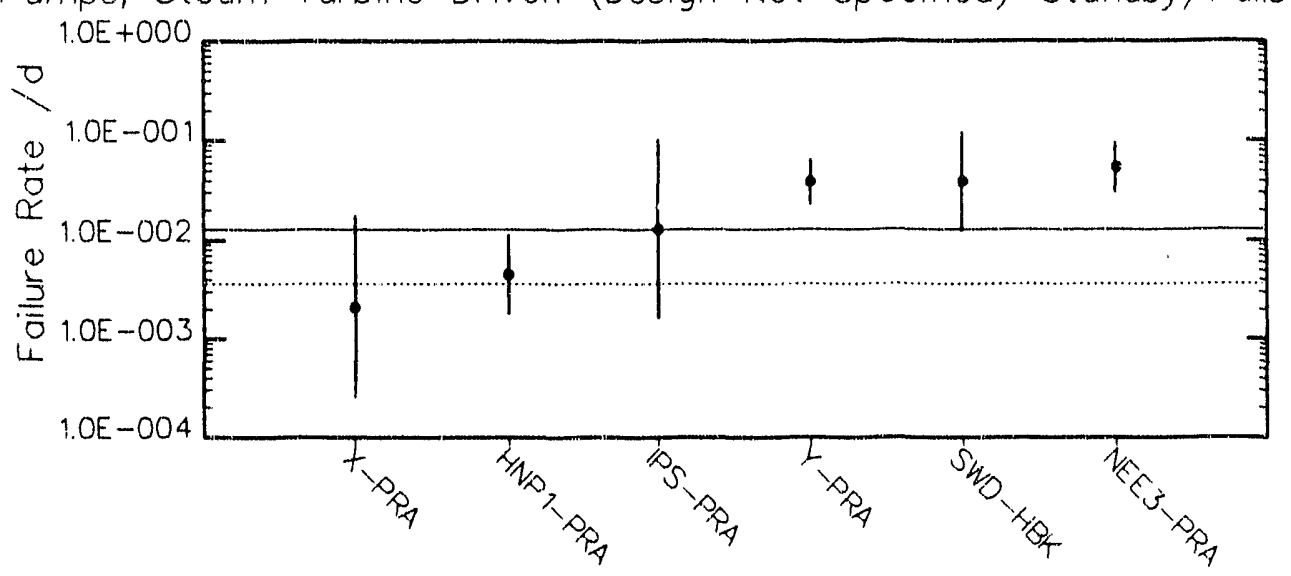

Figure B-3. Failure rates and bounds for mechanical components with various designs and normal states (continued). 
Pumps, Driver Not Specified (Design Not Specified)-Standby/Fails to Run

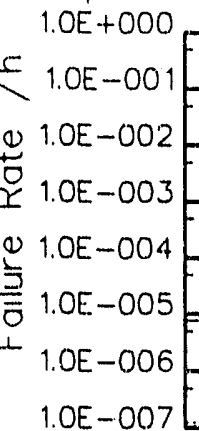
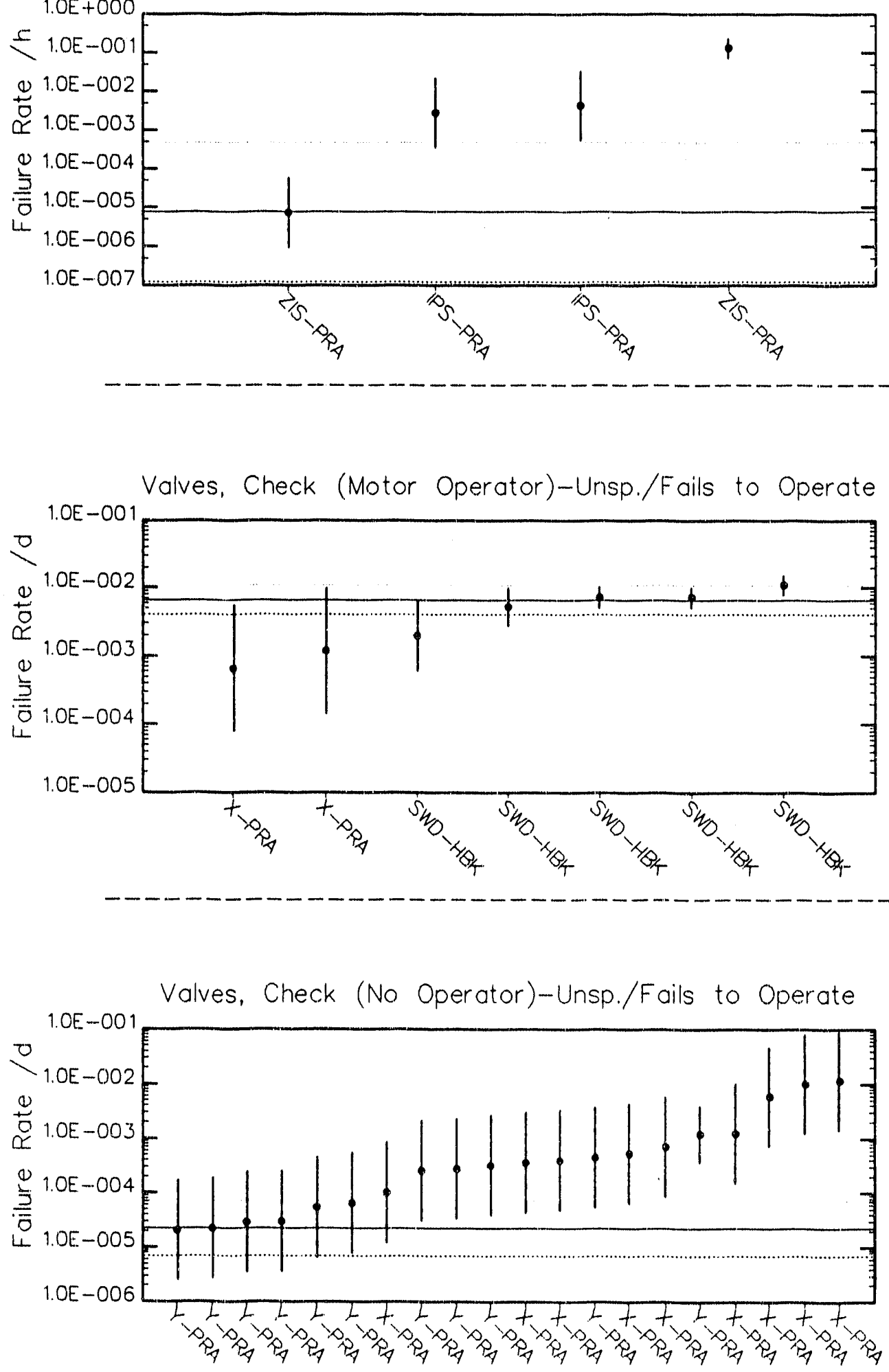

Figure B-3. Failure rates and bounds for mechanical components with various designs and normal states (continued). 


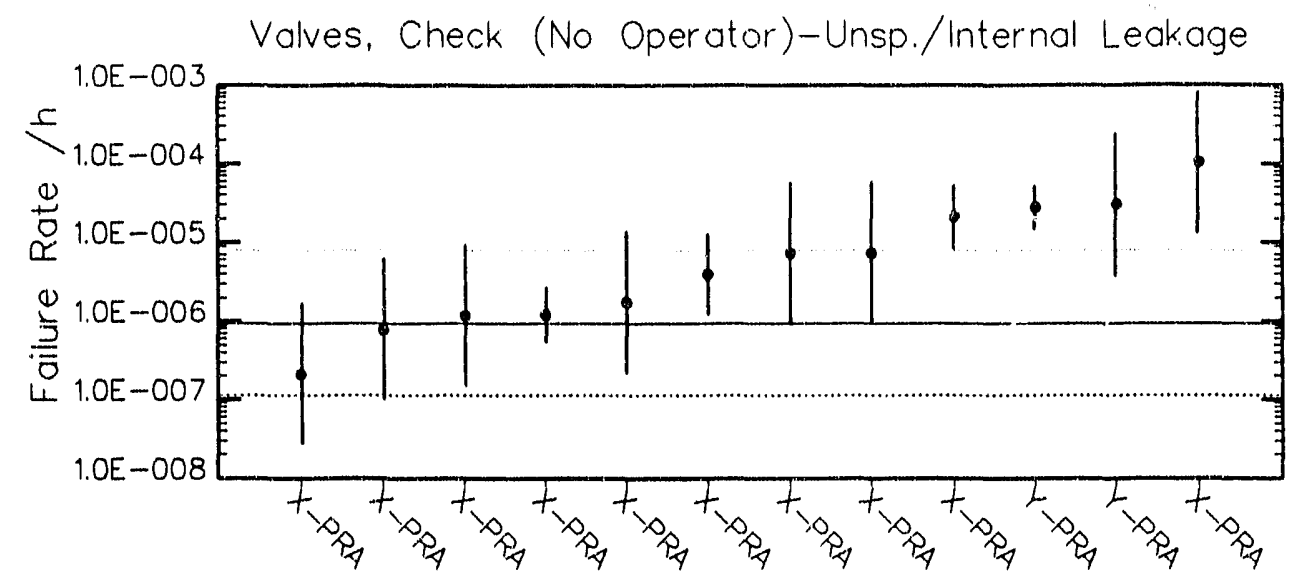

Valves, Check (No Operator (tilting disk check valve))-Unsp./Fails to Operate

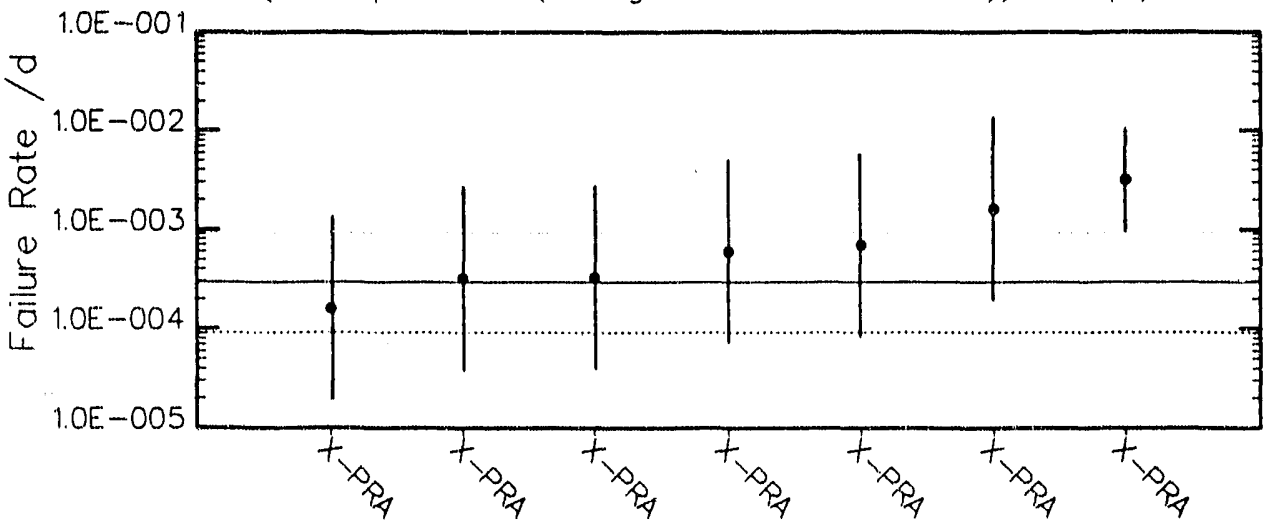

Valves, Check (No Operator (tilting disk check valve))-Unsp./Internal Leakage

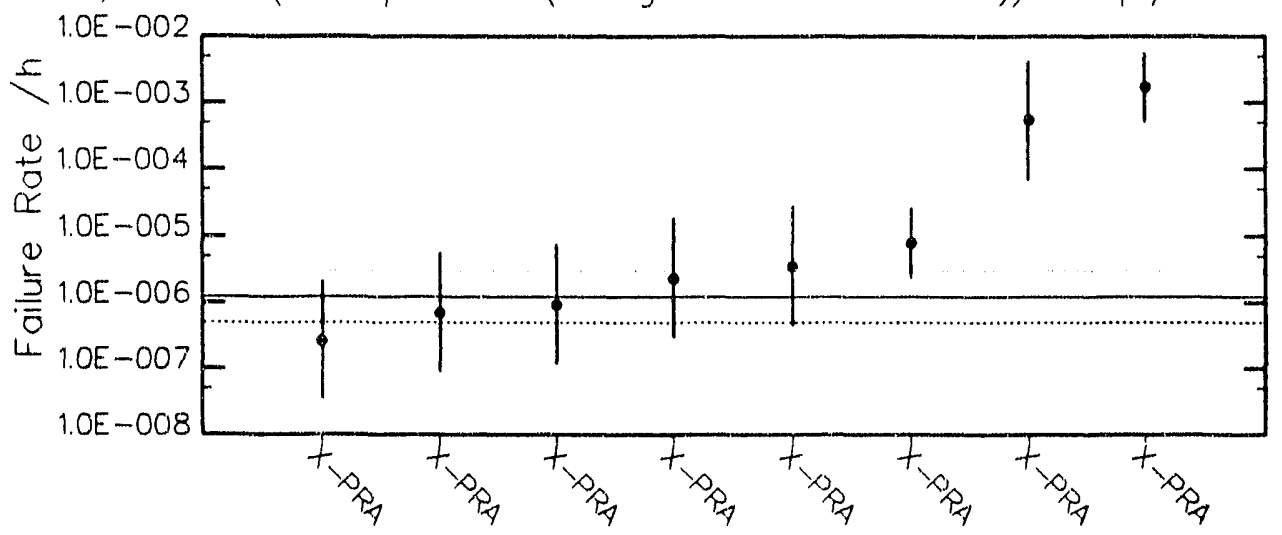

Figure B-3. Failure rates and bounds for mechanical components with various designs and normal states (continued). 

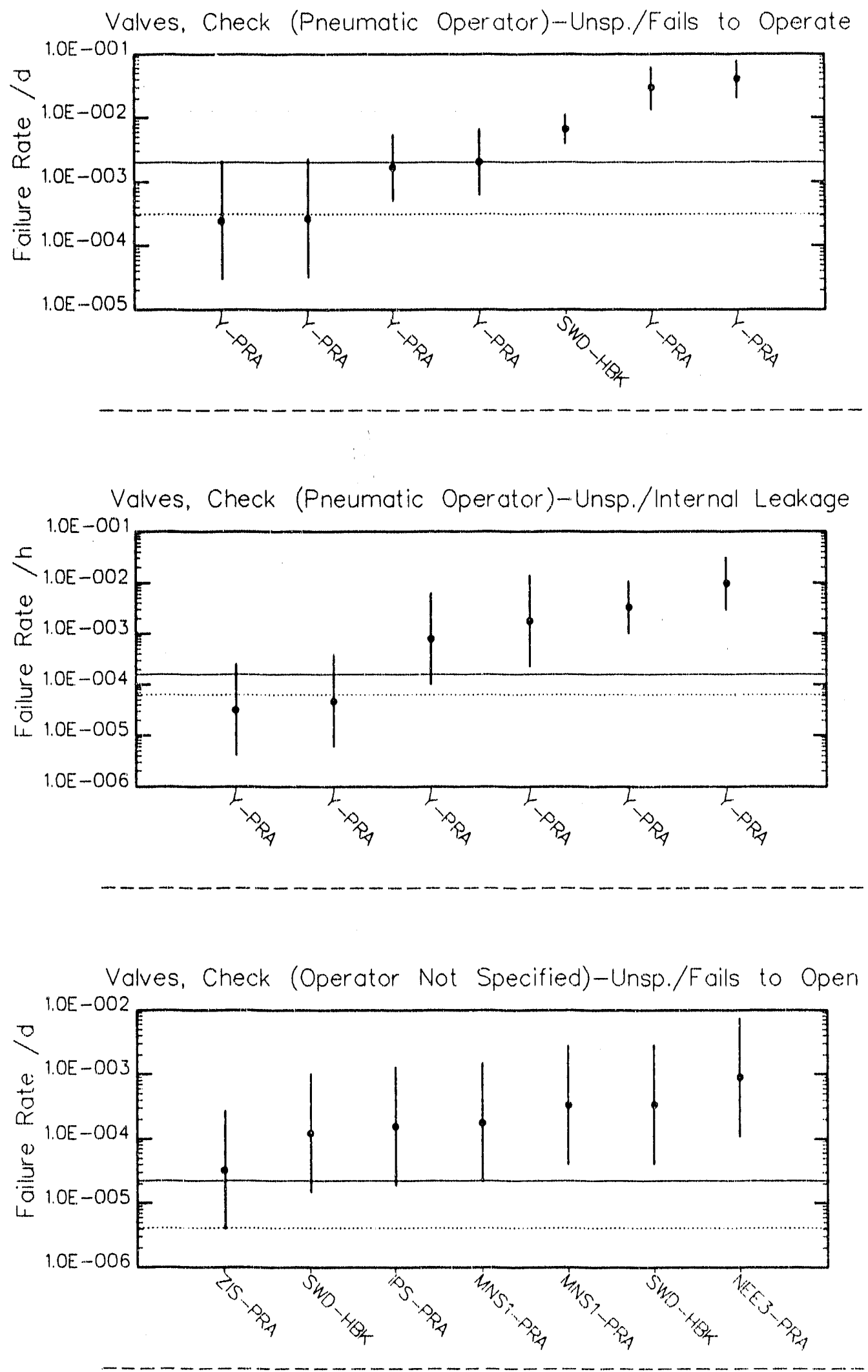

Figure $\mathrm{B}-3$. Failure rates and bounds for mechanical components with various designs and normal states (continued). 

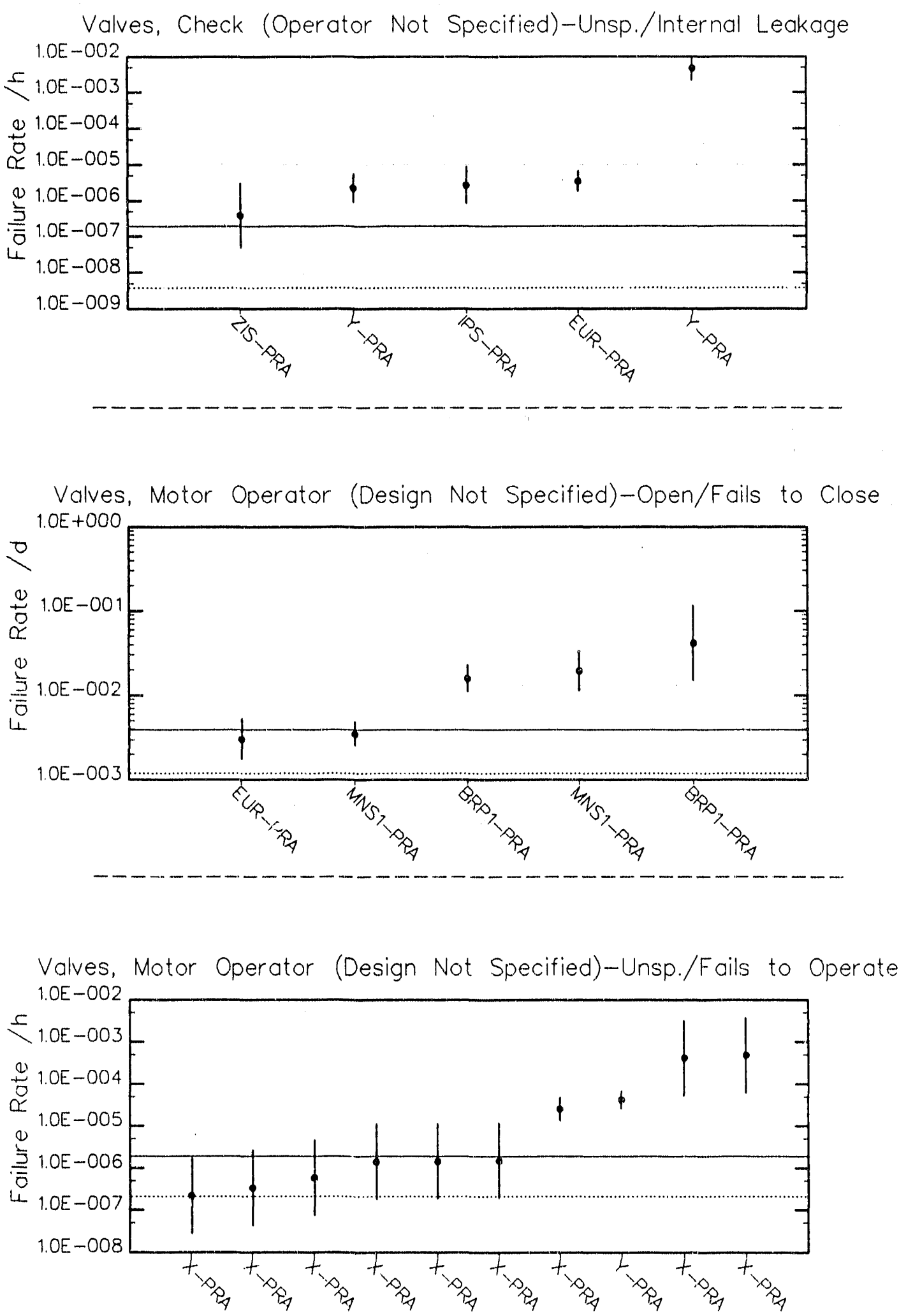

Figure B-3. Failure rates and bounds for mechanical components with various designs and normal states (continued). 

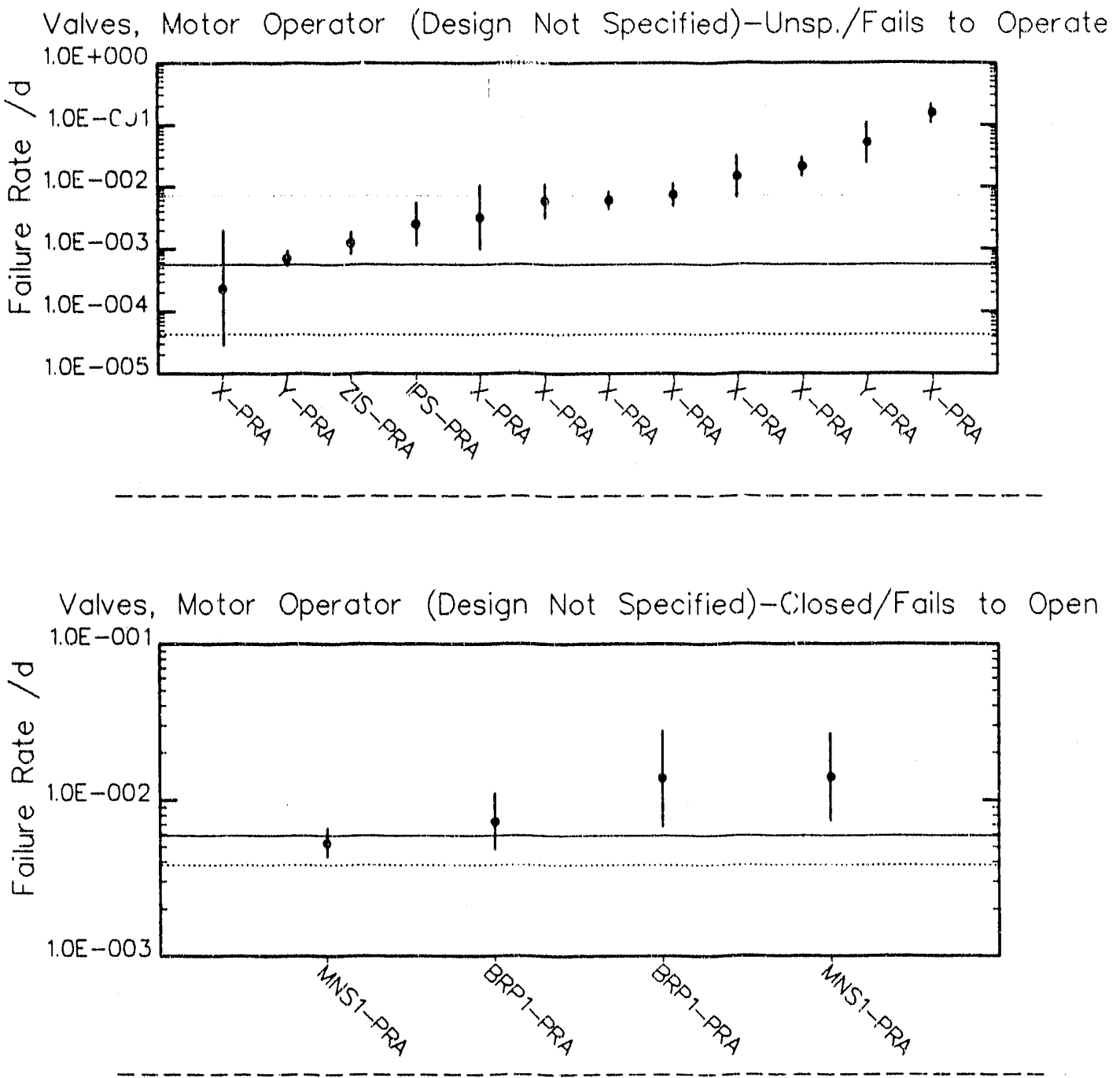

Valves, Manual Operator (mechanical handwheel) (Design Not Specified)-Unsp./Fails to Operc

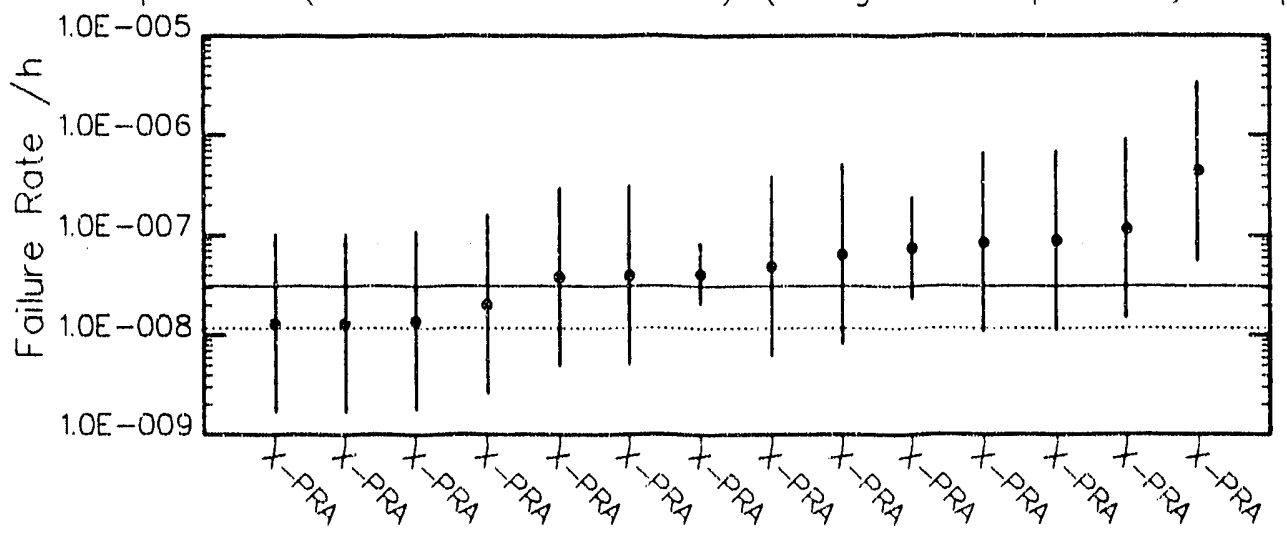

Figure B-3. Failure rates and bounds for mechanical components with various designs and normal states (continued). 
Valves, Manual Operator (mechanical handwheel) (Design Not Specified)-Unsp./Fails to Operate

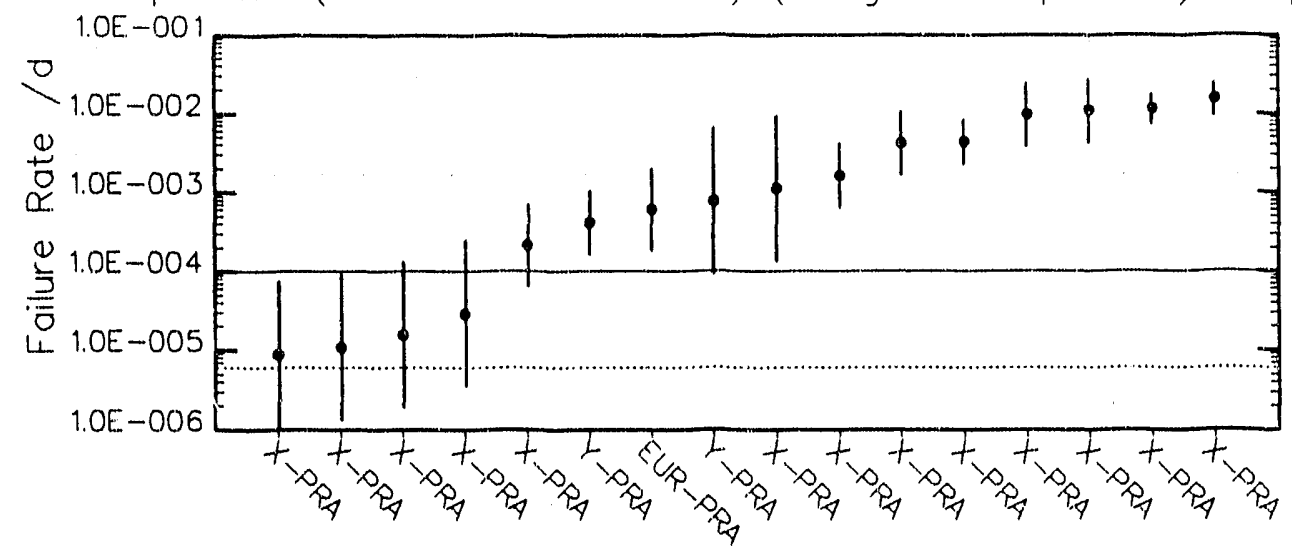

Valves, Pneumatic Operator (Design Not Specified)-Unsp./Fails to Operate

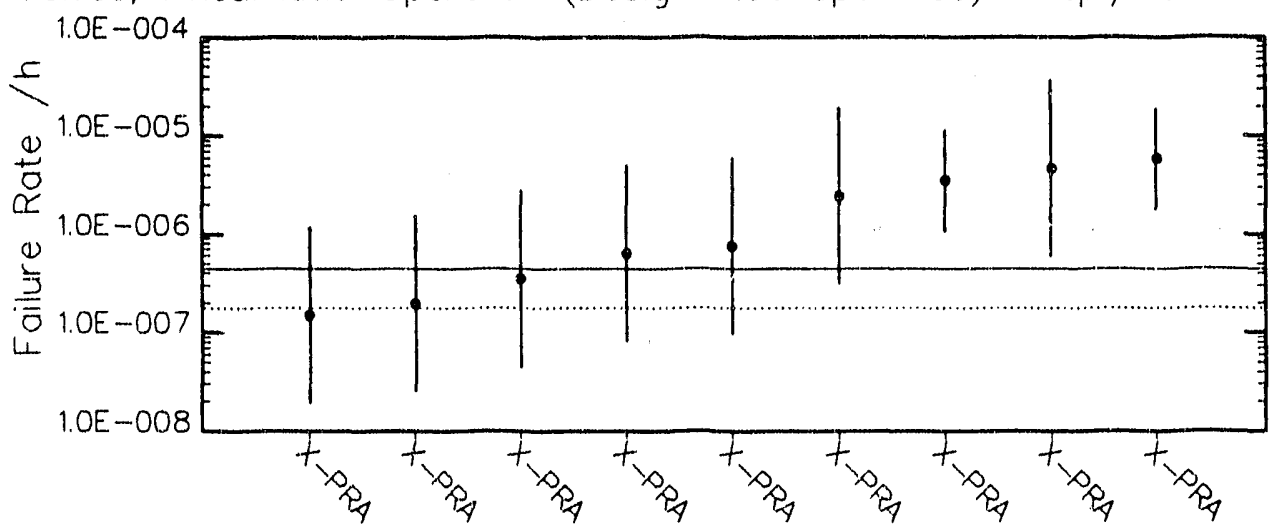

Valves, Pneumatic Operator (Design Not Specified)--Unsp./Fails to Operate

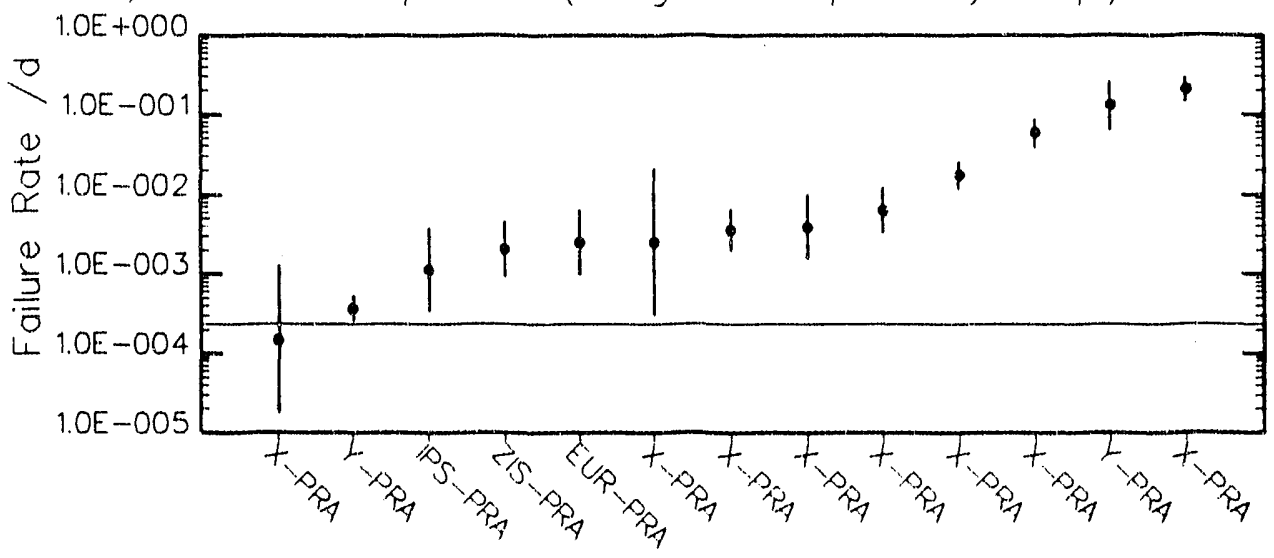

Figure B-3. Failure rates and bounds for mechanical component: with various designs and normal states (continued). 
Valves, Pneumotic Operotor (Design Not Specified)-Open/Spurious Close

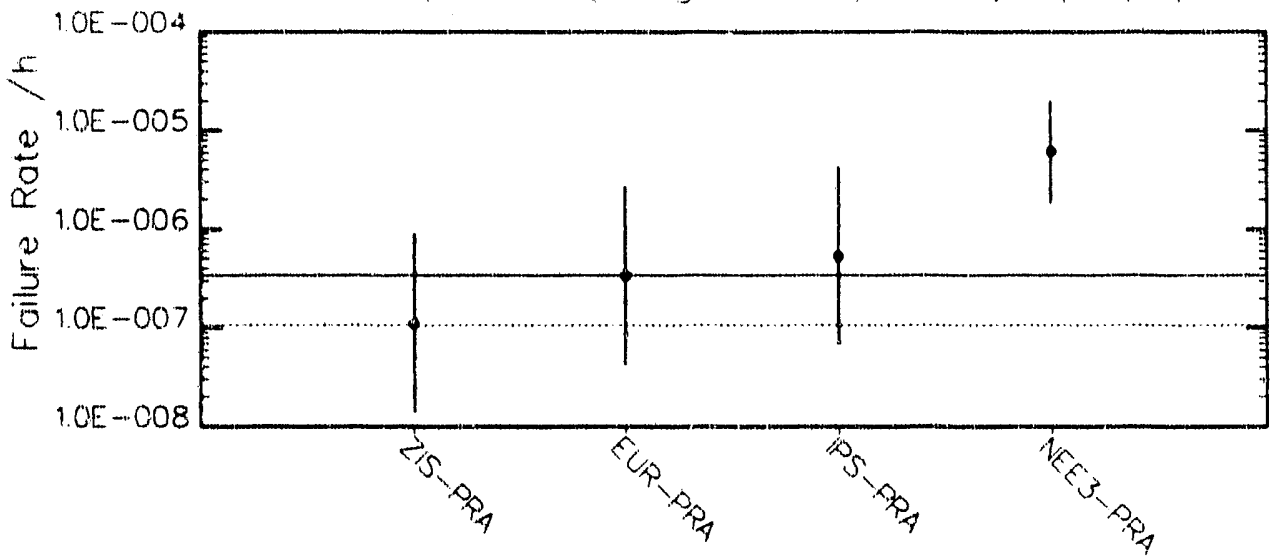

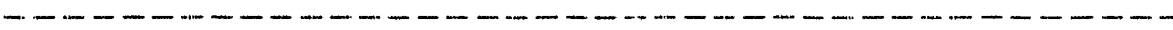

Valves, Relief (Design Not Specified)-Closed/Foils to Operate

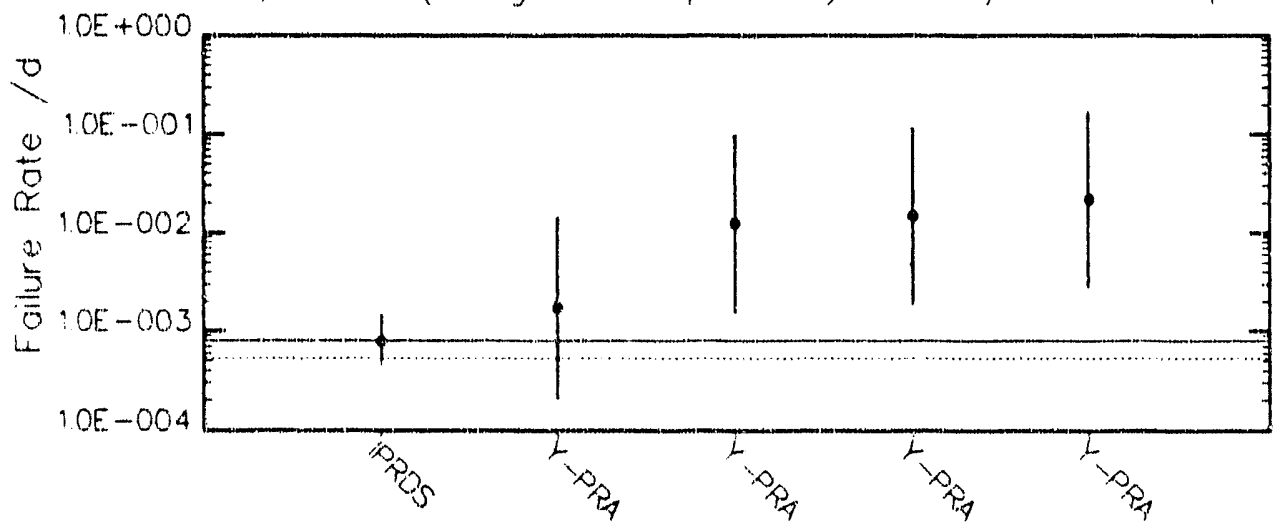

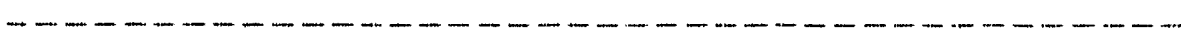

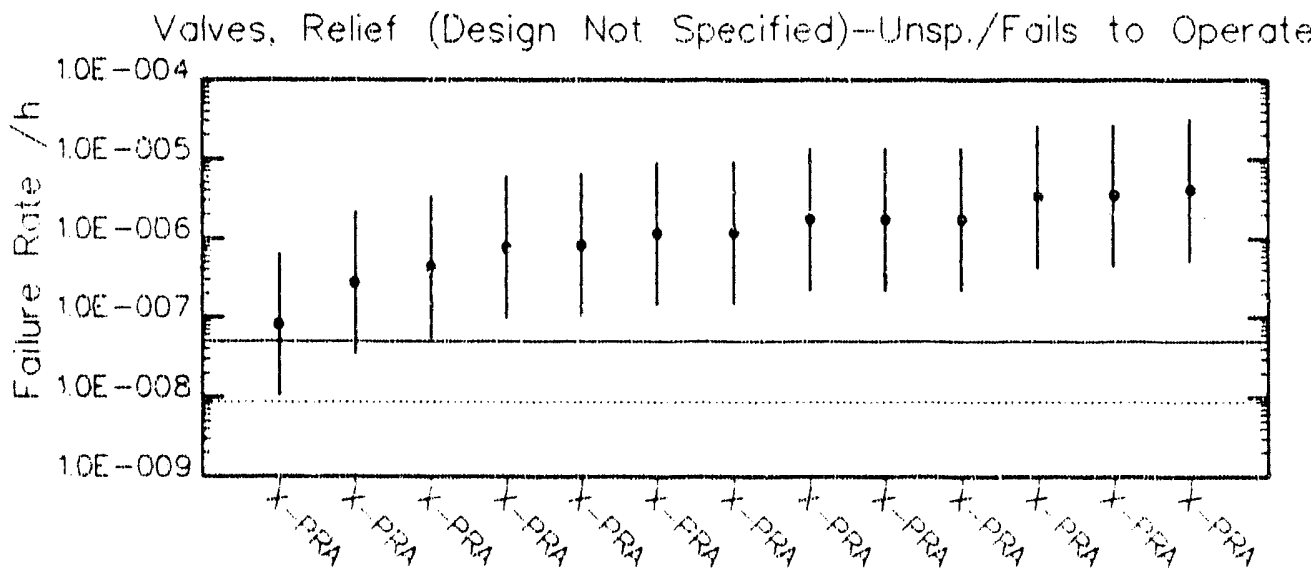

Figure $B-3$. Foilure rotes and bounds for mechanical components with vorious designs ard normol stotes (continued). 

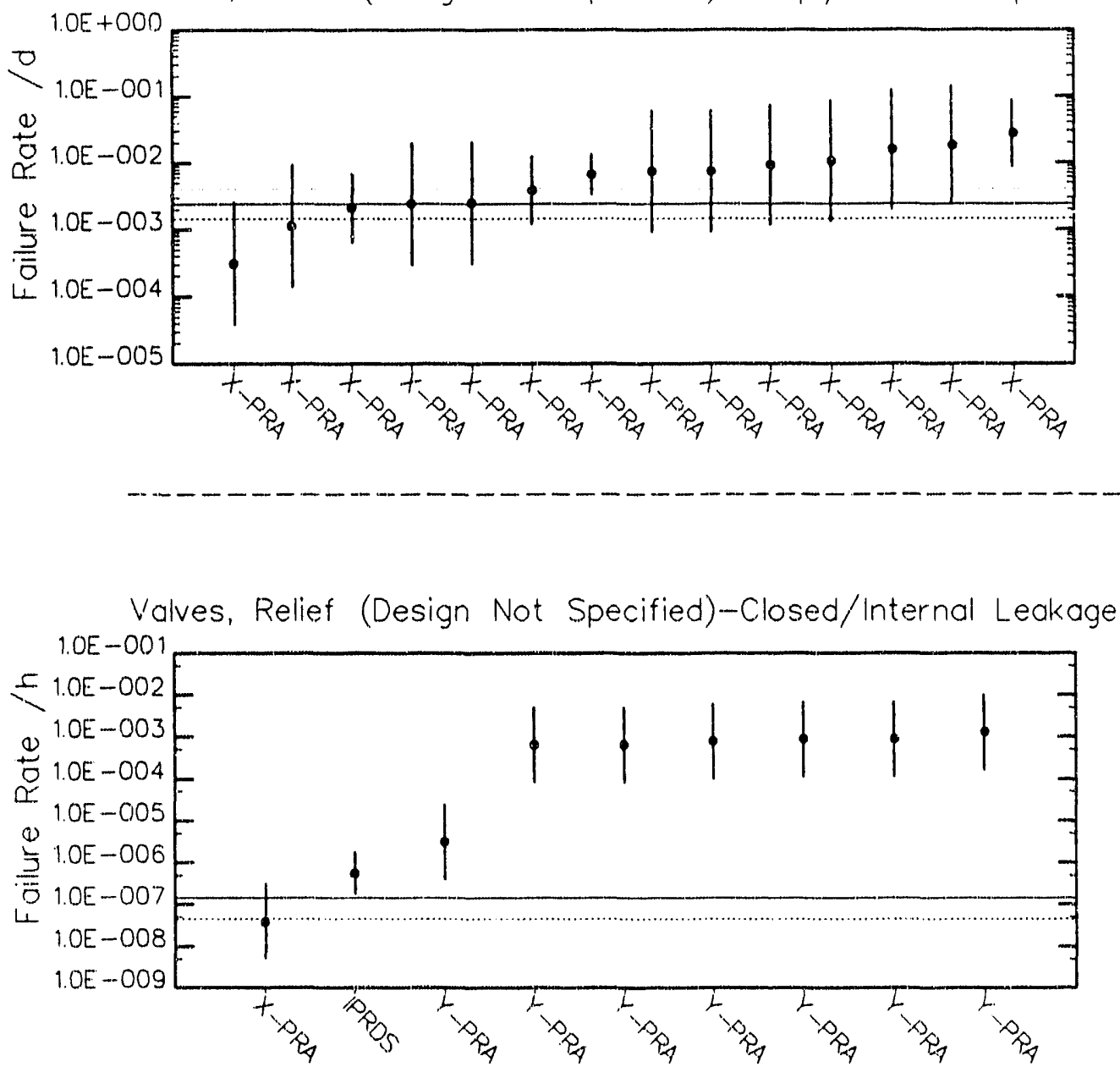

Valves, Solenoid Operator (Design Not Specified)-Unsp./Fails to Operate

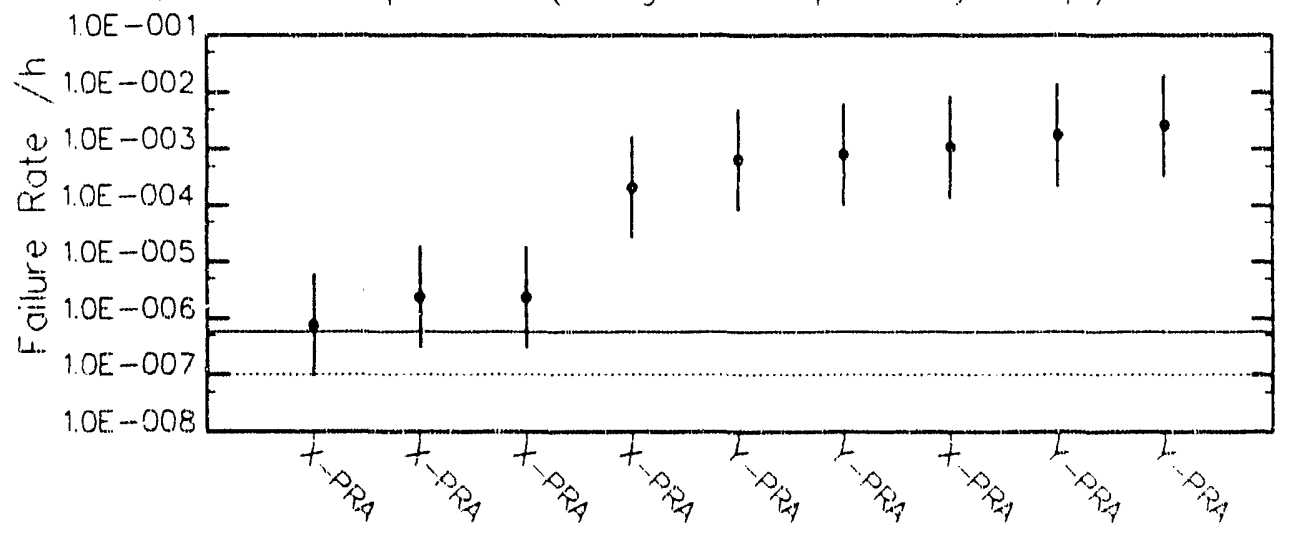

Figure B-3. Foilure rates and bounds for mechonical components with various designs and normal states (contiriued). 


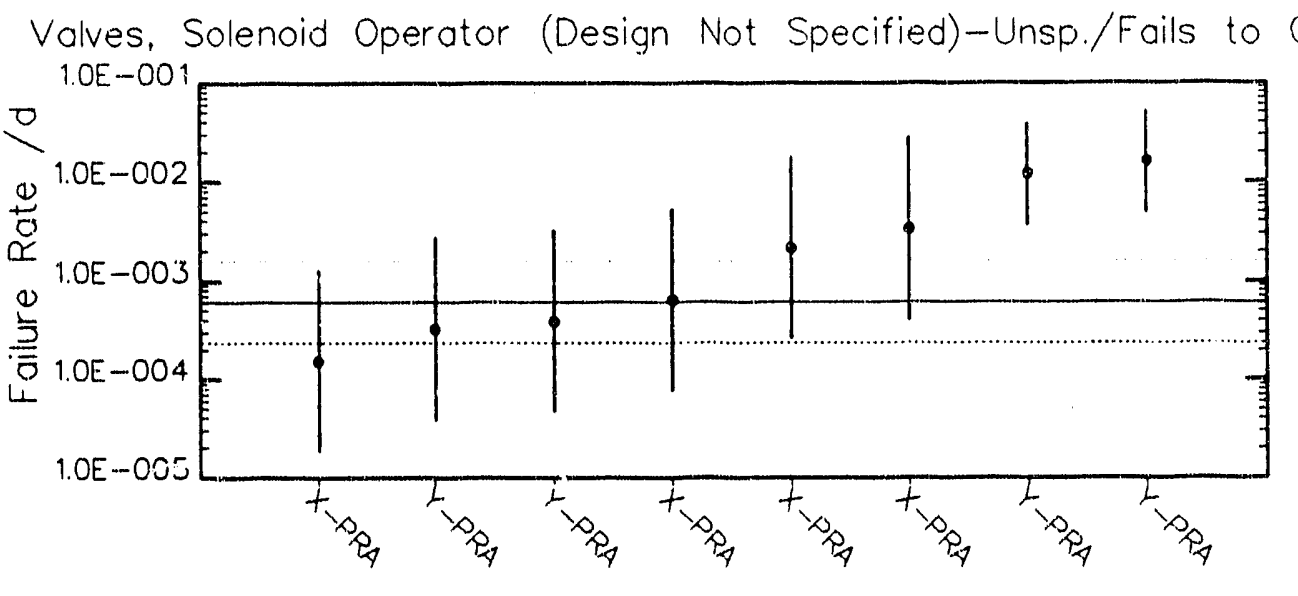

Figure B-3. Failure rates and bounds for mechonical components with various Jesigns and normal states (continued). 

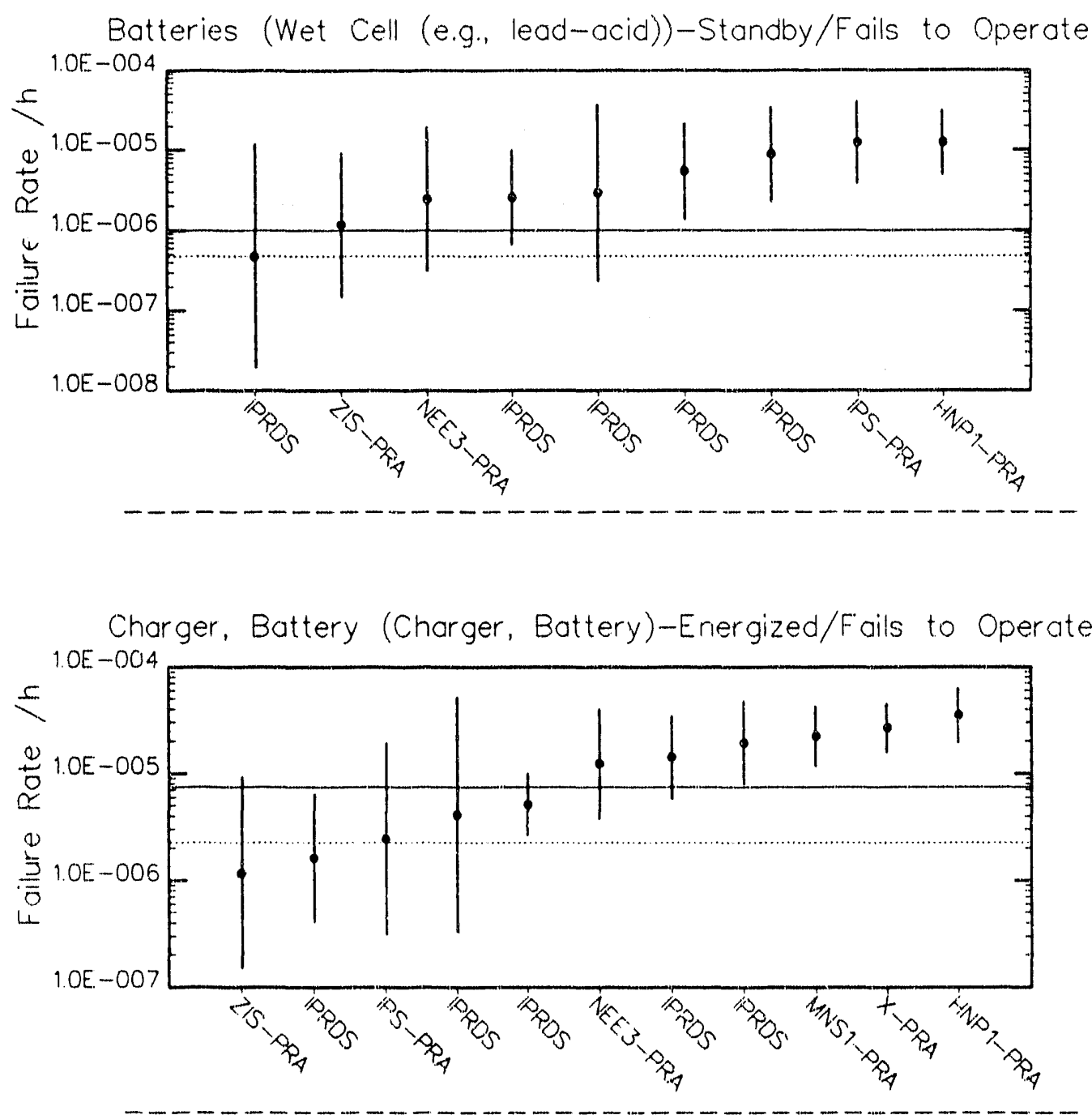

Circuit Breakers, Power (Design Not Specified)-Unsp./Fails to Operate

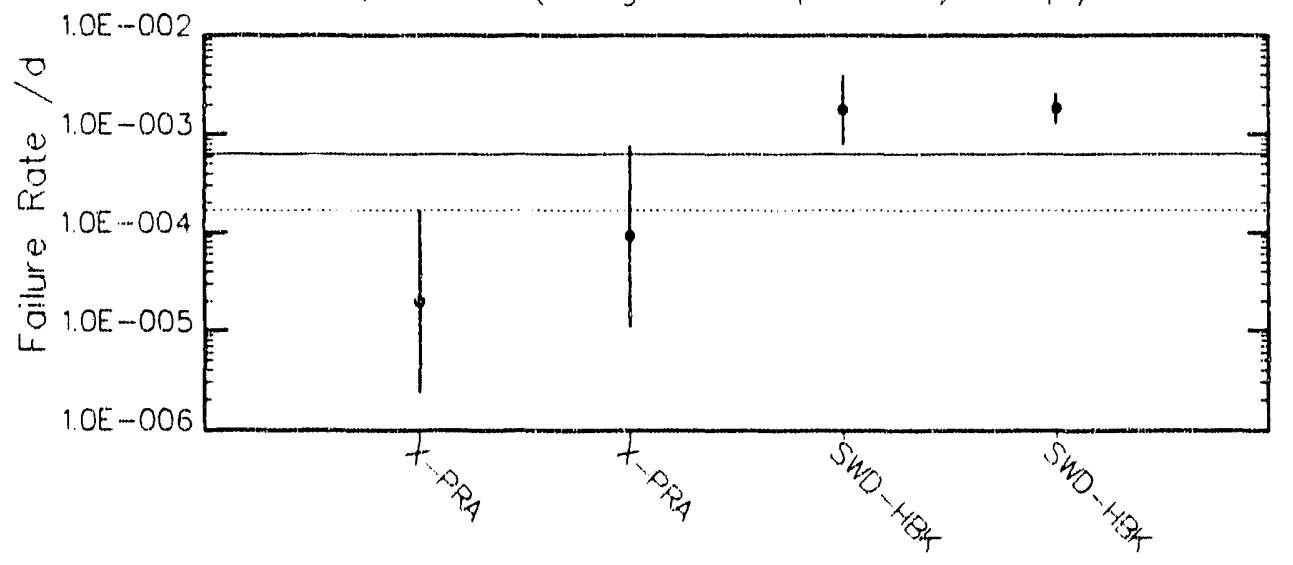

Figure B-4. Foilure, ates and bounds for electricai and instrumentation components with various designs and normal states. 

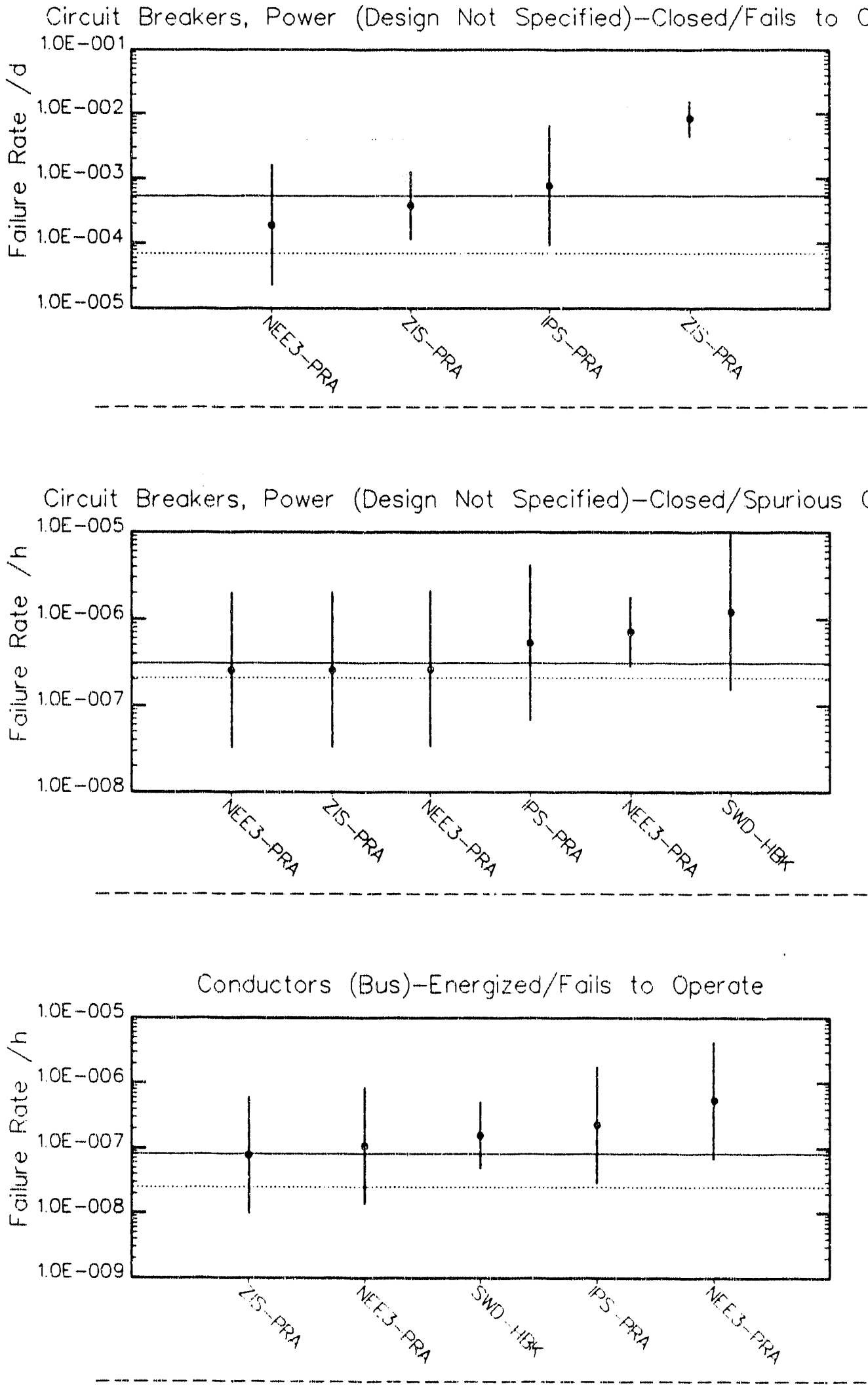

Figure B-4. Failure rates and bounds for electrical and instrumentation components with various desigris and normol states (continued). 

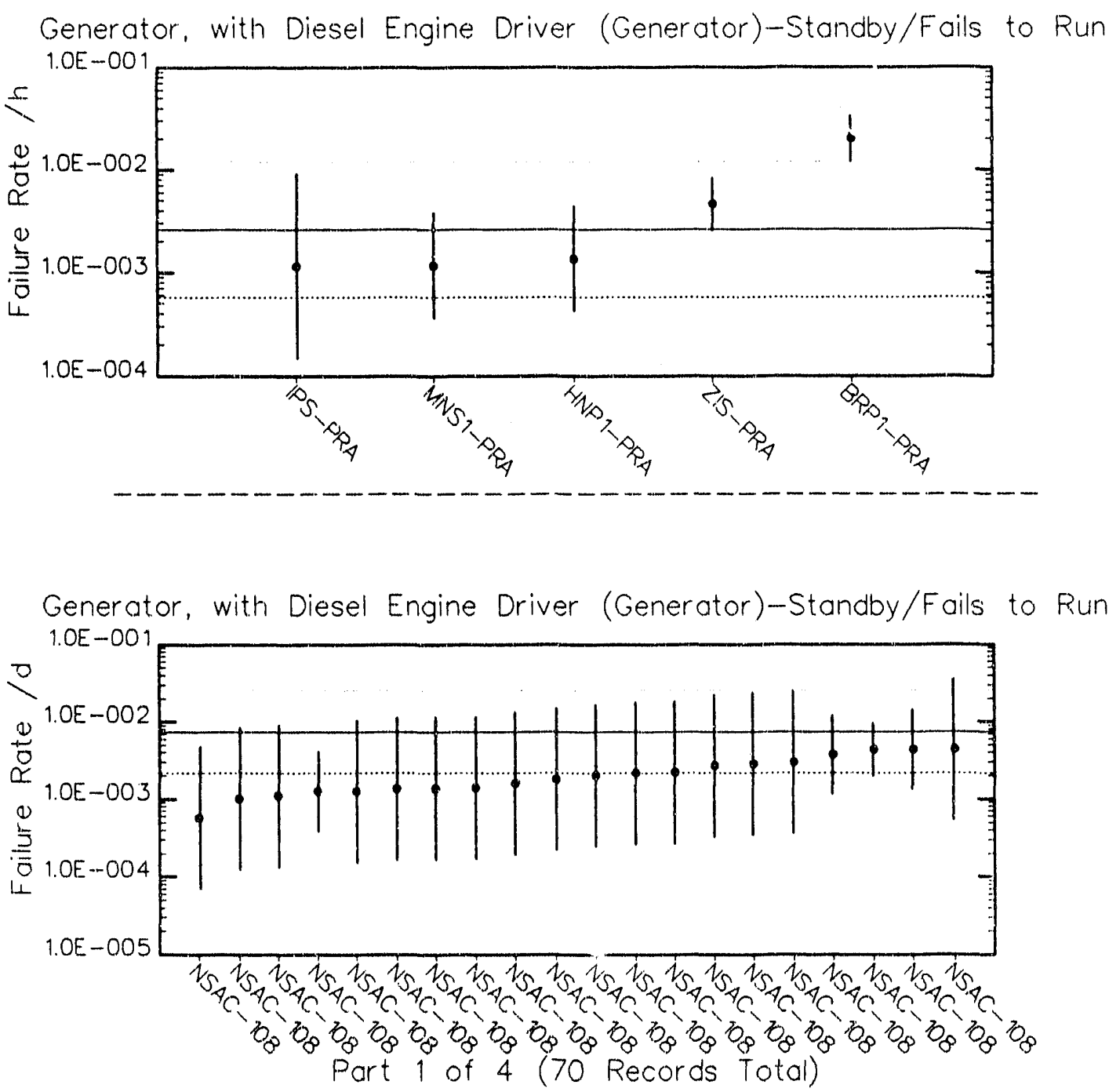

Generator, with Diesel Engine Driver (Generator)-Standby/Fails to Run

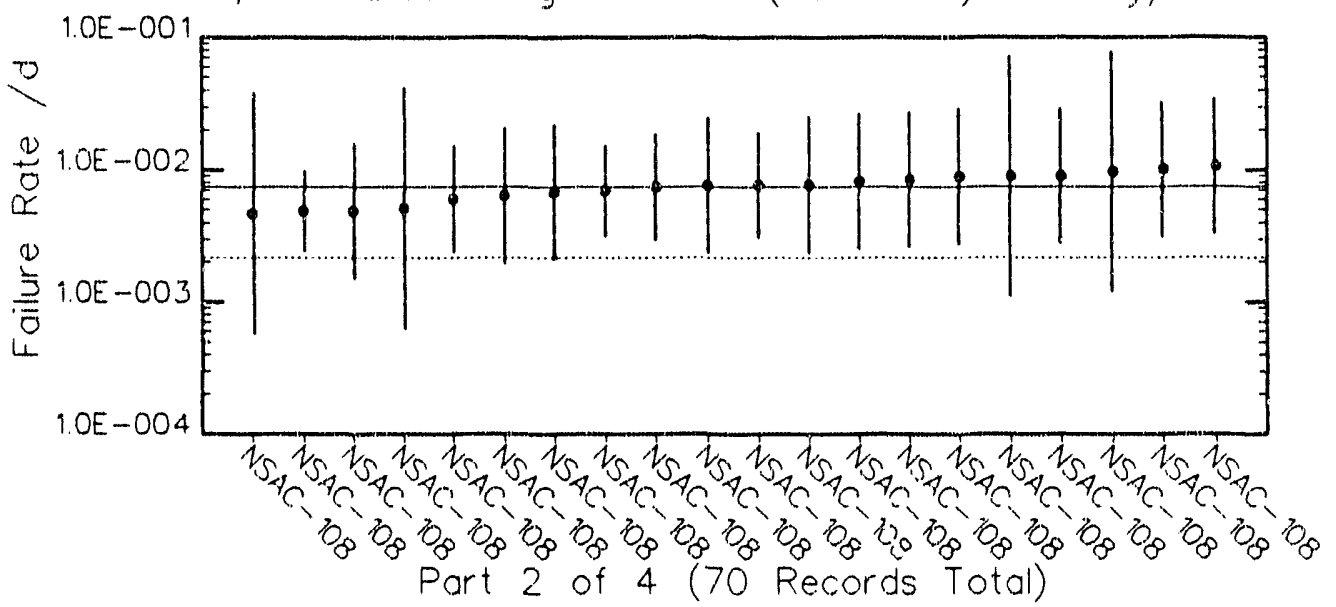

Figure B-4. Failure rates and bounds for electrical and instru-... mentation components with various designs and normal states (continued). 


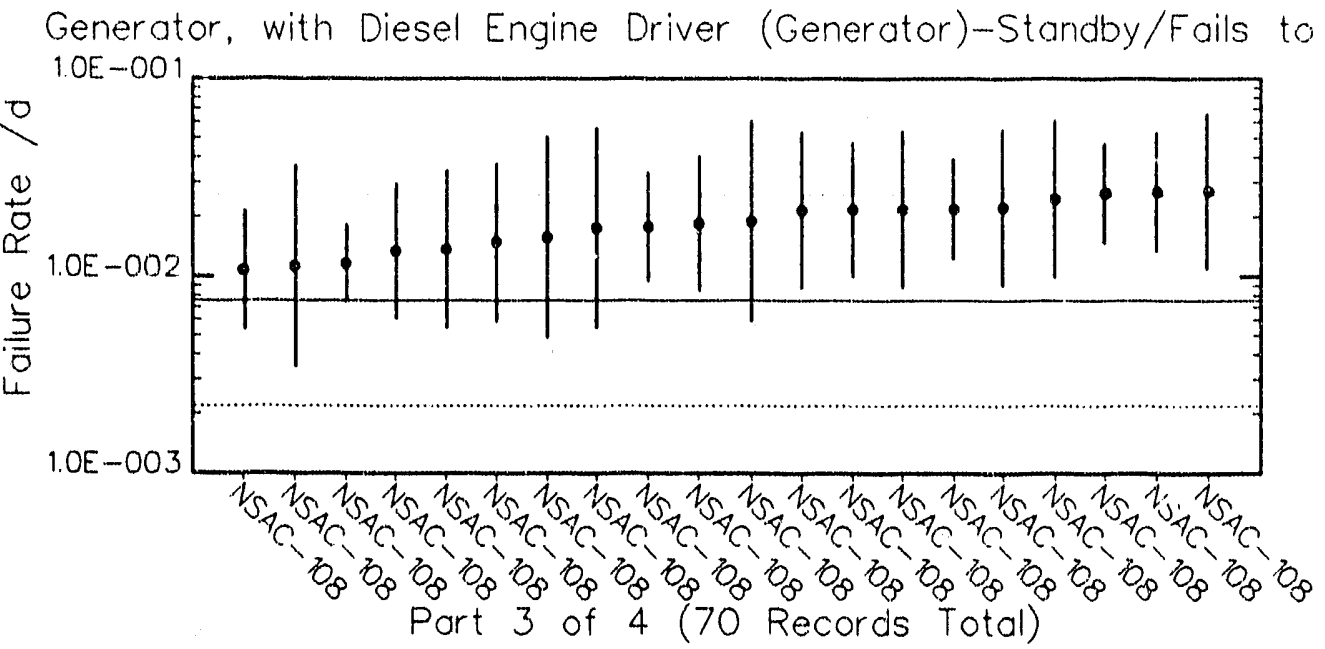

Generator, with Diesel Engine Driver (Generator)-Standby/Fails to Run

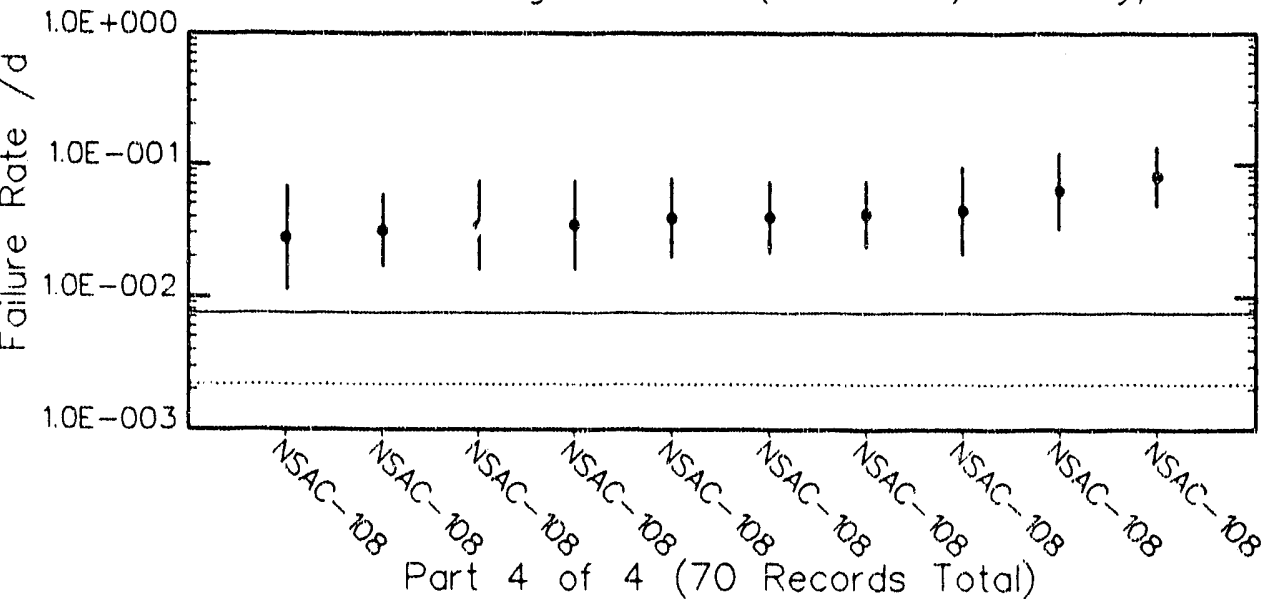

Generator, with Diesel Engine Driver (Generator)-Standby/Fails to Start

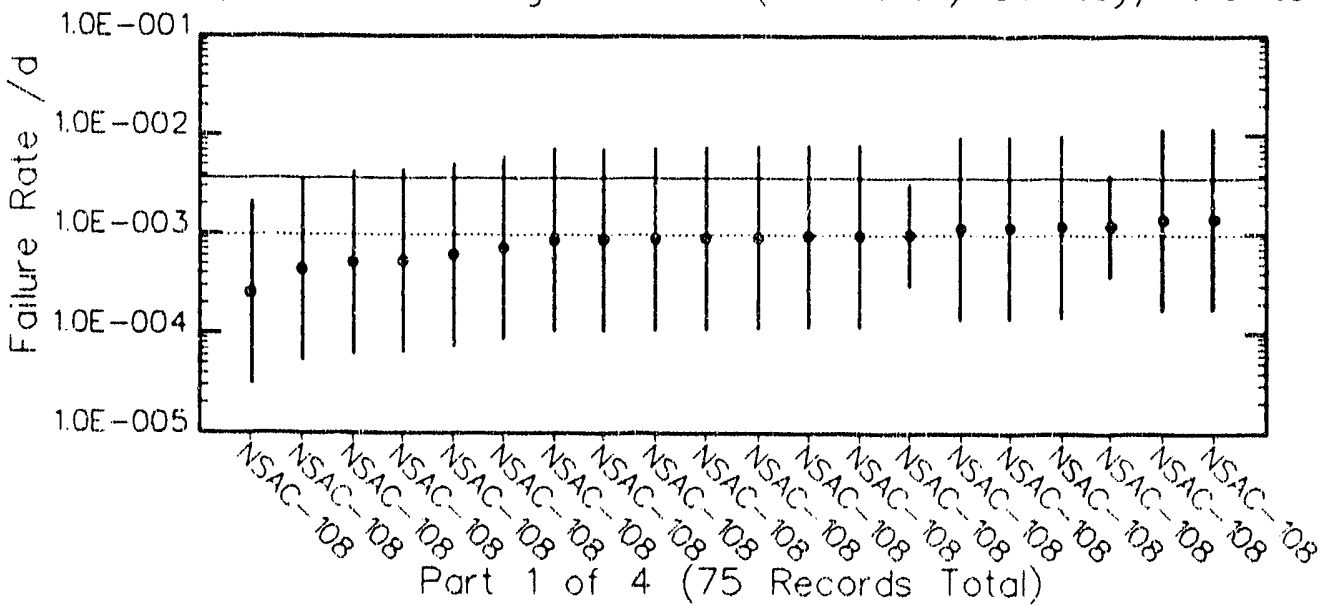

Figure $\mathrm{B}-4$. Failure rates and bounds for electrical and instrumentation components with various designs and normal states (continued). 

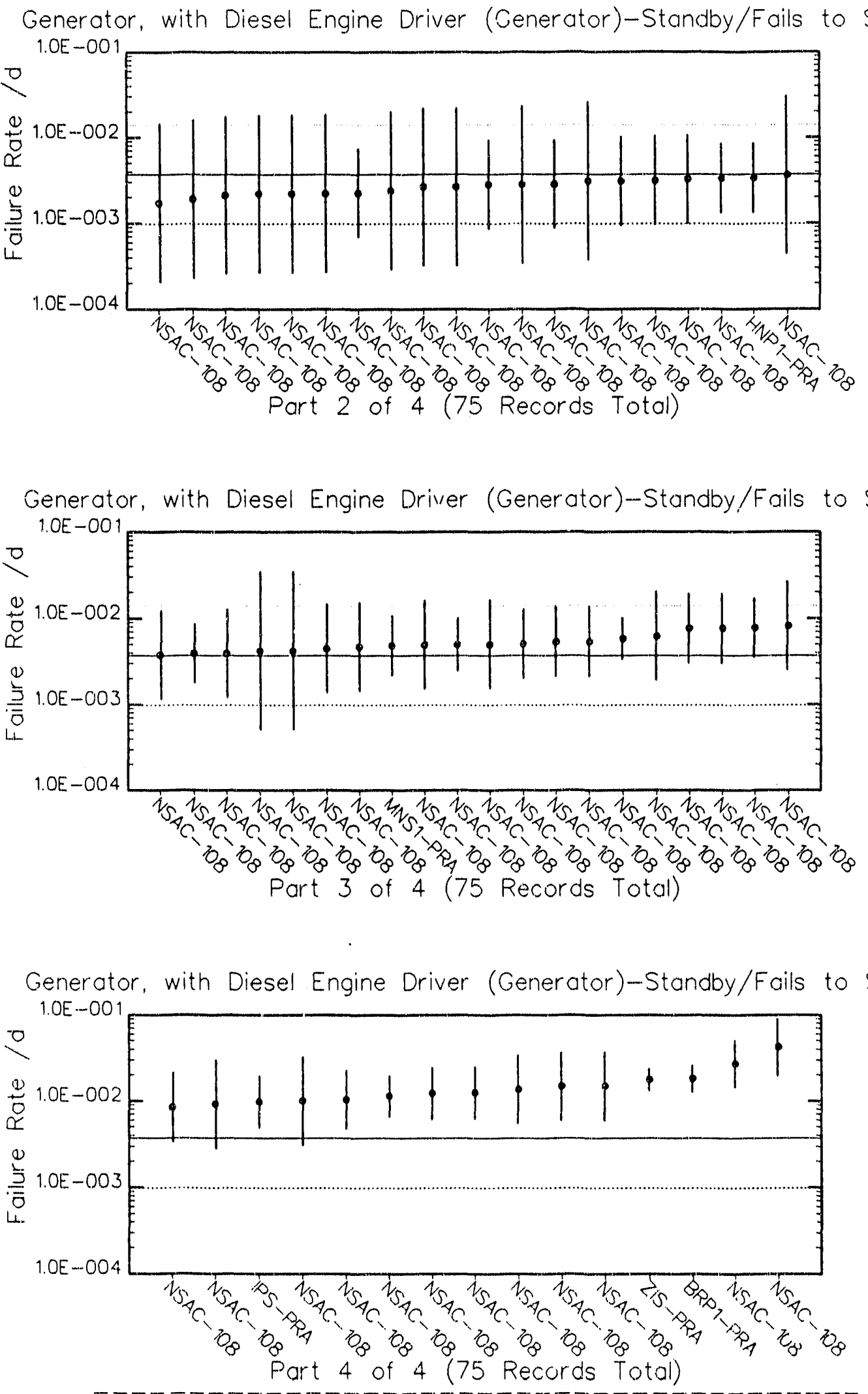

Figure B-4. Failure rates and bounds for electrical and instrumentation components with various designs and normal states (continued). 
Power Electronics (Solid-state) (Inverter (not motor ctrlr.))-Energized/Fails to Operate
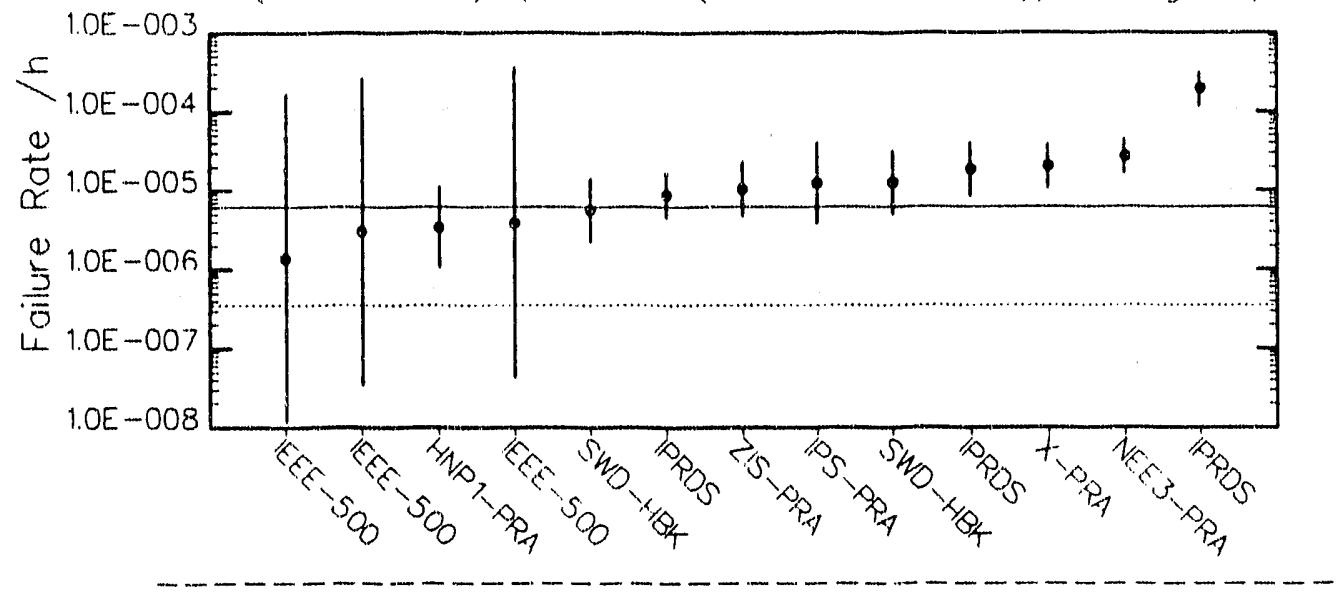

Power Electronics (Solid-state) (Inverter (not motor ctrir.))-Energized/Fails to Operate
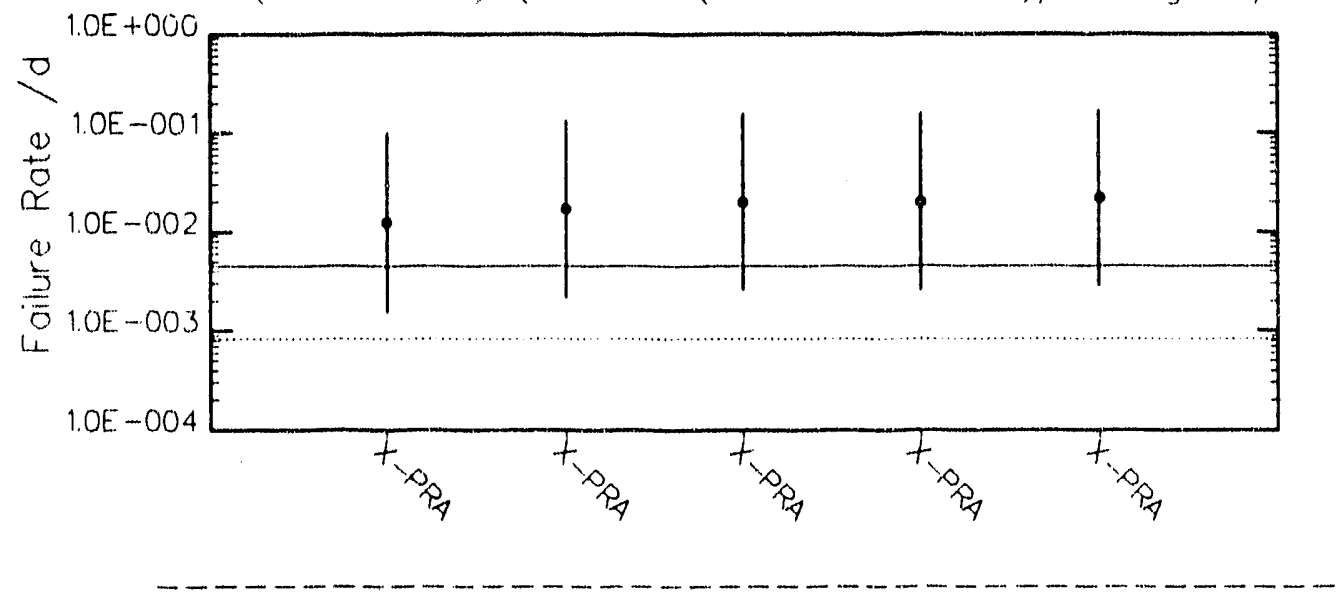

Relays, Protective (Design Not Specified)-Unsp./Fails to Operate

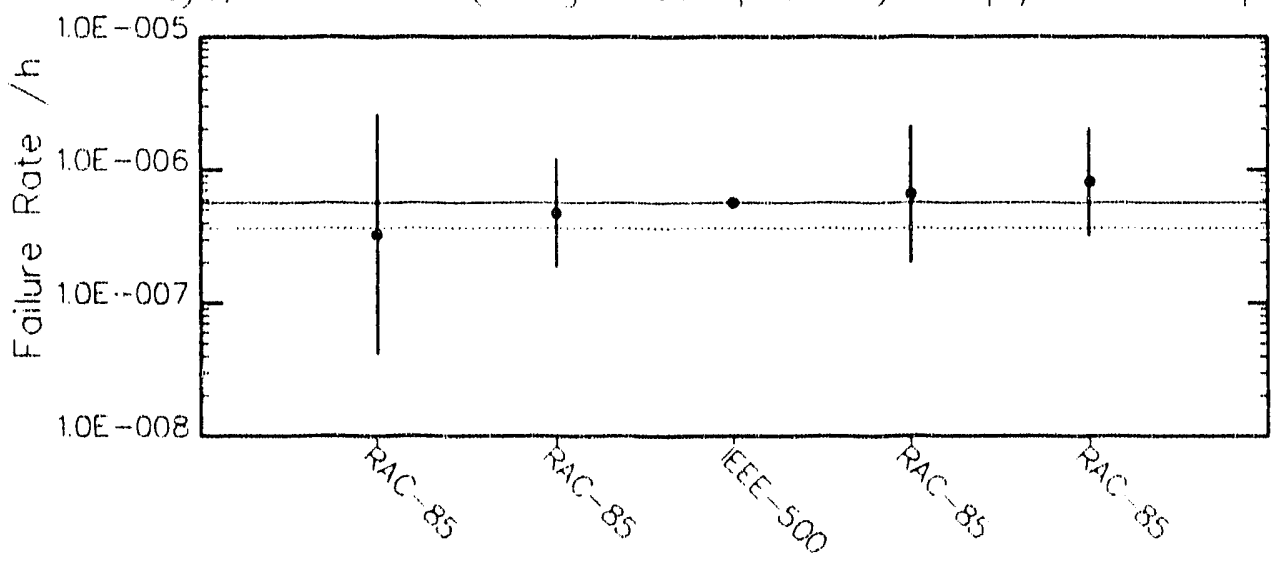

Figure B-4. Failure rates and bounds for electrical and instrumentation components with various designs and normal states (continued). 
Transducers (Detectors/Elements/Sensors) (Sensors)-Energized/Fails to Operate

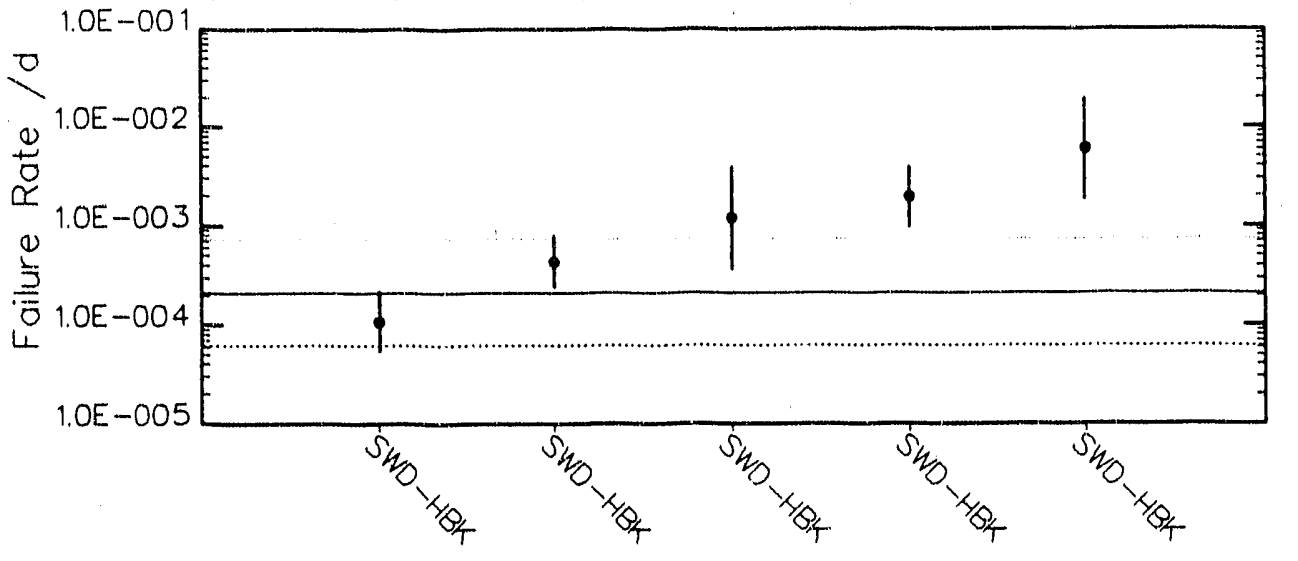

Transducers (Detectors/Elements/Sensors) (Sensors)-Energized/Spurious Operation
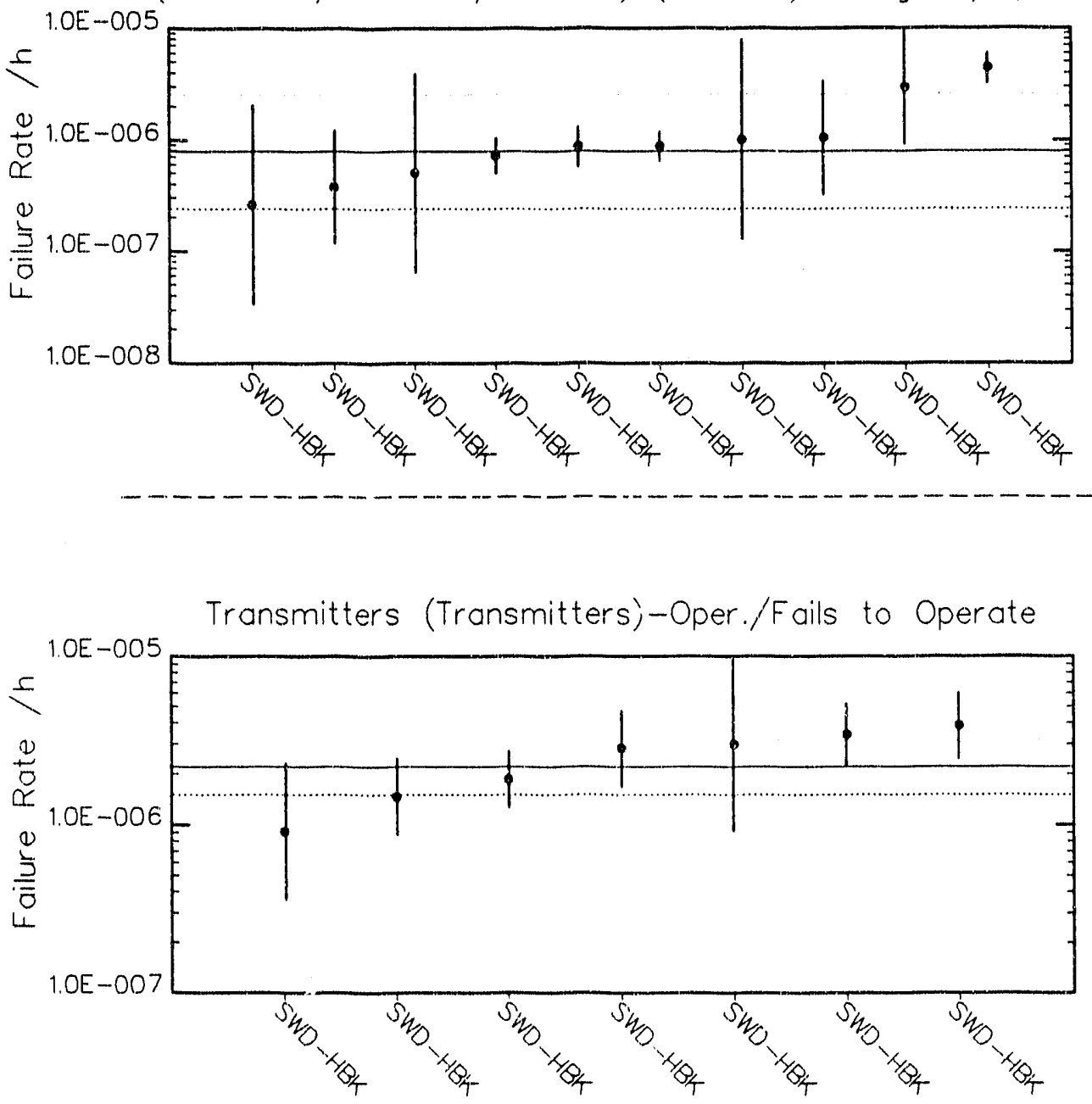

Figure B-4. Failure rates and bounds for electrical and instrumentation components with various designs and normal states (continued). 


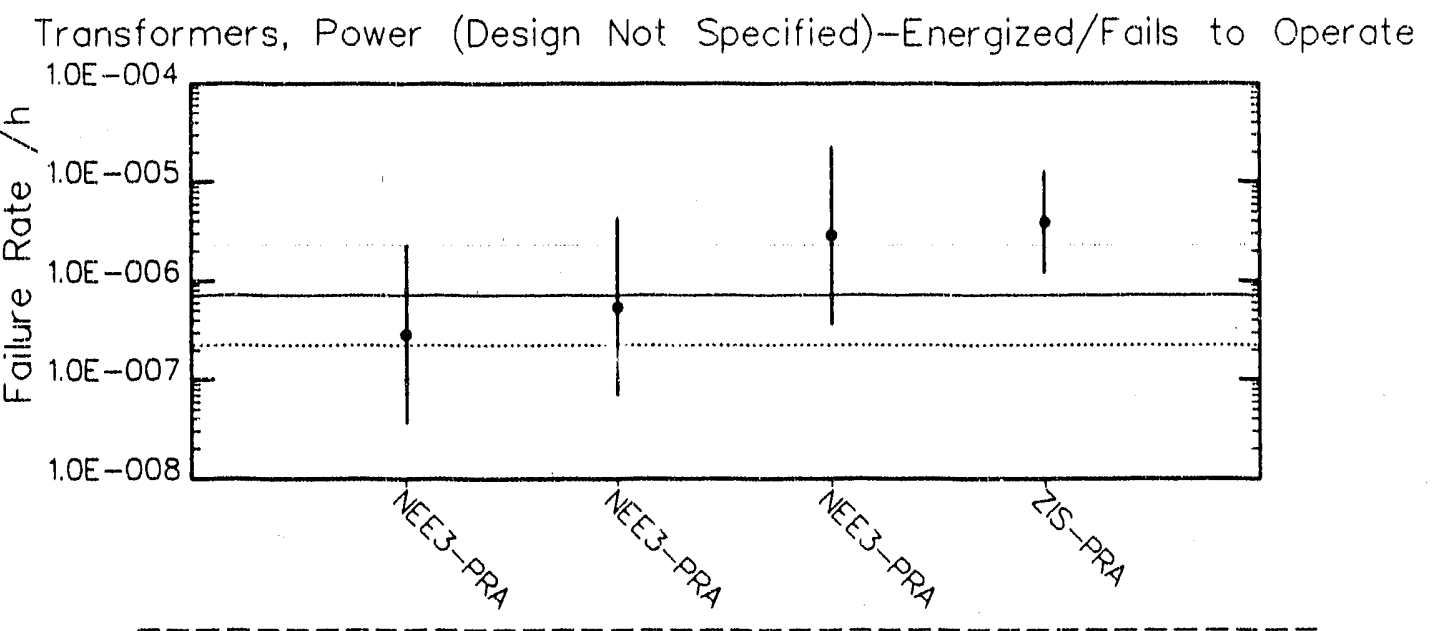

Figure B-4. Failure rates and bounds for electrical and instrumentation components with various designs and normal states (continued). 


\section{APPENDIX C}

AGGREGATION METHODS 


\section{CONTENTS}

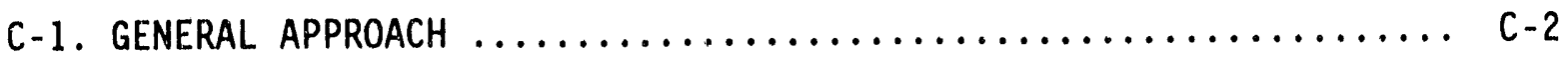

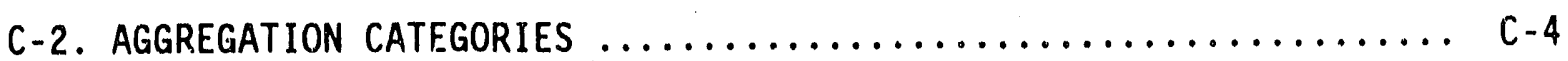

C-3. AGGREGATION ALGORITHMS $\ldots \ldots \ldots \ldots \ldots \ldots \ldots \ldots \ldots \ldots \ldots \ldots \ldots \ldots \ldots \ldots \ldots$

C-4. EXAMPLE OF AGGREGATION METHOD $\ldots \ldots \ldots \ldots \ldots \ldots \ldots \ldots \ldots \ldots, c-10$

C-5. SUMMARY OF AGGREGATION METHODS $\ldots \ldots \ldots \ldots \ldots \ldots \ldots \ldots \ldots \ldots, 12$

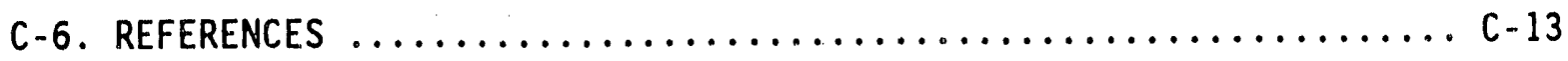

\section{TABLES}

C-1. Data Sets for Aggregation Methods $\ldots \ldots \ldots \ldots \ldots \ldots \ldots \ldots$ C -6

C-2. CFD Aggregation Algotithms ..................... C-8

C-3. Example Data for Battery Chargers ................... C-9

FIGURE

C-1. Battery Charger Failure Data $\ldots \ldots \ldots \ldots \ldots \ldots \ldots \ldots \ldots . \ldots . \ldots . . .6$ 


\section{APPENDIX C AGGREGATION METHODS}

This appendix provides a brief description of the methods implemented in the NUCLARR program for treating the uncertainty in the failure data and for aggregating or combining data from different sources. Understanding how the data are aggregated and how the upper bounds are formed will help the user to better appreciate their use.

Two main quantities result from the aggregation methods: a point estimate and an upper tolerance bound. The point estimate is a weighted average of the component failure data contained in the set being aggregated. The upper bound is a percentile of a distribution that is intended to describe the population of failure rates or demand probabilities that are being combined. It is not intended to be a confidence interval describing how well the mean or median of that distribution is known. Rather, the tolerance bound is a number that the failure rates or probabilities are expected to remain less than with a probability specified by the user. In this sense, the interval from 0 to the bound is intended to cover that specified amount of the distribution of the failure rates for an event. The specified probability is thus a coverage probability rather than a confidence. It is useful for predicting where future failure rates or probabilities sampled from the population variability distribution might lie.

A further remark about the tolerance interval is warranted. A classical statistical tolerance bound has two probabilities associated with it: a coverage probability and a confidence indicating how likely it is that the interval actualiy does cover a distribution as desired. These bounds consider the sample size and the fact that parameters influencing the tolerance bound are not really known but are estimated from the data. Atwood ${ }^{c-1}$ describes a method for correcting tolerance bounds to account for the uncertainties in parameters estimated from the data and 
thus for increasing the confidence. However, in applications with diesel generator data, he found that the correction had little effect. Based on additional experience with the method, he concludes in Reference $\mathrm{C}-1$ that, when the sample size is at least moderately larne, the uncertainty due to lack of data is small compared with the inherert variability in each failure rate popilation. That is, generally, the variation betweer records dominates over the variation within records and thus, these corrections are not needed.

The following sections provide an overview of the aggregation methods, including the major formulas. For a more detailed presentation, see Reference $\mathrm{C}-2$.

\section{C-1. GENERAL APPROACH}

The component failure data aggregation algorithms are based primarily on the treatment of generic data described in "On Combining Data for Estimating the Frequency of Low-Probability Events with Application to Sodium Valve Failure Rates" by H. F. Martz and M. C. Bryson. ${ }^{C-3}$ This article discusses the combining of various types of generic data to form prior distributions describing population variability. Although the article does not discuss the per demand type of rate, the methods for combining data therein are easily extended to this case.

In nearly all cases, the variability distributions are taken to be lognormal. This distribution is discussed in the PRA Procedures Guide. ${ }^{C-4}$ Apostolakis et a1. C.5 make use of lognormal prior distributions, as did the

Reactor Safety Study. ${ }^{C-E}$ it is appropriate for quantities that vary by or. ders of magnitude. Although it is not bounded, it is appropriate for probabilities as well as rates if the probabilities are small. The aggregation methods inciude adjustments for the lognormal distributions that model failure on demand probabilities that approach one; the autput lognormal 
distribution is checked to ensure that at least $95 \%$ of its values are less than 1 and a truncated distribution is used if this test fails.

The data treatment discussed in the Martz/Bryson article focuses on the type of data supplied by the various data sources. For generic data, there are two main possibilities. The data may be raw data; i.e., historical observed frequency data on similar events in similar applications. Alternatively, the data may be reduced, in the form of point or interval estimates for frequencies of similar events. In the latter case, there are several possible ways to specify bounds for the rates. Tolerance bounds (for one or two-sided intervals) may be specified, or error factors may be given. These methods have been extended to allow standard deviations or variances to be used to describe the variability.

For all of these cases, the underlying hypotheses are that the information from each separate source (i.e., individual data record) has a withinsource variation and that the goal of the aggregation is to provide a point estimate and a tolerance bound that describes the between-source variation. This motivates an empirical Bayes (EB) treatment of the data in which the within-source variation is modelled by a conditional distribution, conditioned on the particular (but unknown) value of the occurrence rate for a particular source. The (unconditional) distribution that this value comes from is the desired population variability distribution. Tolerance intervals for aggregated rates are thus based on this distribution.

Further remarks on the nature of the assumed within-source variation are appropriate. For raw data, Martz and Bryson assume that a constant failure rate applies for each source and that the within-source variability is thus the variability that is characteristic of a Poisson distribution. For reduced data, likewise, the bounds or other measures of variation for each source are assumed to describe the variation of data for that source. However, in this case the data may have already been aggregated by the data supplier and may already reflect population variability. This is particularly the case for generic component failure data; some individual data 
reccrds may describe aggregated data. The aggregation procedures consider this distinction and do not attempt to remove within-source variation in such cases.

In all cases the point estimates recommended by Martz and Bryson are the geometric means of the values from the individual sources. In some cases, the means are weighted inversely according to the variances of the individual sources.

After combining or aggregating various sources based on the form of data provided, several aggregates may result. Each of these is characterized by a lognormal distribution with an associated point estimate (its median) and upper tolerance bound (related in a simple manner to the variance of its underlying normal distribution). To form a single overall aggregate, a mixture distribution is formed. This, in turn, is fitted to a lognormal distribution by matching moments. The individual distributions are weighted by the number of individual records contributing to each aggregate.

\section{C-2. AGGREGATION CATEGORIES}

Following the basic approach of Reference $C-3$, the set of data records to be aggregated is first split into sets based on the type of information supplied (whether a data record describes homogeneous data and whether it contains raw or reduced data). An aggregate is formed for each set that is present among the data being considered, then the resulting aggregates are combined into a mixture distribution.

A single data point may represent homogenous data or it may represent data that have been previously aggregated from several sources. Data points from different $p l a n t s$ and studies are not expected to be homogeneous. The Bayes procedures described by Martz are not applicable unless 
individual records are homogeneous. A single record is treated as homogeneous if (a) it has at least component design detail and (b) it is from a single plant and/or was used as plant-specific data for a Bayesian update. Reference $\mathrm{C}-2$ contains a discussion of the rationale for these rules.

The remainder of this section is a discussion of how the form of data for a record is classified based on the minimal information that is present. If an entry is present for the number of failures and for either the total number of operating hours or demands or for both the average number of operating hours or demands per component and the number of components whose experience is being combined, raw data are being provided.

The aggregation methods recognize just two types of rate variation information beyond the raw data: confidence intervals and tolerance intervals. Error factors and standard deviations or variances are assumed to be supplying tolerance interval information. Specifying any type of rate variation information except. for standard deviations and variances requires a specification of the coverage probability or confidence as well as an upper bound. Lower bounds are optional; if they are not specified the bounds are assumed to be one-sided. For error factors, the "error factor type" that indicates whether the corresponding tolerance interval is one or two-sided is required. If one of these sets of data is present, variation information is provided.

There are several possible ways to describe tolerance intervals. The aggregation methods check first the upper tolerance bound and associated coverage probability; if this is complete, tolerance interval data are provided and any remaining tolerance interval information will be ignored. otherwise, the error factor information will be used; the variance or standard deviation information will be used only if no other tolerance interval information is provided in the data record.

These considerations lead to six possible categories of data for ag ip egation. These are described in Table C-1. 


\section{Table C-1. Data Sets for aggregation Methods}

\begin{tabular}{|c|c|c|c|}
\hline $\begin{array}{l}\text { Set } \\
\text { anumber }\end{array}$ & $\begin{array}{l}\text { Aggregation } \\
\text { Type }\end{array}$ & Form of Data Present & Aggregation Method \\
\hline $\begin{array}{l}1 \\
a \\
b\end{array}$ & Homogeneous & $\begin{array}{l}\text { Raw data } \\
k=1 \text { or all } f_{1}<2 \\
k>1 \text { and at least one } \\
f_{i}>1\end{array}$ & $\begin{array}{l}\text { Noninformative prior } \\
\text { Empirical Bayes Pro- } \\
\text { cedure \#1 }\end{array}$ \\
\hline 2 & Homogeneous & $\begin{array}{l}\text { No raw data; confidence } \\
\text { interval only }\end{array}$ & Raw data conversion \\
\hline $\begin{array}{l}3 \\
a \\
b\end{array}$ & Homogeneous & 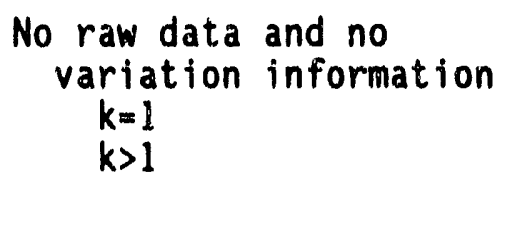 & $\begin{array}{l}\text { No bound possible } \\
\text { Fit rates to lognor- } \\
\text { mal distribution }\end{array}$ \\
\hline $\begin{array}{l}4 \\
a \\
b\end{array}$ & Homogeneous & $\begin{array}{l}\text { No raw data; tolerance } \\
\text { interval } \\
k=1 \\
k>1\end{array}$ & $\begin{array}{l}\text { Use single point } \\
\text { Empirical Bayes Pro- } \\
\text { cedure \#2 }\end{array}$ \\
\hline $\begin{array}{l}5 \\
a \\
b \\
c\end{array}$ & Aggregated & $\begin{array}{l}\text { Tolerance interval } \\
k=1 \\
k>1 \\
\text { No raw data } \\
\text { Raw data }\end{array}$ & $\begin{array}{l}\text { Use single point } \\
\text { Mixture } \\
\text { (unweighted) } \\
\text { (weighted) }\end{array}$ \\
\hline $\begin{array}{l}b \\
c\end{array}$ & Aggregated & $\begin{array}{l}\text { No tolerance interval } \\
k=1 \\
k>1 \\
\text { No raw data } \\
\text { Raw data }\end{array}$ & $\begin{array}{l}\text { No bound possible } \\
\text { Fit rates to lognor- } \\
\text { mal distribution } \\
\text { (unweighted) } \\
\text { (weighted) }\end{array}$ \\
\hline
\end{tabular}

a. $k$ is the number of points in the set; $\left\{f_{i}\right.$ for $i=1$ to $k$ \} is the set of failure counts. 


\section{C-3. AGGREGATION ALGORITHMS}

The third column of Table $C-1$ identifies the aggregation methods to be used. For most of the data sets, the methods are further subdivided based on the amount of data present. Two other data sets are subdivided because the presence of raw data can affect the weighting of the data. Table C-2 provides an overview of the actual aggregation aigorithms.

In Table C-2, "dealing with 0 rates" requires that a non-zero estimate of the median be obtained. Using a non-informative gamma or beta prior produces, respectively, $0.23 / T$ for per hour rates and $F /(2 n-1+F)$, where $F$ is the median of an $F(1,2 n+1)$ distribution, for per demand probabilities. (Here, $T$ is the exposure time and $n$ is the number of demands). Both of these require that raw data be available; if this is not the case, the data are omitted.

The following equations apply to compute the variance, $S_{i}{ }^{2}$, and the mean, $M_{i}$, of an underiying normal distribution given tolerance information. The normal distribution describes the logarithm of the corresponding failure rate or probability. In these equations, $z_{\alpha}$ is an upper bound from the standard normal distribution (e. g., the ninety-fifth percentile, 1.645, when $\alpha$ is 0.95 ).

- Given the median $\left(r_{i}\right)$ and upper bound $\left(U_{i}\right)$ :

$$
\begin{aligned}
& M_{i}=\ln r_{i} \text { (this holds in all cases) } \\
& S_{i}^{2}=\left[\left(\ln U_{i}-\ln r_{i}\right) / z_{\alpha}\right]^{2}
\end{aligned}
$$

- Given the median and error factor $\left(E F_{i}\right)$ :

$$
S_{i}^{2}=\left[\ln E F_{i} / z_{\alpha}\right]^{2}
$$




\section{Table C-2. CFD Aggregation Algorithms}

For Homogeneous Data Records:

Preferred Data Form: Raw Data

Empirical Bayes (EB) Proc. \#l:

- Compute $^{\mathrm{a}}$

$R=\left(\Sigma f_{i}\right) /\left(\Sigma T_{i}\right)$

$R_{2}=\left[\Sigma f_{i}\left(f_{i}-1\right) / T_{i}\right] /\left(\Sigma T_{i}\right)$

- Match moments. Output underlying normal distribution:

$$
\begin{aligned}
& M=2 \ln R-0.5 \ln R_{2} \\
& S^{2}=\ln R_{2}-2 \ln R
\end{aligned}
$$

- If $S^{2}<0$, compute separate rates and fit them to a lognormal distribution.

- Similar treatment for per demand data.

For Aggregated Data Records:

Preferred Data Form: Tolerance Interval Mixture:

- Deal with 0 rates. ${ }^{b}$

- Find normal dist. stdv. $\left(S_{i}\right)$

- Define weights $\left(w_{i}\right){ }^{b}$

- Output normal distribution:

$M=\Sigma w_{i} \ln r_{i}$

$S^{2}=\Sigma W_{i}\left[\left(\ln r_{i}\right)^{2}+S_{i}{ }^{2}\right]-M^{2}$
Other Data Form

Tolerance Interval

EB Proc. \#2:

- Deal with 0 rates $^{b}$

- Find normal dist.

Neither

Fit rates to lognormal distribution (See below.) stdv., $S_{i}$ (See note b)

- Compute $^{c}$

$X^{*}=\Sigma \ln r_{1} / k$

$S_{S A M}{ }^{2}=\Sigma\left(\ln r_{i}-X^{*}\right)^{2} / k$

$S_{A V G}{ }^{2}=\Sigma S_{i}{ }^{2} / k$

$W_{i}=\left(1 / S_{i}{ }^{2}\right) / \Sigma\left(1 / S_{j}{ }^{2}\right)$

- Output normal distribution:

$S^{2}=S_{S A M}{ }^{2}-S_{A V G}{ }^{2}$

$M=\Sigma W_{i} \ln r_{i}$

- If $S^{2}<0$, use $S^{2}=S_{S A M}^{2}$.

a. Here, $f_{i}$ is the number of failures in time $T_{i}$.

b. See text for a description of the method.

c. Here, $r_{i}$ is the median of the ith rate distribution and $k$ is the number of records being combined. 
- Given the median and variance $\left(V_{1}\right)$ :

$$
S_{i}^{2}=\ln \left[\left(r_{i}+\sqrt{r_{i}^{2}+4 V_{i}}\right) /\left(2 r_{i}\right)\right]
$$

- Given the mean $\left(X_{i}^{*}\right)$ and upper bound:

$$
S_{i}^{2}=\left[z_{\alpha}-\sqrt{z_{\alpha}^{2}-2 \ln \left(U_{i} / X_{i}^{\star}\right)}\right]^{2}
$$

(If this is not possible, $X_{i}{ }^{*}$ is taken to be the median).

- Given the mean and error factor: ${ }^{a}$

$$
S_{i}{ }^{2}=\left[z_{\alpha}-\sqrt{z_{\alpha}{ }^{2}-2 \ln E F_{i}}\right]^{2}
$$

- Given the mean and variance:

$$
S_{i}^{2}=\ln \left[V_{i} /\left(X_{i}^{*}\right)^{2}+1\right]
$$

In the last three cases, where the median is not provided and the mean is used, the median is calculated as

$$
r_{i}=X_{i}^{*} / \exp \left(S_{i}^{2} / 2\right)
$$

The weighting of the data is a subject for further rearch; current$1 y$, in a group of records with raw data weights are based on the exposure (time or number of demands) associated with each record; when groups are combined, the weights depend on the number of records in the group.

In most of the cases in Table $C-2$, special provisions apply if there is only a minimal number of records in a group; for example, a noninformative prior is used to provide $R$ and $R_{2}$ in $E B$ Procedure \#1 if there are insufficient data. See Reference 6 for these details and for further insights on how the formulas are derived. The final result is a lognormal distribution describing the aggregated rates.

a. Here, the EF is treated as the upper bound divided by the mean. If it were $U / r$, the median $r$ should be reported in the data source. 


\section{C-4. EXAMPLE OF AGGREGATION METHOD}

For the "fails to operate" failure mode of battery chargers, most of the data shown in Table $\mathrm{C}-3$ are available. For this handbook, the last two entries are not used; they are not needed since plant-specific data are available. The last point entered in Table C-3 is present for illustration only, so that there is more than one point among the data lacking counts of numbers of failures and operational hours.

The first eleven entries in Table $\mathrm{C}-3$ are used for the component failure data handbook aggregate probability and are plotted in Figure $\mathrm{C}-1$. They provide plant-specific data which are regarded as homogeneous, while the last two represent aggregates that are intended to reflect performance across the industry. For the first eleven entries, the bounds listed are the 5 and 95 percentage confidence limits calculated using a chi-square distribution.

Figure $C-1$ shows the results of fitting each data point to a lognormal distribution. The lognormal distributions match the specified upper bounds and the rate estimates (number of failures divided by operating hours). The rate estimates for the plots are treated as medians. The resulting lognormal 5, 50 and 95 percentiles are shown.

For the aggregation algorithms, the first eleven points fall into Table C-1's Set 1, while the last two are in Set 5. Thus, two aggregates are formed and then combined. For Set 1, using Empirical Bayes Procedure $\# 1$ as outlined in Table $C-2$, one finds that $R$ is $9.7 E-6$ and $R 2$ is $1.6 E-10$; thus; $M_{1}$ is -11.8 and $S_{1}^{2}$ is 0.52 . Note that the upper and lower bounds given in Table $\mathrm{C}-3$ are not used in this calculation.

For the second aggregate, the mixture method at the bottom of Table C-2 applies. From medians and upper bounds, the underlying normal distribution variances are found to be, respectively, 1.81 for the IEEE-500 data and 0.67 for the assumed data; the normal distribution means are simply the logarithms of the point estimates of the rates. (Note that lower bounds are not needed for this calculation). In combining these two data C- 10 
Table C-3. Example Data for Battery Chargers

Source ${ }^{a}$

HNP1 PRA

IPS2 PRA

MNS1 PRA

NEE3 PRA

ZIS-PRA

$X$-PRA

IPRDS (P1 ant 1)

IPRDS (Plant 2)

IPRDS (P1 ant 3)

IPRDS (P1 ant 4)

IPRDS (Plant 5)

IEEE 500

ZZZ (Dummy data)
Failures Operating Hours Lower Bound Upper Bound

6

175200

95800

229488

96426

202000

304128

223375

56950

733320

162930

1007400

5 -(Rate: 6.20E-7)--

--(Rate: $1 \mathrm{E}-6)$..
1.52E-5

0

1.73E-5

5.29E-7

0

1.31E-5

3. $67 \mathrm{E}-6$

0

$1.12 \mathrm{E}-6$

$5.03 \mathrm{E}-6$

$1.95 \mathrm{E}-6$

3 E-7
$6.76 \mathrm{E}-5$

3.11E-5

$3.55 E-4$

4.41E-5

9. $28 \mathrm{E}-6$

4.53E-5

3. $47 \mathrm{E}-5$

5. $23 \mathrm{E}-5$

$1.06 \mathrm{E}-5$

$4.76 \mathrm{E}-5$

$1.04 \mathrm{E}-5$

1.22E-5

a. See Appendix A.

Charger, Battery-Fails to Operate

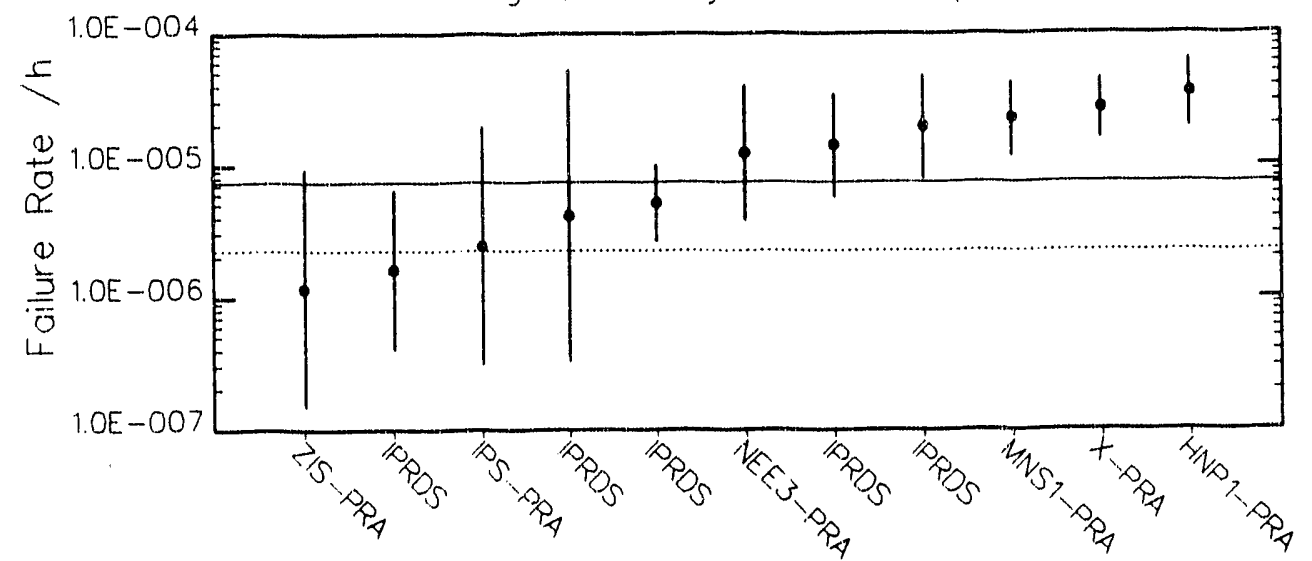

Figure C-1. Battery charger failure data (cases with raw data). 
points, the weights are taken to be inversely proportional to the variances. Thus, the weights are, respectively, 0.12 and 0.88 . Substituting these data in the mixture equation at the bottom of Table $r_{0}-2$ yields -13.9 for $M_{2}$ and 0.81 for $S_{2}{ }^{2}$.

The last step is to use the same mixture equation at the bottom of Table $C-2$ to combine the two overall aggregates, with weights $W_{1}=$ $11 / 13$ and $W_{2}=2 / 13$. The result of the calculation is $M=-12.12$ and $S^{2}=1.13$. This is the mean and variance of a normal distribution; the corresponding lognormal distribution for the rates has median, exp $M$; mean, $\exp M * \exp \left(S^{2} / 2\right)$; and error factor, $\exp (1.645 S)$. The $95 \%$ upper bound is found by multiplying the median times the error factor.

For the battery chargers, the resulting distribution for the rate of failure to operate, per hour, has the following attributes:

$\begin{array}{lr}\text { Number of records: } & 13 \\ \text { Mean: } & 9.6 \mathrm{E}-6 \\ \text { Median: } & 5.4 \mathrm{E}-6 \\ \text { Upper bound: } & 3.1 \mathrm{E}-5 \\ \text { Error Factor: } & 5.7 .\end{array}$

\section{C-5. SUMMARY OF AGGREGATION METHODS}

The aggregation methods work with the data in whatever form the data are given and use a mixture distribution to combine the results. The methods are based on three attributes of each data record: a) whether the record represents homogenous data or is already an aggregate that reflects population variability; b) whether the record contains raw or reduced data; and $c$ ) whether the record describes an actual failure rate or a probability of failure on demand. The methods use lognormal distributions to capture the population variability. The median, mean, upper $95 \%$ bound, and error factor of the aggregate lognormal distribution are output. of course, 
failure rates per hour and rates or probabilities of failure per demand are never aggregated.

Additional features of the aggregation method include the fact that al1 aggregations are based on lowest level information (i.e., individual records), and all standard confidence/tolerance levels are accepted in the input data (not just $95 \%$ ).

An assumption that underlies all the aggregation methods is that the data from the individual records being aggregated are independent. Before component failure data records are entered into the data base, they are checked as much as possible to ensure that they contain unique data. Furthermore, raw data are sought as the primary form of failure data, and they are the primary data used in the aggregation methods, in order to avoid dependence on data that may have originated from common sources such as WASH-1400. ${ }^{10}$

\section{C-6. REFERENCES}

C-1. C. L. Atwood, "Approximate Tolerance Intervals, Based on Maximum Likel ihood Estimates, " Journal of the American Statistical Association, 79:386, June, 1984, p. 459-465.

C-2. C. D. Gentillon, Aggregation Methods for Component Failure Data in the Nuclear Computerized Library for Assessing Reactor Reliability, EGG-REQ-7775 (draft), August 1897.

C-3. H. F. Martz and M. C. Bryson, "On Combining Data for Estimating the Frequency of Low-Probability Events with Application to Sodium Valve Failure Rates," Nuclear Science and Engineering, 83, 1983, pp. 267-280.

C-4. PRA Procedures Guide, NUREG/CR-2300, Vols. 1 and 2, U. S. Nuclear Regulatory Commission, January 1983.

C-5. G. Apostolakis, S. Kaplan, B. J. Garrick, and R. J. Duphily, "Data Specialization for Plant-Specific Risk Studies," Nuclear Engineering and Design, 56, 1980, pp. 321-329.

C-6. Reactor Safety Study, "Appendix III--Failure Data," WASH-1400, NUREG-75/014, U. S. Nuclear Regulatory Commission, 1975. 


\begin{tabular}{|c|c|}
\hline $\begin{array}{l}\text { U.S. NUCLEAA RSGULATOAY COMMISHION } \\
\text { BIBLIOGRAPHIC DATA SHEET } \\
\text { ISE instructions on ine noversos }\end{array}$ & \multirow[t]{2}{*}{$\begin{array}{l}\text { REPOAT VLVIBEA } \\
\text { EGG-EAST - } 8563\end{array}$} \\
\hline 2. TITLE ANO SUBTITLE & \\
\hline \multirow{3}{*}{ Component Failure Data Handbook } & 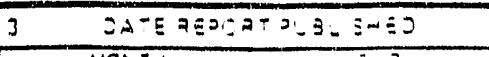 \\
\hline & April $1991^{-2}$ \\
\hline & $\begin{array}{l}\text { FIN OR GAANT YUABEA } \\
\text { D6152 }\end{array}$ \\
\hline \multirow[t]{2}{*}{$\begin{array}{l}\text { 5. AUTHOA(S) } \\
\text { C.D. Gentilion }\end{array}$} & $\begin{array}{l}\text { 8. TYPE OF AEPOAT } \\
\text { Technical Evaluation }\end{array}$ \\
\hline & 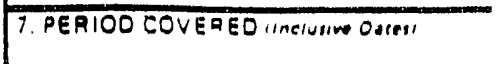 \\
\hline \multicolumn{2}{|c|}{ 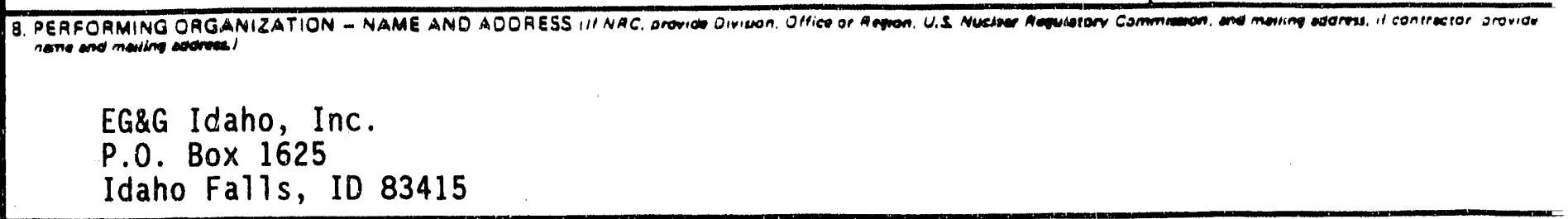 } \\
\hline \multicolumn{2}{|c|}{ 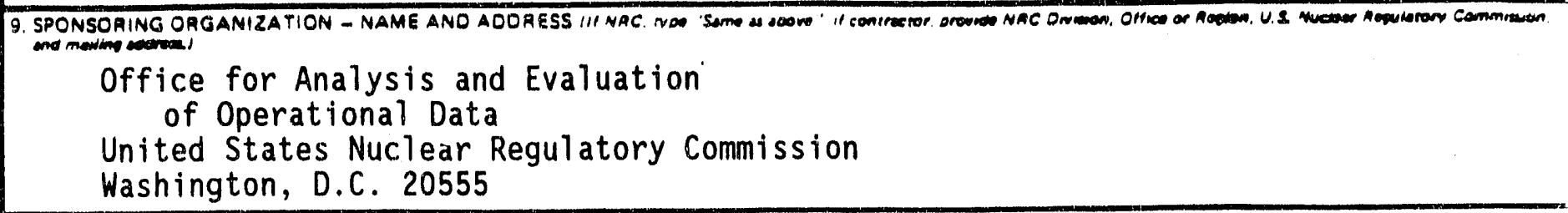 } \\
\hline \multicolumn{2}{|l|}{ 10. SUPPLEMENTAAY NOTES } \\
\hline \multicolumn{2}{|c|}{$\begin{array}{l}\text { This report presents generic component failure rates that are used in } \\
\text { reliability and risk studies of commercial nuclear power plants. The rates are } \\
\text { computed using plant-specific data from published probabilistic risk assessments } \\
\text { supplemented by selected other sources. Each data source is described. For } \\
\text { rates with four or more separate estimates among the sources, plots show the data } \\
\text { that are combined. The method for combining data from different sources is } \\
\text { presented. The resulting aggregated rates are listed with upper bounds that } \\
\text { reflect the variability observed in each rate across the nuclear power plant } \\
\text { industry. Thus, the rates are generic. Both per hour and per demand rates are } \\
\text { included. They may be used for screening in risk assessments or for forming } \\
\text { distributions to be updated with plant-specific data. }\end{array}$} \\
\hline \multirow{4}{*}{$\begin{array}{l}\text { generic component failure data } \\
\text { nuclear power plant risk assessment } \\
\text { failure rates } \\
\text { aggregation of data }\end{array}$} & 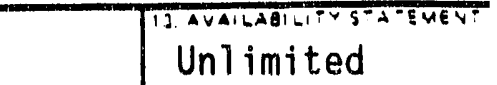 \\
\hline & 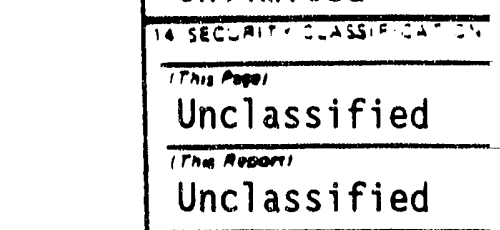 \\
\hline & 15. NUMBEA OF DACES \\
\hline & 18. PACE \\
\hline
\end{tabular}



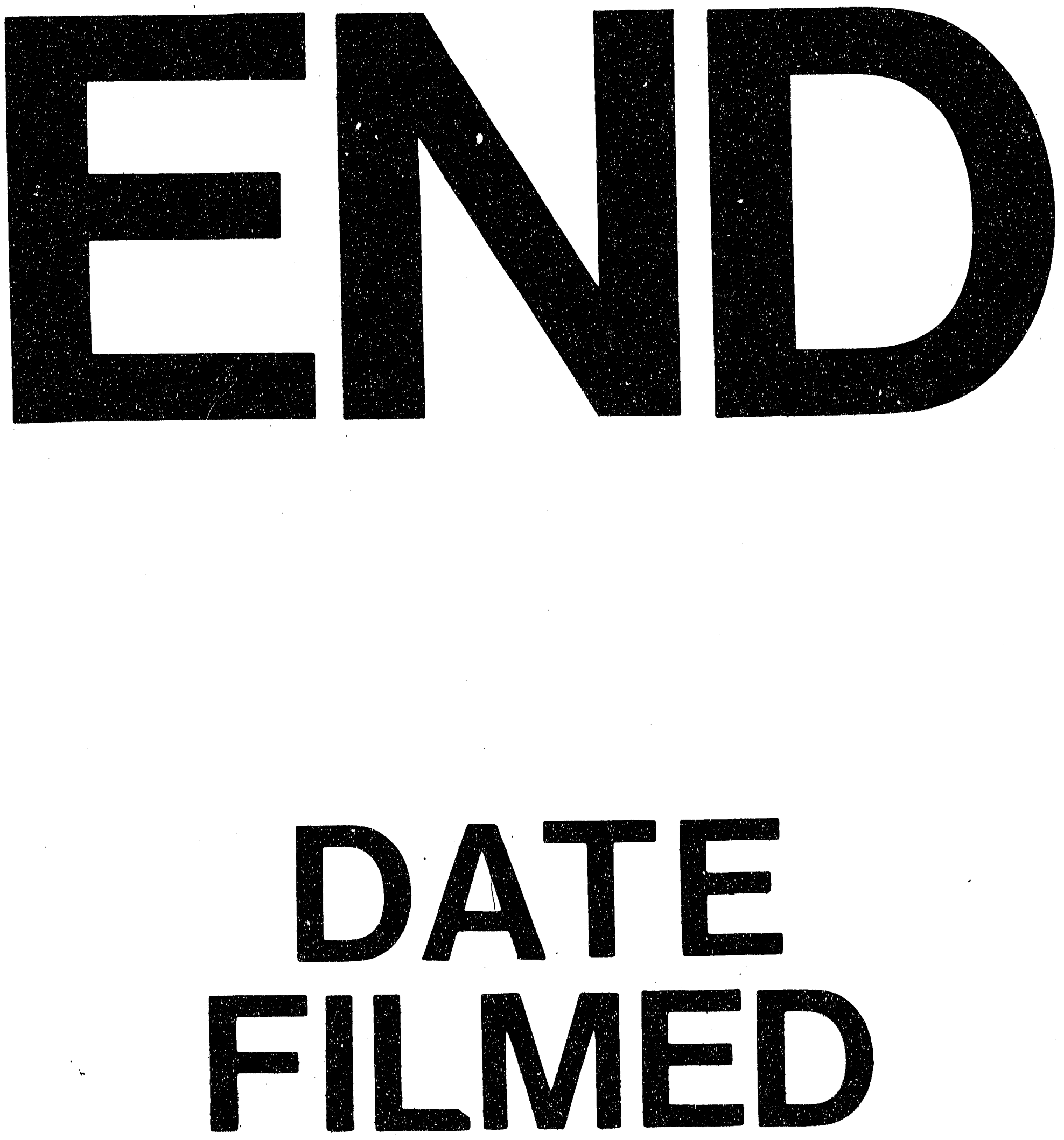

1

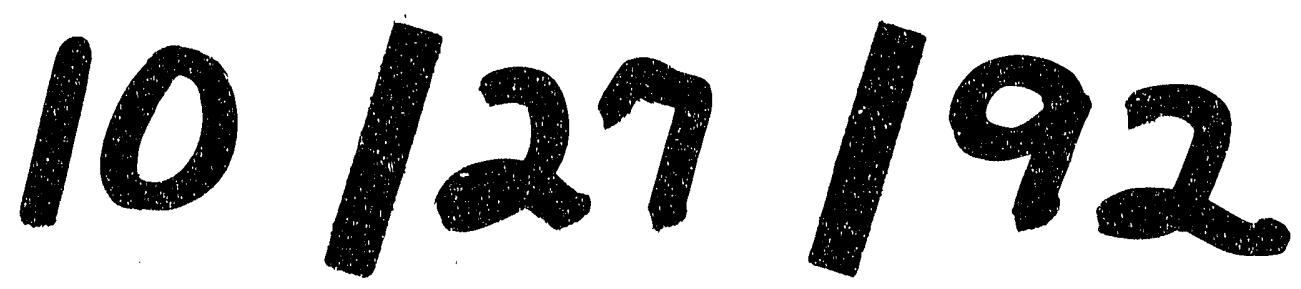

